\title{
THE IMPACT OF THE BUDGETING PROCESS ON PERFORMANCE IN SMALL AND MEDIUM-SIZED FIRMS IN CHINA
}

\author{
杨齐 \\ Yang Qi
}



THE IMPACT OF THE BUDGETING PROCESS ON PERFORMANCE IN SMALL AND MEDIUM-SIZED FIRMS IN CHINA

\section{杨齐}

Yang Qi 
Graduation Committee:

Prof. dr. P. J. J. M. van Loon (chairman)

Prof. dr. P. B. Boorsma (promotor)

Dr. P. A. T. M. Geurts (assistant promotor)

Prof. dr. N. P. Mol

Prof. dr. M. R. Kabir

Prof. dr. A. J. Groen

Prof. dr. ir E. J. de Bruijn

Prof. dr. G. J. van Helden
University of Twente

University of Twente

University of Twente

University of Twente

University of Twente

University of Twente

University of Twente

University of Groningen

Printed by: Print Partners Ipskamp, Enschede

ISBN: 978-90-365-2983-9

DOI: $10.3990 / 1.9789036529839$

Copyright (C 2010 by Yang Qi

All rights reserved. No part of this publication may be reproduced, stored in a database or retrieval system, or published in any form or any way, electronically, mechanically, by print, photoprint, microfilm or any other means without prior written permission from the author and publisher. 


\title{
THE IMPACT OF THE BUDGETING PROCESS ON PERFORMANCE IN SMALL AND MEDIUM-SIZED FIRMS IN CHINA
}

\section{DISSERTATION}

\author{
to obtain \\ the degree of doctor at the University of Twente, \\ on the authority of the rector magnificus, \\ prof. dr. H. Brinksma, \\ on account of the decision of the graduation committee, \\ to be publicly defended \\ on Thursday the $18^{\text {th }}$ of February 2010, at 15:00 hrs
}

\author{
by \\ 杨齐 \\ Yang Qi
}

born on the $29^{\text {th }}$ of May, 1980

in Yue Yang, China 
This dissertation is approved by:

Prof. dr. P. B. Boorsma (promotor)

Dr. P. A. T. M. Geurts (assistant promotor) 
To my parents Yang Shi Tai and Ding Hong 献给我的父母：杨石太和丁红 



\section{Acknowledgements}

I want to show gratitude to many people.

First of all, my warmest appreciations go to my "promotor" Prof. Dr. Peter B. Boorsma and my "assistant promotor" Dr. Peter A.T.M. Geurts. They spent a lot of their time on supervising me during the last years. Their academic knowledge and their spirit have inspired me in so many ways. Without them, I could not get deeper insight into research and finally finish my dissertation.

I deeply appreciate all the professors and staff in the F\&A department of University of Twente. Since my first contact with my promotor Prof. Boorsma, I received a very friendly and warm welcome. I thank Prof. Nico Mol, Dr. Sebastiaan Morssinkhof, PhD students Kolja Loebnitz and Saba Ahmad for showing constantly concern on my study. Additionally, I also would like to express my sincere gratitude to the secretaries: Ms. Jolande Kleine, Ms. Manon Jannink, and Ms. Annette Van der Tuuk. They are always so patient and warm-hearted.

I am indebted to all the Chinese organizations and institutions which made it possible to conduct my research. The key-people who helped me are Mr. Nai SheGuang, Mr. Xiao DaYou, Mr. Xiao JunXiong, and Ms. Yang XiXiu.

I cannot express thoroughly my appreciation and gratefulness to my beloved parents Yang ShiTai and Ding Hong, my twin sister Ding Qi, my boyfriend Sebastiaan and his relatives. My father always supports me to acquire more knowledge. My mother, she is an icon of love, always shows great care to her children. My twin sister and Sebastiaan, they have always encouraged me in my study. Their love and sacrifice have no parallels. They must be happy to see my improvement in academics.

Yang Qi

Enschede, February 2010 


\section{Table of Contents}

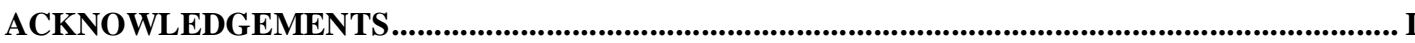

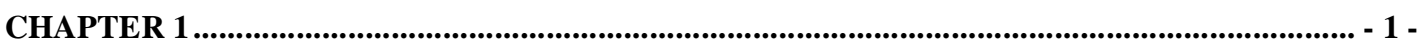

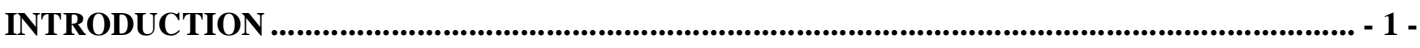

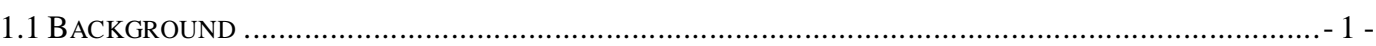

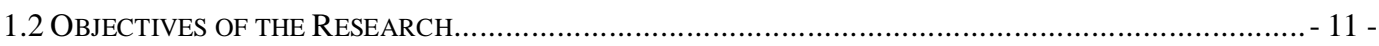

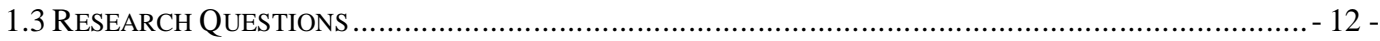

1.4 IMPORTANCE OF THE PROPOSED RESEARCH ……………................................................ 15 -

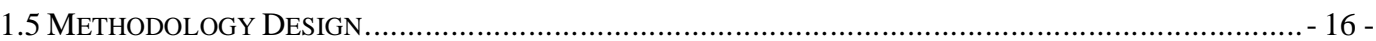

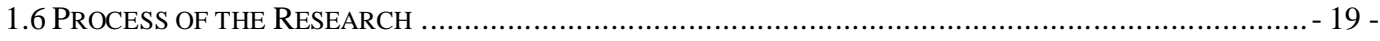

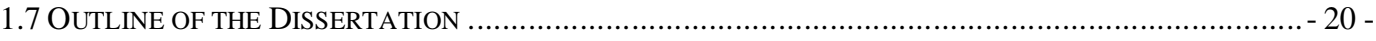

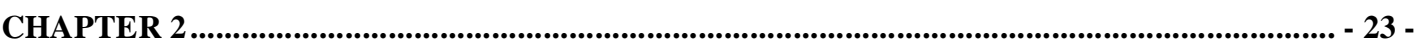

BUDGETING PROCESS AND PERFORMANCE ..................................................................... - 23 -

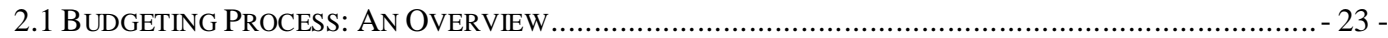

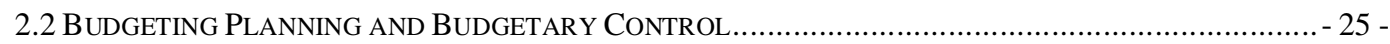

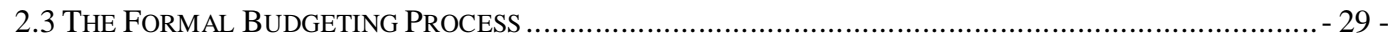

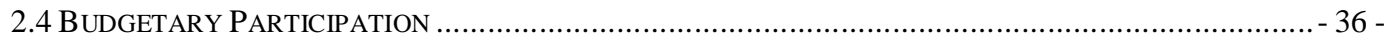

2.5 THE IMPACT OF FIRM SIZE ON BUDGETING PROCESS AND PERFORMANCE ……………................. 41 -

2.6 THE IMPACT OF OWNERSHIP ON BUDGETING PROCESS AND PERFORMANCE.................................... 43 -

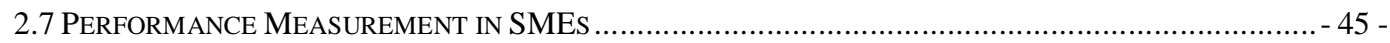

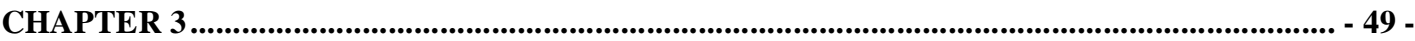

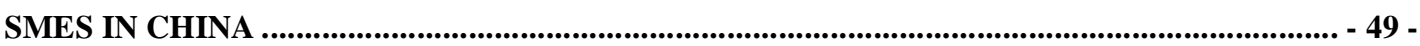

3.1 The Definition of SMALl AND Medium Sized EnTERPRISES ................................................... 49 -

3.2 SMES DEVELOPMENT IN A FAST GROWING ECONOMY …….................................................. 50 -

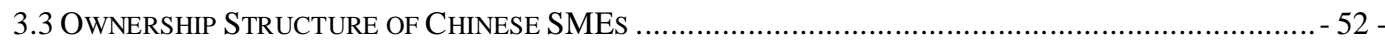

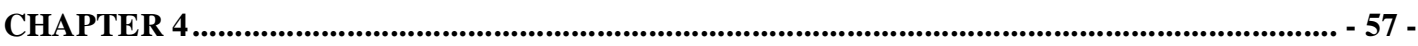

THEORETICAL FRAMEWORK AND MEASUREMENT OF VARIABLES …........................... - 57 -

4.1 THEORETICAL FRAMEWORK AND HYPOTHESES ........................................................................... 57 -

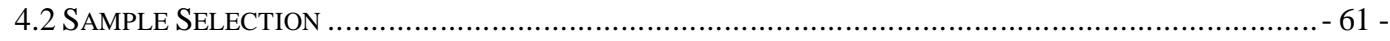

4.3 DATA ColLECTION METHOD: QuESTIONNAIRE ……........................................................... 62 -

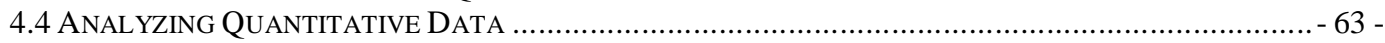

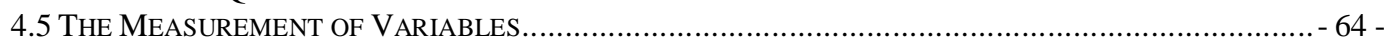

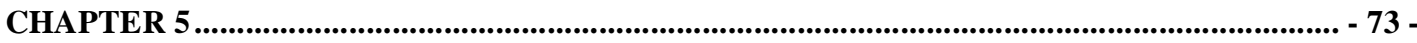

EMPIRICAL RESULTS: DESCRIPTIVE STATISTICS........................................................... - 73 -

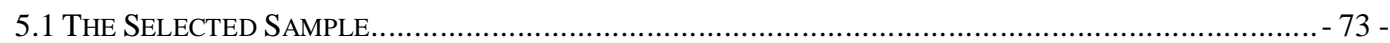

5.2 Descriptive Results: the Formal Budgeting Process And Firm Performance................... 74 -

5.3 Descriptive Results: Budgetary Participation And Managerial Performance ............... 90 -

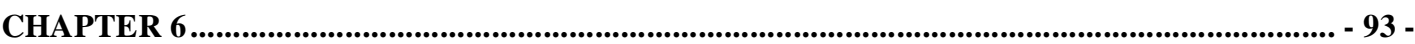

EMPIRICAL RESULTS: THE FORMAL BUDGETING PROCESS AND PERFORMANCE.... - 93 -

6.1 Testing Hypothesis 1: the Formal Budgeting Process and Firm Performance.................. 93 -

6.2 TESTING Hypothesis 2: Budgetary Participation AND MANAGERIAL PERFORMANCE ............ - 107 -

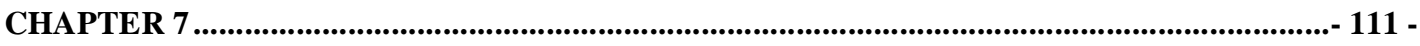

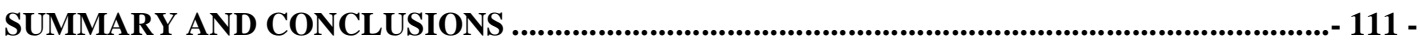

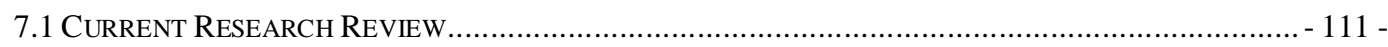

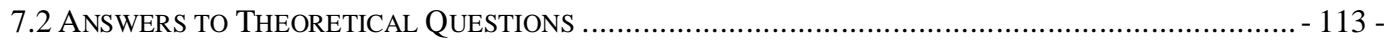

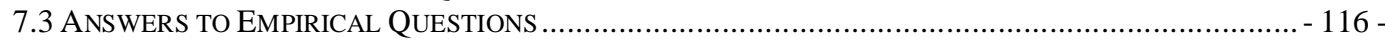

7.4 CURRENT RESEARCH CONTRIBUTIONS .................................................................................... - 120 -

7.5 RESEARCH LIMITATIONS AND IMPLICATIONS FOR FUTURE RESEARCH ....................................... - 121 - 


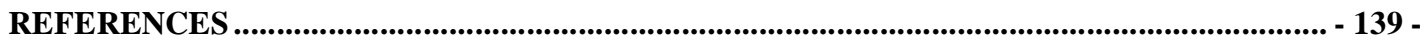

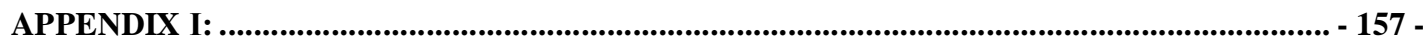

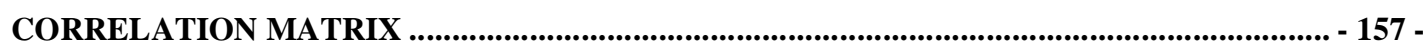

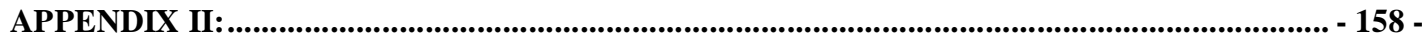

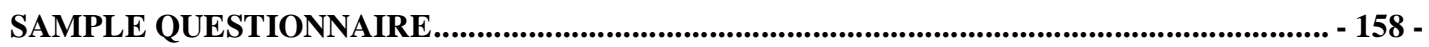

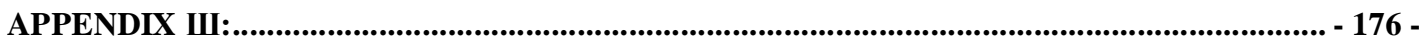

NAME LIST OF THE FIRMS IN THE SAMPLE ............................................................ 176 - 


\section{Chapter 1}

\section{Introduction}

In chapter 1, a variety of research subjects are introduced to the reader related to the research area of budgeting and performance. These subjects include the concept of budgeting (Section 1.1.1), problems in the existing research in terms of budgeting (Section 1.1.1) and performance measurement (Section1.1.2), research objectives (Section 1.2), research questions (Section 1.3), significance of the research (Section 1.4), and research methodology (Section 1.5), research process (Section 1.6), and the dissertation outline (Section 1.7).

\subsection{Background}

The current research intends to gain a deeper understanding about how budgeting affects the performance of small and medium-sized enterprises (SMEs). This preliminary purpose creates three major areas of concern in this study, viz. budgeting in a business organization, performance measurement in SMEs, and (Chinese) SMEs. The following section gives a brief review of each area resulting in a problem statement from previous research.

\subsubsection{Budgeting in Business Organization}

To reveal the nature of budgeting at business organizational level, it would be best to begin with two comparisons of budgeting, viz. with business planning; and with accounting and finance.

\section{- Business Planning VS. Budgeting}

Business planning, as described by several scholars in a similar way ${ }^{1}$ in the past, is, in general, the conscious determination of courses of action to achieve preconceived objectives. It is based on what is known about the present business environment of that future business. Rather than being a fixed document, a business plan must be flexible enough to change to suit the current environment. It must be constantly reassessed to adapt to changing market conditions such as new competition, price changes, personnel availability, and so on (Mclaughlin, 1992). In contrast to business planning, budgeting underlines predicting and quantifying the future in financial terms and predicting the future needs for finance. Therefore, budgeting is situated between the disciplines of

\footnotetext{
${ }^{1}$ Steiner, 1969; Kastens, 1976; Kono, 1990
} 
finance and planning. Budgeting data are the most tangible decision causes considered by decision makers (Wooldridge et. al, 2001). It has been used in the short-term (twoto-one year) for the operational planning in standard costing. It has also been developed to support strategic planning with firm planning and to develop the five-or-ten year plan. So there is a link between budgeting and operational planning and a link between budgeting and strategic planning. However, operational planning, strategic planning, and budgeting are three different concepts with different characteristics. Operational planning is characterized as a wide diversity of practices in different organizations. Strategic planning is an irregular activity that takes place in the higher echelons of an organization (Anthony, 1965). Whereas budgeting as an accounting-based system shows a regular and routine pattern common to all organizations. Aside from the planning role of budgeting, numerous articles on management accounting constantly stress the multi-purpose role of budgeting in business organization, the so-called 'conventional wisdom' as propagated by textbooks. Budgeting is used for forecasting, planning, coordination, communication, control and motivation. In the past 25 year, considerable attention has been paid in particular to the role of management control of budgeting (Otley \& Pollanen, 2000).

\section{- Budgeting, Accounting, and Finance}

Budgeting and accounting have different meanings among managers, planners, and the personnel who use these. Both are critical components that must interact to achieve the goals and objectives of an organization. Accounting is a system used to record, classify, and summarize business operation (Meigs, 1996). The role of keeping the financial information and on-going analysis necessary to provide management and outside interests with the facts necessary for decision, is also considered (Grigg, 1988). Relying on certain standards and GAAP (General Accepted Accounting Principles), the accountant of a company develops and reports data to measure firm performance; to assess its financial position, to comply with and file reports needed by securities regulators; to file and pay taxes; and to prepare the balance sheet, financial statements, and the cash flow of the company to recognize sales revenue, expenses etc. when they are incurred. Therefore, accountants provide accounting information used for individuals external to an organization such as shareholders, customers, suppliers, tax authorities, as well as for employees (so-called financial accounts) and internal 
managers of an organization (so-called management accounts). ${ }^{2}$ Financial accounting systems ensure that the assets and liabilities of a business are properly accounted for, and provide information about profits etc. to shareholders and to other interested parties. In contrast, management accounting systems provide information specifically for the use of managers within an organization to assist in their decision making (Ryan et. al, 2002). Based on the classification above, budgeting is, traditionally, classified in the management accounting domain by the existing accounting literature. In this sense, budgeting is a narrower concept with more specific focus. Budgeting ${ }^{3}$, if it covers financial aspects, reflects the management's expectations regarding income, cash flow, and financial position in monetary terms. (Horngren, 2002) It focuses on a forthcoming accounting period, rather than on the past period on which the accounting is based to make records. Therefore, budget planning focuses more on a forecast purpose to estimate what is likely to occur in the future and how organizational resources are allocated to realize future operations. Moreover, another important part of budgeting is that of feedback, in which both the plan and the action are compared, providing the opportunity to revise future budgets in line with experience. Therefore the characteristic of learning underlies the nature of budgeting. By analyzing uncertainty and the risks related to financing and investment choices, the capital budget aims to project the future outcomes of present decisions. Thus, the capital budget pays closer attention to cash flows - the intake and outgo of cash, and financial decision making. By specifying dayto-day financial actions, the operating budget provides profit and cost information for the internal administration. The current research specifically focuses on the operating budget. Concerning a firm's finance and budgeting activities, these are closely related and even overlap sometimes. Finance as a function can be defined as the process by which money is transferred (financing and investing) among businesses, individuals, and governments (Bodie \& Merton, 2000). Financial institutions have a firm foundation by acting as the financial intermediary between the firm and the capital market (Kaye, 1994). Finance includes a set of activities such as financial planning, funds raising, making capital expenditure decisions, managing cash, managing credit, managing the pension funds, and managing foreign exchange etc. (see Figure 1.1, the role of treasurer)

\footnotetext{
${ }^{2}$ It is noted that the data used to prepare financial accounts and management accounts are the same. The differences between them arise because the data are analyzed differently.

${ }^{3}$ A budget can cover both financial and nonfinancial aspects of a plan, but it is expressed in financial terms.
} 
Figure 1.1 Finance Function

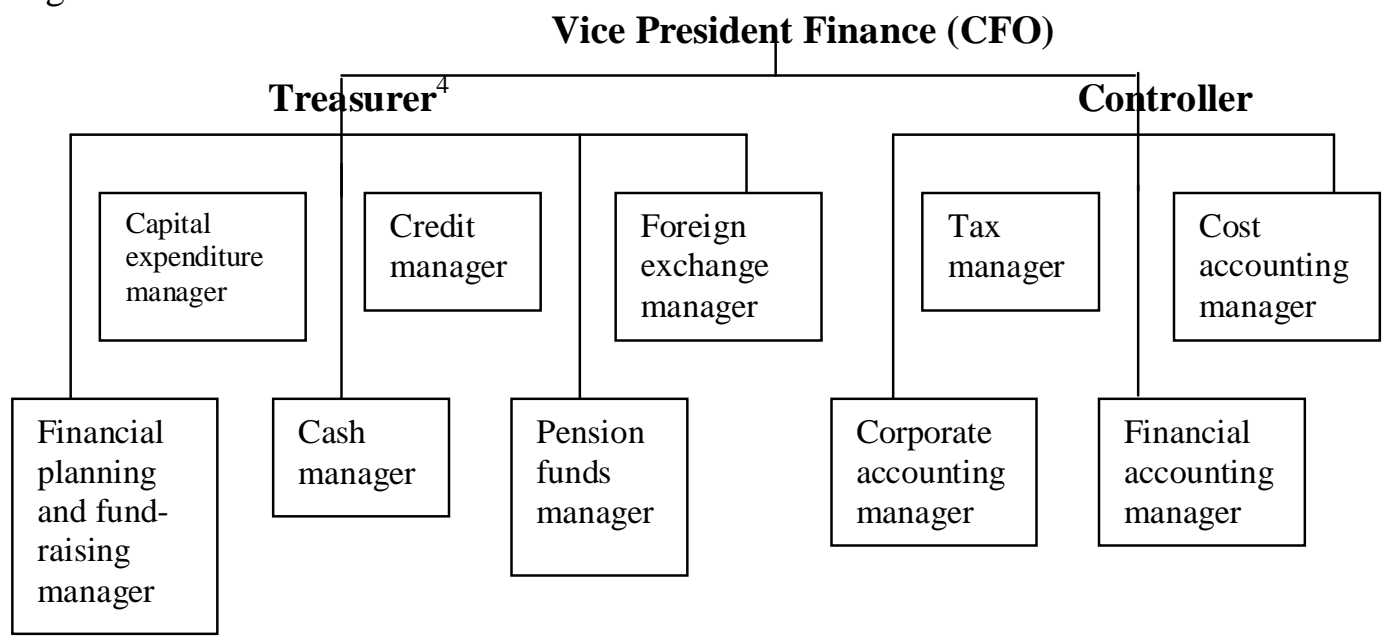

Source: Horngren, C. T., 1996

Budgeting in finance literature is therefore concerned with the planning and management of the firm's financial needs, concerning the alternative sources of and costs of finance. The financial needs of the firm are embodied in capital budgeting decisions on projects within the firm. The money flows are from the capital market, into the firm and into the project, the project in turn generates funds, which are used to pay interest on the loans as well as repayment, and to fund non-capital costs. Any surplus can be used either as profit/dividend payments or reinvested. The above process also reflects the basic activities of finance within business organization (See Figure 1.2).

Figure 1.2 Financial Modeling Process in a Business Organization

Plant, Labor Raw material Machinery

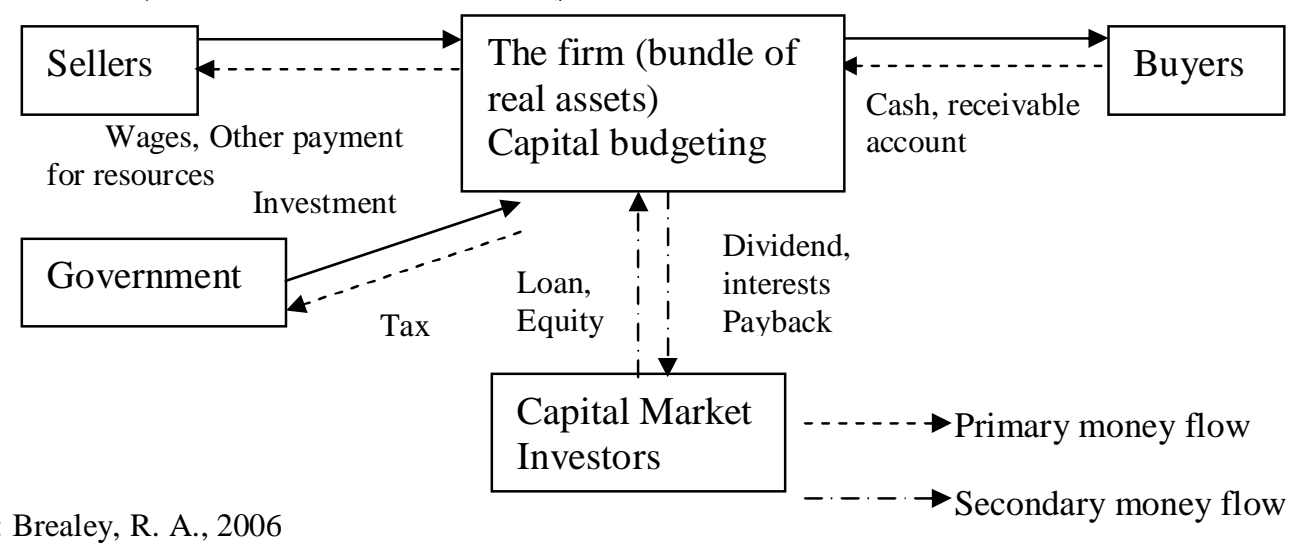

Source: Brealey, R. A., 2006

They consist of financing decisions, investment decisions, and managing assets in organizations after the acquisition of funds (or fixed assets). A major aspect of financial

\footnotetext{
${ }^{4}$ The treasurer is commonly responsible for handling financial activities in an organization
} 
management involves providing the financing necessary to support assets (Van Horne \& Wachowicz. 1998). Financing is classified as either debt financing or equity financing. Funds, on the one hand, are raised by borrowing from creditors in the form of long-term notes, mortgages, leases, or bonds. Funds, on the other hand, are obtained in exchange for ownership in the firm (selling shares of stock). The collected funds through debt financing and equity financing are used to finance investments in projects and the ongoing business. During project investment decisions, financial managers have to calculate the total assets needed by the firm and also assess potential investment opportunities for the firm to determine whether to pursue those opportunities. The return on investment can in turn re-supply the on-going assets need of the firm. Once funds are acquired and appropriate financing is provided, these funds must still be managed efficiently in companies, so the financial manager is charged with varying degrees of operating responsibility over existing assets as well.

As a common example of a financial plan in management accounting, however, budgeting pays attention to the administrative function internal to a firm, especially in terms of planning and control. Budgeting is viewed as a critical element of management control (as above mentioned) by a number of scholars (Anthony, 1965; Flamholtz, 1983; Otley and Pollanen, 2000; Otley, 2003). Given the control-required standards against which performance could be assessed, the budget was the natural standard of comparison. This leads to using the budget with an annual planning period, in practice in many organizations this was subdivided into quarters or sometimes months ${ }^{5}$, as the fundamental building block of the control system.

Literature (Anthony, 1965; Swieringa \& Moncur, 1975; Bruns \& Waterhouse, 1975) has for a long time supported the claim that budgeting is a means for facilitating and enabling the process by which resources are acquired, allocated among subunits, and consumed in the achievement of organizational objectives. The mission that results from this definition is to make budgetary practices more reflective of organizational processes to arrive at better resource allocation decisions. Based on previous research, the present study attempts to analyze the process character of budgeting in the context of small and medium enterprises, and to investigate how budgeting process impact performance in SMEs in China.

\footnotetext{
${ }^{5}$ A survey conducted by Umapathy in 1987 shows that 91 percent of the participating firms use budget for a one-year period; 3 percent for a six-month period; and 1 percent for a three-month period.
} 
Budgets provide a basis for directing and evaluating the performance of individuals or segments of organizations and also structure the decision-making environment (Bruns \& Waterhouse, 1975), so they appear to be appropriate as control devices impacting performance of organizations. Therefore, a considerable stream of research ${ }^{6}$ (Schiff $\&$ Lewin, 1970; Onsi, 1973; Brownell, 1985; Merchant \& Manzoni, 1989; Kren, 1992; Van der Stede, 2000) emphasize the function of budgeting in management control processes and sought to explore the influence of budgetary controls on organizational behavior. For example, Bruns \& Waterhouse (1975) explore the interaction and relationships of budgets with organizational structure. They find a clear positive relationship: those working in highly structured organizations ${ }^{7}$ participate more in budget planning and appear to be more satisfied with the organizational goals they accomplished. In this kind of research, attention is paid traditionally to budgetary participation, as one of budgetary control factors. For example, Schiff and Lewin (1970) review the role of financial budgets in the corporate planning and control process. They argue that since financial budgets are plans they become the criteria by which performance is measured and therefore the basis of the control system. Shield and Young (1993) define budgetary participation as the involvement of managers in the budgetary process and their influence over setting budgetary targets. They state that participative budgetary control is a response to the need by organizations to gain an understanding of their environment, to assist in problem solving, more importantly to promote information sharing among administrative levels and finally to enhance performance. Many researches have discussed budgetary participation (a.o. Brownell, 1990; Frucot \& Shearon, 199; Kren, 2003). However, budgetary participation seems to be a controversial research topic because its results are difficult to integrate, and sometimes even conflicting. Some results are confirmed; some findings are statistically insignificant; but other results are contrary to those reported previously. Brownell and Dunk's research results in 1991 indicate that high budgetary participation is associated with improved managerial performance in difficult situations. Lau et al., (1995) consistently find that budgetary participation interacts significantly with task difficulty to positively affect performance. Schiff and Lewin (1970) state budgeting might be used

\footnotetext{
${ }^{6}$ However, by reviewing those researches, most of them focus on the relationship between participative budgeting (i.e. budgetary participation) and performance especially managerial performance, such as the research of Brownell in 1990 and 1991, Kren's research in 2003 and 2007.

${ }^{7}$ Organization structure in their research is measured by structuring of activities and centralization of authority. Structuring of activity concerns the degree of formal regulation of the intended activities of employees.
} 
as a coercive instrument by top management to "impose" its objectives on subordinates in the organization. Therefore they expect that a participative environment is of positive important to maximize organization effectiveness and individual satisfaction. Their research results, from in-depth interviews, show that the budget process significantly influences the outcome of their budgets. But the participative decision-making results in slack which managers can incorporate into their budgets. The link between budgetary participation and performance is, "at best, weakly" supported by Milani (1975). He finds that a significant impact of participation on performance only exists during the first two months of January and February ${ }^{8}$. In all other months, the effects are not significant. Dunk (1989), Otley and Pollanen (2002) even indicate negative findings for participation-performance relationship. The results from Dunk's research suggest that "high participation together with high budget emphasis lowers managerial performance, rather than increasing it."

Recently, a handful of studies (Awasthi et al., 1998; Chow, et al, 1994; Chow et al., 1996; Harrison, 1992; Harrison, et al, 1994; Chow, et al, 1999) examined management accounting techniques such as budgeting, standard costing from a cultural point of view. They argue that management control tools and management practices found to be effective in one environment, could be ineffective or even dysfunctional in another environment. Additionally, some accounting literature highlights the importance of the firm context including the organization's size, age, and degree of decentralization. They argue that the firm context is strongly contingent on the design and operation of a management accounting system such as budgeting, cost accounting etc. For example, Bruns \& Waterhouse (1975) conclude that budget-related behavior ${ }^{9}$ is found to be contingent on various aspects of the organizational structure such as centralization, autonomy, and the degree to which activities are structured. Budget-related behavior, in their research, is defined as the activities, actions, and interaction of managers with each other and their tasks, that relate, either directly or indirectly, to budgeting. The present study, it is designed to focus specifically on two aspects of firm context viz. firm size and ownership. The reasons to select these two factors for testing are: Firstly, firm size is one of the most popular variables, widely used as a control variable, in previous research, especially in quantitative research; secondly, when research is related to

\footnotetext{
${ }^{8}$ Performance is measured by the percentage of growth for a month in Milani's research.

${ }^{9}$ It is measured by the quantity of such behavior, the kind of behavior, and the quality and satisfaction in terms of the extent to which the budget is seen.
} 
performance, ownership structure is usually considered an important factor affecting performance. There are many empirical studies on ownership structure and performance. Barclay and Holderness (1991) find that different ownerships significantly affect financial performance, which is measured by return on sales and return on equity. Agrawal and Knoeber (1996) analyze the ownership structure and financial performance of 383 large US firms. They conclude that ownership significantly impacts financial performance. Since Chinese SMEs have different ownership structures (to be discussed in Chapter 3), in the present study, it is assumed that ownership will also affect the performance of SMEs; thirdly, studying the previous SMEs' research, we find that, although large firms are excluded from this study, firm size is still a common variable to be used. For example, Wijewardena and De Zoysa (2001) investigate the impact of financial planning and control on performance of SMEs in Australia. They make a clear distinction between small firms and middle sized firms in their research sample. Some 80 per cent of firms in the sample are small firms. Another 20 per cent of sample firms are medium-scale. They define that firms employing fewer than 100 employees belong to the small industry category, while firms with 101 to 300 employees represent medium-sized firms. Based on the reasons above, firm size and ownership, these two variables will be introduced in the present research model as control variables. This study will examine whether they affect the budgeting of Chinese firms.

\subsubsection{Performance Measurement in SMEs}

Financial performance (e.g. profitability, growth) is used, in the vast majority of existing studies, to measure business performance (Murphy et al., 1996). However, the use of financial performance measures to evaluate organizational effectiveness has been criticized for being too narrowly focused. In a pioneering work by Hopwood in 1972, he explores the role of accounting data in performance evaluation and points to five negative aspects of reliance on accounting performance measures (RAPM). Firstly, not all the relevant dimensions of performance are included in an accounting report, for example managerial activity. Secondly, an organization's economic cost function is rarely known precisely and an accounting system can only attempt to approximately represent its complexity. Thirdly, the accounting data are primarily concerned with representing outcome, however, managerial activity in an organization is concerned with the detailed process resulting in the final outcomes. If there are factors that limit 
the reported efficiency of the process, despite the quality of the manager's performance, the accounting data will be an inadequate reflection of his performance. Fourthly, the main emphasis in accounting reports is on short-term performance, without more longterm considerations. Finally, accounting reports can fail to perfectly satisfy the requirements for any single purpose, since the reports are used to serve many purposes. Following Hopwood, a lot of researchers have continued the work on RAPM. For instance, Chakravarthy (1986) states that accounting performance measures are considered necessary, but not sufficient to define overall effectiveness. Bento and White in 2001 also mention the limitations of using accounting data in a small organization. They explain that accounting based performance measures for SMEs research suffer from two key drawbacks: firstly, the non-homogeneity of data (for example, resulting from the use of different depreciation and stock evaluation methods) or different measures and reporting standards used by different organizations; and secondly, the non-availability of data for smaller firms. The latter is particularly pertinent in China, where SMEs will not open their financial information to the public. Mckiernan and Morries in 1994 claim that 'overall' performance measures with a set of multidimensional measures are more appropriate. So, more subjective criteria might be better to gain insight into the performance in small firms and would seem to be more closely aligned with the determinants of performance identified by Keats and Bracker (1988) and Lumpkin and Dess (1996) in their conceptual frameworks for assessing performance in small firms.

Many studies (e.g. Brownell, 1982; Brownell \& Hirst, 1986; Frucot \& Shearon, 1991; Gul et al., 1995) relating to relationships between budgeting and performance have incorporated non-financial measures such as job satisfaction, job related tension, organization goals. Brownell (1982) examines the interaction between supervisory evaluative style and budgetary participation impacting job satisfaction. The results indicate that supervisory evaluative style and budgetary participation exert "a substantial positive" impact on job satisfaction. Brownell and Hirst (1986) test whether budgetary participation (BP) and task uncertainty effect managerial performance or jobrelated tension (JRT). The statistical results show that substantially lower JRT results from the use of BP in low task uncertainty situations. However, "no coefficient of any significance" is yielded between BP and managerial performance. Nevertheless, quite a number of studies adopt this multiple metrics into small organizations' research. 
Therefore, the wide use of multiple dimensions of performance in SMEs' budgeting research has to be reinforced in future research to more appropriately evaluate the budgeting and performance nexus.

\subsubsection{Chinese SMEs}

The growing significance of SMEs in China's economy is difficult to ignore. Because of their flexibility and resilience, their easy start of business, their potential to influence the growth of domestic demands, SMEs are pivotal to the current development of the Chinese economy. According to the National Development and Reform Committee (NDRC, 2004), formally registered SMEs represent more than 99.6 percent of all enterprises in China, accounting for 55.6 percent of GDP and 62.3 percent of imports and exports, and contributing 46.2 percent of tax revenues to the national economy. On the other hand, the Chinese government is also acutely aware of the impact that SME's as creators of jobs can have on forestalling potential social unrest. By the end of 2003, SMEs provided 75 percent of the employment in urban areas, increasing by 24 times compared to 1989 (National Bureau of Statistic of China, 2003). Despite the important role for growth and employment, however, SMEs are still facing particular difficulties due to their limited size and shortcomings in personnel, information, management, and especially financing. The development of small and medium scaled enterprises does not

go smoothly. It is generally believed that many SMEs do not survive their first years in business (Altman, 1983; Persson, 2004). The same situation occurs in China where many private SMEs go bankrupt and the bankruptcy of SMEs in a period of three to five years is some 50 percent (Wang, 2004). Several sampling surveys in recent years in China reflect the difficulty of financing for most SMEs. One survey in 1998 for 2,000 SMEs shows that the major capital (more than 50 percent of the total assets) of threefourths of the surveyed SMEs came from self-accumulation. In another survey by Lin in 2003, 53.8 percent of sample enterprises $(3,027)$ mentioned "scarcity in capital" as the most detrimental problem to enterprise development.

Small and medium enterprises have been a concern of researchers since the 1970s, when they were primarily seen as a job creation tool. Their potential capacity in business society extends from creating jobs at low capital cost, to expanding a pool of skilled and semi-skilled workers; from filling market niches that are not profitable for large enterprises, to contributing significantly to the economy and the output of goods 
and services; and from taking opportunities for developing and adapting the appropriate technology to providing an excellent breeding ground for entrepreneurial and managerial talent (Tolentino, 2000). Public attention for SMEs started in the 1990s. The role of the 'entrepreneurial enterprise' has been particularly emphasized in SME literature, since some researchers (Berger \& Udell, 1998) believe that innovation, as an engine of economic growth, essentially depends on an expansion of entrepreneurial base in SMEs.

Although in the research more and more extensive attention has been paid, compared with large companies, statistical data of Chinese SMEs are still lacking (Hillary, 1999). Taking budgeting research of SMEs as an example, most previous studies focus on the relevance and application of budgets to large, complex and listed organizations or in advanced countries. Pike (1982) indicates the broad trends in the use of budgets in a survey of 150 large and medium manufacturing companies in the UK. Nevertheless, less data are collected from small, unlisted organizations, or from developing countries. The inadequate results and findings, in turn, result in the deficiency of existing conceptual models and the low level of research for SMEs. In summary, an imperative highlight should be given to small and medium-sized organizations.

\subsection{Objectives of the Research}

In response to previous research problems on budgeting and performance, especially the limited research related to small and medium organizations, the purpose of this study is to describe and explore the relationship between budgeting and performance. The exploratory inquiry attempts to discover or identify potential variables regarding budgeting and performance relationship in SMEs from a review of the scholarly literature. The study then tries to examine whether the established relationship between budgeting and performance is confirmed by the actual budgetary practice of Chinese SMEs. The descriptive purposes of this study include, firstly, illustrating the theoretical

linkage of budgeting and performance from previous research, and secondly, presenting how budgeting is conducted in Chinese SMEs. The following is a list of the objectives of this study:

- to explore the theoretical impact of budgeting on performance in small and medium enterprises;

- to define and determine how to measure performance in SMEs; 
- to understand how budgeting affects on the performance in Chinese SMEs;

- Finally, to further investigate whether the theoretical impact is changed by the corporate context (i.e., size of firm, ownership) in SMEs.

\subsection{Research Questions}

\section{Central question:}

\section{- How does the budgeting process impact the performance of SMEs in China?}

First of all, one needs to realize that budgeting, like other accounting concepts such as traditional costing, activities-based costing ( $\mathrm{ABC})$, etc., has different appearances, as a theoretical concept, as a technological term, and as an administrative tool. When we consider its implementation in an organization, we can image that budgeting in its different appearances can influence the diverse actors internal and external to the $\operatorname{organization}^{10}$. Therefore, budgeting at the organizational level is actually a dynamic process, instead of a pure concept. Although the definition of budgeting as a process is commonly accepted in management accounting literature (for example, Little et al. in 2002 state that budgeting is one of the fundamental decision-making process in organization), actually a number of studies attempt to link the extent of the budgeting process with its potential impact on firm performance. The most intensive discussion in previous budgeting studies has been on budgetary participation and its impact on performance, which only focuses on large organizations. Also, the budgeting studies for small and medium-sized enterprises are overlooked by most of researchers. In order to fill in the gaps in previous research, the author poses the central question above and explores the potential relationship between budgeting process and performance in SMEs. This central question will be answered both by theoretical exploration and empirical investigation, so the derived questions are generated accordingly, as follows:

\section{Derived questions:}

- Theoretical questions:

The following theoretical questions are based on the theory.

1. How do we define SMEs?

The first theoretical question addressed in this study is how to define SMEs. This study question is related to the decision how to distinguish small and middle-sized enterprises from big ones. Many standards in terms of determining the size of SMEs are available

${ }^{10}$ Ahrens \& Chapman, 2006 
in the existing literature, such as the number of employees, total assets of an enterprise, annual sales revenues, etc. However, we can only choose a single one to identify SMEs, specifically the one suitable to define the SMEs in China. The second question is which measure is most suitable for Chinese SMEs. To answer this question, a further literature review is necessary. Reviewing the previous literature, especially the literature on Chinese SMEs, will show how SMEs were measured in the past.

\section{How do we measure performance in SMEs?}

The second question is about firm performance. It is taken as the dependent variable in this study. Therefore, it is important to explore how to measure firm performance for small and medium-sized enterprises. It is equally critical to know what limitations have been found from the previous performance literature, and how to improve the existing measurement to reflect the overall performance. Literature review is once again the main research method to answer the second question.

3. What is the formal budgeting process and how does it affect performance of SMEs?

The third theoretical question deals with the independent variable, i.e. the formal budgeting process and to explore how this affects the performance of SMEs. Previous studies indicate that the extent of the budgeting process (ranging from the narrowest, no budget use, to the broadest detailed comparison between actual performance and budgeted performance, with frequently corrective action) impacts the performance of SMEs. The more a formal budgeting process is used, the higher the rating of performance in SMEs. However, the dimension of the formal budgeting process is only restricted in terms of budgeting planning and budgetary control. It is necessary to give a much broader definition of the formal budgeting process, because other aspects or dimensions related to the budgeting process are also, as argued before, strongly linked with performance. Therefore, in this study, the existing model of formal budgeting process in small and medium-sized enterprise will add more dimensions that are expected to positively affect performance of SMEs.

4. How do we define the role of budgetary participation in the budgeting process, and how does it impact managerial performance?

Budgetary participation, when it is discussed, is traditionally only related to performance. Thus, many studies in the past intended to find the link between budgetary participation and managerial performance. It seems that no single research puts budgetary participation into the budgeting process and emphasizes its role under this 
condition. Thus, what the role of budgetary participation is in the budgeting process and how it influences managerial performance is going to be addressed in this study.

- Empirical questions:

The empirical questions shift our research focus from existing literature or theory into the empirical field or practice. Nevertheless, the empirical questions correspond to the theoretical questions mentioned before. Four empirical questions in total will follow. The empirical questions attempt to address, in general, whether some concepts or assumed relationships can be proven further empirically. If not, what are the actual patterns? As we can see, the empirical questions correspond to the theoretical questions.

5. What is the extent of the budgeting process in Chinese SMEs?

In theory, the activities of predicting and qualifying future requirements for finance socalled budgeting, triggers a series of activities and achieves multiple objectives in an organization such as planning, coordinating, communication control, and evaluation. However, in reality, budgeting process presents more diverse patterns. Some organizations have no single budget plan at all. The budgeting process in some organizations covers planning and control. While for other organizations, budgeting process has been implemented to a very advanced level including planning, coordinating, control, and performance evaluation. Therefore, this empirical question attempts to monitor the extent of the budgeting process in Chinese SMEs.

6. Does the formal budgeting process positively affect Chinese SMEs' performance? After monitoring the extent of budgeting process in the sampled SMEs in China, we shall attempt to find what the relationship is between the budgeting process and performance in the sampled Chinese SMEs. The purpose of this research question is to test whether the budgeting process and performance relationship suggested by theoretical literature can be confirmed by the empirical data.

7. Does budgetary participation in the budgeting process of Chinese SMEs enhance managerial performance?

As we discussed (Section 1.1.1), budgetary participation is expected to be a crucial channel to improve the information exchange and sharing among all levels of management. The impact of budgetary participation on managerial performance is widely studied. However, those researches were only applied to large firms and their results are ambiguous. The role of $\mathrm{BP}$ in small and middle-sized firms and its effectiveness on the performance are unclear so far. Therefore, this empirical question 
is going to monitor the role of budgetary participation and its relation with managerial performance among SMEs.

The firm size and ownership are, as the control variables, examined in this study. Therefore, this study tests: firstly whether the impact of the budgeting process on performance differs between Chinese small firms and middle-sized firms and Chinese SMEs; secondly, whether the impact of the budgeting process on performance differs between state-owned and private firms in China.

By addressing all eight questions, this study will show how the budgeting process is related to the performance in SMEs from both theory and practice.

\subsection{Importance of the Proposed Research}

\section{For Theory}

The significance of the current study first of all contributes to budgeting theory. This study draws on researchers' observation from the obviously ignored area of financial planning and control in small and medium-sized enterprises. It tries to fill the gap in previous literature about how budgeting affects performance in small and medium enterprises' business context, especially in China. It gives a fresh insight into the possible correlation between budgeting and performance in SMEs by theoretical exploration. Moreover, through conducting empirical investigation, the present study shows how budgeting undertakes and impacts performance in Chinese SMEs. Finally, it expands the existing findings in the budgeting literature. Because quantitative research is involved in the current study, it will enhance the existing research with more empirical data. Also, the current study contributes to SME literature, particularly in terms of the performance measurement in SMEs. In this study, financial measurements mixed with non-financial measurements are suggested to holistically reflect the whole performance of SMEs.

\section{For Empirical Practice}

Practically, this study, as a whole, caters to a perceived need of most SMEs owners/managers for better budgeting practice to improve performance. The findings of this research will provide owners/managers of SMEs with more useful understanding about budgeting and participation, i.e. how to apply the budgeting system; how to adjust budget practice within organizations; whether it is useful to apply participation in a small organization. They may change their attitude and/or behavior concerning 
budgeting activity, and finally enhance the beneficial outcome of management accounting system at the firm level. The results will simultaneously contribute to business consultants to better understand financial planning implementation in medium and small firms. This study also responds to the fast growth of SMEs, not only domestically but also globally. As developing countries become more industrialized, the implementation of the management accounting systems and techniques in developing countries remains an important issue. Small and medium sized enterprises are quite different from large firms. Therefore, more empirical studies are expected to be addressing this issue, to investigate how budgeting should be suitably applied and covered, which will positively improve their performance. The findings give more evidence on the effectiveness of budgeting practice towards Chinese SMEs and give suggestions to SMEs of other developing countries.

\subsection{Methodology Design}

\subsubsection{Overall Paradigm for the Current Research}

If we consider research as a cycle between theory (explanation) and data (description), then we can distinguish between deductive and inductive modes. Deductive work generates hypotheses from theoretical assumptions and tests them against empirical observation (data). This mode is concerned with the potential falsification of theoretical statements by checking their predicted consequences against real-world observations. Inductive work consists of making generalization from observations resulting in theoretical statements which attempt to explain the occurrence of the observed phenomena. It has been established that the favored research approach for the current study is largely a deductive approach. The reason is that this study starts with using existing theory. According to existing theory, new theory will be developed. Although the new theory may not be explicit at the beginning of a research project, it will be tested as a hypothesis and will be made explicit in the findings and conclusions. For inductive approach, however, theory would follow data rather than vice versa. A deductive approach also determines a quantitative paradigm, which will be the main paradigm of the current study. The quantitative paradigm presents quantitative evidence to all empirical questions, which will describe 'what' the extent of budgeting process is in Chinese SMEs, and 'whether' the budgeting process exerts strong impact on firm performance. 


\subsubsection{Research Methods Design Related to Different Research Questions}

Under the quantitative research paradigm, a number of supplementary research methods ${ }^{11}$ are applied in this research to find the best match for the different research questions (i.e. derived research questions) to be addressed. So the subsequent text tries to give more detailed discussions and explanations on the multiple methods design. It starts with defining the type of each research question, since "the form of the question can provide an important clue regarding the appropriate research strategy to be used" (Yin, 2003). Then, research strategies and methods of data collection are determined. Finally, the argument gives the overall map of the research design of this study.

\section{Descriptive and Exploratory Studies}

The first four research questions (from $\mathrm{Q}^{12} .1$ to Q.4) focus on a theoretical exploration of the performance measurement and budgeting-performance relationship in SMEs. The initial research question is used to find out how performance in SMEs was measured in the past and how it should be measured in future research. According to the statement of Saunders et al. (2003), when the researcher wishes to clarify his/her understanding of a problem, the research will be a desk research of the existing literature. Then, the rest of three questions are formulated to discover or identify from existing literature the potential variables for how budgeting affects performance in SMEs. As McReynolds et al. (2001) define this, exploratory studies are established when variables need to be identified or discovered, when the researcher is investigating phenomena that are not well understood. Therefore, a desk research is also used in dealing with theoretical questions.

From Q.5 to Q.7, these three research questions turn our attention to the empirical exploration of the impact of budgeting on performance in Chinese small and medium enterprises. Instead of pure exploration, however, descriptive quantitative studies are grouped into this level of research. The reason is that the starting point of this study wants to describe how budgeting is undertaken in SMEs, in what forms, and how good the SMEs' performance is. So if the researcher is interested in documenting the phenomenon of interest, the study reflects descriptive purpose (McReynolds et al. 2001). After the description, the study will further investigate how budgeting impacts SMEs'

\footnotetext{
${ }^{11}$ It is noted that the concept of "methods" in this chapter specifically refers to the different research strategies (such as experiment, survey, case study, action research etc.) and the different data collection methods.

12 "Q" in this paper stands for research question.
} 
performance, how firm size and ownership influence budgeting and performance in SMEs. The variables of firm size and ownership are considered control variables (or contextual variables) that moderate the relationship between dependent variables and independent variables in the model of this study.

\section{Literature Review for the Theoretical Questions}

Based on the above arguments, a review of the scholarly literature serves as an initial research strategy to conduct investigation in this study. It also aims to give clear answers to Q.1, Q.2, Q.3, and Q.4. The critical literature review in the next chapter, therefore, begins to provide a logical explanation of the link between budgeting and performance, based on the existing literature framework of the budgeting and performance available. It then continues to explore how budgeting affects performance in the context of small and medium sized enterprises. Specifically, for Q.2, the use of financial and non-financial performance measurements in SMEs is argued from theory and practice. The discussion aims to strengthen our understanding of how performance ought to be measured in SMEs and also serves as a guide to develop the conceptual model of the present research. For Q.3, considering that budgeting has its various functions as financial planning, performance evaluation, administrative tool etc. that its application in organizations can be at different levels, the author tries to analyze how the extent of budgeting that managers and other organizational participants use (or the extent of use of formal budgetary process) can impact the firm performance in SMEs. As to Q.4, the next chapter also defines the role of budgetary participation in budgeting process and analyzes how budgetary participation affects managerial performance in SMEs. Chapter 3 will discuss what measure will be used to define Chinese SMEs to answer Q.1. In general, through reviewing literature, the researcher is able to examine how others have approached the topic concerned in the past and to use the established analysis to fine-tune the possible relationship between budgeting-performance for Chinese SMEs.

\section{Survey and Questionnaire for the Empirical Questions}

This research uses a modest survey as research strategy to answer empirical questions from Q.5 to Q.7. Therefore, a questionnaire was distributed among 150 small and medium-sized firms in China and was answered by 75 firms. The data collected by the survey (see in Chapter 5) attempt to provide descriptive information, such as what dimensions of budgeting process covers in a firm, if those dimensions are implemented 
in each firm and in what form. More importantly, these data are used for statistical analysis to prove/disprove the assumed positive relationships among variables and to accept/reject all hypotheses of this study (all those relationships and hypotheses will be presented in the following Chapter 2). The data collection also determines the type of data to address the empirical questions of this study, i.e. primary and quantitative data.

Table 1.1 Summary of Methodology Design for Each Research Question

\begin{tabular}{|c|c|c|c|}
\hline $\begin{array}{c}\text { Research } \\
\text { Question }\end{array}$ & $\begin{array}{c}\text { Level of } \\
\text { Research } \\
\text { Enquiry }\end{array}$ & Research Strategy & Data Collection (Type of Data) \\
\hline Q.1 to Q.3 & Exploration & Literature Review & $\begin{array}{c}\text { Secondary literature sources such as } \\
\text { books journals in library or the } \\
\text { Internet (Secondary Data) }\end{array}$ \\
\hline Q.4 & Explanation & Literature Review & $\begin{array}{c}\text { Secondary literature sources } \\
\text { (Secondary Data) }\end{array}$ \\
\hline Q.5 to Q.7 & $\begin{array}{c}\text { Description \& } \\
\text { Exploration }\end{array}$ & Modest survey (75 firms) & Questionnaires (Primary Data) \\
\hline
\end{tabular}

\subsection{Process of the Research}

Two procedures (i.e. from previous theory to empirical data and from empirical data to tentative theories) go through the process of this study to address the designed research questions. (Illustrated in figure 1.3)

This research will start with an extensive review of the literature for both budgeting and performance. This phase is subdivided into the phases of theoretical analysis of budgeting impact on performance in general, and of the budgeting-performance relationship towards SMEs, particular Chinese SMEs, in specific. Through this logical exploration of the existing bodies of literature, an initial conceptual framework of budgeting-performance relationship in Chinese SMEs will be established. Based on the implication of the conceptual framework, the tentative propositions also will be generated as assumptions, which shall be checked by empirical results later on. The literature review will, on the other hand, identify previous research deficiencies or gaps. It will then provide a place for current research to make the corresponding development towards those limitations and gaps. The second process of this study is conducting a sample study aimed at obtaining empirical research findings. Within this process, some subdivided phases are grouped, such as crafting instruments, monitoring questionnaires, analyzing quantitative data from the survey, reporting empirical findings, modifying hypothesis (if need be) or providing more explanation of the existing literature, and finally reaching conclusions. 
Figure1.2 Research Process

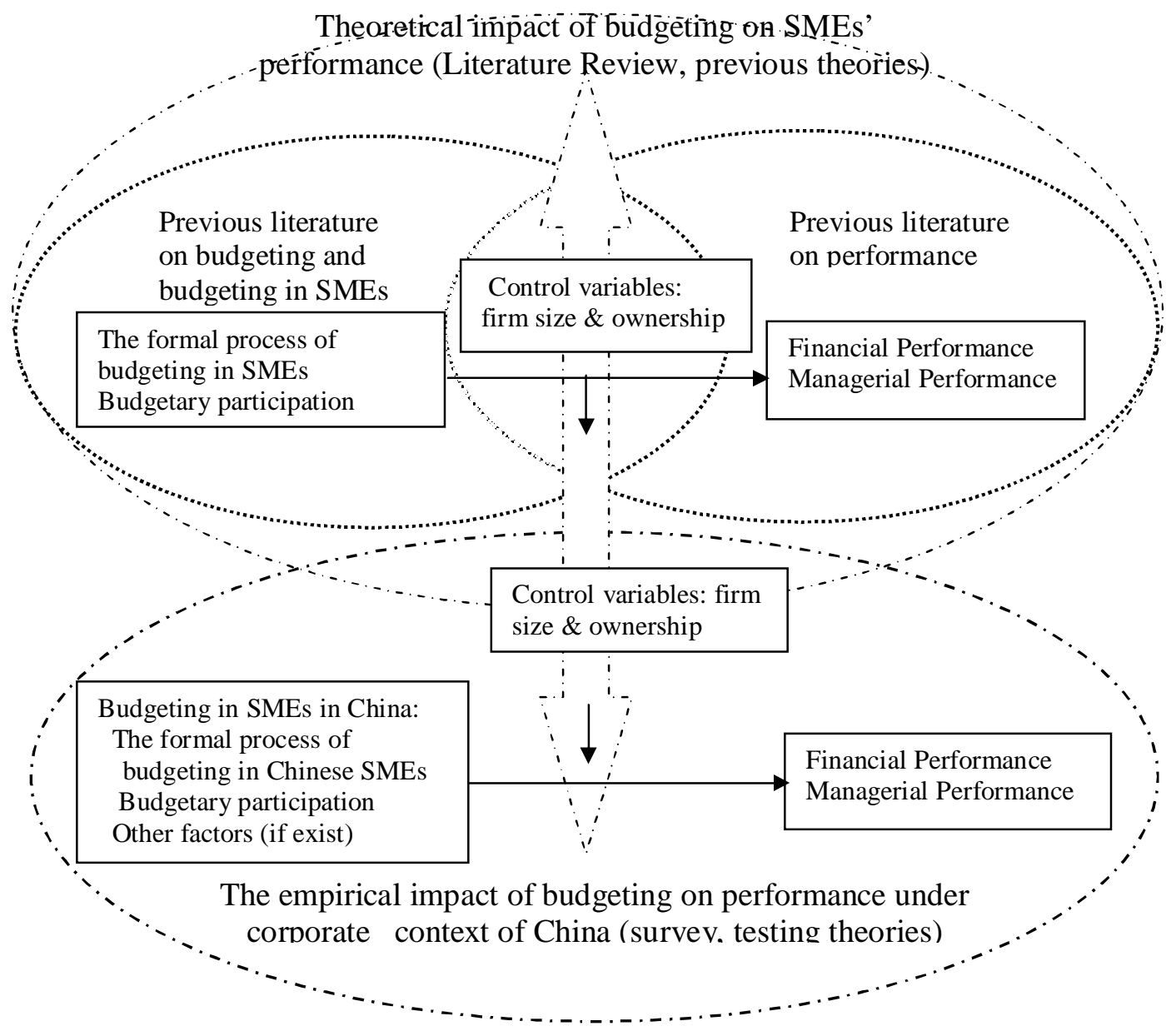

\subsection{Outline of the Dissertation}

- Chapter 2 Budgeting and Performance

After the present chapter, the second chapter will specifically focus on existing theories and knowledge related to budgeting and performance measurement in SMEs. Q1, Q2, Q.3 and Q.4 are dealt with in this chapter. We define and evaluate performance in SMEs. The researcher then attempts to find the impact of budgeting on performance from the existing models/theories, and also analyzes the effect while considering other potential variables' interference.

\section{- Chapter 3 SMEs in China}

There are two issues to be addressed in this section: the first is the definition of SMEs; the second is the general description of SMEs' development in China. The clarification will contribute to operationalize the control variable of SMEs in the background of China and to generate a conceptual model in the following chapter. 
- Chapter 4 Conceptual Model of this study

Based on literature review, a conceptual model will be developed in this chapter. The conceptual model will postulate the relationships among the variables (independent variables, dependent variables, and control variable). Another important task in this chapter is to operationalize all variables emanating from empirical questions to guide thereafter the practical investigation. The reliability of each measure is assessed by Cronbach alpha. Additionally, this chapter will present the methodology design for all empirical questions in detail. It includes the rationale for choosing a combined research method; deciding the methods of data collection and what data have to be collected; describing the function of qualitative data and quantitative data in this study; discussing how to provide questionnaires and conduct interview; and techniques of data analysis.

- Chapter 5 Descriptive Data Analysis

In this chapter, descriptive data from questionnaires are provided. Generally, descriptive statistics from SPSS will give numerical information regarding the extent of budgeting process in Chinese SMEs, how the firm performance of Chinese SMEs is, and the possible implication of their correlations.

- Chapter 6 Statistical Data Analysis

In this part, firstly, the statistical analysis is conducted. The hypotheses are either rejected or accepted. The answers for empirical questions are given based on statistical data. Finally, the study wants to accomplish all the research objectives and answer the questions in this study.

- Chapter 7 Conclusions and Recommendations for Future Research

The last chapter of this thesis will summarize the contributions of current research to the existing budgeting and performance literature and the SMEs' budgetary practice. Pointing out limitations of the current research and give recommendations for future research will be addressed within the final chapter.

\section{Summary:}

- This chapter intends to provide the reader with a brief but complete overview of the current research.

- Three major areas of concern in this study are: budgeting in a business firm, performance measurement in SMEs, and SMEs. 
- The central research question is: how does the budgeting process impact performance of SMEs.

- A quantitative paradigm is designed to address all the research questions (central question and derived questions) and to provide descriptive and explorative data.

- A modest survey is determined to be used as the data collection method of this study.

Figure 1.3 Dissertation Outline and Research Questions to Be Addressed in Chapters

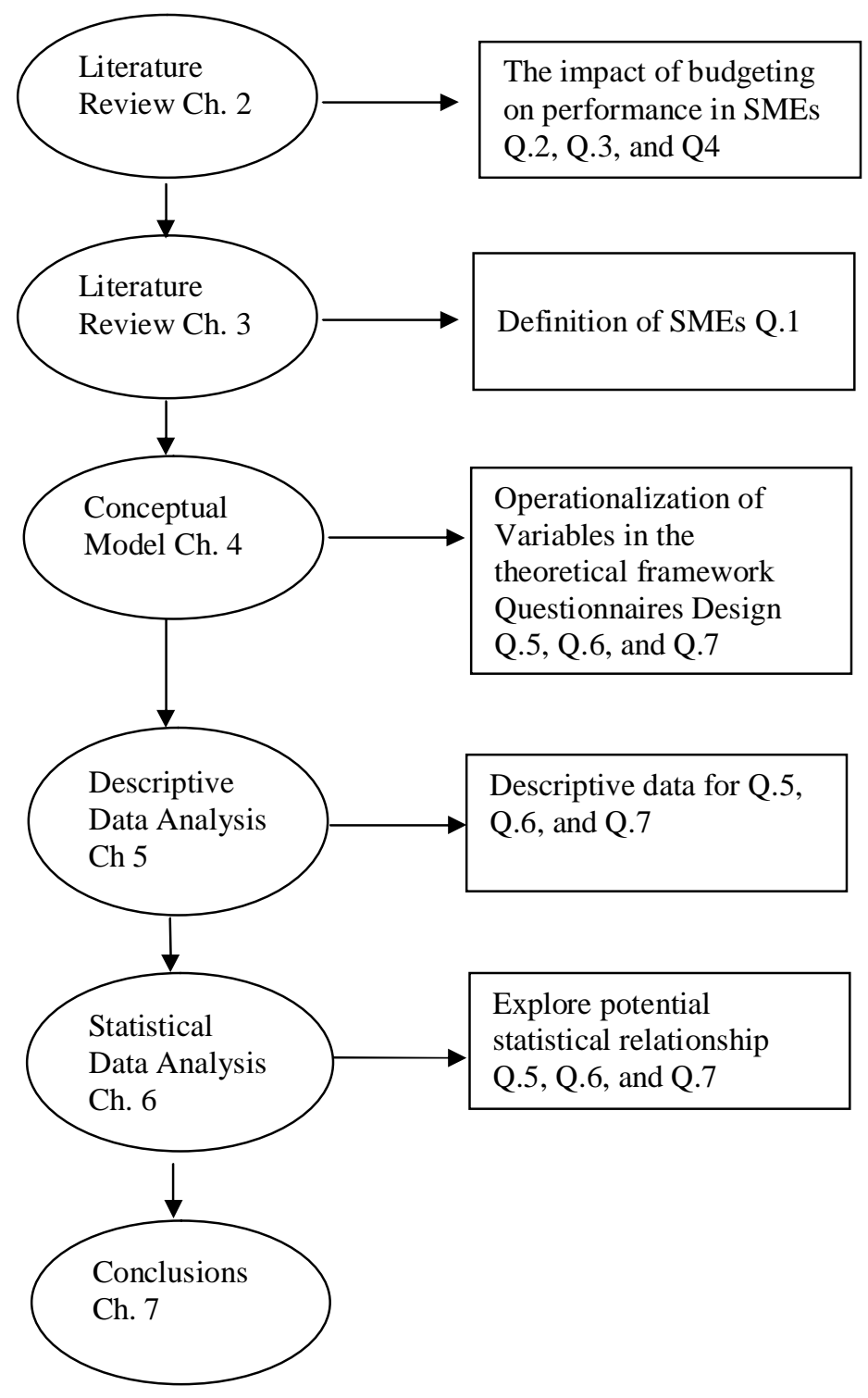




\section{Chapter 2}

\section{Budgeting Process and Performance}

This chapter provides an overview of the previous literature on budgeting process and performance. Some basic concepts such as budgeting process (Section 2.1), budgeting planning and budgetary control (Section 2.2), the formal process of budgeting (Section 2.3), budgetary participation (Section 2.4), and performance (Section 2.5) are defined and explained in this chapter. Additionally, this literature review also aims to find what the existing model is to link budgeting and performance in SMEs, how budgeting impacts SMEs' performance, and whether other potential factors can be found to develop the existing model.

\subsection{Budgeting Process: An Overview}

As we stated in the previous chapter, a budget is a detailed and quantitative plan. It shows the information about the acquisition and use of financial and other resources over a specific time period, either a long-range period (two- to ten-year) or a short-term period (one- to two-year, or monthly, or daily-based). Budgets require management to specify expected sales in the case of a market organization, cash inflows and outflows, and costs (Horngren, 2006). Budgets provide rational and tangible data facilitating and enabling decision-making of organizations. Instead of expressing a budget as a statically financial plan or blueprint, the term "budgeting" refers to the act of preparing a budget or the activities of predicting and qualifying future requirements for finance (Garisson, et al., 2003). In theoretical management accounting literature, some theorists (e.g. Drury, 2000; Joshi, 2003; Garrison et al., 2003 and so on) believe that through budgeting in the process of financial decision-making and internal operation of organization, multiple functions (see in Table 2.1) regarding budgeting behavior can be achieved. These functions are planning, coordinating, communicating, control, and evaluating. If administered wisely, budgeting (a) compels management planning, (b) provides definite expectations that are the best framework for judging subsequent performance, and (c) promotes effective communication and coordination among various segments of the organization (Horngren, 1977, pp. 125). The above view also reflects the processual character of budgeting in a business organization (Covaleski \& Dirsmith, 1985; Ahrens et. al, 2006). We note that budgeting with its multiple functions triggers a series of activities (from the narrowest to the broadest associated with planning, coordinating, communicating, control, and evaluating) within different 
departments of organizations during its adoption. Therefore, another derived term, budgeting process ${ }^{13}$, is created and is widely used by the management accounting literature to reflect the dynamic nature of budgeting practice in a firm. Table 2.1 summarizes the purposes of budgeting in a firm.

Table2.1 The Objectives of Budgeting in Business Organization:

1. To aid the planning of annual operations.

2. To coordinate the activities of the various parts of the organization and to ensure that the parts are in harmony with each other.

3. To communicate plans to the various responsibility center managers.

4. To motivate managers to strive to achieve the organizational goals.

5. To control activities

6. To evaluate the performance of managers.

Source: Drury C., 2000

Although the multiple functions of budgeting are stated in previous research, that research focuses heavily on budgeting and its application to large, publicly listed organizations in developed countries. For example, Dugdale (1994) finds that the U.K. companies derive high benefits from the use of budgeting planning, or Bonn and Christodoulou (1996) indicate that 72 per cent of the largest manufacturing companies in Australia use formalized strategic planning systems.

Joshi, et al. (2003), however, examines budgeting planning, control, and performance evaluation practices in a developing country. He conducts a questionnaire survey of 54 medium- and large-sized firms, including both the listed and non-listed firms located in Bahrain. His research finds that most of the firms prepare long-range plans and operating budgets, and use budget variances to measure a manager's performance, for "timely recognition of problems, and to improve the next period's budget". Additionally, there has been some discussion in the academic literature on the relationship between strategic planning and performance of SMEs (Aram \& Cowen, 1990; Hillidge, 1990; Knight, 1993), but researchers have not paid considerable attention to the possible relationship between budgeting process and performance in SMEs (Wijewardena \& De Zoysa, 2001). So the process of budgeting and its relationship with performance in SMEs are still unclear. Merchant (1981) points out that the budgeting process is adopted differently in forms which differ in size and/or diversity of organizational

\footnotetext{
${ }^{13}$ Budgeting process thus can also be called functional budgeting because the focus is on preparing budgets for various functions. (Horngren, et al. 2005, "Introduction to Management Accounting", pp. 314)
} 
system. Accordingly, due to the restriction of limited size and resources, budgeting process in SMEs is, probably, different from that of large companies. The issue of how budgeting process in SMEs impacts their performance is, therefore, certainly worthwhile to be explored.

Therefore, this chapter begins by discussing the basic processes of budgeting that are supposed to be applied in most of business organizations, i.e. budgeting planning and budgetary control, to set up a theoretical basis for the current research. Then, the question how budgeting process impacts the performance of SMEs will be explored, from previous literature. We noted that a crucial task in this study is to argue the importance of participation in the budgeting process, the factor that is overlooked in the prior budgetary literature of SMEs, and how it affects performance. Finally, some hypotheses in this study are concluded, by a critical review of literature.

\subsection{Budgeting Planning and Budgetary Control}

Although budgeting at the organizational level serves multiple purposes and functions, most studies (Amey, 1979; Ezzamel \& Hart, 1987; Bremser, 1988; Douglas, 1994) still pay much attention to the two basic roles of budgets: planning and control, so-called "dual purpose". Budgeting process in management accounting is thereby generally classified into budgeting planning and budgetary control.

\subsubsection{Basic Process of Budgeting Planning}

Briefly, budgeting planning (budget-setting or budget preparation) refers to developing quantitative goals of the organization and preparing various budgets (Bodie \& Merton, 2000). Figure 2.1 shows a review of the different types of budgets used in a manufacturing sector. Business organizations use long-term budgets to lay out the planned financial goals and actions over periods ranging from two to ten years. Longterm budgets are part of an integrated business strategy that along with production and marketing plans, guides the firm toward strategic goals (Gitman, 2006). So in this regard, long-term budgets ${ }^{14}$ are closely related to strategic plans. Capital budgets, as one example of long-term budgets, are emphasized in financial accounting and budgeting literature. Capital budgeting is defined by Garisson et al. in 2003 as a type of investment decision-making used to describe how managers plan significant outlays on

\footnotetext{
${ }^{14}$ Some accounting literature (Gitman, 2000; McLaney \& Atrill, 2002; Garrison, 2003) group the strategic plan directly into one of long-term budgets in business organizations.
} 
projects that have long-term implications. It details the planned expenditure for facilities, equipment, new products, and other long-term investments. The complete capital budgeting process involves a series of actions, including generating investment project proposals consistent with the firm's strategic objectives, estimating after-tax incremental operating cash flows for the investment projects, evaluating project incremental cash flows, selecting projects based on a value-maximizing acceptance criterion, reevaluating implemented investment projects continually, and performing post audits for completed projects ${ }^{15}$. Apart from long-term budgets, short-term budgets are used to guide day-to-day operations. Short-term (operating) budgeting specifies the acquisition and use of financial and other resources over a short-term period, which most often covers a 1- to 2-year (Garrison et al., 2003). The complete short-term budgeting in an organization consists of a number of separate but interdependent budgets preparations. The total package of those budgets is the Master Budget.

Figure 2.1 The Different Types of Budgets Interrelationship (typical model in manufacturing sector)

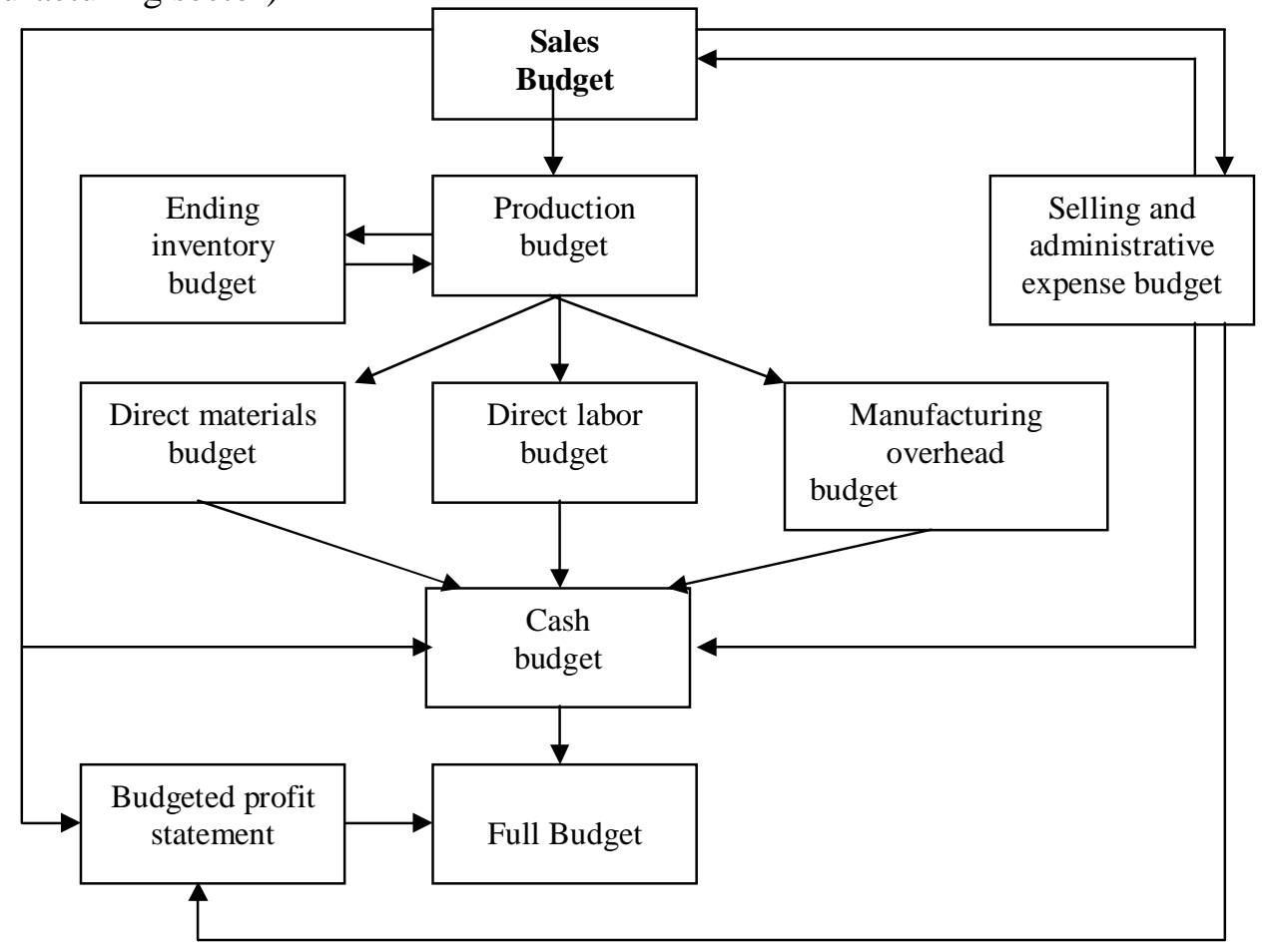

Source: Gitman, L.J., 2006

Figure 2.1 gives an illustration of the various items of the master budget on the basis of the model in manufacturing organizations and how they are related. Generally, the

${ }^{15}$ Horne \& Wachowicz, 1998 
process of short-term planning is actually the process of preparing the master budget. The key inputs of the master budget include the sales budgets, the cash budgets, and full budget.

\subsubsection{Budgetary Control}

Before we discuss budgetary control process, it is necessary to explain the concept of budget variance in advance. When there is a difference between the actual amount incurred or realized, and the corresponding budgeted (forecasted) figure, there is budget variance (Garisson, et al., 2003). It can be further divided into favorable variances and unfavorable variances. For revenue items, if actual revenues exceed budgeted revenues, the variance is favorable; while if actual revenues are less than the budgeted figure, this is unfavorable budget variance. For cost items, an unfavorable variance refers to a variance that decreases operating income relative to the budgeted amount; a favorable variance, however, increases operating income relative to the budgeted amount. Friedlob \& Plewa in 1996 point out that favorable budget variances are "generally signs of efficient, effective cost management and increases in net income". Conversely, unfavorable budget variances are results from inefficient, ineffective cost management, and reduced net income. Hirsch, Jr. (1994) summarizes the causality of variance, subdividing this into four reasons. Firstly, variance can be the result of inaccurate data. Secondly, an upward change in costs (price standard) or production conditions (quantity standard) can result in an unfavorable variance. Thirdly, variance can be the result of random happenings (something that is unlikely to occur on an ongoing basis.) Finally, variance can be the result of especially efficient or inefficient operations. Control, briefly, is the process of ensuring that a firm's activities conform to its plan and that its objectives are achieved (Drury, 1996). Accordingly, this process is commonly referred to as "budgetary control". The mechanism of budgetary control can be dated back to the contribution of Anthony (1965) on management control. In Anthony's framework, control activities in an organization are categorized into three major types, namely strategic planning, management control and operational control. Management control is the process that links strategic planning and operational control. As we have mentioned before, strategic planning is concerned with setting overall corporate strategies and objectives over the long-term; it belongs to one kind of long-term planning. Operational control is the process of ensuring that specific and immediate tasks are carried out. Examples of operational controls include labor, machines and materials utilization 
reports. They are employed within departments at the level where inputs are processed and resources are consumed to produce outputs. Following Anthony's framework, Emmanuel et al. (1990) also state that four conditions must be satisfied before any process can be said to be controlled. Firstly, objectives for the process being controlled must exist. Without an aim or purpose control has no meaning. Secondly, the output of the process must be measurable in terms of the dimensions defined by the objectives. In other words, there must be some mechanism for ascertaining whether the process is attaining its objectives. Thirdly, a predictive model of the process being controlled is required, so causes for non-attainment can be identified and proposed corrective actions evaluated. Finally, there must be a capability for taking action so deviations from objectives can be reduced. In 2000, Drury further introduced a mechanical control system (as shown in Figure 2.2).

Figure2.2 A Mechanical Control Process

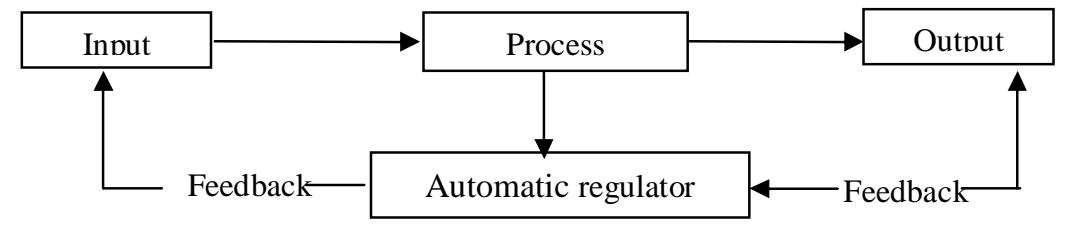

Source: Drury, C., 2000

The system consists of the following: the process is continually monitored by an automatic regulator; deviations from a predetermined level are identified by the automatic regulator, and corrective actions are started if the output is not equal to the predetermined level. As we mentioned in the former section (2.1), in theory, the budget system may not automatically achieve the function of control, but it can contribute to the use of control. Therefore, there is some overlap between budget and control. It is reasonable to conclude that the elements used in a mechanical control process can also be applied in a budgetary control system (Figure 2.3).

Figure2.3 Budgetary Control Process

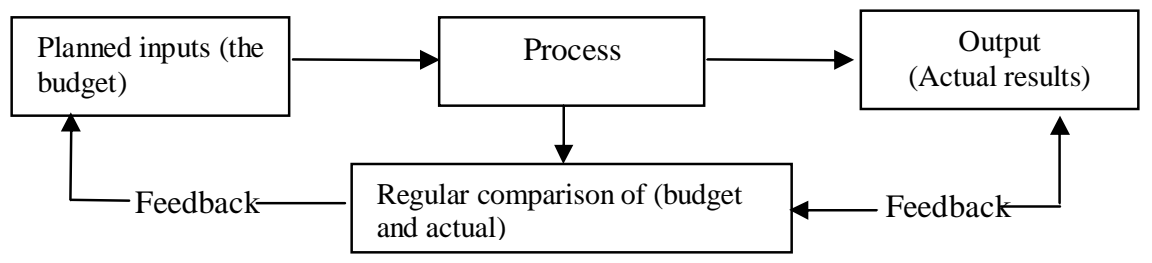

Source: Glynn, et al., 2008 
From the illustration above we can see that planned inputs as reflected in the budgets are compared with the actual results (i.e. the output) and the deviations from the desired inputs are identified. Apart from comparing of actual results with budget in identifying variances, the budgetary control model also emphasizes the importance of feedback management (or feedback control) which includes the required budgetary variances explanation and the corrective actions. Senior management should allow their lower/unit managers to explain variances in budget, and to report actions taken to correct the causes of those variances.

It is common knowledge that effective control is often necessary for achieving the maximum results from a predetermined plan of action in any organization. Even an excellent plan or budget may not produce the results as expected due to numerous unforeseen circumstances, which are internal or external to the firm. Therefore, measuring actual performance against planned performance from time to time and taking remedial action on factors causing unfavorable deviations from the plan are important for maximizing the results anticipated through planning (Koontz \& Weihrich, 1998; Wildavsky, 1975). Merchant (1985) provides empirical evidence that managers perform better when their superiors accepted a reasonable explanation for an unfavorable budget variance. McWatters (2008) also states that the unfavorable variances might not be seen to be harmful to the company when managers are required to provide justifications.

Considering the fact that the size of a firm and its complexity of operations generally influence the budgeting process it should adopt, this study focuses on the basic functions of budgeting in organizations i.e. budgeting planning and budgetary control. Therefore, we define budgeting process in this study as budgeting planning and budgetary control. Moreover, due to the restriction of research time, the current study only attempts to investigate the practice of short-term (operating) budgeting in SMEs.

\subsection{The Formal Budgeting Process}

\subsubsection{The Previous Definition of the Formal Budgeting Process}

It has been noted that budgeting has many aspects according to different identifications and classifications. However, the present study merely focuses on one aspect of budgeting i.e. the formal budgeting process. To explicitly define the formal budgeting 
process, we have to seek to the relevant implication broadly from both budgeting studies and outside of budgeting studies. The first reason is budgeting has the function of planning to predict and qualify future activities in financial term, so budgeting shows relations with business planning, especially with strategic planning. The researcher will firstly show how the formal planning process is defined in the existing planning literature and then provide potential suggestions to the definition of a formalized budgeting process. Secondly, the definition of the formal budgeting process available in previous research so far is also largely based on planning literature. Rue (1973) first defines the "planning formalization" referring to the completeness of the planning process used by the organization. By examining the planning practice of 386 small and medium-sized enterprises in manufacturing and service sectors, firms are accordingly classified into four classes: the first class is "no plan or documented plan" used in firms; the second class refers to those firms which have a "written plan covering at least three years in advance and including specification of goals and objectives" and those firms use long-range strategies; all firms in the third class must reach the criteria in the second class, additionally, those firms are also responsible for making "the determination of resources required in the form of pro forma financial statements and other quantitative projections"; firms in the final class are involved in procedures for anticipating or detecting errors in, or failures of, the plan for preventing or correcting them on a continuing basis, and some attempt to account for factors outside of the immediate environment of the firm. Subsequent researches (Robinson \& Pearce, 1983; Bracker \& Pearson, 1986; Berman, et al., 1997; Rue \& Ibrabim, 1998) further develop classification schemes of formalized planning in small and medium organizations. However, the most common indicators of a formal planning process are the presence of a written long-range plan covering at least three years, the formulation of goals and strategies, and some method for evaluating progress toward the plan.

Wijewardena and De Zoysa (2001) identify the formal process of budgeting in small and medium-scaled enterprises by two aspects, i.e. a formal process of budget planning and a formal process of budgetary control. Figure 2.4 illustrates the classification of those two aspects of budgeting process. They mention that firms in the first category do not use any type of written budget. Those in the second group prepare simple budgets with respect to few areas of operation representing a less comprehensive planning process. In the third group are firms using detailed budgets with respect to many 
different areas of operation. These firms were considered to be engaged in a more comprehensive planning process. In addition, budgeting as management control is also emphasized in their model. Then in terms of budgetary control, the firms falling into the second and third categories are re-classified into three additional categories. Firms in the first category do not calculate differences (variances) between actual performance and budgeted performance. Firms in the second category occasionally use budget variances with respect to a few specific items for taking suitable corrective action. The third category represents firms that use budget variances regularly with respect to many different items of operating activities, revenues and cost for taking appropriate corrective action. Thus, the indicator of a formal budgeting process in Wijewardena $\&$ De Zoysa's model is the presence of written budgets, the specification of operating budget, and the frequency of calculating budget variances and taking corrective actions.

Figure 2.4 The Extent of Formal Process of Budgeting Including Budget Planning and Budgetary Control

\begin{tabular}{|l|l|}
\hline $\begin{array}{l}\text { The extent of a formal process of } \\
\text { budget planning }\end{array}$ & $\begin{array}{l}\text { The extent of a formal process of } \\
\text { budgetary control }\end{array}$ \\
\hline Level 1: No budget & $\begin{array}{l}\text { Level 1: Do not use budgeting variance } \\
\text { Level 2: Simple budgets }\end{array}$ \\
\hline Level 3: Detailed budgets & $\begin{array}{l}\text { Level 3: Regularly use budgeting variance for } \\
\text { taking appropriate corrective action }\end{array}$ \\
\hline
\end{tabular}

Note: The arrows drawn in the figure above shows that the firms falling into the second and third categories of the formal process of budget planning may be possibly reclassified into each level of the formal process of budgetary control.

Wijewardena and De Zoysa (2001) argue that the impact of budget planning and budgetary control on performance may vary from firm to firm depending on the extent of its use. The greater extent of the formal budgeting process should have a positive impact on the performance of SMEs. In their study, performance is measured by two financial indicators: sales growth and return on investment. Data are collected from 2,000 manufacturing SMEs in Australia. The results show a positive and significant relationship between budgeting planning and sales growth, and between budgetary control and sales growth. However, no significant difference is found between budgeting planning and return on investment, nor between budgetary control and return on investment. To explain the insignificant relationships between budgeting planning and ROI, between budgetary control and ROI, they state that, although firms with a greater extent of planning or control report higher rates of growth in sales, "these 
revenues are not bringing about higher profits because of internal inefficiencies." Following Wijewardena and De Zoysa's research, Fonseka and Perera (2004) also study the relationship between the budgeting process and performance in Sri Lanka's SMEs. The findings are consistent with the previous findings, which show that those firms engaged in more formal budgeting planning and control processes have achieved higher growth rate in sales, but no significant relationships are found between budgeting planning and return on investment, nor between budgetary control and return on investment.

\subsubsection{Other Dimensions of the Formal Budgeting Process}

- Budget Goal Clarity and Difficulty

Apart from the extent of budgeting planning and budgetary control processes as we explored above that may have a positive impact on organizational performance, the previous literature on goal setting (Kenis, 1979; Hirst, 1981; Hirst, 1987; Dunk, 1993; Hirst, et al. 1999; Yuen, 2004) has long stressed the beneficial effect of budget goals on promoting performance in an organization. A large group of previous studies (Hirst, 1981; Ivancevich \& McMahon, 1982; Hirst, 1987; Hirst \& Yetton, 1997; Yuen, 2004) analyze the characteristics of the budget goal from two aspects and show their potential link with performance. These two aspects are: goal clarity and goal difficulty.

"Goal clarity refers to the extent to which budget goals are stated specifically and clearly, and are understood by those who are responsible for meeting them" (Yuen, 2004). Researchers believe that managers working with unclear goals are faced with higher uncertainty in relations to goal achievement, while clear goals reduce uncertainties in the budgeting process, which, in turn, will improve performance of enterprises. Moreover, realizing the motivational role of budget goals, previous studies (Weingart, 1992; Yuen, 2004) also state that clear goals promote the performance of employees by urging them to do the best they can. Several empirical research studies have supported the positive effects of task-goal clarity on performance (Ivancevich, 1976; Steers, 1976; Imoisili, 1989). for example, Locke \& Schweiger (1979) indicate that "goal clarity can improve budgetary performance, whereas lack of clarity leads to confusion, tension, and dissatisfaction among employees". So-called budgetary performance means reaching the budget goals (or have favorable variances) by 
employees (Kenis, 1979). Hirst \& Yetton (1999) and Weingart (1992) also indicate that unclear goals can reduce budgetary performance.

On the other hand, budget goals can vary from very loose and easily attainable goals to very tight and unattainable goals. Difficult goals require greater efforts, and possibly more knowledge and skills. On the other hand, easily attainable goals require less effort, knowledge, and skills to attain. Therefore, the level of budget-goal difficulty may impact performance. Actually, empirical research indicated that the perceived budget goal difficulty and performance are strongly related (Ezzamel, 1990; Hirst, 1981; Hofstede, 1968; Kenis, 1979; Locke \& Schweiger, 1979; Mia, 1989). For example, Hirst \& Lowy (1990) found that difficult goals generate higher performance than setting specific moderate goals, specific easy goals, or too general goals. Kenis (1979) shows that a "tight but attainable" budget goal is the most effective way to motivate managers to perform better, while a "too tight" budget goal has a negative impact on the performance of managers and results in higher job tension. On the other hand, easily attainable goals do not generate incentives for managers to pursue a higher level of performance. Therefore, in this study we can assume that budget goals which are more difficult, but attainable, result in higher performance.

- Greater Budgeting sophistication

As we know, traditional accounting literature stresses the technical and rational roles of budgeting in organization. They view budgeting as a technical process to reflect and promote rationality in decision-making or as a technical device for coping with an objective world and to rationally foster efficiency, order, and stability (Covaleski, et al., 1985). Accordingly, the rational level of budgeting decisions is based on the degree of information accuracy. Merchant (1981), however, states that the adoption of more sophisticated budgeting, including greater use of computer, technical staff, and financial modeling, enhances the correctability of budgetary plan, and in turn, results in higher performance in firms. Some research (Peel \& Bridge, 1998; Farragher, et al., 2001) on capital budgeting also suggest that using sophisticated capital budgeting techniques improve the organizational performance. For example, Peel and Bridge (1998) indicate that SMEs that engage in more sophisticated net present value capital budgeting techniques, have a consistent increase of firm performance. However, more empirical research is required to prove the positive relationship between budgeting sophistication and performance. 
Although Wijewardena \& De Zoysa's model is the only framework in previous studies to reveal the formal budgeting process and performance link in SMEs, other dimensions that might lie in SMEs' budgeting process that may significantly impact their performance also have to be considered. This exploration, aids the main purpose of this study, which focuses on how budgeting process impacts SMEs' performance. So in this study, the author groups the clarity and difficulty of budget-goal and greater budgeting sophistication-these two extra dimensions into the prior research model as a comprehensive definition of the formal budgeting process.

Therefore, we shall define the formal budgeting process in SMEs as the completeness of the budgeting process from the four aspects (see Table 2.2, Figure 2.5, Table 2.3, and Table 2.4):

Firstly, in terms of budgeting planning, firms in the first category do not use any budgets to predict and qualify their future activities. Firms in the second group prepare simple budgets for a few areas of operation. In the third group are firms using detailed budgets for many different areas of operation.

Secondly, for budget goal clarity and difficulty, firms in the second or third level of budget planning are grouped into three levels in terms of budget goal clarity and budget goal difficulty. Those firms which use very unclear budgets are classified into the first level representing unclear budget goal use. Firms in the second level are those who use less clear budget goal. Other firms using very clear budget goals are classified into the third level which stands for the highest level of the clarity of budget goals. The classification for the budget goal difficulty is: Firms setting up easily attainable goals are in the first level which represents loose budget goal use; firms who use difficult but attainable goals belong to the second level; firms at highest level are those who use very difficult and unattainable budget goals.

Thirdly, regarding budgeting sophistication, firms with a budget are further divided into: firstly, those firms that use very few technical staff, computer, and financial modeling used in budgeting (representing a low level of budgeting sophistication); secondly, those firms that use a modest technical staff, computer and financial modeling in budgeting (representing the middle level of budgeting sophistication); And thirdly, those firms that use much technical staff, computer and financial modeling in budgeting (representing a high level of budgeting sophistication). 
Finally, as for budgetary control, firms who practice budgetary planning are reclassified into three additional categories. Firms in the first category do not calculate differences (variances) between actual performance and budgeted performance. Firms in the second category occasionally use budget variances with respect to a few specific items and take suitable corrective action. The third category of firms uses budget variances regularly with respect to many different items of operating activities and take appropriate corrective action.

Table 2.2 The Formal Budget Planning Process

\begin{tabular}{|l|}
\hline $\begin{array}{l}\text { The formal budget planning } \\
\text { process }\end{array}$ \\
\hline Level 1: No budget \\
\hline Level 2: Simple budgets \\
\hline Level 3: Detailed budgets \\
\hline
\end{tabular}

Figure 2.5 The Budget Goal Characteristics

\begin{tabular}{|l|}
\hline The extent of budget goal clarity \\
\hline Level 1: Unclear budget goal \\
\hline Level 2: Less clear budget goal \\
\hline Level 3: very clear budget goal
\end{tabular}

The arrows drawn in this figure indicates the potential possibility of the firms which are classified into the lower levels of the budget goal clarity may be reclassified into the higher levels of the budget goal difficulty, or the opposite around.

Table 2.3 The Formal Process of Budgeting Sophistication

\begin{tabular}{|l|}
\hline \multicolumn{1}{|c|}{ The extent of budgeting sophistication } \\
\hline $\begin{array}{l}\text { Level 1: few technical staffs, computers and financial modeling are used in } \\
\text { budgeting }\end{array}$ \\
\hline $\begin{array}{l}\text { Level 2: modest technical staffs, computers and financial modeling are used } \\
\text { in budgeting }\end{array}$ \\
\hline $\begin{array}{l}\text { Level 3: great technical staffs, computers, and financial modeling are } \\
\text { involved in. }\end{array}$ \\
\hline
\end{tabular}

Table 2.4 The Formal Process of Budgetary Control

\begin{tabular}{|l|}
\hline \multicolumn{1}{c|}{ The extent of budgetary control } \\
\hline Level 1: Do not use budgeting variance \\
\hline $\begin{array}{l}\text { Level 2:Occasionally use budgeting variance for taking suitable corrective } \\
\text { action }\end{array}$ \\
\hline $\begin{array}{l}\text { Level 3: Regularly use budgeting variance for taking appropriate corrective } \\
\text { action }\end{array}$ \\
\hline
\end{tabular}

We assume that:

Hypothesis 1: the more formalized the budgeting process, the better firm performance.

\footnotetext{
${ }^{16}$ Firms in the second level of budget goal difficulty also refer to those who use "challenging but attainable budget goal".
} 
Under the main hypothesis, the sub-hypotheses show as follows:

Hypothesis 1a: the more formalized the budgeting planning, the better the firm performance;

Hypothesis 1b1: the clearer the budget goals, the better the firm performance;

Hypothesis 1b2: the more difficult but attainable the budget goals, the better firm performance;

Hypothesis 1c: the more sophisticated the budgeting, the better firm performance;

Hypothesis 1d: the more formalized the budgetary control, the better firm performance;

\subsection{Budgetary Participation}

\subsubsection{The Role of Participation in the Budgeting Process}

From the above discussion we know that budgeting as a plan and a control device has an important impact on firm performance. However, another crucial benefit of the budgeting process, not to be ignored, is the sharing of information (Hopwood, 1976; Parker \& Kyi, 2006) between organizational members. McLaney \& Atrill (1999) argue that the value of the budget as a plan of what is to happen and as a standard against which actual performance will be measured, depends largely on whether and how skillfully this negotiation is conducted. When setting a budget, members of the organization are supposed to participate in defining explicit budgetary goals and to be involved in subsequent revisions to these goals with the management (Chalos \& Poon, 2000). And when budget variance(s) occurs, participation and discussion among different levels of management facilitate and enable accurately identifying the possible reasons for such variance(s) and also the corresponding corrective actions to be taken. Therefore, budgetary participation (BP) refers to the involvement of managers in the budgetary process and their influence over the setting of budgetary targets (Subramaniam \& Ashkanasy, 2001). Budgetary participation has always received considerable interest among researchers. It can be regarded as a negotiation channel linking the communication especially between superiors and subordinates (Shields \& Shields, 1998). Numerous scholars state that through budgetary participation, information sharing can be accomplished. For example, Poon (2001) states that budgetary participation provides a setting in which managers can exchange information and ideas to make budgetary planning and control more effective. Nouri and Parker 
(1998), similarly, state that budget participation can facilitate information sharing between subordinate and superior during budget discussions.

It was also found that the information communication between superiors and subordinates in budgetary participation includes both the upward communication from subordinate to superior and the downward communication from superior to subordinate $^{17}$ (see figure 2.6). Regarding upward communication, a principal agency framework $^{18}$ with two primary actors, the principal and the agent, is always used in the accounting literature to explain the rationale of upward communication. The principal hires the agent to perform a task on behalf of the principal. In an organizational context, the principal is often portrayed as an executive who delegates responsibility for certain tasks to a subordinate who functions as an agent. Agency studies assume that the agent has "private" information about the agent's area of responsibility which the principal (or superiors) cannot acquire and they often know more about their operational areas than do their superiors (e.g. Chow, Cooper, \& Waller, 1988; Christensen, 1982; Merchant, 1981; Nouri \& Parker, 1998; Young, 1985). So the agency perspective finds that a significant reason for the existence of participation is the difference between agent and principal in information level ${ }^{19}$. Shields and Young (1993) give evidence that the larger the differences in information levels between subordinates and superiors, the higher the probability that subordinates participate in the budgeting process. Then, the information (on competitor actions, changes in consumer preferences, technological changes, and so on) is expected to be transferred from the subordinate to the superior. Finally, the potential gains for both parties, such as better information, resources allocation, job satisfaction etc. are fulfilled. Therefore, budget participation can mean that subordinates communicate their information to their superiors, resulting in better budgets and decision-making (e.g., Magner, et al., 1995; Nouris \& Parker, 1998; Shields \& Shields, 1998). On the other hand, downward communication is also examined. Several studies (Chenhall \& Brownell, 1988; Kren, 1992; Magner et al., 1996) suggest that, through budgeting process, subordinates gain additional information from superiors and others including their duties, responsibilities, and expected

\footnotetext{
${ }^{17}$ These two dimensions of communication are also called vertical information sharing by Parker in 2006.

${ }^{18}$ The Principal Agency Theory is one of important theories within the neo-institutional economics (Tijdink, 1998).

${ }^{19}$ It is termed information asymmetry. Some researchers consider information asymmetry as one of the major antecedents of budgetary participation, such as Penno, 1984, 1990; Kirby et al., 1991; Shields \& Young, 1993
} 
performance, which increases a subordinate's effectiveness. As Chell and Brownell (1988) argue, discussions with superiors during budgeting process help clarify the goals and methods of the subordinate.

Figure 2.6 The Participation in Budgeting Process

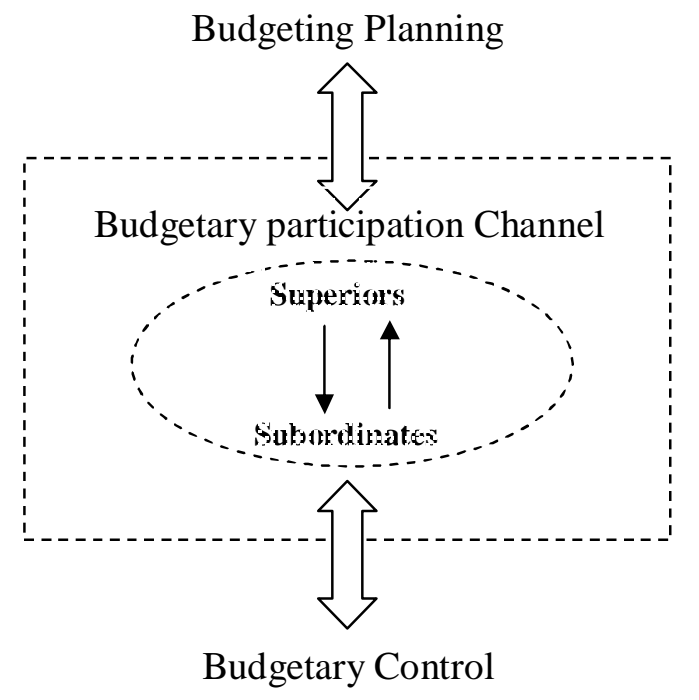

\subsubsection{Budgetary Participation and Performance}

The relationship between budgetary participation and performance (referred to as BPP) has been studied closely by many researchers (Becker \& Green, 1962; Brownell, 1981; Birnberg \& Shields, 1989; Gul et al., 1995; Magner et al., 1995; Tsui, 2001). Generally, there are two major conceptual models linking budgetary participation with performance in current management accounting literature. Firstly, psychological theories (e.g., Murray, 1990) state that the opportunity given to subordinates through participation (the upward information sharing) in budgeting process can stimulate their motivation and commitment with budget-setting, which in turn improves the subordinates' job satisfaction and performance (Brownell \& McInnes, 1986; Chenhall \& Brownell, 1988; Kren, 1992). Shields and Shields (1998) also explore budgetary participation and performance relationship from a psychological aspect. They state that participation enhances a subordinate's trust, sense of control, and ego-involvement with the organization, which then leads to more acceptance of, and commitment to, the budget decisions, in turn causing improved performance. Secondly, the BPP relationship is also explained from a cognitive point of view. It states that, through budget participation (the downward information sharing), subordinates gain information from superiors that helps clarify their organizational roles, including their duties, 
responsibilities, and expected performance, which in turn enhances their performance (Kren, 1992; Shields \& Young, 1993; Chong and Chong, 2002). Therefore, role ambiguity as an important cognitive factor is discussed extensively in existing budgeting literature. Role ambiguity is concerned with the lack of clear information regarding expectations, methods and consequences of the role (Chong \& Bateman, 2000). The empirical evidence of O'Connor (1995) suggests that budgetary participation is useful in reducing the role ambiguity of the subordinate. Jackson and Schuler (1985), Chenhall and Brownell (1988) also find that budgetary participation leads to lower role ambiguity, which, in turn, is associated with higher performance. They state that budgetary participation can clarify the role in the three areas (i.e. expectation, methods, and consequences). The expectations of the role will become clear when goals or budgets are set. By participating, various methods of achieving role expectation can be examined to consider how the expectation can be achieved. And consequences of performance in the role can be clarified by participating in the planning and evaluation stage of budgeting.

With regard to performance measurement, most researchers when exploring the BPP relationship indicate that, with the involvement of different levels of organizational members in budgeting process, budgetary participation will improve the competence of the top managers or unit managers in the areas of eight managerial activities (i.e. planning, investigating, coordinating, evaluating, supervising, staffing, negotiating, and representing). Consequently, these eight dimensions are used to measure the managerial performance of an organization. (The definition for each dimension is described in the table below) Managerial performance is a subjective measurement to measure the organizational performance. Although the role of participation in budgeting has been widely assumed, research findings are somewhat mixed. Some studies have found a positive relationship between participation and performance (Brownell \& McInnes, 1986). Mia (1989) conducted a survey among six companies operating in New Zealand to test the impact of budgetary participation on managerial performance. All six firms in his sample have the same number of employees, between 100 and 1500. His study reports a positive relationship between participation and managerial performance when the level of perceived job difficulty in firms is high. But other studies argue that the BPP relationship has a weak or even negative impact on managerial performance (Milani, 1975; Bryan \& Locke, 1967). For example, Dunk (1990) investigates the 
impact of budgetary participation on managerial performance by distributing a mail questionnaire to 30 randomly selected organizations in the north of the United Kingdom. He finds that higher participation leads to lower managerial performance. He explains that this negative result might have been caused because, in participative budgetary settings, subordinates can manipulate the process to obtain easier operating budgets, which in turn leads to lower managerial performance.

Table 2.5 The Definition of Eight Dimensions of Managerial Performance

\begin{tabular}{|l|l|}
\hline Dimension & \multicolumn{1}{|c}{ Content } \\
\hline Planning & $\begin{array}{l}\text { Determining goals, policies and courses of action; work scheduling, } \\
\text { budgeting, setting up procedures, programming. }\end{array}$ \\
\hline Investigating & $\begin{array}{l}\text { Collecting and preparing information for records, reports and } \\
\text { accounts, measuring output; inventorying, job analysis. } \\
\text { Cxchanging information with people in your organization in order to } \\
\text { relate and adjust program; advising and liaison with other personnel. }\end{array}$ \\
\hline Evaluating & $\begin{array}{l}\text { Assessment and appraisal of proposal for reported or observed } \\
\text { performance; employee appraisals, judging output records, judging } \\
\text { financial report; product inspection. }\end{array}$ \\
\hline Supervising & $\begin{array}{l}\text { Directing, leading and developing your personnel; counseling, } \\
\text { training and explaining work rules to subordinates; assigning work } \\
\text { and handling complaints. }\end{array}$ \\
\hline Staffing & $\begin{array}{l}\text { Maintaining the work force of your organization; recruiting, } \\
\text { interviewing and selecting new employees; placing, promoting and } \\
\text { transferring employees. }\end{array}$ \\
\hline Negotiating & $\begin{array}{l}\text { Purchasing, selling or contracting for goods or services, contacting } \\
\text { suppliers, dealing with sales representatives. }\end{array}$ \\
\hline Representing & $\begin{array}{l}\text { Attending conventions, consultation with other firms, business club } \\
\text { meeting, public speeches, and community drives; advancing the } \\
\text { general interests of your organization. }\end{array}$ \\
\hline
\end{tabular}

Source: Tsui, J.L., 2001

Moreover, budgetary participation and its relationship with performance are very unclear in small and medium-sized enterprises, because few studies attempt to show the characteristics of budgetary participation in SMEs' budgeting process. To respond to the lack of participation research in the field of SMEs and mixed research findings, this study tries to investigate budgetary participation and its impact on the performance of SMEs in China. The research findings will not only improve our understanding of the working of budgetary participation in organizations but also tell us whether there is a positive link between participation and performance in SMEs. Additionally, this study focuses exclusively on one performance measurement, i.e. managerial performance, to 
test the impact of budgetary participation on managerial performance. Therefore, we propose:

Hypothesis 2: The higher the budgetary participation, the better the managerial performance in a firm.

\subsection{The Impact of Firm Size on budgeting process and Performance}

It is generally accepted that budgeting is used differently in firms (Merchant, 1981). Some of the variations are explained by examining influences from the internalcorporation environment (i.e. corporate context) in which budgeting must operate. The aspects related to corporate context, including the organization's diversification ${ }^{20}$, size, structure $^{21}$, and so on (Fisher, 1996), indicate a strong effect on the choice of the organizational process, for example, budgeting. Reid and Smith (2000) review the contingency theory in management accounting system (MAS). They point out that the contingency theory has been used long time in previous research to explain how particular circumstances (that is, contingencies) shape the form of a firm. The earliest work on this subject can be traced back to the research conducted by Burns and Stalker in 1961. They emphasize the influence of technological uncertainty, as one of contingencies, on organizational form. Thompson (1967) in his book "Organization in Action" also recognize that organizations exist with the consent of their environment. Until the mid-1960's, the contingency theory starts to be used in accounting literature. For example, Brignall (1997) uses a contingency approach to design cost systems in services. Otley (1980) defines the contingency approach to management accounting as an appropriate matching between certain defined circumstances and specific aspects of an accounting system. He argues that "the contingency approach is based on the premise that there is no universally appropriate accounting system which applies equally to all organizations in all circumstances". Therefore, contingency theory provides a theoretical basis to link contingent variables and MAS. Numerous contingent variables have been identified in the existing literature. In the work of Hayes (1977), he emphasizes that three contingent variables, including work dynamism of environment, sub-unit interdependence, and work method specification are the important determinants to decide the management accounting practices across organizational subunits. More recent work by Anderson and Lanen (1999) discovers that both national

\footnotetext{
${ }^{20}$ Diversification refers to the level of diversity in a firm's product line and/or structure.

${ }^{21}$ Structure refers to internal patterns of organization relationships (Thompson, 1967)
} 
culture and competitive strategy having a major effect on the MAS. With respect to firm size, as one of the contingent variables, budgeting literature always compares the use of budgeting process in larger firms with that in small firms. Merchant (1981) conducts a study to find "how differences in corporate-level budgeting systems are related to corporate size, diversity and degree of decentralization". The questionnaires dealing with budget-related behavior and attitudes were mailed to nineteen organizations in the electronics industry (in total 201 identified managers). Firstly, his results show that, larger, more diverse firms tend to use more formal sophisticated budgeting. In contrast, smaller firms tend to rely less on formal budgeting. Secondly, Merchant points out that budgeting, including more formal and greater sophistication of budgeting process, appears to have a stronger relationship to good performance in the larger firms, than in the smaller firms. Joshi et al. in 2003 examine budgeting practices by using a questionnaire survey of 54 medium and large sized companies located in Bahrain. The budgeting practices in their research include budgeting planning and control, budget participation and rewards, and performance evaluation. They state that if there is an increase in firm size, firms tend to implement a more comprehensive budgeting process and to achieve a better performance. So, the size of a firm and its complexity of operations generally influence the nature of the budgeting it should adopt and ultimately influences the firm performance. In addition, firm size is also one of common variables used in the quantitative research. Merchant (1980) investigates how differences in budgeting systems and behaviors are related to firm size and how these different system designs finally affect organizational performance and managerial behavior. Firm size functions as an important control variable in Merchant research model. Joshi et al. (2003) conduct a quantitative research to examine budget planning, control, and performance evaluation practices in Bahrain. They also take firm size as an independent variable to test whether this has any effect on budgeting practice. More importantly, some SMEs research use firm size as well in their research. For example, Wijewardena \& De Zoysa (2001) conduct a qualitative research among 473 manufacturing SMEs in Australia to examine the impact of financial planning and control on performance. They classify all firms in the sample into medium-scale firms and small firms. About 80 per cent of sample firms belong to the small industry category, and 20 per cent of sample firms are in the medium-scale category. The formality of budgeting planning and budgetary control in their sample differ between small and medium-sized firms, based on their report. 


\subsection{The Impact of Ownership on budgeting process and Performance}

The theory of the firm is initiated by Coase in 1937. In his article, Coase attempts to explain the functions of the firm and to explore what make the firm a better means of managing production than the market. According to the Coase's opinion, a firm provides a system that allows the entrepreneur to coordinate the production and to take charge of managing resources. Forming a firm which "internalizes" transactions will be less costly than transactions arranged through markets. Thus, Coase concludes that economic efficiency or cost reduction is essentially the reason behind the firm's existence. Coase's firm theory led to considerable follow-up research. This research, in contrast, pays special attention to explaining in what situations firms reduce production costs and why transaction costs are lower in some firms than in others. Kapler (2007) gives a wide survey of all potential factors influencing the transaction costs of a firm. He emphasizes that competition (based on the competition theory) and ongoing collective learning (based on the knowledge-based theory) are two major incentives for a firm to achieve competitive success. Moreover, he points out that ownership choices, in essence, depend on the competitive environments of the firms. To explain why more costs are incurred in some firms than in others, the previous research (Foss, 2000; Stoelhorst \& Van Raaij, 2002; Choo \& Bontis, 2002) emphasizes the theory of performance differences between firms. Thus, the theory of the firm is further developed by adding performance difference theory. Foss (2000) suggests a more direct relationship to the performance difference between firms, when different costs of firms are observed. Followed by theory, the above researchers have tried to examine all potential factors affecting the performance of the firms. In particular, the above empirical research has widely addressed the relationship between ownership and

performance. However, the research results are mixed. Some research shows positive results: Borcherding, et al. (1982) conduct a literature survey in previous empirical studies to find the differential in efficiency between public and private sectors in five countries. They state that most findings are consistent with the notion that public firms have higher unit cost structures. Lauterbach \& Vaninsky (1999) examine the effect of ownership structure on firm performance. Their empirical analysis is based on the data of 280 Israeli firms. Their research found that the open corporation with disperse ownership and non-owner managers promotes better firm performance than family firms run by their owners and owner-manager firms. Xu (2000) conducts a research 
regarding how ownership impacts performance for Chinese SOEs (State-owned enterprises) under the economic transition. He measured the performance by productivity both in level and in growth rate. The finding shows effective SOE reform such as increasing competition, using firm-level pay sensitivity, strengthen both managers' and employees' incentives. Xu points out that firms that have increasing competition in product markets can greatly enhance efficiency. He further emphasizes that "the most important stimuli for productivity improvement came from competition." However, some research results show a negative impact of ownership on performance. Millward \& Parker (1983) compare economic efficiency between public and private enterprise. They conclude that there is no evidence that public enterprises are less cost effective than private firms. Estrin \& Rosevear (1999) use a random survey for 150 firms in Ukraine to test the relationship between enterprise performance and ownership in transitional economies. They reject the hypothesis that private ownership is associated with improved performance. The mixed research results, as shown above, motivate the researcher to check whether ownership impacts on the performance of SMEs in China. For the impact of ownership on budgeting process, no relevant existing research can be relied on. However, some empirical research in the past give positive support to the impact of ownership on the design of management accounting system. Firth (1996) investigates the diffusion of managerial accounting procedures in Chinese firms. He conducted a survey to compare the use of management accounting techniques between SOEs and JVs (joint-venture) in China. Firth's research shows that Chinese firms that operate joint venture with foreign partners appeared to incorporate the more detailed and the newer management accounting techniques better than state-owned enterprises without foreign partnered JV operations. His empirical research reflects the fact that different ownerships have a significant influence on the development of, and content of, management accounting. Firth further explains that two factors that affect the use of more detailed and advanced management accounting techniques are firstly, private ownership of firms and the introduction of competitive markets. Similar research is repeated by O'Connor et al. in 2004. They examine the adoption of "Western" management accounting/controls in China's enterprises during the economic transition. The western management accounting/controls are measured by five instruments: formal procedures, approval procedures, total quality control, budget targets, and performance. In-depth interviews are conducted with managers at four SOEs and two of their joint ventures. The results of the interviews indicate that several 
factors influence the increased use of a range of western management accounting/controls. Those factors are an increasingly competitive environment, joint venture experience, and stock exchange listing. Although a positive relationship is found between ownership and the management accounting system from the Firth and O'Connor's research, their analyses are based on big or listed firms. For small firms, the relationship is still unclear. It is necessary to examine how ownership affects budgeting and performance in small firms. As explained in Chapter 3, a distinction will be made between state-owned and private firms in this study. Therefore, this study will investigate whether the impact of the budgeting process on performance differs between state-owned and private firms in China. Ownership (as a control variable) is used in the current research model.

\subsection{Performance Measurement in SMEs}

\subsubsection{Financial Performance Measures}

Financial performance is generally defined as the use of outcome-based financial indicators that are assumed to reflect the fulfillment of the economic goals of the firm (Venkatraman \& Ramanujam, 1986; Murphy, et al. 1996). It has been widely used to measure business performance in both SMEs and larger firms. A great deal of accounting literature (Hopwood, 1972; Ross, 1994; Kaplan \& Atkinson, 1998; Lau \& Sholihin, 2005) recognizes the inherent advantages of financial measures. They argue that financial measures might be beneficial because they are objective and certain to provide a summary view of the success of the organization's performance and operating tactics. Kaplan and Atkinson (1998) consider financial measures as the traditional, most widely practiced, and popular management accounting tool because they focus on "what matters most in most organizations-profitability". Financial measures consist of a wide range of dimensions, but efficiency (such as return on investment, return on asset etc.), profitability (sub-dimensions include return on sales, net profit margin, gross profit margin etc.), and growth (such as sales growth, market share growth, change in net income etc.), are the commonly chosen output measures. Sales revenue and return on investment are the most frequently used financial ratios (Murphy et al., 1996). Sales revenue as an outcome-based performance indicator offers readily available, reasonably accurate effectiveness measures (Robinson, 1983). Dadzie and Cho (1989), Bento and White (2001) further argue that sales revenue, which is less subject to manipulation for tax reporting purposes and is not affected by the historical cost of input, is one of 
appropriate measures used to reflect financial performance of SMEs. As for return on investment (ROI), this is also a commonly used measure which effectively reflects the manager's ability to improve profit and increase sales from a given level of investment (Atkinson et al., 2001).

\subsubsection{Non-financial Performance Measures}

Besides financial measures, non-financial measures (also called operational performance measures), such as employee's job satisfaction and managerial performance etc., are defined as a broader conceptualization of organizational performance (Kaplan, 1983; Hofer \& Sandberg, 1987). More recently, performance management literature (Lynch \& Cross, 1991; Kaplan \& Norton, 1996, 2001; Otley, 2003) suggests that, when monitoring their firm performance, managers tend to place relatively less emphasis on traditional financial measures of performance such as return on investment or net profit. This is usually explained in terms of traditional performance measures (the accounting-based measures or financial measures) which is unable to satisfactorily reflect firm performance affected by today's changing business environments (Hoque, 2004). Similarly, Chakravarthy (1986) and McKiernan \& Morris (1994) criticize the fact that the measures of financial performance cannot accurately measure organizational effectiveness or total performance. Stemming from these concerns, the academic literature (Otley, 1999; Van Veen-Dirks \& Wijn, 2002) largely supports claims that since non-financial performance measures focus on a firm's longterm success factors such as customer satisfaction, internal business process efficiency, and innovation, they can best capture the overall performance of organization. In fact, in budgeting-performance research managerial performance as one of non-financial performance is often used (e.g. Brownell, 1982; Brownell \& Hirst, 1986; Frucot \& Shearon, 1991; Gul et al., 1995). It seems that financial performance is the only beneficial outcome of a rational and formalized budgeting process. However, when we realize that budget-related behavior ${ }^{22}$ (e.g., budgetary participation) and budget-related attitudes (such as, budget commitment, motivation) raised from budgeting process will enhance an organization's managerial competency, we have no reason to move our concern away from the non-financial measures to identify the non-accounting benefits

\footnotetext{
${ }^{22}$ Budget-related behavior refers to the activities, actions, and interactions of managers with each other and their tasks that relate either directly or indirectly to budgeting process. And budget-related attitudes are the affective feelings of managers toward budgets and budget-related behaviors of themselves and others. (Bruns \& Waterhouse, 1975, pp.181)
} 
of this organization. Camillus, in 1975, states that "the attitudinal and cognitive effects of organizational system" impact non-financial outcomes, for example managerial performance. In relation to budgeting, attitudinal effect is about managerial involvement in budgeting process leading to improved loyalty and commitment. Cognitive effect relates to the goal clarity and the technical skills acquired by managers in budgeting process. The combined result is enhanced managerial competency. Some research even indicates that non-financial measures can lead to the final improvement of financial performance in firms. Banker et al. (2000) finds a positive relationship between customer satisfaction measures and financial performance. In another study, Anderson et al. (1994) find evidence to support their hypothesis that customer satisfaction in firms is significantly and positively associated with financial performance measured by return on investment. Therefore, non-financial performance measures such as job satisfaction and managerial competency are closely linked to the budgeting process (McKiernan \& Morris, 1994). On the other hand, in some literature on measures evaluation, researchers (Lind \& Tyler, 1988; McFarlin \& Sweeney, 1992) give their rationale for non-financial measures used from the fairness point of view. They state that subordinates usually consider performance evaluation as important because it is often linked to the rewards system, which determines their "remunerations and promotions". Subordinates, therefore, expect the process used to evaluate their performance to be fair. If the process is perceived as unfair, subordinates are likely to have unfavorable attitudes towards their supervisors. Lau \& Sholihin (2005) argue that non-financial performance measures may be perceived by subordinates as fair. They then indicate that the adoption of non-financial performance measures may lead to favorable job satisfaction, because non-financial performance measures show consideration for subordinates' needs and interests, and act in a way that protects the subordinates' interests.

It is noted that, although there is considerable support for the use of non-financial performance measures in organizations, no suggestion is made to abandon the use of the more traditional financial measures. Accurate and appropriate measurement of performance is essential to SMEs to develop useful descriptions of their performance. Therefore, a multi-dimension system of performance measures combining financial performance, non-financial performance, and managerial performance is used in this study to reflect the overall performance of SMEs. More specifically, financial 
performance measures applied in this study include sales revenues and profit (before tax). For the non-financial performance, it consists of budgetary performance and other performance. Budgetary performance in this study is defined in two respects. Firstly, it refers to achieving budget goals by the employees in a firm or having favorable variances (i.e. budget-goal achievement). It also includes the motivation which employees gain from budget-setting. As for other performance, this study only covers job satisfaction and job involvement. Measurements for performance variables will be further discussed in the Chapter 4.

\section{Summary:}

- A critical review of the literature on budgeting is necessary to help the researcher and the readers to develop a thorough understanding of and insight into previous research that is related to the questions and objectives of this study.

- Some previous research finds the positive effects of the formalized budgeting on firm performance. Formal budgeting is defined by the previous literature as formal budgeting planning and formal budgetary control.

- The formal budgeting process is re-defined in this study as the completeness of the four aspects i.e. budgeting planning, budget goal clarity and difficulty, budgeting sophistication, and budgetary control.

- In this study, budgetary participation is introduced and placed in the budgeting process to be checked as well.

- Hypotheses are also generated in this chapter. The main hypothesis is to test the positive relationship between the formal budgeting process and overall performance.

- Firm size and ownership are, as two control variables, investigated in this study. We assumed that the impact of the budgeting process on performance differs between small and middle-sized firm and also differs between state-owned and private firms. 


\section{Chapter 3}

\section{SMEs in China}

The main purpose of this chapter is to give a clear definition of Chinese SMEs. Therefore, the standards used to identify SMEs are extensively reviewed from previous literature. Another issue is a brief introduction of Chinese SMEs, including their contributions to Chinese economy, their magnitude, ownership structure, and their difficulties in financing during development.

\subsection{The Definition of Small and Medium Sized Enterprises}

Although small and medium sized enterprises have been extensively researched since the 1970s', a definition of SMEs cannot be easily settled. SMEs can range from fastgrowing firms to private family firms, that have not changed much for decades, from a part-time business with no staff to a semiconductor manufacturer employing hundreds of people, and from independent or stand-alone businesses to those that are part of technology and that have investment partners based abroad. Many researchers define SMEs in terms of the numbers of people employed. Storey (1994), for example, defines micro-enterprises as those with 0 to 9 employees, those with 10 to 99 workforces as small business, and medium-sized enterprises as having 100 to 499 employees. Gunasekaran et al. (2000), however, state that SMEs have to be defined within the context of the economies in which they operate. Empirical evidence ${ }^{23}$ also shows that the definition used for an SME in APEC (Asia Pacific Economy Cooperation) varies widely. The most common measure is the number of employees, but capitalization, assets, sales (or turnover), and production capacity are also used by various economists as monetary measures. As for the definition of Chinese SMEs, the standards used to distinguish small- and medium-sized enterprises in China includes the number of employees, sales volume and total assets of an enterprise (see Table 3.1 below). The database of China's National Bureau of Statistics (NBS), an authoritative statistics organization in China, however, chooses a single standard to identify SMEs, viz. annual sales revenue. In accordance with the definition used by the National Bureau of Statistics of China, in this study, we shall use annual sales revenue to define the size of SMEs. Therefore, the definition is: small enterprises are those with annual sales revenue

\footnotetext{
23 "Definition of SMEs in APEC", Journal of Enterprising Culture, Vol. 11(3), September 2003, PP. 173-337
} 
less than 5 million RMB; medium enterprises are those with annual sales revenue above 5 million RMB but less than 30 million RMB.

Table 3.1 Preliminary Standard of Enterprises by Size in 2005

Unit: per worker/ten million RMB

\begin{tabular}{|l|l|c|c|}
\hline Sectors & Criteria for definition & Medium-sized enterprises & Small-sized enterprises \\
\hline \multirow{4}{*}{ Industry } & Number of workers & $\geq 300$ and $<2000$ workers & $<300$ workers \\
& Annual sales revenues & $\geq 3$ and $<30 \mathrm{RMB}$ & $<3 \mathrm{RMB}$ \\
& Total assets & $\geq 4$ and $<40 \mathrm{RMB}$ & $<4 \mathrm{RMB}$ \\
\hline \multirow{5}{*}{ Construction } & Number of workers & $\geq 600$ and $<3000$ workers & $<600$ workers \\
& Annual sales revenues & $\geq 3$ and $<30 \mathrm{RMB}$ & $<3 \mathrm{RMB}$ \\
& Total assets & $\geq 4$ and $<40 \mathrm{RMB}$ & $<4 \mathrm{RMB}$ \\
\hline \multirow{2}{*}{ Wholesale } & Number of workers & $\geq 100$ and $<200$ workers & $<100$ workers \\
& Annual sales revenues & $\geq 3$ and $<30 \mathrm{RMB}$ & $<3$ RMB \\
\hline \multirow{2}{*}{ Retail } & Number of workers & $\geq 100$ and $<500$ workers & $<100$ workers \\
& Annual sales revenues & $\geq 1$ and $<15 \mathrm{RMB}$ & $<1$ RMB \\
\hline \multirow{2}{*}{ Transport } & Number of workers & $\geq 500$ and $<3000$ workers & $<500$ workers \\
& Annual sales revenues & $\geq 3$ and $<30 \mathrm{RMB}$ & $<3$ RMB \\
\hline \multirow{2}{*}{ Telecommunication } & Number of workers & $\geq 400$ and $<1000$ workers & $<400$ workers \\
\cline { 2 - 5 } & Annual sales revenues & $\geq 3$ and $<30 \mathrm{RMB}$ & $<3$ RMB \\
\hline \multirow{2}{*}{ Hotel \& restaurant } & Number of workers & $\geq 400$ and $<800$ workers & $<400$ workers \\
\cline { 2 - 5 } & Annual sales revenues & $\geq 3$ and $<15 \mathrm{RMB}$ & $<3$ RMB \\
\hline
\end{tabular}

Notes: The shaded columns are the standards used in the National Bureau of Statistics of China. Industry refers to the material production sector engaged in extraction of natural resources and processing and reprocessing of minerals and agricultural products, including (1) extraction of natural resources, such as mining, salt production (but not including hunting and fishing); (2) processing and reprocessing of farm and sideline produces, such as rice husking, flour milling, wine making, oil pressing, silk reeling, spinning and weaving, and leather making; (3) manufacture of industrial products, such as steel making, iron smelting, chemicals manufacturing, petroleum processing, machine building, timber processing; water and gas production; and electricity generation and supply; (4) repairing of industrial products such as the repairing of machinery and means of transport (including cars).

Source: National Bureau of Statistics of China, 2005.

\subsection{SMEs Development in a Fast Growing Economy}

As we know, the Chinese economy experienced rapid growth especially after the reform and opening up in 1978. This created a good environment for the development of small and medium-sized enterprises. In the 1980s, there was a tremendous boost in the number of SMEs. Until 1990, the total number of industrial enterprises reach 7,957,800 (Table 3.2 demonstrates the structure of independent accounting industrial enterprises in China). The proportions of large, medium and small enterprises are 0.95, 2.27 and 96.78 percent respectively. At the end of 2007, the total number of SMEs registered by the Ministry of Commerce and Industry has exceeded 4.3 million. Chinese SMEs are 
getting stronger and contribute to the development of Chinese society and economy. They have the same functions as SMEs in other countries, mainly expressed by promoting employment, technological innovation, accelerating market competition, maintaining economic vitality, and so on. It is estimated (2009) that SMEs are now responsible for about $60 \%$ of China's industrial output and employ about $75 \%$ of the workforce in China's cities and towns. Particularly, SMEs are the main destination for workers laid-off from state-owned enterprises (SOEs) that re-enter the workforce.

Table 3.2 The Scale Structure of Independent Accounting Industrial Enterprises (19802001)

Unit: One Million

\begin{tabular}{lcllllll}
\hline Year & Number of & \multicolumn{2}{c}{ Large Enterprises } & \multicolumn{2}{c}{ Medium Enterprises } & \multicolumn{2}{c}{ Small Enterprises } \\
& Independent & Number & $\%$ & Number & $\%$ & Number & $\%$ \\
\hline 1980 & 3.773 & 0.014 & 0.37 & 0.034 & 0.90 & 3.725 & 98.73 \\
1990 & 4.171 & 0.04 & 0.95 & 0.095 & 2.27 & 4.037 & 96.78 \\
1995 & 5.921 & 0.064 & 1.01 & 0.166 & 2.80 & 5.691 & 96.11 \\
$1997 \mathrm{a}$ & 5.344 & 0072 & 1.35 & 0.168 & 3.13 & 5.104 & 95.51 \\
$1997 \mathrm{~b}$ & 4.685 & 0.072 & 1.53 & 0.167 & 3.57 & 4.446 & 94.89 \\
$1999 \mathrm{c}$ & 1.62 & 0.079 & 4.85 & 0.144 & 8.87 & 1.398 & 86.28 \\
$2000 \mathrm{c}$ & 1.629 & 0.08 & 4.90 & 0.137 & 8.44 & 1.411 & 86.66 \\
$2001 \mathrm{c}$ & 1.713 & 0.086 & 5.01 & 0.144 & 8.41 & 1.483 & 86.58 \\
\hline
\end{tabular}

Notes: "a" refers to various industrial enterprises funded by organizations above the township level, excluding villages, individual enterprises and other business. "b" refers to independent accounting industrial enterprises. "c" refers to all state-owned enterprises and non-state-owned enterprises with a scale of (or above) annual total sales of 5 million Yuan.

Source: NBS, China Statistical Yearbook (1981, 1991, 1996, 1998, 2000, 2001). China Statistical Press.

Especially after the Asian financial crisis of 1997, developing SMEs became a very important strategy in China. Chinese government and scholars realized that economic development can be problematic if it relies only on large firms. A SME department was established in the State Economic and Trade Commission in 1998, the highest-level comprehensive management department in charge of reform and development policy. Besides establishing the SMEs department, accommodating policies are launched as well to support Chinese SMEs' development. Such as from 1999 when the Ministry of Finance and other departments started to actively establish a SMEs loan guarantee system. By 2001, they published laws and regulations such as the Provisional Regulation of SME Credit Guarantee System and Management Methods of Credit Guarantees for $\mathrm{SMEs}^{24}$. Wang (2004) states that by the end of 2000, more than 200

\footnotetext{
${ }^{24}$ The main targets to guarantee are hi-tech SMEs. (Xiang, 1999)
} 
credit-guarantee institutions had been established, and a guarantee fund of 10 billion RMB has been raised to improve the credit environment of SMEs. Generally, China has begun emphasizing on the issue of supporting SME development.

\subsection{Ownership Structure of Chinese SMEs}

In general, a mixed ownership structure has become the main feature of Chinese enterprises including Chinese SMEs of today. To explain this situation and to clearly identify the ownership of Chinese enterprises, it is necessary to discuss the reform of China's economic system at the end of 1978. Also, it is important to compare the different economic systems before China's economy transition and after the transition. From the comparison, we can gain a better impression of how large the change was for Chinese enterprises during the transition. Before addressing the Reform of 1978 indepth, let us first trace back the time before China's economic transition. When the People's Republic was founded in 1949, the Chinese government used a simple economic model, called the traditional planned economic system. As Lin et al. (1996) states, under this system, "plans and administrative controls replaced markets as the mechanism for allocating living necessities, raw materials, supply and demand, and foreign reserves and so on, ensuring that limited resources would be used for the targeted projects." Moreover, if enterprises were privately owned, the state could not be sure that private entrepreneurs would reinvest the policy-created profits on projects intended by the state. Therefore, private enterprises were soon nationalized and all enterprises were state-owned. Chinese state-owned enterprises can be defined as nationalized corporations publicly owned by central government or by provincial and municipal governments. The planned economic system created a series of problems, because of the lack of market discipline: competition was suppressed; the prices of products were determined by pricing authorities, which resulted in low profit; workers' and managers' motivation was discouraged since their wages and salaries were not related to performance; investment and working capital were financed mostly by appropriations from the state budget or loans from the banking system, according to state plans. In sum, the traditional planned economic system in China was a distorted structure and limited the development of economy in China. Since 1978, a transformation from the traditional economic system to socialist market economic system was instigated, known as the Reform. The Reform involves most parts of China in a course of privatization and huge state enterprises are restructured. The 
consequences of privatization are: firstly, the scale of change has expanded to affect almost every kind of state-owned enterprises - small, medium, large, and very largeunder both central and local control; secondly, ownership diversification has been so extensive that the role of the wholly state-owned non-financial company has declined substantially; thirdly, the range of restructuring mechanisms being used has expanded dramatically to include bankruptcies, liquidations, listings and de-listings, debt-forequity swaps, sales to private parties (domestic and foreign), and auctioning of state firms, their assets, or liabilities. Due to privatization, a mixed ownership structure has become a major form in the Chinese economy today. It will be very confusing to distinguish the specific ownership of a company under this situation, if we have no clear definition. For example, some Chinese SMEs separated from large state-owned firms during privatization. Parts of their shares are already held privately, but part of the shares are still controlled by the state. Are they private SMEs or are they still stateowned SMEs? Thus, state-owned enterprises, after the Reform in 1978, are re-defined as those corporations of which their whole/major assets ${ }^{25}$ are invested and owned by the state or local government. As in the above example, ownership can be identified by checking who controls the largest part of the assets. If most of assets are still controlled by the state, those SMEs are state-owned SMEs, otherwise, they are private. According to Regulations of the People's Republic of China for Controlling the Registration of Enterprises as Legal Persons, all state-owned enterprises in China are classified into three categories:

1. Enterprises with special legal entities ${ }^{26}$. These state-owned enterprises are primarily focused on providing public services, rather than making profit. They follow a series of regulations and polices specifically created by state, instead of following the Corporate Law. These enterprises cover national defense, city transportation, city landscaping, water conservancy, etc.

2. Enterprises completely owned by the state ${ }^{27}$. For this kind of enterprise, a business must be conducted, with the emphasis on public service. Making profit only ranks second. All enterprises in this category are subject to the Corporate Law. These enterprises include the railways, gas and water supply, electricity, and airports etc.

\footnotetext{
${ }^{25}$ According to international convention, if the state invests above $50 \%$ of a company's assets or control above $50 \%$ of the company's stock share, the company is state-owned company.

${ }^{26}$ All enterprises in this category do not follow the Corporate Law of China.

${ }^{27}$ Enterprises in the second and third categories must follow the Corporate Law of China.
} 
3. Enterprises with more than half of their shares controlled by government. These firms are just like normal business firms that regard making profit as their main task. They all follow the Corporate Law.

As we can see, state-owned enterprises are different from private firms in two aspects. First, not all of state-owned enterprises are bound by the Corporation Law of China. Second, state-owned enterprises combine non-profit and profit-making objectives, rather than private firms which purely conduct business with a view to profit. Moreover, it is necessary to emphasize that Chinese state-owned enterprises are not merely owned by the central government. Some are owned by the local government. Some Chinese state-owned enterprises are not non-profit but profit driven, which is different from the state-owned enterprises defined by western countries.

Apart from state-owned and private SMEs, other types of SMEs are used, in both practice and research. In some firms, parts of their property are controlled by foreign investors, the so-called joint-ventures. Some firms with an outstanding performance issue their shares in the stock market. Therefore, these are stock-holding firms. It might be that both joint-venture and stock-holding firms are state-owned companies. The second situation for Chinese SMEs is that it is common for family members (or those in the same region or those who have no connections, but who trust each other) to start up business together. Therefore, the family- or collective-owned SMEs also exist in China. Li \& Ren (2002) state that even though some China's SMEs are not textbook familyowned as far as ownership is concerned, they still place family members on different levels of the organization. For important positions such as finance and purchase, family members will be preferred because this means that there is usually business "privacy" within the firm. Moreover, some small and medium-sized firms in China have neither a mixed ownership structure nor a family-owned structure. Those firms are completely controlled by a single domestic owner. We call this type of firms the private SMEs. Thus, in general, Chinese SMEs are divided into state enterprises, family enterprises, joint-ventures, share-holding firms, and private enterprises. However, the ownership categories used by NBS are far more complex than the above classification. Table 3.3 shows the NBS classification of industrial enterprises between 1988 and 1996. 
Table 3.3 Period Structures for Enterprises outside the State and Collective Sectors, 1988-1996

\begin{tabular}{llll}
\hline \multicolumn{1}{c}{\begin{tabular}{c} 
Period categories \\
\multicolumn{1}{c}{ 1988-1992 }
\end{tabular}} & \multicolumn{1}{c}{ Period categories } & Period categories & Period categories \\
\hline Domestic: & Domestic: & Other domestic: & Other domestic: \\
SOE-COE JV [1] & Private [a] & ODE=1+2+3+9 & \\
SOE-dom. Private JV [2] & Domestic JV [b] & & \\
COE-dom. Private JV [3] & & & \\
\hline Foreign-linked: & Foreign-linked: & Foreign-linked: & Foreign-linked: \\
SOE-HQ JV [4] & Non-Chinese [c] & FIE=4+5+6+7+8 & FIE=c+d \\
COE-HQ JV [5] & Overseas Chinese [d] & & \\
JV with non-Chinese [6] & & & \\
Control by HQ [7] & Shareholding [e] & Shareholding SHE, & Shareholding SHE=e \\
& & no information & \\
Foreign control [8] & & & \\
Other firms [9] & Other firms [f] & & \\
\hline
\end{tabular}

Note: JV, joint venture; COE, collective-owned enterprise; ODE, other domestic enterprise; HQ, overseas Chinese (huaqiao).

a foreigners who have no Chinese ethnicity or heritage.

Source: Jefferson, G. H., Rawski, T. G., Wang, L., \& Zheng, Y. X., 2000.

The result of this complicated and shifting classification structure is that desirable data categories cannot always be created (Jefferson et. al, 2000). Therefore, for most empirical research ownership structure of Chinese firms is simplified. Four types of firms are usually discussed in previous research, i.e. the state-owned firms, jointventures, stock-holding firms, and private firms. The possible reason is that privatization was a popular focus in previous research, especially in the mid-90s. For example, Wei \& Zhang (2005) investigate how privatization affects on firm value. They focus on three types of firms, i.e. state-owned firms, stock-holdings, and joint-ventures. They found a higher performance for stock-holding and joint-venture firms, since those firms face a more competitive environment than state-owned firms.

In this study, four types of ownership structure (i.e. state-owned, joint-venture, stock companies, and private) are used. However, for statistical analysis, because of the modest statistical data, we classify all firms as either state-owned firms or as private firms. Therefore, the main focus of current research is on domestic state-owned and private firms only. 


\section{Summary:}

- The Chinese economy experienced rapid growth especially after the Reform and Opening up of 1978. This created a good environment for the development of small and medium-sized enterprises.

- Small and medium sized enterprise are defined by using the Annual sales revenue in the current study. The definition is: small enterprises are those with annual sales revenue less than 5 million RMB; medium enterprises are those with annual sales revenue above 5 million RMB but less than 0.3 billion RMB.

- Since the reform and privatization, Chinese SMEs include private and stateowned SMEs. 


\section{Chapter 4}

\section{Theoretical Framework and Measurement of Variables}

The literature review in chapter 2 and chapter 3 discussed theory and concepts regarding the budgeting process, performance, and Chinese SMEs. It is necessary to turn the literature review into an explicit theoretical framework or a conceptual model. This framework or model is usually presented as a circle-and-arrow diagram. The ideas and variables underlying the conceptual model will be used to formulate three (main) hypotheses. To test these hypotheses, it is also necessary to select a sample, design a questionnaire, and measure each of the variables in this study's model. Accordingly, several tasks need to be accomplished in this chapter. They are: firstly, to develop the theoretical framework of this study (section 4.1) by explaining how it emerges from the literature review and how the variables explored from the previous literature are related to each other; secondly, to determine a sample (section 4.2); thirdly, to design a questionnaire (section 4.3). Fourthly, to decide about the statistical technique necessary to analyze the quantitative data (section 4.4). Finally, to operationalize all variables in this study (section 4.5).

\subsection{Theoretical Framework and Hypotheses}

\subsubsection{Development of the Theoretical Framework}

A critical literature review shows research on the relationship between the budgeting process and performance in small and medium-sized enterprises (SMEs). We rely on Wijewardena \& De Zoysa's model (2001) in terms of the formal budgeting process. Wijewardena and De Zoysa define the formal budgeting process as the formal financial planning process and the formal financial control process. Both of these aspects of the formal budgeting process are important contributors to enterprise performance of small and medium-sized organizations. Specifically, firms using detailed budgets (or "comprehensive budgets") for planning recorded significantly higher sales growth than those having "no written budgets". And firms using more comprehensive budget variances also achieved better performance in sales growth, compared to firms using less comprehensive budget variances. Despite other studies not so strictly related to the small and medium-sized sector, they suggest a potential link between the budgeting process and performance in a business organization. Since this study is explorative in nature, we shall also consider these works. It aims to provide sufficient evidence to 
answer the central question of this study (i.e., how does the budgeting process impact performance in SMEs in China?). The previous model is developed from three sides. The first side is about redefining the concept of the formal budgeting process by adding more dimensions of the budgeting process. Budget goal characteristics, including goal clarity and goal difficulty, are stressed in Yuen's (2004) work. It reveals that a "tight but attainable" budget goal is the most effective way to motivate the employees' performance. Therefore, clear goals reduce budgeting process uncertainty and improve firm performance. A similar statement is also made by other studies such as Ivancevich (1976), Steers (1976), Imoisili (1989), Locke \& Schweiger (1979), Mia (1989), Ezzamel (1990), Hirst \& Lowy (1990) etc. Another study on the formal budgeting process and performance relationship is research on budgetary sophistication. Budgetary sophistication is defined by scholars (Merchant, 1980; Peel \& Bridge, 1988; Edward, et al., 2001) as greater use of computer, technical staff, and advanced financial modeling. Empirical results (Merchant, 1980) show that budgetary sophistication enhances the accuracy of the budget plan and the degree of information accuracy. In turn, it results in higher performance in organizations. By mixing Yuen's (2004) and Merchant's (1980) models with Wijewardena \& De Zoysa's model, we redefine the formal budgeting process as the completeness of the formal budgeting planning process, budget-goal clarity and difficulty, budgeting sophistication, and the formal process of budgetary control. The second side is the introduction of budgetary participation into the budgeting study of small and medium-scaled enterprises. It is triggered by the vacuum of empirical data from SMEs. As we know, almost all studies on budgetary participation and performance relationship (BPP) are based on large enterprises. The characteristics of budgetary participation in SMEs and its effects on SMEs' performance are unclear. To explore the relationship between budgetary participation and performance in SMEs, Parker \& Kyj's (2006) model is adopted. As to performance measurement, most existing literature on budgetary participation use managerial performance as a dependent variable. Some studies use non-financial performance which includes budgetary performance and other performance. The facts coincide with the last side of the model development. Therefore, the measurement in this study includes not only financial performance but also non-financial performance and managerial performance. The theoretical framework in this study is derived from the combined models of several studies, including the formal budgeting process, budgetary participation, and the measurement of performance (Wijewardena \& De Zoysa, 2001; 
Yuen, 2004; Merchant, 1980; Parker \& Kyj, 2006). The conceptual model in this study (see figure 4.1 below) consists of boxes and circles representing variables, and arrows connecting them to denote relationships. Hypotheses are also included into the model.

Figure 4.1 The Basic Conceptual Model of this study

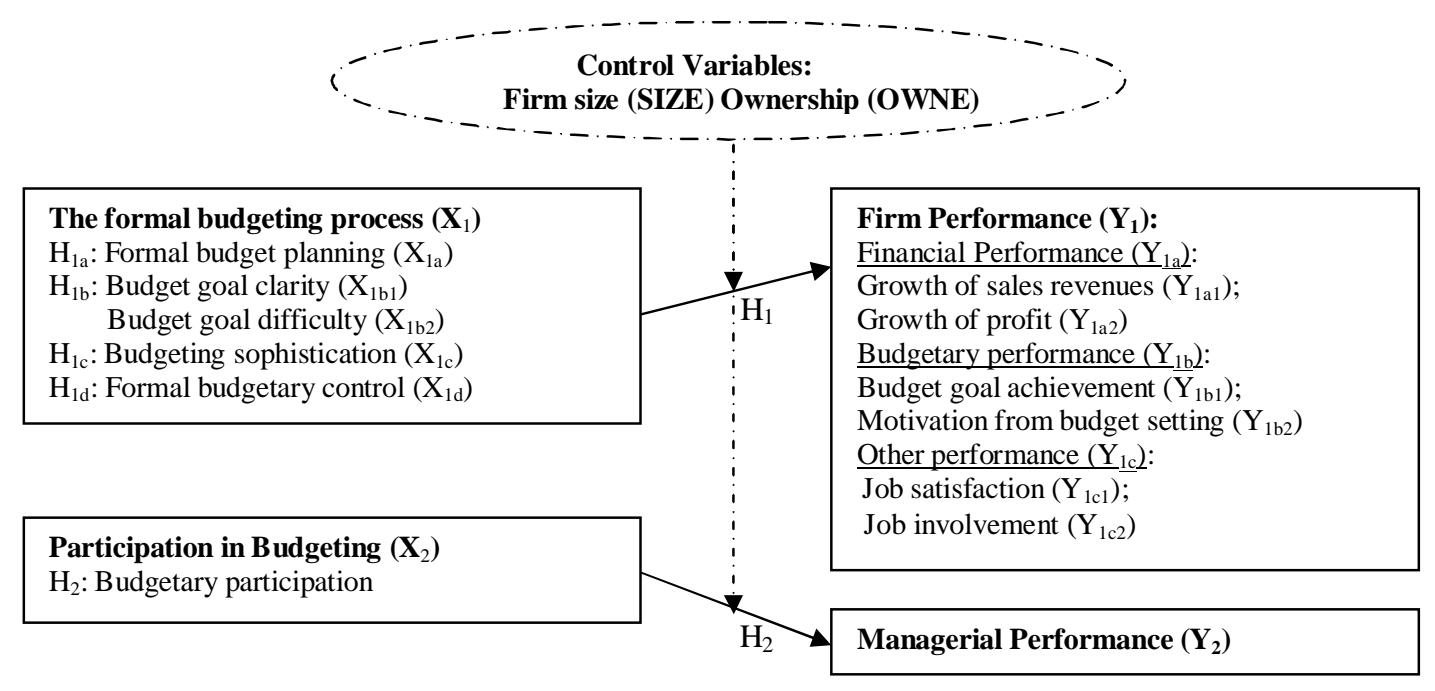

\subsubsection{Hypotheses}

According to the conceptual model, this section displays the hypotheses and explains the relationships among variables.

v The Formal Budgeting Process and Firm Performance

Hypothesis 1: The more formalized the budgeting process, the better the firm performance.

In this hypothesis, the formal budgeting process functions as the independent variable and firm performance as the dependent variable. Firm performance includes financial performance, budgetary performance, and other performance. A positive effect of the formal budgeting process on firm performance in SMEs is expected.

To test hypothesis 1 , the following regression model (Model $1_{\mathrm{a}}$ ) is used (Eq. $\left(1_{\mathrm{a}}\right)$ ):

$$
\mathrm{Y}_{1}=\mathrm{a}_{1}+\mathrm{b}_{1} \mathrm{X}_{1}
$$

v Budgetary Participation and Performance

Hypothesis 2: The higher the budgetary participation, the better the managerial performance. 
This hypothesis highlights the relationship between budgetary participation and managerial performance. It is supposed that budgetary participation (the independent variable) will have a positive impact on managerial performance of SMEs.

To test hypothesis 2, the following regression model (Model $1_{\mathrm{b}}$ ) is used (Eq. $\left(1_{\mathrm{b}}\right)$ ):

$$
\mathrm{Y}_{2}=\mathrm{a}_{2}+\mathrm{b}_{2} \mathrm{X}_{2}
$$

Because the concept of the formal budgeting process is redefined, accordingly Hypothesis 1 is divided into sub-hypotheses. They are listed as follows:

Hypothesis la: the more formalized the budgeting planning, the better the firm performance.

Hypothesis 1al: the more formalized the budgeting planning, the better the financial performance;

Hypothesis 1a: the more formalized the budgeting planning, the higher the growth of sales revenues;

Hypothesis $1 a_{2}$ : the more formalized the budgeting planning, the higher the growth of profit.

Hypothesis 1b1: the clearer the budget goals, the better the firm performance.

Hypothesis 1b1 : the clearer the budget goals, the better the budget goals achievement;

Hypothesis $1 b 1_{2}$ : the clearer the budget goals, the better the job satisfaction. Hypothesis 1b2: the more difficult but attainable the budget goals, the better the firm performance.

Hypothesis 1b22: the more difficult but attainable the budget goals, the more motivation from budget setting;

Hypothesis 1b22: the more difficult but attainable the budget goals, the more job involvement.

Hypothesis 1c: the more sophisticated the budgeting, the better the firm performance.

Hypothesis 1c1: the more sophisticated the budgeting, the better the financial performance;

Hypothesis $1 c_{1}$ : the more sophisticated the budgeting, the higher the growth of sales revenues;

Hypothesis $1 c_{2}$ : the more sophisticated the budgeting, the higher the growth of profit. Hypothesis 1d: the more formalized the budgetary control, the better the firm performance. 
Hypothesis 1d1: the more formalized the budgetary control, the better the financial performance;

Hypothesis $1 d_{1}$ : the more formalized the budgetary control, the higher the growth of sales revenues;

Hypothesis $1 d_{2}$ : the more formalized the budgetary control, the higher the growth of profit.

\subsection{Sample Selection}

China is a country with twenty two provinces, five autonomous regions, four municipalities under the direct administrative guidance of the central government, two special administrative regions (Hong Kong and Macao), and Taiwan. Beijing considers Taiwan as a province, but Taiwan is actually not under the administration of the People's Republic of China. It is extremely difficult to obtain data from all parts of China covering all industries. In this study, we only focus on the manufacturing sector, and samples are selected from the provinces of HuNan, HuBei, and GuangDong. All firms in the sample must have already existed at least three years. The main reason for selecting these three provinces is that they are located in mid-south area of China and have a similar level of economic development. These provinces also have a large base of manufacturing companies and fairly good supply of labor and raw materials. As to the selection of industries, data are collected from the mechanical industry. The machine industry in China knows twelve different major categories. It is the country's major industrial sector. Its operations range from electrical equipment manufacturing to agricultural equipment manufacturing, from construction machinery to food-processing and packaging producing. The whole country has 120,000 machinery enterprises and research institutes, with approximately 20 million employees. The value of China's heavy machinery reached 211.65 billion RMB and the value of China's electrical equipment reached 964.72 billion RMB in 2005. Propelled by a huge demand for auto products and services, the automotive industry, as one segment of China's machinery industry, has experienced rapid development from 1980 to 2005. China currently has the largest market for automobiles. The total output of cars increased from 1.48 million in 1996 to 8.88 million in $2007^{28}$. Therefore, the mechanical industry, as one of the major industries in China, contributes considerably to the economic development of

\footnotetext{
${ }^{28}$ Wang, 2008
} 
China. An empirical examination of the effect of budgeting process on the performance in this industry will be used to reflect the overall budgeting practice of Chinese SMEs.

\subsection{Data Collection Method: Questionnaire}

In this study, questionnaires function as a preliminary data collection technique providing empirical analysis in this study. They aim to describe the general pattern of budgeting practice in Chinese SMEs and to determine how formal budgeting planning and control is undertaken in a firm. The owner/senior manager or financial manager of SMEs will be asked to rate the extent of budgeting planning and control practice in their companies and indicate the firm performance. The senior manager or functional departmental manager is to answer the questions regarding budgetary participation.

\subsubsection{Designing the Questionnaire}

Saunders et al. (2003) state that the validity and the reliability of the data you collect, as well as the response rate you achieve, depend, to a large extent, on the design and the structure of your questionnaire. In this study, the questionnaire design is approached in two ways:

First, adopt questions used in other questionnaires;

Second, develop questions by the researcher.

Questions used to measure variables such as budgetary goal clarity and difficulty, budgetary participation, managerial performances are directly adopted from other research. The consistency of questions with previous literature is necessary if we intend to replicate or to compare research findings with another study. It is also more efficient and time-saving than developing your own questions, provided that you can still collect the data you need to answer the research questions and to meet the research objectives. For some questions, both positive and negative statements are used. The answer of respondents can then be checked once again by re-reading and comparing both questions. For example, questions regarding goal difficulty are stated as both "I do not have too much difficulty in reaching my budget goals. They appear to be fairly easy" and "My budget goals are quite difficult to attain." This can also improve the internal consistency of questionnaire design. However, some questions, such as budget planning and control, budgetary sophistication, and some items of firm performance are developed by the researcher. This is determined by the nature of the data which need to be collected. With regards to the types of the questions, the questionnaire includes a 
combination of open-ended questions and closed-ended questions (Dillman, 2000). Open questions are used in the first section of the questionnaire to obtain general information from a company. For instance, "what is your position in your company?" (See appendix) is an open-ended question. The last section of questionnaire uses closed questions. Those questions either offer the respondent a list of answers, of which he/she can choose, or a Likert-scale rating to ask the respondent how strongly he/she agrees or disagree with a statement or series of statements. Most of the rating questions in the questionnaire use a seven-point rating scale, such as the question on the level of budget planning, the extent of budgeting control, the level of sophistication etc. In addition, the language most commonly used in business operation and communication in SMEs in China is Chinese. All of the respondents who are approached are Chinese. Therefore, the questionnaire used is translated into Chinese.

\subsubsection{Administering the Questionnaire}

A simple random sample of 150 small and medium-sized firms is selected from the population of machinery organizations listed in China Statistical Yearbook 2007. All firms in the sample are from three provinces (i.e., GuangDong, HuNan, and HuBei). For each province, 50 companies are selected. Three criteria are used to select the organizations. Firstly, the number of employees should be less than 2,000; secondly, sales revenue should be below 0.3 billion RMB; and finally the selected companies should have run their business at least three years. The 150 self-administered questionnaires are delivered either by hand to each respondent and collected later (delivery and collection questionnaires) or delivered and returned electronically using email (on-line questionnaires). Questionnaires are completed by senior managers, chief financial officers, or the lower level managers in the machine industry. All of them have more or less budgetary responsibility during the budget setting. The questionnaires aim to inquire into the participants' personal opinion about the formal budgeting process, budgetary participation, and the performance of the sampled firms.

\subsection{Analyzing Quantitative Data}

In this study, parametric statistics are the major technique of statistical analysis. To analyze the impact of the formal budgeting process on enterprise performance, regression methods, (and especially linear regression) are the major statistical methods. The rationale for using regression methods are: firstly, almost all variables in the 
present study are measured by interval/ratio scales; secondly, if the sample size is sufficient, regression is undoubtedly a more powerful way to test the correlation between two or more variables than other statistical methods like non-parametric tests.

\subsection{The Measurement of Variables}

The variables measured in the questionnaire include the formal budgeting process, budgetary participation, firm size, ownership, firm performance, and managerial performance. In this section, the measurement of variables in the conceptual framework of this study is discussed. Firstly, it is necessary to determine the instrument/indicators used for measuring each variable. For reasons explained previously, some instruments are adopted directly from previous research, others are self-developed. Secondly, it is necessary to check the invariance and inter-relation among the indicators. Cronbach alpha is also applied to test the consistence among the indicators. Table 4.1 summarizes the measurement results for all variables used in the present research.

Table 4.1 Measurement of the Variables in the Research

\begin{tabular}{|l|l|}
\hline Variables & Measurement \\
\hline Independent Variables $(\mathbf{X}):$ & \\
\hline The Formal Budgeting Process $\left(\mathbf{X}_{1}\right)$ & \\
\hline The formal budgeting planning $\left(\mathrm{X}_{1 \mathrm{a}}\right)$ & Frequency \& Extension \\
\hline Goal Clarity $\left(\mathrm{X}_{1 \mathrm{~b} 1}\right)$ & Kenis $(1979)$ \\
\hline Goal Difficulty $\left(\mathrm{X}_{1 \mathrm{~b} 2}\right)$ & \\
\hline Budgetary sophistication $\left(\mathrm{X}_{1 \mathrm{c}}\right)$ & Gorden $(1978)$ \\
\hline The formal budgeting control $\left(\mathrm{X}_{1 \mathrm{~d}}\right)$ & Frequency \& Extension \\
\hline Budgetary Participation $\left(\mathbf{X}_{2}\right)$ & Milani (1975) \\
\hline Control Variables: & \\
\hline Size $(S I Z E)$ & Sales Revenue \\
\hline Ownership $(\mathbf{O W N E})$ & Private V.S. State-owned Firms \\
\hline Dependent Variables $(\mathbf{Y}):$ & \\
\hline Firm Performance $\left(\mathbf{Y}_{1}\right):$ & \\
\hline Financial Performance $\left(\mathrm{Y}_{1 \mathrm{a}}\right)$ & Growth of sales revenues \& profit \\
\hline Budgetary performance $\left(\mathrm{Y}_{1 \mathrm{~b}}\right)$ & Budget achievement \& Motivation \\
\hline Other performance $\left(\mathrm{Y}_{1 \mathrm{c}}\right)$ & Job involvement \& Job satisfaction \\
\hline Managerial performance $\mathbf{Y}_{2}$ & Mahoney (1963) \\
\hline
\end{tabular}

The reminder of the section presents the detailed measurement process from independent variables to dependent variables.

\subsubsection{The Formal Budgeting Process}

The formal budgeting process, an independent variable, is measured by four subvariables (see Table 4.1 ), i.e., the formal budget planning $\left(\mathrm{X}_{1 \mathrm{a}}\right)$, budget-goal clarity and difficulty $\left(\mathrm{X}_{1 \mathrm{~b}}\right)$, budgetary sophistication $\left(\mathrm{X}_{1 \mathrm{c}}\right)$, and the formal budgeting control $\left(\mathrm{X}_{1 \mathrm{~d}}\right)$. 
For each sub-variable, the method of measurement is explained:

1) The formal process of budget planning

In the designed questionnaire of this study, an instrument consisting of three items is used to assess the formal budget planning in a firm. The respondents are asked to indicate:

(1) "How often budgets are prepared to qualify a firm's plan for the future period?";

(2) "To what extent do you think budgets are prepared to qualify different areas of operation in your firm?";

(3) "Please report what are those operation areas that budgets cover in your firm?".

For the first two questions, a seven-point Likert scale from 1 (never) to 7 (quite often/great extent) is given to rate by the respondents. For the last question, a list with different operational areas such as sales, production etc. should be ticked. Respondents who indicate in the first question "no budget use" in their firms can stop answering the questionnaire. In this case, the first question's score will be marked with one. Those who respond that budget planning is adopted in their firms are asked to continue to question two and further.

The result from factor analysis reveals that the correlation among the three indicators of the formal budgeting planning are highly interrelated. The variance explained is $82.09 \%$. The Eigen value is 2.46. The internal reliability assessed by Cronbach (1951) alpha for the three-item measure in this study is 0.89 .

2) Budget goal characteristics

As discussed in Chapter 2, the characteristics of budget goal are tested from two dimensions: budget goal clarity and budget goal difficulty.

- Budget goal clarity

Budget goal clarity is described using a three-item instrument from Kenis (1979). The three items are:

(1) "My budget goals are very clear and specific. I know exactly what my budget goals are.”;

(2) "I think my budget goals are ambiguous and unclear.";

(3) "I understand fully which of my budget goals are more important than others. I have a clear sense of priorities on these goals.". 
The instrument asks each respondent to answer on a seven-point Likert-type scale if he/she "extremely disagree" (1) to "extremely agree" (7). Factor analysis indicates that these three items are loaded adequately into one factor. Eigen value is 2.09 and the variance explained is 69.76 per cent. These values can be considered good. The yielded Cronbach alpha coefficient for budget goal clarity is 0.77 , which indicates a high internal reliability.

- Budget goal difficulty

As to the measurement of budget goal difficulty, a five-item instrument developed by Kenis (1979) is used. These five items comprise:

(1) "I should not have too much difficulty in reaching my budget goals. They appear to be fairly easy.";

(2) "My budget goals are quite difficult to attain.";

(3) "My budget goals require a great deal of effort from me to achieve them.";

(4) "It takes a high degree of skill and know-how on my part to attain fully my budget goals";

(5) "In general, how would you characterize the budgetary goals of your unit?". A seven-point Likert-type scale instrument ranging from 1 (extremely disagree) to 7 (extremely agree) is used for the first four items. For the fifth item, the response format is a list of five points of view about budget goal (--too loose; --fairly loose; --just right; -tight but attainable; --too tight). Here participants have to tick a budget goal.

The 5-item questionnaire for budget goal difficulty shows a low internal reliability (Cronbach alpha 0.50). Therefore, we also use factor analysis as an additional method. Two factors are extracted representing 59.45 per cent of the total variance of all indicators. The Eigen value is equal to 1.16. The results from the factor analysis indicate that the last three items out of the five-item instrument for the budget goal difficulty can be grouped into one factor. These results also indicate that the first two items for budget goal difficulty can be classified into another factor. The last three items are placed together to be checked, a reliability test shows that its Cronbach alpha increases to 0.63 . 


\section{3) Budgeting Sophistication}

Based on Gordon's instrument (1978), the instrument is further developed to measure budgeting sophistication. The original instrument includes only one item 5-point scale ${ }^{29}$ with respect to the sophistication of computer support. Gordon's questionnaire is modified into a three-item instrument. As mentioned before, greater budgeting sophistication includes three dimensions, i.e., greater use of computers, technical staff, and financial modeling. It is necessary to measure each dimension. Therefore, all respondents are asked:

(1) "To what extent does software support the budget setting in your company?";

(2) "How many technical staff members are involved in the budget setting in your firm?";

(3) "In your company, to what extent is financial modeling used in the process of budget setting?".

The response format is a seven-point Likert-type scale ranging from 1 (representing very low budgeting sophistication) to 7 (very high budgeting sophistication).

Again, factor analysis is undertaken to ascertain the uni-dimensional nature of the three items of budgetary sophistication. The Eigen value is 2.19; it is good enough to use a single indicator to reflect the overall level of budgetary sophistication. The internal reliability of the three-item measure assessed by Cronbach alpha is 0.81 .

4) The Formal Process of Budgetary Control

The formal process of budgetary control is captured using a five-item instrument. Those five items include:

(1) "How often do you think your organization calculates the difference between actual performance and budgeted performance?";

(2) "To what extent do budget variances (calculating difference between actual performance and budgeted performance) cover, with respect to different items of operation activities, revenues, and cost for taking appropriate corrective action?"; (3) "Please report which operation areas are covered by budget variance in your firm.";

(4) "In your firm, will any corrective actions be undertaken if negative budget variances occur?";

(5) "Are rewards given in the case that positive budgetary variances occur?".

\footnotetext{
${ }^{29}$ The 5-point scale ranges from 1 (no computer support) to 5 (availability of remote terminals in an interactive mode)
} 
A seven-point Likert-type scale ranging from 1 (representing low budgeting control) to 7 (representing high budgeting control) is used for the first two items. A list is presented in the questionnaire and participants are required to tick answers. For the third item, the response format is a list of items of operating areas which the budgeting control covers. Participants are required to tick relevant answers. "Yes" and "No" style questions are applied for the last two items.

For analyzing correlation among the indicators of the formal budgeting control, a factor analysis is used. The outcome shows that only one factor is derived, which explains 81.49 per cent of the total variance, with an Eigen value of 2.45 (over 1.000).

The Cronbach alpha of 0.87 for the five-item measure in this study indicates an acceptable level of internal reliability.

\subsubsection{Budgetary Participation}

Budgetary participation has to be measured as another independent variable. Based on Milani's (1975) six-item questionnaire, the author developed a nine-item participation continuum scale to assess owner's and employees' perceived amount of participation. These items measure the subjects' perceptions of the amount of influence and involvement an owner or a lower level manager has on a jointly-set budget. A threeitem instrument is designed for senior managers and a six-item instrument for financial or front-line managers. The level of perceived participation is rated on a seven-point Likert type scale. The six-item instrument has been extensively used in earlier studies and has provided high internal reliability (Mia, 1989; Harrison, 1992; Subramaniam \& Ashkanasy, 2001). Specifically, the three-item instrument for senior managers includes the questions:

(1) "Which category below best describes your activity when the budget is being set?";

(2) "How much influence do you feel you have on the final budget?";

(3) "How do you view your contribution to the budget?"

The six items for lower level managers included in this study are:

(1) "Which category below best describes your activity when the budget is being set?";

(2) "Which category below best describes the reasoning provided by your superior when budget revisions are made?"; 
(3) "How often do you state your request, opinions, and/or suggestions about the budget to your superior without being asked?";

(4) "How much influence do you feel you have on the final budget?";

(5) "How do you view your contribution to the budget?";

(6) "How often does your superior seek for your requests, opinions, and/or suggestions when the budget is being set?".

The managers rated their level of perceived participation in budgeting for each of the 6 items on a 7-point Likert-type scale.

Factor analysis is repeated to check the correlation between the three and six-items of participation. As to the three-item instrument for senior managers, one component is extracted. For the six-item instrument for lower level managers, although two components are extracted, the first component contributes to 58.20 per cent of the total correlation and its Eigen value is 3.35. The reliability test shows that the Cronbach's alpha is 0.75 and 0.83 for the three-item and six-item measures respectively.

\subsubsection{Firm Size}

The criterion used for determining the corporate size is based on the standard in the China Statistical Yearbook. It classifies small enterprises as those with annual sales revenue less than 5 million RMB and medium-sized enterprises as those with annual sales revenue above 5 million RMB but less than 0.3 billion RMB.

\subsubsection{Ownership}

All firms in this study are classified into either private firms or state-owned firms.

\subsubsection{Overall Performance}

Firm Performance

\section{5) Financial Performance}

Sales revenues and profit (before tax) are selected to measure the financial performance of SMEs. However, considering the inherent reluctance of small business managers to disclose exact financial data, the questionnaire is designed by asking the respondents to indicate the percentage of growth in sales revenues and profit over the last three financial years. 


\section{6) Budgetary Performance and Budget-related Attitude}

The self-rated budgetary performance is measured by asking the respondents to indicate on a five-point scale how often they have met their budget goals (or have favorable variances). This is so-called goal achievement. The possible answers range from 'never' to 'always'. Secondly, by asking the respondents to indicate how much motivation they get during budget setting, budgetary performance is measured by so-called budgetary motivation. Budgetary performance measures are partly based on the Kenis model from 1979.

\section{7) Other Performance}

In this research, other performance refers specifically to job satisfaction and job involvement. Likert-type questionnaire items, scored from one to five, are used to measure job satisfaction and job involvement. For job satisfaction, the scale intends to measure the extent to which employees are satisfied with their work. For job involvement, the scale intends to measure to which extent individuals identify themselves psychologically with their jobs.

\section{Managerial Performance}

A subjective measure of managerial performance is adopted in the current study. Managerial performance is assessed with Mahoney et al.'s (1963) and Heneman's (1974) eight-item self-rating performance measure, which shows as follows:

(1) Planning: Determining goals, policies and courses of action; work scheduling, budgeting, setting up procedures, programming;

(2) Investigating: Collecting and preparing information for records, reports and accounts, measuring output; inventorying, job analysis;

(3) Coordinating: Exchanging information with people in your organization in order to relate and adjust programs; advising and liaison with other personnel;

(4) Evaluating: Assessment and appraisal of proposals for reported or observed performance; employee appraisals, judging output records, judging financial reports; product inspection;

(5) Supervising: Directing, leading and developing your personnel; counseling, training and explaining work rules to subordinates; assigning work and handling complaints; 
(6) Staffing: Maintaining the work force of your organization; recruiting, interviewing and selecting new employees; placing, promoting and transferring employees;

(7) Negotiating: Purchasing, selling or contracting for goods or services, contacting suppliers, dealing with sales representatives;

(8) Representing: Attending conventions, consultation with other firms, business club meetings, public speeches, community drives; advancing the general interests of your organization.

Respondents are asked to rate on a seven-point Likert Scale (Ranging from "well below average performance" to "well above average performance") their own perceived performance on these eight sub-dimensions of managerial performance (Brownell \& Hirst, 1986; Gul, 1991; Tsui, 2001).

Factor analysis is conducted once again to check the correlation among the eight indicators of managerial performance. It is found that two components are extracted, representing 55.95 per cent of the total correlation. The Eigen value is 1.16. The Cronbach's alpha is 0.79 .

\section{Summary:}

- A theoretical framework is developed in this chapter. The framework indicates all assumed relationships between the formal budgeting process and performance, which need to be further elaborated in Chapter 6

- A quantitative method is determined as the main research paradigm. A questionnaire is used for data collection.

- A modest survey, consisting of 75 Chinese small and medium sized enterprises, is used as input for the quantitative analysis of this study.

- All variables involved in this study are operationalized. Factor analysis and Cronbach alpha tests are adopted to check all the instruments' correlations and reliabilities. 


\section{Chapter 5}

\section{Empirical Results: Descriptive Statistics}

When the empirical data from the questionnaires are available, it is necessary to continue into the next stage: data analysis. This chapter focuses on presenting the empirical results, especially the results from descriptive statistics. The descriptive analysis tries to give a general impression of values on individual variables and their components. These values include mean (or the average) and standard deviation, which can measure the central tendency of a selected sample. The descriptive data in this chapter also show, on the one hand, how each variable related to the budgeting process is distributed over different size of firms and different types of business, and on the other hand, how the variables (the budgeting process, the formal budgeting planning, the formal budgeting sophistication, and the formal budgetary control) are distributed in different scales of growth of sales revenues and profit.

\subsection{The Selected Sample}

Of the 150 questionnaires distributed, 75 were returned. The response rate is 50 percent. All these 75 firms are used in the following descriptive chapter (Chapter 5) and statistic analysis chapter (Chapter 6). Among these responses, 36 out of 75 are from mediumsized firms with sales revenues ranging from 30 to 300 million RMB and 39 out of 75 are from small companies with sales revenue less than 30 million RMB. The two dominant business types are private organizations and stockholding companies, which account for 39 and 21 of the total amount, respectively.

Most respondents of the questionnaires are senior managers (31 out of 75) and frontline managers (26 out of 75) of organizations, accounting for 41 per cent and 35 per cent of the total. The bigger the firm size, the more financial managers responded. As we can see from Table 5.1 below, there are 11 financial managers (31 per cent) from medium-sized firms filling in the questionnaires, but only 7 financial managers (18 per cent) from small firms. In terms of business type, there are four types of business in the data, i.e., state-owned enterprise, private enterprise, joint-venture, and stock-holding firms (see in Table 5.2). Most of the stock-holding firms and some of the joint-ventures have state-owned ownership rights. Differing from ordinary state-owned enterprises, these companies represent the most profitable state-owned enterprises in China. As stated in Chapter 3, the Reform and Opening propel China to restructure the state sector. 
The stockholding company structure is based on clear ownership rights that legally separate the enterprise from state administration and encourage investors to buy state stocks. In this sense, the joint stockholding structure mobilizes capital in a way ideal to the need of market and improves the competitive capability of enterprises themselves. As stock-holding firms diversify their equity structures, joint venture firms include two different kind of capital: some of them are mainly private but with foreign capital, some of them still keep the state-owned ownership. To distinguish these two types of enterprise (i.e. the stock-holding and joint-venture) from the ordinary state-owned enterprise, the descriptive statistics in this Chapter analyze these separately. As Table 5.2 shows, most state-owned companies (6 out of 8 ), join-ventures (6 out of 7), and stock-holding companies (12 out of 21) are medium-sized enterprises. However, most private enterprises (27 out of 39 ) are small.

Table 5.1 Firm Size and Positions of Interviewees

\begin{tabular}{|l|cc|cc|cc|}
\hline \multirow{2}{*}{ Position of interviewees } & \multicolumn{6}{|c|}{ Firm Size } \\
\cline { 2 - 7 } & \multicolumn{2}{|c|}{ Small Firms } & \multicolumn{2}{c|}{ Medium Firms } & \multicolumn{2}{c|}{ Total } \\
\hline \multirow{3}{*}{ Senior manager } & Firms & $\%$ & Firms & $\%$ & Firms & $\%$ \\
\cline { 2 - 7 } Financial manager & 17 & 44 & 12 & 33 & 29 & 39 \\
Front-line manager & 6 & 15 & 14 & 39 & 20 & 27 \\
Total & 16 & 41 & 10 & 28 & 26 & 35 \\
& 39 & 100 & 36 & 100 & 75 & 100 \\
\hline
\end{tabular}

Table 5.2 Firm Size and Business type

\begin{tabular}{|l|cc|cc|cc|}
\hline \multirow{2}{*}{ Business Types of the Enterprises } & \multicolumn{5}{|c|}{ Firm Size } \\
\cline { 2 - 7 } & \multicolumn{2}{|c|}{ small firms } & medium firms & \multicolumn{2}{c|}{ Total } \\
\hline \multirow{3}{*}{ state-owned enterprise } & Firms & $\%$ & Firms & $\%$ & Firms & $\%$ \\
\cline { 2 - 7 } private enterprise & 2 & 5 & 6 & 17 & 8 & 11 \\
joint venture & 27 & 69 & 12 & 33 & 39 & 52 \\
stock-holding & 1 & 3 & 6 & 17 & 7 & 9 \\
Total & 9 & 23 & 12 & 33 & 21 & 28 \\
& 39 & 100 & 36 & 100 & 75 & 100 \\
\hline
\end{tabular}

\subsection{Descriptive Results: the Formal Budgeting Process and Firm Performance}

The overall formalization degree of the budgeting process is, as can be seen in Table 5.3, 3.75 (the mean number is 3.75 with the Likert Scale ranging from 1 to 7). An overwhelming majority $^{30}$ (97 per cent) uses a budget plan to qualify future operations. There is a slight variance regarding the mean for each dimension of the formal budgeting process (i.e., the formal budget planning, budget goal clarity and difficulty, budgetary sophistication, and the budgeting control). The difference is 2.39 with the

\footnotetext{
${ }^{30}$ Two firms out of 75 firms in the sample do not employ any forms of budget planning and control.
} 
maximum score 4.81 and the minimum score 2.42 . Specifically, for budget goal clarity and difficulty, the average score is 4.81 and 4.70 respectively, which ranks the first. The formal budget planning stands at the second position with a mean value of 3.83 . This is followed by budgetary sophistication with a mean value of 3.57. Budgetary control takes the lowest position (the average score is 2.42). This distribution suggests that it is more difficult for SMEs to accomplish a higher level of the formal budgeting process.

Table 5.3 Mean \& Standard Deviation of the Formal Budgeting Process of Chinese SMEs $(\mathrm{N}=75)$

\begin{tabular}{|l|c|c|}
\hline \multicolumn{1}{|c|}{ Formal Budgeting Process } & $\begin{array}{c}\text { Mean } \\
\text { (the middle value is 4) }\end{array}$ & Std. Deviation \\
\hline The formal budgeting process & 3.75 & 0.73 \\
(Overall) & 3.83 & 1.34 \\
The formal budgeting planning & 4.81 & 1.02 \\
Budgetary clarity & 4.70 & 0.78 \\
Budgetary difficulty & 3.57 & 1.17 \\
Budgeting sophistication & 2.42 & 0.77 \\
The formal budgeting control & & \\
\hline
\end{tabular}

Note: the Likert scale to measure the variables above is used from " 1 " to " 7 ".

Table 5.4 Mean \& Standard Deviation for the performance of Chinese SMEs $(\mathrm{N}=75)$

\begin{tabular}{|l|c|c|}
\hline \multicolumn{1}{|c|}{ Performance } & $\begin{array}{c}\text { Mean } \\
\text { (the middle value is 3) }\end{array}$ & Std. Deviation \\
\hline Overall firm performance & 3.08 & 0.71 \\
The growth of sales revenues & 2.71 & 1.75 \\
The growth of profit & 1.72 & 1.03 \\
Budgetary performance: budget goals achievement & 3.97 & 1.06 \\
Budgetary performance: budgetary motivation & 3.12 & 1.03 \\
Other performance: job involvement & 3.80 & 0.84 \\
Other performance: job satisfaction & 2.88 & 0.82 \\
\hline
\end{tabular}

Note: the Likert scale ranged from " 1 " to " 5 " is used to measure all variables in the table above.

The results from descriptive statistics (in Table 5.4) show that the average overall firm performance for the investigated Chinese SMEs is 3.08. However, financial performance, especially the growth of profit is much lower than the average level. The mean value for profit growth is 1.72 which is 1.36 points less than the average score of overall firm performance. The mean of sales growth is 2.71 , which is 0.37 less than the average. Except for financial performance, the average score of job satisfaction also shows a weak point. It is 2.88 , which is 0.20 points lower than the average score. The remaining performance indicators show a higher rank. Goal achievement shows the highest mean value (3.97), compared to the other indicators. The mean value of job 
involvement also reaches to 3.80. Among all performance indicators, budget goals achievement, which is one of the budgetary performance indicators, ranks the highest with 3.97 points on average.

To conduct descriptive analyses and to reflect how the overall level of the formal budget process in each firm is related to its size and business type, the mean (average) is calculated by dividing the sum of the total score by the number of measures. The maximum mean value for the formal budgeting process in the sample is 2.44 and the minimum mean value is 5.50. All firms in the sample, according to their mean value, are classified into three categories representing a low, a medium, and a high level of the formal budget process. This classification is not statistically valid. It is only used to show descriptive results in this chapter. Firms in the first category with average scales interval from 2.44 to 3.45 points stand for the lower level of the formal budgeting process. Firms with average scales ranging from 3.46 to 4.47 belong to the second category, representing a moderate level of the formal budgeting process. Firms with a scale from 4.48 to 5.50 are in the last category representing a higher level of the formal budgeting process.

Table 5.5 The Level of the Formal Budgeting Process in Small Firms and Big Firms

\begin{tabular}{lcccccccc}
\hline \multirow{2}{*}{ Firm Size } & \multicolumn{6}{c}{ The General Level of Formal Budgeting Process } \\
\cline { 2 - 10 } & \multicolumn{2}{c}{ Low level } & Medium level & High level & \multicolumn{2}{c}{ Total } \\
\cline { 2 - 9 } & Firms & $\%$ & Firms & $\%$ & Firms & $\%$ & Firms & $\%$ \\
\hline Small Firms & 20 & 69 & 18 & 56 & 1 & 7 & 39 & 52 \\
Medium-sized Firms & 9 & 31 & 14 & 44 & 13 & 93 & 36 & 48 \\
\hline Total & 29 & 100 & 32 & 100 & 14 & 100 & 75 & 100 \\
\hline
\end{tabular}

Generally, 39 per cent (29/75) of firms report a low level of budgeting use. Descriptive results (Table 5.5 and Table 5.6) show the variation in the number of the formal budgeting process over different size of firms and different types of business. As can be seen from Table 5.5, for small firms, a downward distribution pattern occurs as the level of the formal budgeting process increase. The number changes from 20 firms at a low level to 18 firms at a middle level, and only 1 firm at a high level. Most of the small firms (20 out of 39) implement only a low level of the budgeting process. Compared to the budgeting use in small firms, more middle-sized firms report a more advanced level of budgeting process use. There are 14 and 13 medium-sized firms in the sample reporting a middle-level and a high-level of budgeting respectively. This is 39 per cent $(14 / 36)$ and 36 per cent (13/36) of the total medium firms, respectively. In addition, the 
level of the formal budget planning varies in different types of organizations (see in Table 5.6). In general, stock-holding firms and joint ventures tend to adopt a more formalized budgeting process than state-owned and private firms. The results show that 93 per cent (26/28) of the joint-ventures and stock-holding firms are in the middle or high level of the formal budgeting process. However, only 43 per cent (20/47) of the state-owned and private firms are in the middle or high level of the formal budgeting process. 57 per cent (27/47) of state-owned firms and private firms are in the first category, representing a low level of the budgeting process. The percentage of the jointventures and stock-holding firms at a low level is only 7 per cent $(2 / 28)$. One possible reason is that most of the private firms in the sample are small-sized. The implementation of the budget planning is restricted because of their firms' size. The stock-holding firms and joint-ventures, on the other hand, are more middle-sized or larger-sized. They have more resources available for adopting more advanced budget planning processes.

Table 5.6 The Level of the Formal Budgeting Process in Different Types of Business

\begin{tabular}{lccccccccc}
\hline \multirow{2}{*}{ Business Type } & \multicolumn{6}{c}{ The General Level of Formal Budgeting Process } \\
\cline { 2 - 10 } & \multicolumn{2}{c}{ Low level } & Medium level & High level & \multicolumn{2}{c}{ Total } \\
\cline { 2 - 10 } & Firms & $\%$ & Firms & $\%$ & Firms & $\%$ & Firms & $\%$ \\
\hline State-owned enterprise & 4 & 14 & 2 & 6 & 2 & 14 & 8 & 11 \\
Private enterprise & 23 & 79 & 12 & 38 & 4 & 29 & 39 & 52 \\
Joint-venture & 0 & 0 & 4 & 12 & 3 & 21 & 7 & 9 \\
Stock-holding & 2 & 7 & 14 & 44 & 5 & 36 & 21 & 28 \\
\hline Total & 29 & 100 & 32 & 100 & 14 & 100 & 75 & 100 \\
\hline
\end{tabular}

Table 5.7 summarizes the descriptive results of the budgeting process and financial performance. As we can see from Table 5.7, the sales growth rate for most firms in the sample is between 11 per cent and 30 per cent, which accounts for 54 per cent of the total. If we consider the sales growth rate between 21 per cent and 30 per cent as a breaking point, it can be seen in Table 5.7 that sales growth sharply decreases from this growth rate onward. For the firms that adopt a low level of budgeting, 41 per cent of firms report less than 10 per cent of the growth of sales revenue. Also 41 per cent of firms at the second category (represent medium-level of budgeting use) report a sales growth rate between 11 and 20 per cent. The profit growth between firms shows a similar pattern. Over half of the firms (38 firms in total) report less than 10 per cent of profit growth. Most firms have a growth percentage up to 30 per cent. 
Table 5.7 The Distribution of the Formal Budgeting Process in different Scales of Financial Performance

\begin{tabular}{lcccccccc}
\hline & \multicolumn{7}{c}{ The Level of the Formal Budgeting Process } \\
\cline { 2 - 9 } Sales Revenues Growth & \multicolumn{2}{c}{ Low level } & Medium level & high level & \multicolumn{2}{c}{ Total } \\
\cline { 2 - 9 } & Firms & Firms & $\%$ & Firms & $\%$ & Firms & $\%$ \\
\hline below 10\% & 12 & 41 & 5 & 16 & 2 & 25 & 19 & $25 \%$ \\
between 11\% and 20\% & 7 & 24 & 13 & 41 & 0 & 27 & 20 & $27 \%$ \\
between 21\% and 30\% & 6 & 21 & 9 & 28 & 5 & 27 & 20 & $27 \%$ \\
between 31\% and 40\% & 2 & 7 & 3 & 9 & 3 & 11 & 8 & $11 \%$ \\
between 41\% and 50\% & 2 & 7 & 1 & 3 & 2 & 6 & 5 & $7 \%$ \\
between 81\% and 90\% & 0 & 0 & 1 & 3 & 2 & 4 & 3 & $4 \%$ \\
\hline
\end{tabular}

\begin{tabular}{lcccccccc}
\hline \multirow{2}{*}{ Profit Growth } & \multicolumn{8}{c}{ The Level of the Formal Budgeting Process } \\
\cline { 2 - 9 } & \multicolumn{2}{c}{ Low level } & \multicolumn{2}{c}{ medium level } & \multicolumn{2}{c}{ high level } & \multicolumn{2}{c}{ Total } \\
\cline { 2 - 10 } & Firms & $\%$ & Firms & $\%$ & Firms & $\%$ & Firms & $\%$ \\
\hline below 10\% & 18 & 62 & 16 & 50 & 4 & 29 & 38 & $51 \%$ \\
between 11\% and 20\% & 10 & 35 & 13 & 41 & 5 & 36 & 28 & $37 \%$ \\
between 21\% and 30\% & 1 & 3 & 1 & 3 & 3 & 21 & 5 & $7 \%$ \\
between 31\% and 40\% & 0 & 0 & 0 & 0 & 2 & 14 & 2 & $3 \%$ \\
between 41\% and 50\% & 0 & 0 & 1 & 3 & 0 & 0 & 1 & $1 \%$ \\
between 61 and 70\% & 0 & 0 & 1 & 3 & 0 & 0 & 1 & $1 \%$ \\
\hline & 29 & 100 & 32 & 100 & 14 & 100 & 75 & $100 \%$ \\
\hline
\end{tabular}

\subsubsection{Descriptive Results: Budget Planning}

The classification criterion used for the formal budgeting process above is also applied to classify different levels of the formal budget planning. Its mean values range from minimum level of 1.67 to a maximum of 6.67 (see Appendix I). Accordingly, firms in the first category with average scales interval from 1.67 to 3.33 points stand for the lower level of the formal budget planning. Firms with average scales from 3.34 to 5.00 belong to the second category representing a moderate level of the formal budget planning. Firms with average scales from 5.01 to 6.67 are in the last category representing a higher level of the formal budget planning.

Descriptive statistics in Table 5.8 show that 81 per cent of the sample firms are either in the first category or in the second category and 19 per cent of the firms is in the third category.

Table 5.8 The Level of the Formal Budget Planning in General

\begin{tabular}{lcc}
\hline Level of formal budget planning & Frequency & Percent \\
\hline Low level & 33 & 44 \\
Medium level & 28 & 37 \\
High level & 14 & 19 \\
\hline Total & 75 & 100 \\
\hline
\end{tabular}


Table 5.9 The Level of the Formal Budget Planning in Small and Medium-size Firms

\begin{tabular}{lcccccccc}
\hline \multirow{2}{*}{ Firm Size } & \multicolumn{6}{c}{ The General Level of Formal Budget Planning } \\
\cline { 2 - 10 } & \multicolumn{2}{c}{ Low level } & Medium level & High level & \multicolumn{2}{c}{ Total } \\
\cline { 2 - 10 } & Firms & $\%$ & Firms & $\%$ & Firms & $\%$ & Firms & $\%$ \\
\hline Small Firms & 24 & 73 & 14 & 50 & 1 & 7 & 39 & 52 \\
Medium-sized Firms & 9 & 27 & 14 & 50 & 13 & 93 & 36 & 48 \\
\hline Total & 33 & 100 & 28 & 100 & 14 & 100 & 75 & 100 \\
\hline
\end{tabular}

Table 5.9 further reveals the distribution status of the formal budget planning level between small and medium-sized firms. We can see that over half of the small firms (62 per cent, 24/39) are in the first category. Only one small firm from the sample indicates the use of a high level of the formal budget planning. In contrast, far more mediumsized firms indicate having a high level of the formal budget planning, compared to small firms (13 versus 1$)$.

Table 5.10 The Level of the Formal Budget Planning in Different Business Types

\begin{tabular}{lccccccccc}
\hline \multirow{2}{*}{ Business Type } & \multicolumn{6}{c}{ The General Level of Formal Budget Planning } \\
\cline { 2 - 10 } & \multicolumn{2}{c}{ Low level } & \multicolumn{1}{c}{ Medium level } & High level & \multicolumn{2}{c}{ Total } \\
\cline { 2 - 10 } & Firms & $\%$ & Firms & $\%$ & Firms & $\%$ & Firms & $\%$ \\
\hline State-owned enterprise & 4 & 12 & 1 & 4 & 3 & 21 & 8 & 11 \\
Private enterprise & 27 & 82 & 11 & 39 & 1 & 7 & 39 & 52 \\
Joint-venture & 0 & 0 & 4 & 14 & 3 & 21 & 7 & 9 \\
Stock-holding & 2 & 6 & 12 & 43 & 7 & 51 & 21 & 28 \\
\hline Total & 33 & 100 & 28 & 100 & 14 & 100 & 75 & 100 \\
\hline
\end{tabular}

Concerning the distribution of the budget planning in different types of organizations (see Table 5.10), there seems to be a pattern consistent with what we discussed before. 57 per cent (16/28) of the joint-ventures and stock-holding firms against 26 per cent (12/47) of the state-owned and private firms are in the middle level of the formal budget planning. The corresponding percentage at the high level of the formal budget planning is 36 per cent $(10 / 28)$ of the joint-ventures and stock-holding firms against 9 per cent (4/47) of the state-owned and private firms.

Table 5.11 The Distribution of the Formal Budget Planning in Different Scales of Sales Revenues Growth

\begin{tabular}{lcccccccc}
\hline & \multicolumn{7}{c}{ The Level of the Formal Budgeting Planning } \\
\cline { 2 - 10 } Sales Revenues Growth & \multicolumn{2}{c}{ Low level } & \multicolumn{2}{c}{ Medium level } & high level & \multicolumn{2}{c}{ Total } \\
\cline { 2 - 10 } & Firms & Firms & $\%$ & Firms & $\%$ & Firms & $\%$ \\
\hline below 10\% & 13 & 40 & 4 & 14 & 2 & 25 & 19 & $25 \%$ \\
between 11\% and 20\% & 9 & 27 & 10 & 36 & 1 & 27 & 20 & $27 \%$ \\
between 21\% and 30\% & 7 & 21 & 9 & 32 & 4 & 27 & 20 & $27 \%$ \\
between 31\% and 40\% & 2 & 6 & 3 & 10 & 3 & 11 & 8 & $11 \%$ \\
between 41\% and 50\% & 2 & 6 & 1 & 4 & 2 & 6 & 5 & $7 \%$ \\
between 81\% and 90\% & 0 & 0 & 1 & 4 & 2 & 4 & 3 & $4 \%$ \\
& 33 & 100 & 28 & 100 & 14 & 100 & 75 & $100 \%$ \\
\hline
\end{tabular}


Table 5.12 The Distribution of the Formal Budget Planning in Different Scales of Profit Growth

\begin{tabular}{lcccccccc}
\hline \multirow{2}{*}{ Profit Growth } & \multicolumn{7}{c}{ The Level of the Formal Budgeting Planning } \\
\cline { 2 - 10 } & \multicolumn{2}{c}{ Low level } & medium level & high level & \multicolumn{2}{c}{ Total } \\
\cline { 2 - 10 } & Firms & $\%$ & Firms & $\%$ & Firms & $\%$ & Firms & $\%$ \\
\hline below 10\% & 21 & 64 & 12 & 42 & 5 & 36 & 38 & $51 \%$ \\
between 11\% and 20\% & 11 & 33 & 13 & 46 & 4 & 29 & 28 & $37 \%$ \\
between 21\% and 30\% & 1 & 3 & 1 & 4 & 3 & 21 & 5 & $7 \%$ \\
between 31\% and 40\% & 0 & 0 & 0 & 0 & 2 & 14 & 2 & $3 \%$ \\
between 41\% and 50\% & 0 & 0 & 1 & 4 & 0 & 0 & 1 & $1 \%$ \\
between 61 and 70\% & 0 & 0 & 1 & 4 & 0 & 0 & 1 & $1 \%$ \\
\hline & 33 & 100 & 28 & 100 & 14 & 100 & 75 & $100 \%$ \\
\hline
\end{tabular}

Table 5.11 and Table 5.12 above show how the formal budget planning is distributed among different percentage levels of sales and profit. In general, this pattern is consistent with what we found in the former part for the formal budgeting process and firm performance (see Table 5.7). A declining trend exists for both two models, especially for the second model regarding the formal budget planning and growth of profit. As we can see from the two tables above: with sales and profit growth increasing, the number of firms is decreases. 79 per cent of the firms report their sales growth rate to be lower than 31 per cent. 88 per cent of the firms report their growth rate of profit is no more than 20 per cent. The data from the tables above also tells us that only few firms can actually achieve the most advanced level in terms of both financial performance and the budget planning. Only 4 firms (3 firms with upmost 90 per cent of sales growth and 1 firm with up to 70 per cent of profit growth) are in the sample.

\subsubsection{Descriptive Results: Budgetary Goal Clarity and Difficulty}

Table 5.13 The Level of Budget Goal Clarity in General

\begin{tabular}{lcc}
\hline Level of budget goal clarity & Frequency & Percent \\
\hline Low level & 11 & 14 \\
Medium level & 44 & 59 \\
High level & 20 & 27 \\
\hline Total & 75 & 100 \\
\hline
\end{tabular}

According to the range from the maximum to minimum mean value (2.33-7.00), all firms are divided into three different levels of budget goal clarity. Firms with average scales interval from 2.33 to 3.88 are in the first category, standing for the lowest level of budget goal clarity. Firms with average scales ranging from 3.89 to 5.44 belong to the second category, representing a moderate level of budget goal clarity. Firms in a scale from 5.45 to 7.00 are in the last category, representing a higher level of budget goal clarity. The number of firms with different levels of budget-goal clarity is summarized 
in Table 5.13. 44 firms, accounting for 59 per cent, are located at the middle level of using budget-goal clarity. 86 per cent firms in total report clear budget-goal use at advanced level including the second and highest level. Almost one third of the firms (27 per cent) reports having very clear budget-goals.

Table 5.14 The Level of Budget Goal Clarity in Small and Medium-Sized Firms

\begin{tabular}{lccccccccc}
\hline \multirow{2}{*}{ Firm Size } & \multicolumn{6}{c}{ The General Level of Budget Goal Clarity } \\
\cline { 2 - 10 } & \multicolumn{2}{c}{ Low level } & Medium level & \multicolumn{2}{c}{ High level } & \multicolumn{2}{c}{ Total } \\
\cline { 2 - 10 } & Firms & $\%$ & Firms & $\%$ & Firms & $\%$ & Firms & $\%$ \\
\hline Small Firms & 5 & 45 & 28 & 64 & 6 & 30 & 39 & 52 \\
Medium-sized Firms & 6 & 55 & 16 & 36 & 14 & 70 & 36 & 48 \\
\hline Total & 11 & 100 & 44 & 100 & 20 & 100 & 75 & 100 \\
\hline
\end{tabular}

Table 5.14 shows the distribution of small and medium-sized firms among the different levels of budget goal clarity. Most firms (28 firms) are classified in the second category, representing a moderate level use of budget goal clarify. More medium-sized firms (6 out of 36 firms), compared to small firms (5 out of 39), use unclear-stated budget goals. However, the number of middle-sized firms (14) using a budget goal with high clarity is more than two times higher than the number of small firms (6).

Table 5.15 The Level of Budget Goal Clarity in Different Types of Business

\begin{tabular}{lcccccccc}
\hline \multirow{2}{*}{ Business Type } & \multicolumn{7}{c}{ The Level of Budget Goal Clarity } \\
\cline { 2 - 9 } & \multicolumn{2}{c}{ Low level } & \multicolumn{2}{c}{ Medium level } & High level & Total \\
\cline { 2 - 9 } & Firms & $\%$ & Firms & $\%$ & Firms & $\%$ & Firms & $\%$ \\
\hline State-owned enterprise & 2 & 18 & 3 & 7 & 3 & 15 & 8 & 11 \\
Private enterprise & 7 & 64 & 24 & 55 & 8 & 40 & 39 & 52 \\
Joint-venture & 0 & 0 & 4 & 9 & 3 & 15 & 7 & 9 \\
Stock-holding & 2 & 18 & 13 & 29 & 6 & 30 & 21 & 28 \\
\hline Total & 11 & 100 & 44 & 100 & 20 & 100 & 75 & 100 \\
\hline
\end{tabular}

Additionally, Table 5.15 illustrates the distribution of the budget-goal clarity in different business types. In general, the data indicate that all types of firms focus on how clear their budget-goals are. Only a few firms seem to use unclear budget-goals. In particular, all join-ventures report using clear or very clear goals in their budgeting process. 62 per cent (24/39) and 21 per cent (8/39) of private firms report a medium and a high level of clarity use, respectively.

Table 5.16 shows the frequency of budget goal achievement at different levels of budget goal clarity. 56 per cent of the firms in the sample (no matter at which level of budget goal clarity the firms are) occasionally achieve their budget goal. 41 per cent of the firms report that their actual performances are frequently reached as their budget 
goals planned. Only very few firms ( 2 firms in total) never achieve their budget goals. Observing the descriptive results shown in Table 5.16, we can find some facts: Firstly, more firms at a high level of budget goal clarity report more frequently achieving budget goal, compared to other firms at other levels. For example, there are 13 out of 20 firms (65 per cent) at a high level of budget goal clarity that report "very often". However, 17 firms at the medium level (39 per cent) and only 1 firm at the lowest level (9 per cent) reported "very often". Secondly, a decreasing line can also be seen at the second level of the budget goal achievement. As we can conclude from the data in Table 5.16, 82 per cent of the firms at the first level of budget goal clarity show low frequency of budget goal achievement. The corresponding percentage at the second and the third level of budget goal clarity is 62 and 30 per cent, respectively.

Table 5.16 The Distribution of Budget Goal Clarity in Different Levels of Budget Goal Achievement

\begin{tabular}{lcccccccc}
\hline \multirow{2}{*}{$\begin{array}{c}\text { Budget goal achievement } \\
\text { (frequency) }\end{array}$} & \multicolumn{7}{c}{ The Level of Budget Goal Clarity } \\
\cline { 2 - 10 } & Low level & \multicolumn{2}{c}{ Medium level } & High level & \multicolumn{2}{c}{ Total } \\
\cline { 2 - 10 } & Firms & $\%$ & Firms & $\%$ & Firms & $\%$ & Firms & $\%$ \\
\hline Never (1) & 1 & 9 & 0 & 0 & 1 & 5 & 2 & 3 \\
Few (2-3) & 9 & 82 & 27 & 62 & 6 & 30 & 42 & 56 \\
Very Often (4-5) & 1 & 9 & 17 & 38 & 13 & 65 & 31 & 41 \\
\hline Total & 11 & 100 & 44 & 100 & 20 & 100 & 75 & 100 \\
\hline
\end{tabular}

Table 5.17 The Distribution of Budget Goal Clarity in Different Levels of Job Satisfaction

\begin{tabular}{lcccccccc}
\hline & \multicolumn{7}{c}{ The Level of Budget Goal Clarity } \\
\cline { 2 - 9 } Level of Job Satisfaction & \multicolumn{2}{c}{ Low level } & \multicolumn{2}{c}{ Medium level } & High level & \multicolumn{2}{c}{ Total } \\
\cline { 2 - 9 } & Firms & $\%$ & Firms & $\%$ & Firms & $\%$ & Firms & $\%$ \\
\hline Low Level (1) & 1 & 9 & 4 & 9 & 1 & 5 & 6 & 8 \\
Middle Level (2-3) & 9 & 82 & 33 & 75 & 14 & 70 & 56 & 75 \\
High Level (4-5) & 1 & 9 & 7 & 16 & 5 & 25 & 13 & 17 \\
\hline Total & 11 & 100 & 44 & 100 & 20 & 100 & 75 & 100 \\
\hline
\end{tabular}

Compared with budgetary performance, job satisfaction in the sample firms shows weaker outcomes (see in Table 5.17). 17 per cent of the firms (13 firms) replied with a high level (with the Likert scale from 4 to 5) of job satisfaction. 8 per cent of the employees from the sample replied with a very low level of job satisfaction. However, most employees ( 75 per cent) in the sample responded that their job satisfaction is at the middle level. 82 per cent (9/11) of firms with unclear budget goals report a modest job satisfaction. When firms use clear budget goals, the percentage decreases to 75 per cent (33/44 for budget goal clarity at the second level) and 70 per cent (14/20 for budget 
goal clarity at the third level). In contrast, for the advanced level of job satisfaction, an upward trend can be seen as the level of budget goal clarity increases. It means that more firms reporting a higher job satisfaction having higher clarity of budget goals. As we can see from Table 5.17, 25 per cent of the firms at a high level of budget goal clarity achieve high job satisfaction. Only 16 per cent (7/44) firms at the medium level of the budget goal clarity report a high level of job satisfaction. The percentage declines down to 9 per cent (1/11) for the firms at the lowest level of budget goal clarity.

Table 5.18 The Level of Budget Goal Difficulty in General

\begin{tabular}{lcc}
\hline Level of budget goal difficulty & Frequency & Percent \\
\hline Low level & 7 & 9 \\
Medium level & 47 & 63 \\
High level & 21 & 28 \\
\hline Total & 75 & 100 \\
\hline
\end{tabular}

Following a similar way of classification, all firms are divided into three different levels based on the mean values calculated (ranging from the minimum 2.25 to the maximum 6.50). Firms with average scales interval from 2.25 to 3.66 points are in the first category standing for loose budget-goal use. Firms with average scales ranging from 3.67 to 5.08 are those with tough but attainable budget-goal use. Firms with the scale from 5.09 to 6.50 (i.e., the last category) represents a very tough budget-goal use. From Table 5.18 above, we can see that 63 per cent of the firms set up tough but attainable budget goals (i.e. the middle level of budget goal difficulty).

Table 5.19 The Level of Budget Goal Difficulty in Small and Medium-Sized Firms

\begin{tabular}{lcccccccc}
\hline \multirow{2}{*}{ Firm Size } & \multicolumn{7}{c}{ The Level of Budget Goal Difficulty } \\
\cline { 2 - 10 } & \multicolumn{2}{c}{ Low level } & \multicolumn{2}{c}{ Medium level } & High level & \multicolumn{2}{c}{ Total } \\
\cline { 2 - 10 } & Firms & $\%$ & Firms & $\%$ & Firms & $\%$ & Firms & $\%$ \\
\hline Small Firms & 4 & 57 & 27 & 57 & 8 & 38 & 39 & 52 \\
Medium-sized Firms & 3 & 43 & 20 & 43 & 13 & 62 & 36 & 48 \\
\hline Total & 7 & 100 & 47 & 100 & 21 & 100 & 75 & 100 \\
\hline
\end{tabular}

Table 5.20 The Level of Budget Goal Difficulty in Different Types of Business

\begin{tabular}{lcccccccc}
\hline & \multicolumn{7}{c}{ The Level of Budget Goal Difficulty } \\
\cline { 2 - 8 } \multicolumn{1}{c}{ Business Type } & $\begin{array}{c}\text { Low level of } \\
\text { difficulty }\end{array}$ & $\begin{array}{c}\text { Medium level of } \\
\text { difficulty }\end{array}$ & $\begin{array}{c}\text { High level of } \\
\text { difficulty }\end{array}$ & Total \\
\cline { 2 - 9 } & Firms & $\%$ & Firms & $\%$ & Firms & $\%$ & Firms & $\%$ \\
\hline State-owned enterprise & 0 & 0 & 5 & 11 & 3 & 14 & 8 & 11 \\
Private enterprise & 4 & 57 & 23 & 49 & 12 & 57 & 39 & 52 \\
Joint-venture & 1 & 14 & 4 & 8 & 2 & 10 & 7 & 9 \\
Stock-holding & 2 & 29 & 15 & 32 & 4 & 19 & 21 & 28 \\
\hline Total & 7 & 100 & 47 & 100 & 21 & 100 & 75 & 100 \\
\hline
\end{tabular}


Compared to the number of small firms, more big firms tend to use very difficult budget goals. 13 out of 36 medium-sized firms in the third level of budget goal difficulty indicated to use very difficult budget goals, compared to 8 out of 39 small firms. Most small firms (27 firms out of 39) use tough but attainable budget goals. For mediumsized firms, this indicated by 20 out of 36 firms.

For the different business types, more private and stock-holding firms use budget goals with a reasonable level of difficulty. For private firms, only 4 firms use very easy attainable budget goals. Most of these firms are in the second category. About 31 per cent of private firms (12 out of 39) in the sample apply very difficulty budget goals. For stock-holding firms, almost all firms (19 out of 21) set moderate or high levels of budget-goal difficulty. More than half (15 out of 21) are in the second category reporting tough but attainable budget goals.

Moreover, 80 per cent of the sample firms (in Table 5.21) indicate that they get considerable motivation for budget setting. Only 5 per cent of the firms announce no motivation from budget setting. However, a lower level of budgetary motivation is reported relatively often by firms with loose budget goals. The proportion is 14 per cent, compared to 4 and 5 per cent of the firms with a middle or high level of budget goal difficulty.

Table 5.21 The Distribution of Budget Goal Difficulty in Different Levels of Budgetary Motivation

\begin{tabular}{lcccccccc}
\hline & \multicolumn{7}{c}{ The Level of Budget Goal Difficulty } \\
\cline { 2 - 9 } Level of Budgetary Motivation & \multicolumn{2}{c}{ Low level } & Medium level & High level & \multicolumn{2}{c}{ Total } \\
\cline { 2 - 9 } & Firms & $\%$ & Firms & $\%$ & Firms & $\%$ & Firms & $\%$ \\
\hline Low Level (1) & 1 & 14 & 2 & 4 & 1 & 5 & 4 & 5 \\
Middle Level (2-3) & 5 & 72 & 40 & 85 & 15 & 71 & 60 & 80 \\
High Level (4-5) & 1 & 14 & 5 & 11 & 5 & 24 & 11 & 15 \\
\hline Total & 7 & 100 & 47 & 100 & 21 & 100 & 75 & 100 \\
\hline
\end{tabular}

Table 5.22 The Distribution of Budget Goal Difficulty in Different Levels of Job Involvement

\begin{tabular}{lcccccccc}
\hline & \multicolumn{7}{c}{ The Level of Budget Goal Difficulty } \\
\cline { 2 - 9 } Level of Job Involvement & \multicolumn{2}{c}{ Low level } & \multicolumn{2}{c}{ Medium level } & High level & Total \\
\cline { 2 - 9 } & Firms & $\%$ & Firms & $\%$ & Firms & $\%$ & Firms & $\%$ \\
\hline Low Level (1) & 0 & 0 & 0 & 0 & 0 & 0 & 0 & 0 \\
Middle Level (2-3) & 2 & 29 & 17 & 36 & 6 & 29 & 25 & 33 \\
High Level (4-5) & 5 & 71 & 30 & 64 & 15 & 71 & 50 & 67 \\
\hline Total & 7 & 100 & 47 & 100 & 21 & 100 & 75 & 100 \\
\hline
\end{tabular}


Table 5.22 shows that the employees from the sample firms, in general, use formidable efforts to achieve their firms' budget goals. 67 per cent of firms report a job involvement at a high level (the Likert scale at this level is from 4 to 5). Instead, no firm reported job involvement at a low level. However, the descriptive data do not provide sufficient evidence that a higher goal difficulty will lead to the higher level of job involvement. Although 71 per cent firms with very difficult budget goals report that they need a great deal of effort to achieve their goal, the same percentage of firms with very loose budget goals turns out to have a very high level of job involvement.

\subsubsection{Descriptive Results: Budgeting Sophistication}

Based on the average scores, the original data of the budgetary sophistication are categorized into three levels representing a low, middle, or high extent of budgeting sophistication. Firms in the first category have an average scale interval from 1.33 to 3.21 points. Firms with average scales ranging from 3.22 to 5.10 belong to the second category, which represents a moderate level of budgeting sophistication. Firms with a scale from 5.11 to 7.00 are in the last category. Descriptive statistics summarize the extent of the budgeting sophistication in the sample as the following tables shown. We note that 48 per cent of the firms (36 firms from the sample) report a moderate level of budgeting sophistication. However, the general level of budgeting sophistication is still less advanced, as 91 per cent of firms are at either a low or middle level.

Table 5.23 The Level of Budgeting Sophistication in General $(\mathrm{N}=75)$

\begin{tabular}{|l|c|c|}
\hline Level of budgetary sophistication & Frequency & Percent \\
\hline Low level & 32 & 43 \\
Medium level & 36 & 48 \\
High level & 7 & 9 \\
Total & 75 & 100 \\
\hline
\end{tabular}

Table 5.24 The Level of Budgeting Sophistication in Small Firms and Medium-sized Firms

\begin{tabular}{lcccccccc}
\hline \multirow{2}{*}{ Firm Size } & \multicolumn{7}{c}{ The Level of Budgeting Sophistication } \\
\cline { 2 - 9 } & \multicolumn{2}{c}{ Low level } & Medium level & High level & \multicolumn{2}{c}{ Total } \\
\cline { 2 - 9 } & Firms & $\%$ & Firms & $\%$ & Firms & $\%$ & Firms & $\%$ \\
\hline Small Firms & 24 & 75 & 14 & 39 & 1 & 14 & 39 & 52 \\
Medium-sized Firms & 8 & 25 & 22 & 61 & 6 & 86 & 36 & 48 \\
\hline Total & 32 & 100 & 36 & 100 & 7 & 100 & 75 & 100 \\
\hline
\end{tabular}

Comparing the level of budgeting sophistication between small and medium-sized firms (the frequencies for three different level are presented in Table 5.24), we find that the bigger the firm size, the more advanced the level of budgeting sophistication. Most 
small firms (24 firms) indicated having a low level of budgeting sophistication. In contrast, only 8 medium-sized firms report a low level of budgeting sophistication. Most medium-sized firms adopt a medium level of budgeting sophistication.

Table 5.25 The Level of Budgeting Sophistication in Different Types of Business

\begin{tabular}{lcccccccc}
\hline \multirow{2}{*}{ Business Type } & \multicolumn{7}{c}{ The Level of Budgetary Sophistication } \\
\cline { 2 - 10 } & \multicolumn{2}{c}{ Low level } & Medium level & High level & \multicolumn{2}{c}{ Total } \\
\cline { 2 - 10 } & Firms & $\%$ & Firms & $\%$ & Firms & $\%$ & Firms & $\%$ \\
\hline State-owned enterprise & 4 & 13 & 4 & 11 & 0 & 0 & 8 & 11 \\
Private enterprise & 26 & 81 & 12 & 33 & 1 & 14 & 39 & 52 \\
Joint-venture & 1 & 3 & 4 & 11 & 2 & 29 & 7 & 9 \\
Stock-holding & 1 & 3 & 16 & 45 & 4 & 57 & 21 & 28 \\
\hline Total & 32 & 100 & 36 & 100 & 7 & 100 & 75 & 100 \\
\hline
\end{tabular}

Concerning the status of budgeting sophistication among different business types, we can see from Table 5.25 that stock-holding firms achieve a higher level of budgeting sophistication than other types of firms. There are 20 stock-holding companies in the second or the third category, the number ranks the highest among other types of firms. It also shows that stock-holding firms implement their budgeting sophistication at a higher level, compared to other firms. For most private enterprises, budgeting sophistication is still at a low level, since 26 out of 39 are in the first category. Only 1 private firm fulfills its budgeting sophistication at an advanced level (i.e. in the third category).

Table 5.26 and Table 5.27 show the distribution pattern for budgeting sophistication and financial performance. Table 5.26 shows that a high percentage of firms has sales revenues' growth rate below 31 per cent. There are 59 firms with less than 31 per cent of sales growth in the past three year. This accounts for almost 79 per cent (59/75) of the total number of firms in the sample. Nevertheless, the frequency is declining as budgeting sophistication becomes more advanced. Descriptive results show that 84 per cent of the firms (27/32) with a low level of budgeting sophistication have a sales growth less than 31 per cent. The percentage at the middle level of budgeting sophistication slightly decreases to 83 per cent (30/36). 71 per cent of firms (5/7) that adopt an advanced budgeting sophistication report that they achieved a sales growth rate of more than 30 per cent. All firms with a high level of budgetary sophistication report a sales growth of more than 20 per cent.

In addition, Table 5.27 reflects the frequency distribution for the budgeting sophistication and growth rate of profit. The pattern of distribution is similar to the 
pattern illustrated in the sales revenues growth. 66 firms from the sample ( 88 per cent of firms, 66/75) increase their profit lower than 20 per cent. There are more firms with a higher rate of profit growth (higher than 20 per cent) at a high level of budgeting sophistication, compared to the number of firms at other levels. But the percentage of firms with a profit growth of more than 20 per cent in the total sample is quite small.

Table 5.26 The Distribution of Budgeting Sophistication in Different Scales of Sales Revenues Growth

\begin{tabular}{lcccccccc}
\hline & \multicolumn{7}{c}{ The Level of Budgeting Sophistication } \\
\cline { 2 - 9 } Sales Revenues Growth & \multicolumn{2}{c}{ Low level } & \multicolumn{2}{c}{ Medium level } & High level & Total \\
\cline { 2 - 9 } & Firms & $\%$ & Firms & $\%$ & Firms & $\%$ & Firms & $\%$ \\
\hline below 10\% & 12 & 38 & 7 & 14 & 0 & 0 & 19 & $25 \%$ \\
between 11\% and 20\% & 6 & 19 & 14 & 36 & 0 & 0 & 20 & $27 \%$ \\
between 21\% and 30\% & 9 & 28 & 9 & 32 & 2 & 28 & 20 & $27 \%$ \\
between 31\% and 40\% & 2 & 6 & 3 & 10 & 3 & 43 & 8 & $11 \%$ \\
between 41\% and 50\% & 2 & 6 & 1 & 4 & 2 & 28 & 5 & $7 \%$ \\
between 81\% and 90\% & 1 & 3 & 2 & 4 & 0 & 0 & 3 & $4 \%$ \\
\hline & 32 & 100 & 36 & 100 & 7 & 100 & 75 & $100 \%$ \\
\hline
\end{tabular}

Table 5.27 The Distribution of Budgeting Sophistication in Different Scales of Profit Growth

\begin{tabular}{lcccccccc}
\hline \multirow{2}{*}{ Profit Growth } & \multicolumn{7}{c}{ The Level of Budgeting Sophistication } \\
\cline { 2 - 9 } & \multicolumn{2}{c}{ Low level } & \multicolumn{2}{c}{ Medium level } & High level & \multicolumn{2}{c}{ Total } \\
\cline { 2 - 9 } & Firms & Firms & $\%$ & Firms & $\%$ & Firms & $\%$ \\
\hline below 10\% & 20 & 63 & 17 & 47 & 1 & 14 & 38 & $51 \%$ \\
between 11\% and 20\% & 10 & 31 & 16 & 44 & 2 & 29 & 28 & $37 \%$ \\
between 21\% and 30\% & 1 & 3 & 2 & 6 & 2 & 29 & 5 & $7 \%$ \\
between 31\% and 40\% & 0 & 0 & 0 & 0 & 2 & 29 & 2 & $3 \%$ \\
between 41\% and 50\% & 0 & 0 & 1 & 3 & 0 & 0 & 1 & $1 \%$ \\
between 61 and 70\% & 1 & 3 & 0 & 0 & 0 & 0 & 1 & $1 \%$ \\
\hline
\end{tabular}

\subsubsection{Descriptive Results: The formal Budgetary Control}

As mentioned in section 5.2, the mean value of the formal budgetary control (2.42) in the sample is much lower than the mean value of the formal budget planning (3.83). To show how firms with different sizes and business types are distributed in different levels of the formal budgetary control, all firms are classified into three levels. These levels are based on the minimum average score (0.4) and the maximum average value (1.5) calculated from the descriptive statistics. Firstly, firms with average scales from 0.40 to 1.59 points are in the first category representing the lower level of the formal budgetary control. Secondly, firms with average scales ranging from 1.60 to 2.79 belong to the second category representing the moderate level of the formal budgetary control. 
Finally, firms with scale from 2.80 to 4.00 are in the last category representing the higher level of the formal budgetary control.

Table 5.28 The Level of Budgetary Control in General

\begin{tabular}{|l|c|c|}
\hline Level of Budgetary Control & Frequency & Percent \\
\hline Low level & 8 & 11 \\
Medium level & 45 & 60 \\
High level & 22 & 29 \\
Total & 75 & 100 \\
\hline
\end{tabular}

The level of formal budgetary control in the sample firms is illustrated in the above table. It shows that 11 per cent of firms occasionally use budget variance and 60 per cent have a considerable coverage of budgetary control in different functional areas. Therefore, most firms in this research project use a medium level of the formal budgetary control (i.e. the second category). 29 per cent firms regularly use budget variance. The budgetary control extensively covers different functional areas, which represents an advanced application of the budgeting control. The descriptive statistics results show, in Table 5.29 and Table 5.30, the distribution of the formal budgeting control in different firm sizes and different business types.

Table 5.29 The Level of the Formal Budgetary Control in Small- and Medium-sized Firms

\begin{tabular}{lcccccccc}
\hline \multirow{2}{*}{ Firm Size } & \multicolumn{7}{c}{ The Level of the Formal Budgetary Control } \\
\cline { 2 - 9 } & \multicolumn{2}{c}{ Low level } & Medium level & High level & \multicolumn{2}{c}{ Total } \\
\cline { 2 - 9 } & Firms & $\%$ & Firms & $\%$ & Firms & $\%$ & Firms & $\%$ \\
\hline Small Firms & 7 & 88 & 28 & 62 & 4 & 18 & 39 & 52 \\
Medium-sized Firms & 1 & 12 & 17 & 38 & 18 & 82 & 36 & 48 \\
\hline Total & 8 & 100 & 45 & 100 & 22 & 100 & 75 & 100 \\
\hline
\end{tabular}

Table 5.30 The Level of Budgetary Control in the Different Types of Business

\begin{tabular}{lcccccccc}
\hline & \multicolumn{7}{c}{ The Level of the Formal Budgetary Control } \\
\cline { 2 - 10 } \multicolumn{1}{c}{ Business Type } & \multicolumn{2}{c}{ Low level } & Medium level & High level & Total \\
\cline { 2 - 10 } & Firms & $\%$ & Firms & $\%$ & Firms & $\%$ & Firms & $\%$ \\
\hline State-owned enterprise & 1 & 12 & 4 & 9 & 3 & 14 & 8 & 11 \\
Private enterprise & 7 & 88 & 27 & 60 & 5 & 23 & 39 & 52 \\
Joint-venture & 0 & 0 & 1 & 2 & 6 & 27 & 7 & 9 \\
Stock-holding & 0 & 0 & 13 & 29 & 8 & 36 & 21 & 28 \\
\hline Total & 8 & 100 & 45 & 100 & 22 & 100 & 75 & 100 \\
\hline
\end{tabular}

Three-fifths of the firms have a medium level of formal budgetary control. Compared to medium-sized firms, more small firms (7 versus 1 ) use budgetary control at a low level. In contrast, far more medium-sized firms (18 firms vs. 4 firms) apply the formal budgetary control at a higher level. Only 5.6 per cent of the medium-sized firms (1 out 
of 36) adopt a low level of formal budgetary control. Furthermore, the statistics (in Table 5.30) for budgetary control use in different business types, show that 60 per cent of the private firms in the sample report use a middle level of formal budgeting control. The descriptive statistics indicate that stock-holding, and especially the joint-venture companies tend to adopt a more advanced budgetary control. The number of these two firms' types in the third category is 14 , accounting for 63 per cent of the total firms in this category. The descriptive data below shows how firms with different levels of budgeting control are distributed in different ranges of financial performance.

Table 5.31 The Distribution of Budgetary Control in Different Scales of Sales Revenues Growth

\begin{tabular}{lcccccccc}
\hline & \multicolumn{7}{c}{ The Level of the Formal Budgetary Control } \\
\cline { 2 - 9 } Sales Revenues Growth & \multicolumn{2}{c}{ Low level } & \multicolumn{2}{c}{ Medium level } & High level & \multicolumn{2}{c}{ Total } \\
\cline { 2 - 9 } & Firms & $\%$ & Firms & $\%$ & Firms & $\%$ & Firms & $\%$ \\
\hline below 10\% & 3 & 37 & 13 & 29 & 3 & 25 & 19 & $25 \%$ \\
between 11\% and 20\% & 2 & 25 & 12 & 27 & 6 & 27 & 20 & $27 \%$ \\
between 21\% and 30\% & 3 & 37 & 11 & 24 & 6 & 27 & 20 & $27 \%$ \\
between 31\% and 40\% & 0 & 0 & 5 & 11 & 3 & 11 & 8 & $11 \%$ \\
between 41\% and 50\% & 0 & 0 & 3 & 7 & 2 & 6 & 5 & $7 \%$ \\
between 81\% and 90\% & 0 & 0 & 1 & 2 & 2 & 4 & 3 & $4 \%$ \\
& 8 & 100 & 45 & 100 & 22 & 100 & 75 & $100 \%$ \\
\hline
\end{tabular}

In Table 5.31, we see that 59 firms report their growth of sales revenues to be less than 31 per cent, which accounts for 79 per cent (59/75) of the total number of firms. 15 firms with a high level of budgetary control have a sale growth rate which is less than 31 per cent and 7 of these firms have a sales growth rate of more than 30 per cent. A further observation shows that more firms achieve a higher growth of sales revenues when an advanced budgetary control is used. For example, it is shown that no firms at the low level of budgetary control can achieve more than 30 per cent growth of sales revenues grow. However, there are 9 firms at the second level of budgetary control reporting their growth rate of sales revenues of more than 30 per cent.

Table 5.32 The Distribution of Budgetary Control in Different Scales of Profit Growth

\begin{tabular}{lcccccccc}
\hline \multirow{2}{*}{ Profit Growth } & \multicolumn{7}{c}{ The Level of the Formal Budgetary Control } \\
\cline { 2 - 9 } & \multicolumn{2}{c}{ Low level } & Medium level & High level & \multicolumn{2}{c}{ Total } \\
\cline { 2 - 9 } & Firms & $\%$ & Firms & $\%$ & Firms & $\%$ & Firms & $\%$ \\
\hline below 10\% & 6 & 75 & 24 & 53 & 8 & 36 & 38 & $51 \%$ \\
between 11\% and 20\% & 2 & 25 & 18 & 40 & 8 & 36 & 28 & $37 \%$ \\
between 21\% and 30\% & 0 & 0 & 1 & 2 & 4 & 18 & 5 & $7 \%$ \\
between 31\% and 40\% & 0 & 0 & 0 & 0 & 2 & 9 & 2 & $3 \%$ \\
between 41\% and 50\% & 0 & 0 & 1 & 2 & 0 & 0 & 1 & $1 \%$ \\
between 61 and 70\% & 0 & 0 & 1 & 2 & 0 & 0 & 1 & $1 \%$ \\
\hline & 8 & 100 & 45 & 100 & 22 & 100 & 75 & $100 \%$ \\
\hline
\end{tabular}


In Table 5.32, we can see that most firms (66 out of 75) have less than 20 per cent of profit growth. Only 2 firms at the middle level of budgetary control achieve more than 40 per cent of profit growth. The maximum rate is 70 per cent.

\subsection{Descriptive Results: Budgetary Participation and Managerial Performance}

The questions about budgetary participation are answered by 46 financial managers or front-line managers and 29 top managers from different firms. The mean value, as the following descriptive table shows, is 3.76. This represents a low level of budgetary participation. It is calculated by taking the average scores of all nine-item instrument of budgetary participation. This result may indicate that, for small and medium-sized Chinese enterprises, lower level managers, such as financial manager or front-line managers are, to some extent, involved, together with the CEO, in budget setting. Nevertheless, top managers still have critical influence over the final set-up of the budget. Average managerial performance for all the sampled firms is also shown in Table 5.33. The mean for the managerial performance is 5.62 .

Table 5.33 Mean and Standard Deviation of Budgetary Participation

\begin{tabular}{|l|c|c|c|}
\hline & N & Mean & Std. Deviation \\
\hline Budgetary Participation & 75 & 3.76 & 1.33 \\
Valid N (list wise) & 75 & & \\
\hline
\end{tabular}

Mean \& Standard Deviation of Managerial Performance

\begin{tabular}{|l|c|c|c|}
\hline & N & Mean & Std. Deviation \\
\hline Managerial performance & 75 & 5.62 & 1.05 \\
Valid N (list wise) & 75 & & \\
\hline
\end{tabular}

Note: the Likert scale to measure budgetary participation is used from " 1 " to " 7 ".

Furthermore, to show how different levels of budgetary participation are related to different firm sizes and business types, all firms are classified into a low, middle, or high level of budgetary participation. This classification is based on the average score available in the database. Higher values indicate higher participation. This results in a classification of 50 firms into the first category (i.e. lower level of budgetary participation) with average score lower than 4.44. The number of firms in the second level of budgetary participation is 20 . Their average budgetary participation scores range from 4.45 to 5.72 . In the highest level, there are 5 firms, which accounts for only 6 percent of the total firms. Their average scores range from 5.73 to 7.00 . 
Table 5.34 Frequency of Budgetary Participation in Different Levels

\begin{tabular}{|l|c|c|}
\hline Level of Budgetary Participation & Frequency & Percent \\
\hline Low level & 50 & 67 \\
Medium level & 20 & 27 \\
High level & 5 & 6 \\
Total & 75 & 100 \\
\hline
\end{tabular}

The results summarized in Table 5.35 show that most of the small firms in the sample (74 per cent, 29/39) are at a low level of budgetary participation. Only 1 small firm has a high budgetary participation. The contribution to the whole sample is about 1.33 per cent, which is rather small. For medium-sized firms, most of them (58 per cent) are also at a low level of budgetary participation. However, the number of firms at a high level of budgetary participation (4 firms) is still larger than the number of small firms. The number of middle-sized firms at the second level of budgetary participation equals 11, compared to 9 for small firms. Additionally, results summarized in Table 5.36 show how firms with different levels of budgetary participation are distributed in different business types. As the data indicates, state-owned and stock-holding enterprises tend to achieve a higher level of budgetary participation, compare to other business types (i.e., private enterprises and joint-ventures). Most of them are at a medium-level or highlevel. 5 out of 8 state-owned enterprises indicated that their budgetary participation is at a middle level. 8 out of 21 stock-holding enterprises classified their budgetary participation as middle or high. However, 29 out of 39 private firms are allocated at the category of low budgetary participation.

Table 5.35 The Level of Budgetary Participation in Small- and Medium-sized Firms

\begin{tabular}{lccccccccc}
\hline & \multicolumn{7}{c}{ The Level of Budgetary Participation } \\
\cline { 2 - 9 } \multicolumn{1}{c}{ Firm size } & \multicolumn{2}{c}{ Low level } & Medium level & High level & \multicolumn{2}{c}{ Total } \\
\cline { 2 - 9 } & Firms & $\%$ & Firms & $\%$ & Firms & $\%$ & Firms & $\%$ \\
\hline Small firms & 29 & 58 & 9 & 45 & 1 & 20 & 39 & 52 \\
Medium-sized firms & 21 & 42 & 11 & 55 & 4 & 80 & 36 & 48 \\
\hline & 50 & 100 & 20 & 100 & 5 & 100 & 75 & 100 \\
\hline
\end{tabular}

Table 5.36 The Level of Budgetary Participation in the Different Types of Business

\begin{tabular}{lcccccccc}
\hline \multirow{2}{*}{ Business type } & \multicolumn{7}{c}{ The Level of Budgetary Participation } \\
\cline { 2 - 10 } & \multicolumn{2}{c}{ Low level } & \multicolumn{2}{c}{ Medium level } & High level & Total \\
\cline { 2 - 10 } & Firms & $\%$ & Firms & $\%$ & Firms & $\%$ & Firms & $\%$ \\
\hline State-owned enterprise & 3 & 6 & 5 & 25 & 0 & 0 & 8 & 11 \\
Private enterprise & 29 & 58 & 9 & 45 & 1 & 20 & 39 & 52 \\
Joint-venture & 5 & 10 & 1 & 5 & 1 & 20 & 7 & 9 \\
Stock-holding & 13 & 26 & 5 & 25 & 3 & 60 & 21 & 28 \\
\hline & 50 & 100 & 20 & 100 & 5 & 100 & 75 & 100 \\
\hline
\end{tabular}




\section{Summary}

- The descriptive analysis in this chapter shows the frequency, mean value, and standard deviations of all variables in the research model.

- With respect to the independent variables in this study (the formal budgeting process), we found that except for the two variables "budget goal clarity" and "budget goal difficulty", the mean values are less than the middle value "4". Especially, the formal budgetary control has a low mean value of only 2.42 . The results indicate a low level of the formal budgeting process in Chinese SMEs.

- With respect to the dependent variables in this study (performance), it is found that budgetary performance, job involvement, and managerial performance show high mean values. However, the financial performance in the sample firms show low mean values. The values are less than the middle value "3". In particular, the growth of profit has a low mean value (1.72).

- Descriptive data also show that medium-sized firms in the sample tend to adopt a more formal budgeting process than small firms. In addition, stock-holding firms and joint ventures adopt a more formal budgeting process than stateowned and private firms. 


\section{Chapter 6}

\section{Empirical Results: the Formal Budgeting Process and Performance}

The data analysis in this chapter specifically focuses on testing the proposed hypotheses in this study. To analyze those hypotheses in a logical way, the discussion is instigated using the following approach: Firstly, the hypothesis for each factor under discussion is given; secondly, the expected outcomes from the previous literature are presented; thirdly, the statistical models used for testing the corresponding hypotheses are displayed; finally, the actual research outcomes and testing the model together with the two control variables (i.e. firm size and ownership) are reported.

\subsection{Testing Hypothesis 1: the Formal Budgeting Process and Firm Performance}

As discussed in the previous chapters (Chapter 2 and Chapter 4), the formal budgeting process as a general independent variable, is subdivided into the variables of the formal budgeting planning, budget-goal clarity and difficulty, budgetary sophistication, and the formal budgetary control. These four sub-variables and their assumed effects on firm performance are shown in the hypotheses below. In the current model, financial performance, budgetary performance, and other performance are first combined (by taking the mean value) to be checked as "firm performance", since these performances show very strong correlations. In the later sections (sections 6.1.1, 6.1.2, and 6.1.3), the model is estimated separately for the different aspects of dependent variables (i.e. financial performance, budgetary performance, and other performance).

Hypothesis 1a: the more formalized the budgeting planning, the better the firm performance;

Hypothesis 1b1: the clearer the budget goals, the better the firm performance;

Hypothesis 1b2: the more difficult but attainable the budget goals, the better the firm performance;

Hypothesis 1c: the more sophisticated the budgeting, the better the firm performance;

Hypothesis 1d: the more formalized the budgetary control, the better the firm performance.

The hypotheses above, in general, posit that there is a significant and positive effect of the formal budgeting process on firm performance. They are all tested by OLS regression. All sub-hypotheses in this study are tested by both OLS and Lisrel models. By conducting statistical analysis, we can either reject or accept the hypotheses under 1. 
For OLS model, it has been verified by linearity and homoscedasticity that the data have met the regression assumptions. The remainder of this section will display their relevant empirical outcomes.

Figure 6.1 The Model with All Variables under the Formal Budgeting Process and Firm Performance

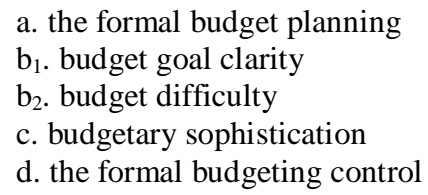

Firm Performance

An equation (Eq. 1-a) is shown below to reflect the statistical relationship between the all variables under the general variable of the formal budgeting process and firm performance.

$$
Y_{1}=a_{1-a}+b_{1-a 1} X_{1 a}+b_{1-a 2} X_{1 b 1}+b_{1-a 3} X_{1 b 2}+b_{1-a 4} X_{1 c}+b_{1-a 5} X_{1 d}
$$

Where $\mathrm{Y}_{1}=$ firm performance; $\mathrm{X}_{1 \mathrm{a}}=$ the formal budget planning, $\mathrm{X}_{1 \mathrm{~b} 1}=$ budget goal clarity; $\mathrm{X}_{1 \mathrm{~b} 2}=$ budget goal difficulty; $\mathrm{X}_{1 \mathrm{c}}=$ budgetary sophistication; $\mathrm{X}_{1 \mathrm{~d}}=$ the formal budgetary control.

To support the hypotheses, T-statistics must be significant and ' $b$ ' in equation (1-a) must be positive. Table 6.1 presents the regression results for the variables in this model.

Table 6.1 Regression Results on Firm Performance $\left(\mathrm{Y}_{1}\right)$ : The Impact of All Variables $\left(\mathrm{X}_{1 \mathrm{a}}, \mathrm{X}_{1 \mathrm{~b} 1}, \mathrm{X}_{1 \mathrm{~b} 2}, \mathrm{X}_{1 \mathrm{c}}, \mathrm{X}_{1 \mathrm{~d}}\right)$ under the Formal Budgeting Process

\begin{tabular}{|c|cccc|}
\hline Model & Variables & Coefficient & Coefficient value (b) & T-stat value \\
\hline \multirow{6}{*}{$1-\mathrm{a}$} & $\mathrm{X}_{1 \mathrm{a}}$ & $\mathrm{b}_{1-\mathrm{a} 1}$ & 0.29 & $2.18^{*}$ \\
& $\mathrm{X}_{\mathrm{bb} 1}$ & $\mathrm{~b}_{1-\mathrm{a} 2}$ & 0.09 & 0.69 \\
& $\mathrm{X}_{1 \mathrm{~b} 2}$ & $\mathrm{~b}_{1-\mathrm{a} 3}$ & 0.34 & $2.50^{*}$ \\
& $\mathrm{X}_{1 \mathrm{c}}$ & $\mathrm{b}_{1-\mathrm{a} 4}$ & 0.05 & 0.28 \\
& $\mathrm{X}_{1 \mathrm{~d}}$ & $\mathrm{~b}_{1-\mathrm{a} 5}$ & 0.25 & 1.45 \\
& & $\mathrm{a}_{1-\mathrm{a}}$ & 0.81 & $1.77^{*}$ \\
\hline \multicolumn{6}{|l}{$\mathrm{R}^{2}=0.34, \mathrm{~N}=75$} & & & \\
\hline
\end{tabular}

Results: By checking each variable in the model individually, we can see that there are only two sub-variables significantly and positively affecting firm performance. These two variables are the formal budgeting planning $\left(\mathrm{X}_{1 \mathrm{a}}\right)$ and budget goal difficulty $\left(\mathrm{X}_{1 \mathrm{~b} 2}\right)$. Their $\mathrm{t}$ values are 2.18 and 2.50 respectively, and the coefficient values are 0.29 and 0.34 respectively. For the sub-variable formal budgetary control, although the coefficient value is positive $(b=0.25)$, the $t$ value is insignificant. 
Based on the previous model 1-a, a new model (model 1-b) is developed by adding two control variables, i.e. firm size and ownership. As we know, firm size is widely used as a control variable in previous research. In the current study, it is also assumed that firm size will affect the budgeting process and the performance of Chinese SMEs. As for ownership, as already discussed in Chapter 2 and Chapter 3, different ownerships of firms in China could perform differently. So in this new model, we attempt to check whether the formal budgeting process and firm size, together with ownership, significantly and positively impact the firm performance of the SMEs. The model 1-b is shown in the equation (Eq. 1-b) below:

$$
Y_{1}=a_{1-b}+b_{1-b 1} X_{1 a}+b_{1-b 2} X_{1 b 1}+b_{1-b 3} X_{1 b 2}+b_{1-b 4} X_{1 c}+b_{1-b 5} X_{1 d}+b_{s 1} S I Z E+b_{o w 1} O W N E \text { (1-b) }
$$

Where $Y_{1}=$ firm performance; $X_{1 a}=$ the formal budget planning, $X_{1 b 1}=$ budget goal clarity; $\mathrm{X}_{1 \mathrm{~b} 2}=$ budget goal difficulty; $\mathrm{X}_{1 \mathrm{c}}=$ budgetary sophistication; $\mathrm{X}_{1 \mathrm{~d}}=$ the budgetary control; $\mathrm{SIZE}=$ firm size; $\mathrm{OWNE}=$ ownership.

Table 6.2 Regression Results on Firm Performance $\left(\mathrm{Y}_{1}\right)$ : The Impact of All Variables under the Formal Budgeting Process $\left(\mathrm{X}_{1 \mathrm{a}}, \mathrm{X}_{1 \mathrm{~b} 1}, \mathrm{X}_{1 \mathrm{~b} 2}, \mathrm{X}_{1 \mathrm{c}}, \mathrm{X}_{1 \mathrm{~d}}\right)$, Firm Size (SIZE), and Ownership (OWNE)

\begin{tabular}{|c|lccc|}
\hline Model & Variables & Coefficient & Coefficient value (b) & T-stat value \\
\hline \multirow{6}{*}{$1-\mathrm{b}$} & $\mathrm{X}_{1 \mathrm{a}}$ & $\mathrm{b}_{1-\mathrm{b} 1}$ & 0.27 & $1.93^{*}$ \\
& $\mathrm{X}_{1 \mathrm{~b} 1}$ & $\mathrm{~b}_{1-\mathrm{b} 2}$ & 0.11 & 0.84 \\
& $\mathrm{X}_{1 \mathrm{~b} 2}$ & $\mathrm{~b}_{1-\mathrm{b} 3}$ & 0.32 & $2.26^{*}$ \\
& $\mathrm{X}_{1 \mathrm{c}}$ & $\mathrm{b}_{1-\mathrm{b} 4}$ & -0.01 & -0.03 \\
& $\mathrm{X}_{1 \mathrm{~d}}$ & $\mathrm{~b}_{1-\mathrm{b} 5}$ & 0.22 & 1.28 \\
\cline { 2 - 6 } & SIZE & $\mathrm{b}_{\mathrm{s} 1}$ & 0.18 & 1.08 \\
& OWNE & $\mathrm{b}_{\text {ow1 }}$ & -0.04 & -0.26 \\
& & $\mathrm{a}_{1-\mathrm{b}}$ & 0.83 & 1.32 \\
\hline \multicolumn{2}{|l}{$\mathrm{R}^{2}=0.35, \mathrm{~N}=75$} & & & \\
\hline
\end{tabular}

Results: The results from the model 1-b are consistent with the results from the former model 1-a. Two sub-variables under the formal budgeting process, i.e. the formal budgeting planning and budget goal difficulty, show significant and positive impacts on firm performance. The t values are 1.93 and 2.26, respectively. The coefficient value (b) " 0.27 " for the formal budgeting planning tells us that a one level increase of the formal budgeting planning leads to 0.27 higher firm performance. A similar explanation also applies to the coefficient value " 0.32 " for budget goal difficulty. The R square value of the model shows that the variables $\left(X_{1 \mathrm{a}}, X_{1 \mathrm{~b} 1}, X_{1 \mathrm{~b} 2}, X_{1 \mathrm{c}}, X_{1 \mathrm{~d}}, \mathrm{SIZE}\right.$, and OWNE) together explain 35 per cent of the variance of firm performance. However, the rest of sub-variables have either an insignificant (i.e. budget goal clarity $\mathrm{X}_{1 \mathrm{~b} 1}$ ) or a negative effect on firm performance (i.e. budgetary sophistication $\mathrm{X}_{1 \mathrm{c}}$ ). For both control 
variables "SIZE" and "OWNE" are not crucial factors, because non-significant effects on firm performance are found. To be more specific, the variable "OWNE" has an negative coefficient value -0.04 , which means that private enterprises do not lead to better performance; the variable "SIZE" has no significant effect on overall performance, since the t values is only 1.08 .

6.1.1 Testing Hypotheses 1a1, 1c1, and 1d1: the Formal Budgeting Planning, Budgetary Sophistication, the Formal Budgetary Control, and Financial Performance

Hypothesis 1al: the more formalized the budgeting planning, the better the financial performance;

Hypothesis 1c1: the more sophisticated the budgeting, the better the financial performance;

Hypothesis 1d1: the more formalized the budgetary control, the better the financial performance.

These three independent variables in the hypothesis $1 \mathrm{a}, 1 \mathrm{c}$, and $1 \mathrm{~d}$ share the same dependent variable, i.e. financial performance. Therefore, they are placed together in one model to be checked, as Figure 6.2 shows below.

Figure 6.2 The Model for the Formal Budget Planning, Budgetary Sophistication, the Budgetary Control, and Financial Performance

The Formal Budget Planning Budgetary Sophistication The Budgetary Control
Financial Performance

Equation 1-c for the formal budget planning, budgetary sophistication, the formal budgetary control, and financial performance relationship (Eq. (1-c)):

$$
\mathrm{Y}_{1 \mathrm{a}}=\mathrm{a}_{1-\mathrm{c}}+\mathrm{b}_{1-\mathrm{c} 1} \mathrm{X}_{1 \mathrm{a}}+\mathrm{b}_{1-\mathrm{c} 2} \mathrm{X}_{1 \mathrm{c}}+\mathrm{b}_{1-\mathrm{c} 3} \mathrm{X}_{1 \mathrm{~d}}
$$

Table 6.3 Regression Results on Financial Performance $\left(\mathrm{Y}_{1 \mathrm{a}}\right)$ : the impact of the Formal Budget Planning $\left(\mathrm{X}_{1 \mathrm{a}}\right)$, Budgetary Sophistication $\left(\mathrm{X}_{1 \mathrm{c}}\right)$, and the formal Budgetary Control $\left(\mathrm{X}_{1 \mathrm{~d}}\right)$

\begin{tabular}{|c|cccc|}
\hline Model & Variables & Coefficient & Coefficient value (b) & T-stat value \\
\hline \multirow{4}{*}{$1-\mathrm{c}$} & $\mathrm{X}_{1 \mathrm{a}}$ & $\mathrm{b}_{1-\mathrm{c} 1}$ & 0.49 & $1.80^{*}$ \\
& $\mathrm{X}_{1 \mathrm{c}}$ & $\mathrm{b}_{1-\mathrm{c} 2}$ & -0.11 & -0.35 \\
& $\mathrm{X}_{1 \mathrm{~d}}$ & $\mathrm{~b}_{1-\mathrm{c} 3}$ & 0.25 & 0.71 \\
& & $\mathrm{a}_{1-\mathrm{a}}$ & 0.88 & 1.57 \\
\hline \multicolumn{2}{l}{$\mathrm{R}^{2}=0.10, \mathrm{~N}=75$} & & & \\
\hline
\end{tabular}


The equation below adds the two control variables in this study, as we know, firm size and ownership. Then, the new equation is:

$$
\mathrm{Y}_{1 \mathrm{a}}=\mathrm{a}_{1-\mathrm{d}}+\mathrm{b}_{1-\mathrm{d} 1} \mathrm{X}_{1 \mathrm{a}}+\mathrm{b}_{1-\mathrm{d} 2} \mathrm{X}_{1 \mathrm{c}}+\mathrm{b}_{1-\mathrm{d} 3} \mathrm{X}_{1 \mathrm{~d}}+\mathrm{b}_{\mathrm{s} 2} \mathrm{SIZE}+\mathrm{b}_{\mathrm{ow} 2} \mathrm{OWNE}
$$

Table 6.4 Regression Results on Financial Performance ( $\left.\mathrm{Y}_{1 \mathrm{a}}\right)$ : The Impact of the Formal Budget Planning $\left(\mathrm{X}_{1 \mathrm{a}}\right)$, Budgetary Sophistication $\left(\mathrm{X}_{1 \mathrm{c}}\right)$, the Formal Budgetary Control $\left(\mathrm{X}_{1 \mathrm{~d}}\right)$, Firm Size (SIZE), and Ownership (OWNE)

\begin{tabular}{|c|lccc|}
\hline Model & Variables & Coefficient & Coefficient value (b) & T-stat value \\
\hline \multirow{6}{*}{$1-\mathrm{d}$} & $\mathrm{X}_{1 \mathrm{a}}$ & $\mathrm{b}_{1-\mathrm{d} 1}$ & 0.55 & $1.96^{*}$ \\
& $\mathrm{X}_{1 \mathrm{c}}$ & $\mathrm{b}_{1-\mathrm{d} 2}$ & -0.14 & -0.41 \\
& $\mathrm{X}_{1 \mathrm{~d}}$ & $\mathrm{~b}_{1-\mathrm{d} 3}$ & 0.26 & 0.74 \\
\cline { 2 - 5 } & SIZE & $\mathrm{b}_{\mathrm{s} 2}$ & 0.36 & 1.12 \\
& OWNE & $\mathrm{b}_{\text {ow2 } 2}$ & 0.42 & 1.25 \\
& & $\mathrm{a}_{1-\mathrm{d}}$ & -0.40 & -0.37 \\
\hline
\end{tabular}

Results: The statistical results are summarized in Table 6.3 and Table 6.4 above. As Table 6.3 shows, only one sub-variable $\mathrm{X}_{1 \mathrm{a}}$ (the formal budgeting planning) under the formal budgeting process has a significant and positive effect on financial performance $(\mathrm{T}=1.80$; Coefficient=0.49). The other sub-variables show insignificant effect on financial performance. R square in the model tell us that the variables of the formal budgeting planning, budgetary sophistication, and the formal budgetary control together explain 10 per cent of the variance of financial performance. Similar conclusions can also be obtained from the results in Table 6.4. The coefficient value for the formal budgeting planning in the model $1-\mathrm{d}$ is 0.55 , which explains that a one level increase of the formal budgeting planning leads to 0.55 higher financial performances. Both the sub-variable $X_{1 c}$ (budgetary sophistication) and the sub-variable $X_{1 d}$ (the formal budgetary control) have no significant impact on financial performance. The coefficient value of $\mathrm{X}_{1 \mathrm{c}}$ is consistently negative. Also, the results from Table 6.4 prove once again that both firm size and ownership do not significantly affect financial performance.

\subsubsection{Testing Hypotheses $1 a_{1}, 1 c_{1}, 1 d_{1}$ : The Formal Budgeting Planning, Budgeting Sophistication, the Formal Budgetary Control, and Growth of Sales Revenues}

Hypothesis $1 a_{1}$ : the more formalized the budgeting planning, the higher the growth of sales revenues;

Hypothesis $1 c_{1}$ : the more sophisticated the budgeting, the higher the growth of sales revenues; 
Hypotheses $1 d_{1}$ : the more formalized the budgetary control, the higher the growth of sales revenues.

Figure 6.3 The Specific Model for the Formal Budget Planning, Budgetary Sophistication, the Budgetary Control, and Growth of Sales Revenues

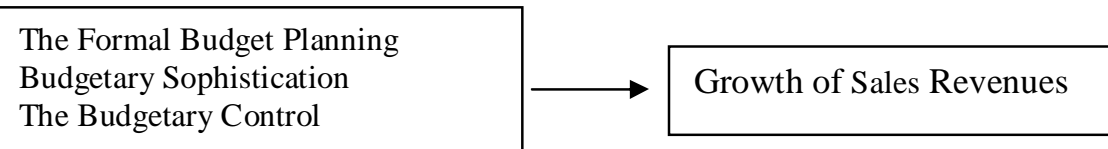

The equation (Eq. (1-e)) to test the effect of the Formal Budget Planning, budgetary sophistication, the formal budgetary control, on growth of sales revenues is shown as follows:

$$
\mathrm{Y}_{1 \mathrm{a} 1}=\mathrm{a}_{1-\mathrm{e}}+\mathrm{b}_{1-\mathrm{e} 1} \mathrm{X}_{1 \mathrm{a}}+\mathrm{b}_{1-\mathrm{e} 2} \mathrm{X}_{1 \mathrm{c}}+\mathrm{b}_{1-\mathrm{e} 3} \mathrm{X}_{1 \mathrm{~d}}
$$

Table 6.5 Regression Results on Growth of Sales Revenues $\left(\mathrm{Y}_{1 \mathrm{a} 1}\right)$ : The Impact of the Formal Budget Planning $\left(\mathrm{X}_{1 \mathrm{a}}\right)$, Budgetary Sophistication $\left(\mathrm{X}_{1 \mathrm{c}}\right)$, and the Formal Budgetary Control $\left(\mathrm{X}_{1 \mathrm{~d}}\right)$

\begin{tabular}{|c|cccc|}
\hline Model & Variables & Coefficient & Coefficient value (b) & T-stat value \\
\hline \multirow{4}{*}{$1-\mathrm{e}$} & $\mathrm{X}_{1 \mathrm{a}}$ & $\mathrm{b}_{1-\mathrm{e} 1}$ & 0.77 & $2.05^{*}$ \\
& $\mathrm{X}_{1 \mathrm{c}}$ & $\mathrm{b}_{1-\mathrm{e} 2}$ & 0.04 & 0.08 \\
& $\mathrm{X}_{1 \mathrm{~d}}$ & $\mathrm{~b}_{1-\mathrm{e} 3}$ & 0.03 & 0.05 \\
& & $\mathrm{a}_{1-\mathrm{e}}$ & 0.93 & 1.20 \\
\hline \multicolumn{2}{l}{$\mathrm{R}^{2}=0.10, \mathrm{~N}=75$} & & & \\
\hline
\end{tabular}

Now the new equation including the two controls (Size and Ownership) is checked:

$$
\mathrm{Y}_{1 \mathrm{a} 1}=\mathrm{a}_{1-\mathrm{f}}+\mathrm{b}_{1-\mathrm{f} 1} \mathrm{X}_{1 \mathrm{a}}+\mathrm{b}_{1-\mathrm{f} 2} \mathrm{X}_{1 \mathrm{c}}+\mathrm{b}_{1-\mathrm{f} 3} \mathrm{X}_{1 \mathrm{~d}}+\mathrm{b}_{\mathrm{s} 3} \mathrm{SIZE}+\mathrm{b}_{\mathrm{ow} 3} \mathrm{OWNE}
$$

Table 6.6 Regression Results on Growth of Sales Revenues $\left(\mathrm{Y}_{1 \mathrm{a} 1}\right)$ : The Impact of the Formal Budgeting Planning $\left(\mathrm{X}_{\mathrm{la}}\right)$, Budgetary Sophistication $\left(\mathrm{X}_{\mathrm{lc}}\right)$, the Formal Budgetary Control $\left(\mathrm{X}_{1 \mathrm{~d}}\right)$, Firm Size (SIZE), and Ownership (OWNE)

\begin{tabular}{|c|lccc|}
\hline Model & Variables & Coefficient & Coefficient value (b) & T-stat value \\
\hline \multirow{6}{*}{ 1-f } & $\mathrm{X}_{\text {la }}$ & $\mathrm{b}_{1-\mathrm{f} 1}$ & 0.89 & $2.29^{*}$ \\
& $\mathrm{X}_{1 \mathrm{c}}$ & $\mathrm{b}_{1-\mathrm{f} 2}$ & 0.08 & 0.18 \\
& $\mathrm{X}_{1 \mathrm{~d}}$ & $\mathrm{~b}_{1-\mathrm{f} 3}$ & 0.09 & 0.18 \\
\cline { 2 - 5 } & SIZE & $\mathrm{b}_{\mathrm{s} 3}$ & 0.23 & 0.50 \\
& OWNE & $\mathrm{b}_{\text {ow3 }}$ & 0.67 & 1.44 \\
& & $\mathrm{a}_{1-\mathrm{f}}$ & -0.91 & -0.61 \\
\hline \multicolumn{4}{|l}{} \\
\hline
\end{tabular}

Results: The results both from the model 1-e and from the model 1-f strongly support Hypothesis $1 \mathrm{a}_{1}$. The coefficient values $\left(\mathrm{b}_{1-\mathrm{e} 1}\right.$ and $\left.\mathrm{b}_{1-\mathrm{f} 1}\right)$ are 0.77 and 0.89 respectively, which suggest that formal budgeting planning has a positive impact on the growth of sales revenues. However, for budgetary sophistication and the formal budgetary control, non-significant effects are found. The t values are only 0.18 (see Table 6.6). 


\subsubsection{Testing Hypotheses $1 \mathrm{a}_{2}, 1 \mathrm{c}_{2}, 1 \mathrm{~d}_{2}$ : The Formal Budgeting Planning, Budgeting Sophistication, the Formal Budgetary Control, and Growth of Profit}

Hypothesis 1 $a_{2}$ : the more formalized the budgeting planning, the higher the growth of profit;

Hypothesis $1 c_{2}$ : the more sophisticated the budgeting, the higher the growth of profit;

Hypotheses $1 d_{2}$ : the more formalized the budgetary control, the higher growth of profit.

Figure 6.4 The Specific Model for the Formal Budget Planning, Budgetary Sophistication, the Formal Budgetary Control, and the Growth of Profit

\section{The Formal Budget Planning Budgetary Sophistication The Budgetary Control}

\section{Growth of Profit}

The following equation is to test the effect of the formal budget planning, budgetary sophistication, and the formal budgetary control, on the growth of profit (Eq. (1-g)):

$$
\mathrm{Y}_{1 \mathrm{a} 2}=\mathrm{a}_{1-\mathrm{g}}+\mathrm{b}_{1-\mathrm{g} 1} \mathrm{X}_{1 \mathrm{a}}+\mathrm{b}_{1-\mathrm{g} 2} \mathrm{X}_{1 \mathrm{c}}+\mathrm{b}_{1-\mathrm{g} 3} \mathrm{X}_{1 \mathrm{~d}}
$$

Table 6.7 Regression Results on Growth of Profit ( $\left.\mathrm{Y}_{1 \mathrm{a} 2}\right)$ : The Impact of the Formal Budget Planning $\left(\mathrm{X}_{1 \mathrm{a}}\right)$, Budgetary Sophistication $\left(\mathrm{X}_{1 \mathrm{c}}\right)$, and the Formal Budgetary Control $\left(\mathrm{X}_{1 \mathrm{~d}}\right)$

\begin{tabular}{|c|cccc|}
\hline Model & Variables & Coefficient & Coefficient value (b) & T-stat value \\
\hline \multirow{4}{*}{$1-\mathrm{g}$} & $\mathrm{X}_{1 \mathrm{a}}$ & $\mathrm{b}_{1-\mathrm{g} 1}$ & 0.21 & 0.93 \\
& $\mathrm{X}_{1 \mathrm{c}}$ & $\mathrm{b}_{1-\mathrm{g} 2}$ & -0.26 & -0.98 \\
& $\mathrm{X}_{1 \mathrm{~d}}$ & $\mathrm{~b}_{1-\mathrm{g} 3}$ & 0.48 & 1.64 \\
& & $\mathrm{a}_{1-\mathrm{g}}$ & 0.84 & 1.79 \\
\hline \multicolumn{2}{l|}{$\mathrm{R}^{2}=0.08, \mathrm{~N}=75$} & & & \\
\hline
\end{tabular}

After showing the results of the main variables, the two control variables are subsequently added in the following equation to be checked:

$$
\mathrm{Y}_{1 \mathrm{a} 2}=\mathrm{a}_{1-\mathrm{h}}+\mathrm{b}_{1-\mathrm{h} 1} \mathrm{X}_{1 \mathrm{a}}+\mathrm{b}_{1-\mathrm{h} 2} \mathrm{X}_{1 \mathrm{c}}+\mathrm{b}_{1-\mathrm{h} 3} \mathrm{X}_{1 \mathrm{~d}}+\mathrm{b}_{\mathrm{s} 4} \mathrm{SIZE}+\mathrm{b}_{\mathrm{ow} 4} \mathrm{OWNE}
$$

Table 6.8 Regression Results on Growth of Profit ( $\left.\mathrm{Y}_{1 \mathrm{a} 2}\right)$ : The Impact of the Formal Budgeting Planning $\left(\mathrm{X}_{1 \mathrm{a}}\right)$, Budgetary Sophistication $\left(\mathrm{X}_{1 \mathrm{c}}\right)$, the Formal Budgetary Control $\left(X_{1 d}\right)$, Firm Size (SIZE), and Ownership (OWNE)

\begin{tabular}{|c|lccc|}
\hline Model & Variables & Coefficient & Coefficient value (b) & T-stat value \\
\hline \multirow{6}{*}{$1-\mathrm{h}$} & $\mathrm{X}_{1 \mathrm{a}}$ & $\mathrm{b}_{1-\mathrm{h} 1}$ & 0.21 & 0.90 \\
& $\mathrm{X}_{1 \mathrm{c}}$ & $\mathrm{b}_{1-\mathrm{h} 2}$ & -0.36 & -1.31 \\
& $\mathrm{X}_{1 \mathrm{~d}}$ & $\mathrm{~b}_{1-\mathrm{h} 3}$ & 0.44 & 1.52 \\
\cline { 2 - 5 } & SIZE & $\mathrm{b}_{\mathrm{s} 4}$ & 0.50 & $1.87^{*}$ \\
& OWNE & $\mathrm{b}_{\text {ow4 }}$ & 0.17 & 0.63 \\
& & $\mathrm{a}_{1-\mathrm{h}}$ & 0.11 & 0.12 \\
\hline \multicolumn{2}{l}{$\mathrm{R}^{2}=0.12, \mathrm{~N}=75$} & &
\end{tabular}


Results: Comparing the $t$ values (1.64 vs. 0.05$)$ and coefficient values (0.48 vs. 0.03$)$ between the model 1-g and the model 1-e, we can conclude that the formal budgetary control has a much stronger impact on profit than on sales revenues. Its $t$ value increases into 1.64. However, inconsistently with the results from the former models, the impact of the formal budgeting planning on the growth of profit turns out to be insignificant. The $\mathrm{t}$ value is just 0.93 . As to budgetary sophistication, it still shows an insignificant link to profit. Additionally, it is noted that the control variable "SIZE" in the model 1-h show a significant and positive effect on profit growth. The corresponding $\mathrm{t}$ value for this variable is 1.87 . The $\mathrm{R}^{2}$ in Table 6.8 tell us that all variables $\left(\mathrm{X}_{1 \mathrm{a}}, \mathrm{X}_{1 \mathrm{c}}, \mathrm{X}_{1 \mathrm{~d}}\right.$, SIZE, and OWNE) together explain 12 per cent the variance of the growth of profit.

It is noted that the OLS models (linear regression models) used in the statistical tests above can only estimate the value of the dependent variable (Y) from the independent variables (X). It is impossible for the OLS model to predict the relative contributions from other dependent variables, if dependent variables are correlated. Due to this limitation, the model 1-f and the model 1-h are checked again by the Lisrel model, since the dependent variables (i.e. growth of sales revenues and growth of profit) are related (Correlation=0.63, see Appendix I). The Lisrel model will estimate, for example, how the dependent variable (the growth of sales revenues, $\mathrm{Y}_{1 \mathrm{a} 1}$ ) is affected by the independent variables $\left(\mathrm{X}_{1 \mathrm{a}}, \mathrm{X}_{1 \mathrm{c}}\right.$, and $\mathrm{X}_{1 \mathrm{~d}}$ ), control variables (SIZE and OWNE), and another dependent variable (rate of profit, $\mathrm{Y}_{1 \mathrm{a} 2}$ ). The results from the Lisrel Estimate are reported in Table 6.9 .

Table 6.9 Lisrel Results on Growth of Sales Revenues ( $\left.\mathrm{Y}_{1 \mathrm{al}}\right)$ and Growth of Profit $\left(\mathrm{Y}_{1 \mathrm{a} 2}\right)$ : The Impact of the Formal Budgeting Planning $\left(\mathrm{X}_{1 \mathrm{a}}\right)$, Budgetary Sophistication $\left(X_{1 c}\right)$, the Formal Budgetary Control $\left(X_{1 d}\right)$, Firm Size (SIZE), and Ownership (OWNE)

\begin{tabular}{|c|c|c|}
\hline Variables & $\begin{array}{c}\mathrm{Y}_{\text {lal }} \\
\text { Coefficient Value b (T-stat) }\end{array}$ & $\begin{array}{c}\mathrm{Y}_{\mathrm{la} 2} \\
\text { Coefficient Value b (T-stat) }\end{array}$ \\
\hline $\mathrm{Y}_{\mathrm{lal}}$ & - & 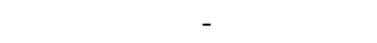 \\
\hline$Y_{1 \mathrm{a} 2}$ & $0.30(6.60)^{*}$ & - \\
\hline $\mathrm{X}_{1 \mathrm{a}}$ & $0.83(2.37)^{*}$ & $-0.06(-0.30)$ \\
\hline $\mathrm{X}_{1 \mathrm{c}}$ & $0.19(0.46)$ & $-0.38(-1.77)^{*}$ \\
\hline$X_{1 d}$ & $-0.05(-0.10)$ & $0.42(1.80)^{*}$ \\
\hline SIZE & $0.08(0.19)$ & $0.43(2.04)^{*}$ \\
\hline OWNE & $0.62(1.47)$ & $-0.03(-0.12)$ \\
\hline $\mathrm{a}_{\mathrm{lis}-1}$ & $-0.93(-0.70)$ & $0.37(0.54)$ \\
\hline $\mathrm{R}^{2}(\mathrm{~N}=75)$ & 0.29 & 0.45 \\
\hline RMSEA & \multicolumn{2}{|c|}{0.000} \\
\hline Chi-square & \multicolumn{2}{|c|}{0.00} \\
\hline Degrees of freedom & \multicolumn{2}{|c|}{0} \\
\hline
\end{tabular}


Consistently with the OLS regression result in the model 1-f, the formal budgeting planning $\left(\mathrm{X}_{1 \mathrm{a}}\right)$ shows a significant and positive effect on the growth of sales (the t value is $2.37, \mathrm{~b}$ is 0.83$)$. Budgetary sophistication $\left(\mathrm{X}_{1 \mathrm{c}}\right)$ and the formal budgetary control $\left(\mathrm{X}_{1 \mathrm{~d}}\right)$ are found to have no significant impact on the growth of sales. These two results also stay the same with the results from the OLS regression estimation. Both two control variables ("SIZE" and "OWNE") show a non-significant impact on the growth of sales revenues. Their t values are 0.19 and 1.47, respectively. In addition, we have to point out that two dependent variables $\left(\mathrm{Y}_{1 \mathrm{a} 1}\right.$ and $\left.\mathrm{Y}_{1 \mathrm{a} 2}\right)$ are found to be highly related in the Lisrel model. The $t$ value in the first Lisrel equation is 6.60 and coefficient value is 0.30 . As we can see, the R square in this estimate is 0.29 , which shows much higher than the R square (0.13) from the OLS regression model.

Furthermore, a significant and positive impact of the formal budgetary control $\left(\mathrm{X}_{1 \mathrm{~d}}\right)$ on growth of profit $\left(\mathrm{Y}_{1 \mathrm{a} 2}\right)$ is approved in this Lisrel model. The $\mathrm{t}$ value of the formal budgetary control becomes significant (1.80) compared to the $t$ value (1.52) which indicates an insignificant impact in the former regression model 1-h. The reason for this difference is that the OLS regression estimation ignores the strong correlation between the dependent variables the growth of sales revenues and of profit. The Lisrel model, however, considers possible correlations between dependent variables and takes this correlation into account before estimating the values of the independent variables. In doing so, the Lisrel model reflects the real (or "pure") correlation of the formal budgeting process on the growth of sales revenues and of profit. Additionally, "SIZE" in this model also shows a significant and positive impact on the growth of profit (the $t$ value is 2.04), which is in line with the finding from the previous regression model. This result can be explained by the fact that medium-sized firms achieve higher growth of profit than small firms. However, the independent variable (the formal budgeting planning, $\mathrm{X}_{1 \mathrm{a}}$ ) and another control variable (ownership, “OWNE”) report no significant effect on profit $\left(\mathrm{Y}_{1 \mathrm{a} 2}\right)$. It is noted that another result also turns out to be different from the result in the former regression model 1-h. The Lisrel model estimates budgetary sophistication $\left(\mathrm{X}_{1 \mathrm{c}}\right)$ having a significant but negative effect on profit $\left(\mathrm{Y}_{1 \mathrm{a} 2}\right)$, since the $\mathrm{t}$ value is -1.77 .

\subsubsection{Testing Hypothesis 1b1: Budget Goal Clarity and Budgetary Performance}

Hypothesis $1 b 1_{1}$ : the clearer the budget goals, the better the budget goals achievement; 
Hypothesis $1 b 1_{2}$ : the clearer the budget goals, the better the job satisfaction;

Figure 6.5 The Specific Model between the Budget Goal Clarity and Budgetary Performance, between the budget Goal Clarity and Other Performance

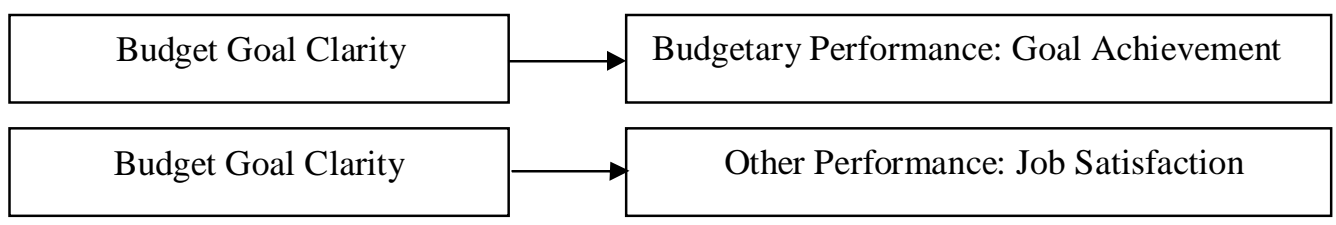

To test the model above, multiple-regression equations (Eq. $\left(1 \mathrm{~b} 1_{1}\right) \&$ Eq. $\left.\left(1 \mathrm{~b} 1_{2}\right)\right)$ are presented as follows:

$$
\begin{aligned}
& Y_{1 b 1}=a_{1 b 11}+b_{1 b 11} X_{1 b 1} \\
& Y_{1 c 1}=a_{1 b 12}+b_{1 b 12} X_{1 b 1}
\end{aligned}
$$

Where $\mathrm{Y}_{1 \mathrm{bl}}=$ budget goal achievement; $\mathrm{Y}_{1 \mathrm{c} 1}=$ job satisfaction; $\mathrm{X}_{1 \mathrm{bl}}=$ =budget goal clarity.

Table 6.10 Regression Results of Budget Goal Clarity ( $\left.\mathrm{X}_{1 \mathrm{~b} 1}\right)$ and Goal Achievement $\left(\mathrm{Y}_{1 \mathrm{~b} 1}\right)$

\begin{tabular}{|cccc|}
\hline Variables & Coefficient & Coefficient value (b) & T-stat value \\
\hline $\mathrm{X}_{1 \mathrm{~b} 1}$ & $\mathrm{~B}_{1 \mathrm{~b} 11}$ & 0.40 & $1.81^{*}$ \\
& $\mathrm{~A}_{1 \mathrm{~b} 11}$ & 3.01 & $5.51^{*}$ \\
\hline $\mathrm{R}^{2}=0.04, \mathrm{~N}=75$ & & \\
\hline
\end{tabular}

Table 6.11 Regression Results of Budget Goal Clarity ( $\left.\mathrm{X}_{1 \mathrm{~b} 1}\right)$ and Job Satisfaction ( $\left.\mathrm{Y}_{1 \mathrm{c} 1}\right)$

\begin{tabular}{|cccc|}
\hline Variables & Coefficient & Coefficient value (b) & T-stat value \\
\hline $\mathrm{X}_{1 \mathrm{~b} 1}$ & $\mathrm{~B}_{1 \mathrm{~b} 12}$ & 0.18 & 1.02 \\
& $\mathrm{~A}_{1 \mathrm{~b} 12}$ & 2.45 & $5.66^{*}$ \\
\hline $\mathrm{R}^{2}=0.01, \mathrm{~N}=75$ & & \\
\hline
\end{tabular}

Results: According to the statistical results in Table 6.10, we can conclude that budget goal clarity significantly and positively impacts goal achievement. The $t$ value is 1.81 . The R square value tells us that budget goal clarity explains 4 per cent the variance of goal achievement. When the values from Table 6.10 are inserted into the equation $\left(1 \mathrm{~b} 1_{1}\right)$, we obtain the following equation:

$$
\mathrm{Y}_{1 \mathrm{~b} 1}=3.01+0.40 \mathrm{X}_{1 \mathrm{~b} 1} \quad\left(1 \mathrm{~b} 1_{1}-1\right)
$$

Additionally, based on the statistical results from Table 6.11, we get the equation $\left(1 \mathrm{~b} 1_{2^{-}}\right.$ 2), as shown below, to indicate how much effect budget goal clarity has on job satisfaction:

$$
\mathrm{Y}_{1 \mathrm{c} 1}=2.45+0.18 \mathrm{X}_{1 \mathrm{~b} 1} \quad\left(1 \mathrm{~b} 1_{2}-2\right)
$$

A comparison of the regression coefficient of budget goal clarity in equation $1 b 1_{1}-1$ and $1 \mathrm{~b} 1_{2}-2$ shows that budget goal clarity has much more impact on goal achievement than 
on job satisfaction (0.40 vs. 0.18). The t value (1.02) shows an insignificant impact of budget goal clarity on job satisfaction. In this case, it is difficult to accept the Hypothesis $1 \mathrm{~b} 1_{2}$.

The two controls variables (Size and Ownership) are also put into the equations (Eq. $\left(1 \mathrm{~b} 1_{3}\right) \&$ Eq. $\left.\left(1 \mathrm{~b} 1_{4}\right)\right)$ to be checked:

$$
\begin{aligned}
& Y_{1 b 1}=a_{1 b 13}+b_{1 b 13} X_{1 b 1}+b_{s 21} \text { SIZE }+b_{\text {ow } 21} \text { OWNE } \\
& Y_{1 c 1}=a_{1 b 14}+b_{1 b 14} X_{1 b 1}+b_{\text {s22 } 2} \text { SIZE }+b_{\text {ow } 22} \text { OWNE }
\end{aligned}
$$

Where $Y_{1 b 1}=$ budget goal achievement; $Y_{1 \mathrm{cl}}=$ job satisfaction; $X_{1 b 1}=$ budget goal clarity; SIZE=firm size; OWNE=ownership.

Table 6.12 Regression Results on Goal Achievement ( $\left.\mathrm{Y}_{1 \mathrm{~b} 1}\right)$ : The Impact of Budget Goal Clarity $\left(\mathrm{X}_{1 \mathrm{~b} 1}\right)$, Firm Size (SIZE), and Ownership (OWNE)

\begin{tabular}{|cccc|}
\hline Variables & Coefficient & Coefficient value (b) & T-stat value \\
\hline $\mathrm{X}_{\mathrm{lb} 1}$ & $\mathrm{~b}_{1 \mathrm{~b} 13}$ & 0.21 & $1.80^{*}$ \\
\hline $\mathrm{SIZE}$ & $\mathrm{b}_{\mathrm{s} 21}$ & 0.24 & $3.45^{*}$ \\
OWNE & $\mathrm{b}_{\mathrm{ow} 21}$ & 0.24 & 0.62 \\
& $\mathrm{a}_{\mathrm{b} 13}$ & 0.82 & $1.96^{*}$ \\
\hline $\mathrm{R}^{2}=0.19, \mathrm{~N}=75$ & & \\
\hline
\end{tabular}

Table 6.13 Regression Results on Job Satisfaction ( $\left.\mathrm{Y}_{1 \mathrm{c1}}\right)$ : The Impact of Budget Goal Clarity $\left(\mathrm{X}_{1 \mathrm{~b} 1}\right)$, Firm Size (SIZE), and Ownership (OWNE)

\begin{tabular}{|cccc|}
\hline Variables & Coefficient & Coefficient value (b) & T-stat value \\
\hline $\mathrm{X}_{1 \mathrm{~b} 1}$ & $\mathrm{~b}_{1 \mathrm{~b} 14}$ & 0.08 & 0.49 \\
\hline $\mathrm{SIZE}$ & $\mathrm{b}_{\mathrm{s} 22}$ & 0.16 & 0.84 \\
OWNE & $\mathrm{b}_{\mathrm{ow} 22}$ & -0.64 & $-3.43^{*}$ \\
& $\mathrm{a}_{1 \mathrm{~b} 14}$ & 1.06 & $5.41^{*}$ \\
\hline \multicolumn{2}{|c|}{$\mathrm{R}^{2}=0.20, \mathrm{~N}=75$} & & \\
\hline
\end{tabular}

Results: A significant and positive effect of budget goal clarity on goal achievement is found again in Table $6.12(\mathrm{~T}=1.96)$. The coefficient value is 0.21 , which means that a one level increase of goal clarity will lead to 0.21 higher goal achievements. Additionally, The R square value indicates that budget goal clarity, together with size and ownership, explains 19 per cent of the variance of goal achievement. Consistent with the former findings, budget goal clarity shows a non-significant effect on job satisfaction, the t value is only 0.49 ( $>>0.05$ ). As to the control variable "SIZE", in the statistical model $1 \mathrm{~b} 1_{3}$, this becomes a significant factor which positively impacts goal achievement. However, in model $1 \mathrm{~b} 1_{4}$, its significance disappears again. In addition, a significant but negative value (see in Table 6.13) is found in "OWNE", since the t value is -3.43 . This negative value means that the state-owned enterprises in the sample show higher job satisfaction than the private firms. 


\subsubsection{Testing Hypothesis 1b2: Budget Goal Difficulty and Budgetary Performance}

Hypothesis 1b2 1 : the more difficult but attainable the budget goals, the more the motivation from budget setting;

Hypothesis $1 b 2_{2}$ : the more difficult but attainable the budget goals, the more the job involvement;

Figure 6.6 The Specific Models between the Budget Goal Difficulty and Budgetary Performance between the Budget Goal Difficulty and Other Performance

\begin{tabular}{|c|c|}
\hline Budget Goal Difficulty & Budgetary Performance: Goal Motivation \\
\hline Budget Goal Difficulty & Other Performance: Job Involvement \\
\hline
\end{tabular}

The effect of the budget goal difficulty on the related performance is tested by the following two equations (Eq. $\left(1 \mathrm{~b} 2_{1}\right) \&$ Eq. $\left.\left(1 \mathrm{~b} 2_{2}\right)\right)$ :

$$
\begin{aligned}
& Y_{1 b 2}=a_{1 b 21}+b_{1 b 21} X_{1 b 2} \\
& Y_{1 c 2}=a_{1 b 22}+b_{1 b 22} X_{1 b 2}
\end{aligned}
$$

Where $Y_{1 \mathrm{~b} 2}=$ motivation from budget setting; $Y_{1 \mathrm{c} 2}=$ job involvement; $\mathrm{X}_{1 \mathrm{~b} 2}=$ budget goal difficulty.

Table 6.14 Regression Results of Budget Goal Difficulty $\left(\mathrm{X}_{1 \mathrm{~b} 2}\right)$ and Budgetary Motivation $\left(\mathrm{Y}_{1 \mathrm{~b} 2}\right)$

\begin{tabular}{|cccc|}
\hline Variables & Coefficient & $\begin{array}{c}\text { Coefficient value } \\
(\mathrm{b})\end{array}$ & $\begin{array}{c}\text { T-stat } \\
\text { value }\end{array}$ \\
\hline $\mathrm{X}_{1 \mathrm{~b} 2}$ & $\mathrm{~b}_{\mathrm{bb} 21}$ & 0.62 & $2.83^{*}$ \\
& $\mathrm{a}_{1 \mathrm{~b} 21}$ & 1.63 & $3.03^{*}$ \\
\hline $\mathrm{R}^{2}=0.10, \mathrm{~N}=75$ & & \\
\hline
\end{tabular}

Table 6.15 Regression Results of Budget Goal Difficulty $\left(\mathrm{X}_{1 \mathrm{~b} 2}\right)$ and Job Involvement $\left(\mathrm{Y}_{1 \mathrm{c} 2}\right)$

\begin{tabular}{|cccc|}
\hline Variables & Coefficient & $\begin{array}{c}\text { Coefficient value } \\
(\mathrm{b})\end{array}$ & $\begin{array}{c}\text { T-stat } \\
\text { value }\end{array}$ \\
\hline $\mathrm{X}_{1 \mathrm{~b} 2}$ & $\mathrm{~b}_{1 \mathrm{~b} 22}$ & 0.35 & $1.90^{*}$ \\
& $\mathrm{a}_{1 \mathrm{~b} 22}$ & 2.96 & $6.55^{*}$ \\
\hline $\mathrm{R}^{2}=0.05, \mathrm{~N}=75$ & & \\
\hline
\end{tabular}

Results: The hypothesis $1 \mathrm{~b} 2{ }_{1}$ is supported by the results from Table $6.14(\mathrm{~T}=2.83$, Coefficient=0.62). Budget goal difficulty explains 10 per cent of the variance of budgetary motivation. To present the difference in the slope of the relationship between budget goal difficulty and budgetary motivation more clearly, the values (coefficients) from Table 6.14 are inserted in equation $\left(1 \mathrm{~b} 2_{1}\right)$ to obtain the following equation:

$$
\mathrm{Y}_{1 \mathrm{~b} 2}=1.63+0.62 \mathrm{X}_{1 \mathrm{~b} 2} \quad\left(1 \mathrm{~b} 2_{1}-3\right)
$$


Additionally, the results from Table 6.15 also indicate a strong effect of the budget goal difficulty on job involvement. Budgetary goal difficulty explains 5 per cent of the variance of job involvement. As the results show, the $t$ value is 1.90 . The statistical results from Table 6.15 are added to the equation $\left(1 \mathrm{~b} 2_{2}\right)$ to indicate the linear effect of budget goal difficulty on job involvement. The new equation then reads as follows:

$$
\mathrm{Y}_{1 \mathrm{c} 2}=2.96+0.35 \mathrm{X}_{1 \mathrm{~b} 2} \quad\left(1 \mathrm{~b} 2_{2}-4\right)
$$

The model $1 \mathrm{~b} 2$ explains 15 per cent of the variance of performance $\left(R^{2}=0.10+0.05\right)$. $A$ comparison of the regression coefficient of budget goal difficulty in equation $1 \mathrm{~b} 2{ }_{1}-3$ and $1 \mathrm{~b} 2_{2}-4$ reflects that budget goal difficulty has more impact on job involvement than on budgetary motivation ( 0.35 vs. 0.62$)$.

The two controls variables (Size and Ownership) are once again placed in this model to be checked, as shown in the multiple-regression equations (eq. ( $\left.1 b 2_{3}\right) \&$ eq. (1b2 4$)$ ) as follows:

$$
\begin{aligned}
& Y_{1 b 2}=a_{1 b 23}+b_{1 b 23} X_{1 b 2}+b_{s 31} S I Z E+b_{o w 31} \text { OWNE } \\
& Y_{1 c 2}=a_{1 b 24}+b_{1 b 24} X_{1 b 2}+b_{s 32} S I Z E+b_{o w 32} \text { OWNE }
\end{aligned}
$$

Where $\mathrm{Y}_{1 \mathrm{~b} 2}=$ motivation from budget setting; $\mathrm{Y}_{1 \mathrm{c} 2}=\mathrm{job}$ involvement; $\mathrm{X}_{1 \mathrm{~b} 2}=$ budget goal difficulty; SIZE=firm size; OWNE=ownership.

Table 6.16 Regression Results on Budgetary Motivation ( $\left.\mathrm{Y}_{1 \mathrm{~b} 2}\right)$ : The Impact of Budget Goal Difficulty $\left(\mathrm{X}_{1 \mathrm{~b} 2}\right)$, Firm Size (SIZE), and Ownership (OWNE)

\begin{tabular}{|cccc|}
\hline Variables & Coefficient & $\begin{array}{c}\text { Coefficient value } \\
(\mathrm{b})\end{array}$ & $\begin{array}{c}\text { T-stat } \\
\text { value }\end{array}$ \\
\hline $\mathrm{X}_{\mathrm{lb} 2}$ & $\mathrm{~b}_{1 \mathrm{~b} 23}$ & 0.62 & $2.82^{*}$ \\
\hline $\mathrm{SIZE}$ & $\mathrm{b}_{\mathrm{s} 31}$ & -0.20 & -0.83 \\
OWNE & $\mathrm{b}_{\mathrm{ow} 31}$ & -0.54 & $-2.26^{*}$ \\
& $\mathrm{a}_{\mathrm{b} 23}$ & 0.99 & $3.66^{*}$ \\
\hline $\mathrm{R}^{2}=0.16, \mathrm{~N}=75$ & & \\
\hline
\end{tabular}

Table 6.17 Regression Results on Job Involvement ( $\left.\mathrm{Y}_{1 \mathrm{c} 2}\right)$ : The Impact of Budget Goal Difficulty $\left(\mathrm{X}_{1 \mathrm{~b} 2}\right)$, Firm Size (SIZE), and Ownership (OWNE)

\begin{tabular}{|cccc|}
\hline Variables & Coefficient & $\begin{array}{c}\text { Coefficient value } \\
(\mathrm{b})\end{array}$ & $\begin{array}{c}\text { T-stat } \\
\text { value }\end{array}$ \\
\hline $\mathrm{X}_{1 \mathrm{~b} 2}$ & $\mathrm{~b}_{1 \mathrm{~b} 24}$ & 0.29 & 1.62 \\
\hline $\mathrm{SIZE}$ & $\mathrm{b}_{\mathrm{s} 32}$ & 0.06 & 0.31 \\
OWNE & $\mathrm{b}_{\text {ow32 }}$ & -0.55 & $-2.85^{*}$ \\
& $\mathrm{a}_{\mathrm{b} 24}$ & 3.85 & $6.32^{*}$ \\
\hline \multicolumn{2}{l}{$\mathrm{R}^{2}=0.17, \mathrm{~N}=75$} & & \\
\hline
\end{tabular}

Results: The statistical analysis to test model $1 \mathrm{~b} 2{ }_{3}$ reveals a significant and positive impact of budget goal difficulty on budgetary motivation. As the results in Table 6.16 
show, the t value 2.82 is significant. The coefficient value " 0.62 " tells us that a one level increase of budget goal difficulty leads to 0.62 higher budgetary motivations. However, no significant relationship is found between budget goal difficulty and job involvement, since the $t$ value is 1.62, representing an insignificant level. As for the control variables, the insignificant or negative $t$ values are both in the Table 6.16 and in Table 6.17. Specifically, the t values "- 0.83 " and " 0.31 " for the control variable "SIZE" indicate that firm size insignificantly affects on both budgetary motivation and job involvement. For another control variable "OWNE", t values are -2.26 and -2.85 respectively. The negative values tell us that ownership negatively affects budgetary motivation and job involvement in these two models.

Apart from the regression results, the results from the Lisrel Model are also summarized below to show the relationships of all variables from models $1 \mathrm{~b} 1$ and $1 \mathrm{~b} 2$. Specifically, the results will show how dependent variables including budgetary performance and other performance impact each other in the Lisrel models.

Table 6.18 Lisrel Results on Goal Achievement ( $\left.\mathrm{Y}_{1 \mathrm{~b} 1}\right)$, Budgetary Motivation ( $\left.\mathrm{Y}_{1 \mathrm{~b} 2}\right)$, Job Satisfaction $\left(\mathrm{Y}_{1 \mathrm{c} 1}\right)$, and Job Involvement $\left(\mathrm{Y}_{1 \mathrm{c} 2}\right)$ : The Impact of Budget Goal Clarity $\left(\mathrm{X}_{1 \mathrm{~b} 1}\right)$, Budget Goal Difficulty $\left(\mathrm{X}_{1 \mathrm{~b} 2}\right)$, Firm Size (SIZE), and Ownership (OWNE)

\begin{tabular}{|c|c|c|c|c|}
\hline Variables & $\begin{array}{c}\mathrm{Y}_{1 \mathrm{~b} 1} \\
\text { Coefficient } \\
\text { Value (T-stat) }\end{array}$ & $\begin{array}{c}\mathrm{Y}_{1 \mathrm{~b} 2} \\
\text { Coefficient } \\
\text { Value (T-stat) }\end{array}$ & $\begin{array}{c}\mathrm{Y}_{\text {1c1 }} \\
\text { Coefficient } \\
\text { Value (T-stat) }\end{array}$ & $\begin{array}{c}\mathrm{Y}_{1 \mathrm{c} 2} \\
\text { Coefficient } \\
\text { Value (T-stat) }\end{array}$ \\
\hline$Y_{1 b 1}$ & & - & - & - \\
\hline $\mathrm{Y}_{1 \mathrm{~b} 2}$ & $-0.01(-0.16)$ & - & - & - \\
\hline $\mathrm{Y}_{1 \mathrm{c} 1}$ & $0.18(3.49)^{*}$ & $0.12(0.52)$ & - & - \\
\hline$Y_{1 c 2}$ & $0.02(0.36)$ & $0.12(2.07)^{*}$ & $0.24(4.40)^{*}$ & - \\
\hline $\mathrm{X}_{1 \mathrm{bl}}$ & $0.18(3.46)$ & 0 & $-0.08(-0.61)$ & 0 \\
\hline$X_{1 b 2}$ & 0 & $0.59(2.69)^{*}$ & 0 & $0.18(0.22)$ \\
\hline SIZE & $0.35(1.78)^{*}$ & $-0.21(-0.84)$ & $-0.03(-0.18)$ & $0.04(0.22)$ \\
\hline OWNE & $0.27(1.15)$ & $-0.45(-1.90)^{*}$ & $-0.54(-3.30)^{*}$ & $-0.33(-1.85)^{*}$ \\
\hline $\mathrm{a}_{\mathrm{lis}-2}$ & $0.93(1.09)$ & $2.23(2.82)$ & $2.19(3.57)$ & $2.67(4.44)$ \\
\hline $\mathrm{R}^{2}(\mathrm{~N}=75)$ & 0.26 & 0.19 & 0.35 & 0.44 \\
\hline RMSEA & \multirow{2}{*}{\multicolumn{4}{|c|}{$\begin{array}{c}0.0049 \\
4.68\end{array}$}} \\
\hline Chi-square & & & & \\
\hline Degrees of freedom & \multicolumn{4}{|c|}{4} \\
\hline
\end{tabular}

As we can see in Table 6.18, the Lisrel result related to the impact of budget goal clarity $\left(\mathrm{X}_{1 \mathrm{~b} 1}\right)$ on goal achievement $\left(\mathrm{Y}_{1 \mathrm{~b} 1}\right)$ stays the same with the OLS regression (the $\mathrm{t}$ value is 3.46). Firm size significantly and positively affects budget goal achievement with the $t$ value 1.78 , which is in line with the previous regression result. This result can be explained by the assumption that medium-sized firms tend to set a clearer budget goal than smaller firms. Moreover, a new finding from this estimate is that the dependent 
variable (job satisfaction, $\mathrm{Y}_{1 \mathrm{c} 1}$ ) highly impacts another dependent variable (budget goal achievement, $\left.\mathrm{Y}_{1 \mathrm{~b} 1}\right)$. The responding $\mathrm{t}$ value is 3.49. However, other dependent variables (budgetary motivation, $\mathrm{Y}_{1 \mathrm{~b} 2}$ and job involvement, $\mathrm{Y}_{1 \mathrm{c} 2}$ ) and another control variable (“OWNE”) are reported as having insignificant impact on goal achievement ( $\left.\mathrm{Y}_{1 \mathrm{bl}}\right)$.

Again, the result stays same with respect to budget goal difficulty on budgetary performance. The $\mathrm{t}$ value is 2.69. The control variable "OWNE" shows a negative impact on budgetary motivation ( $\mathrm{T}$ value is -1.90). This result tells us that state-owned enterprises in the sample report higher budgetary motivation than private firms. Another new finding from the second estimate equation is that job involvement $\left(\mathrm{Y}_{1 \mathrm{c} 2}\right)$ has a significant and positive impact on budgetary motivation $\left(\mathrm{Y}_{1 \mathrm{~b} 2}\right)$. $\mathrm{T}$ corresponding $\mathrm{t}$ value is 2.07 .

The Lisrel test further estimates that budget goal clarity has no significant impact on job satisfaction (the $t$ value is -0.61) and budget goal difficulty has no significant impact on job involvement (the $t$ value is 1.10). These two results are consistent with the OLS regression result. Additionally, the control variable ownership consistently shows a negative impact on both job satisfaction and job involvement with the t value -3.30 and -1.85 respectively. The results can be explained as follows: firstly, more job involvement to achieve target budget goals are reported by state-owned enterprises than by private firms, secondly, state-owned enterprises show higher job satisfaction than the small firms in the sample.

\subsection{Testing Hypothesis 2: Budgetary Participation and Managerial Performance}

Figure 6.7 The Specific Model for Budgetary Participation and Managerial Performance

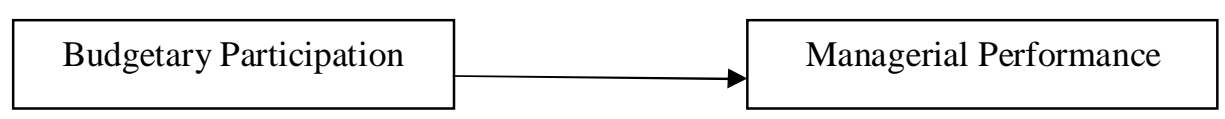

The effect of budgetary participation on performance has been the subject of much accounting research interest recently (such as Lau \& Buckland 2000; Chalos \& Poon, 2000; Subramaniam \& Ashkanasy, 2001 etc.). However, the effect is less clear because of mixed research findings31. In this study, we examine the impact of BPP (budgetary participation and performance) exclusively on managerial performance. It is expected that:

\footnotetext{
${ }^{31}$ As discussed in previous chapters, some research indicates a strong positive relationship of budgetary participation and managerial performance. Some research, however, suggests a weak or negative relationship.
} 
Hypothesis 2: The higher the budgetary participation, the better the managerial performance.

The hypothesis is tested using the following regression equation (Eq. (2)):

$$
\mathrm{Y}_{2}=\mathrm{a}_{2}+\mathrm{b}_{2} \mathrm{X}_{2}
$$

Where $Y_{2}=$ managerial performance; $X_{2}=$ budgetary participation level based on the average score of budgetary participation.

Table 6.19 Regression Results of Budgetary Participation $\left(\mathrm{X}_{2}\right)$ and Managerial Performance $\left(\mathrm{Y}_{2}\right)$

\begin{tabular}{|cccc|}
\hline Variables & Coefficient & $\begin{array}{c}\text { Coefficient value } \\
(\mathrm{b})\end{array}$ & $\begin{array}{c}\text { T-stat } \\
\text { value }\end{array}$ \\
\hline $\mathrm{X}_{2}$ & $\mathrm{~b}_{2}$ & 0.59 & $3.18^{*}$ \\
& $\mathrm{a}_{2}$ & 4.79 & $16.83^{*}$ \\
\hline $\mathrm{R}^{2}=0.24, \mathrm{~N}=75$ & & \\
\hline
\end{tabular}

Results: Statistic results with the $\mathrm{T}$ and coefficient values from the regression analysis (see in Table 6.19 above) ensure a significant and positive effect of budgetary participation on managerial performance. The $t$ value is $3.18(\mathrm{p}<0.05)$. The coefficient value is 0.59 . The $\mathrm{R}$ square value shows that budgetary participation explains 24 per cent of the variance of managerial performances.

Now the model including the two controls (Size and Ownership) is checked. To test this model, a multiple-regression equation is presented as follows (Eq. (3)):

$$
\mathrm{Y}_{2}=\mathrm{a}_{23}+\mathrm{b}_{23} \mathrm{X}_{2}+\mathrm{b}_{\mathrm{s} 6} \mathrm{SIZE}+\mathrm{b}_{\mathrm{ow} 6} \mathrm{OWNE}
$$

Where $\mathrm{Y}_{2}=$ managerial Performance; $\mathrm{X}_{2}=$ budgetary participation; SIZE=firm size; OWNE=ownership.

Table 6.20 Regression Results on Managerial Performance $\left(\mathrm{Y}_{2}\right)$ : The Impact of the Formal Budgetary Control $\left(\mathrm{X}_{2}\right)$, Firm Size (SIZE), and Ownership (OWNE)

\begin{tabular}{|cccc|}
\hline Variables & Coefficient & $\begin{array}{c}\text { Coefficient value } \\
(\mathrm{b})\end{array}$ & $\begin{array}{c}\text { T-stat } \\
\text { value }\end{array}$ \\
\hline $\mathrm{X}_{2}$ & $\mathrm{~b}_{23}$ & 0.44 & $2.47^{*}$ \\
$\mathrm{SIZE}$ & $\mathrm{b}_{\mathrm{s} 6}$ & 0.25 & 1.08 \\
OWNE & $\mathrm{b}_{\text {ow6 }}$ & -0.68 & $-2.30^{*}$ \\
& $\mathrm{a}_{23}$ & 4.52 & $9.12^{*}$ \\
\hline \multicolumn{2}{c}{$\mathrm{R}^{2}=0.51, \mathrm{~N}=75$} & & \\
\hline
\end{tabular}

Results: The positive impact of the budgetary participation on managerial performance has been proven, as the statistical results show above. Therefore, Hypothesis 2 is accepted. The coefficient value " 0.44 " explains that a one level increase of budgetary participation leads to 0.44 higher managerial performances. The control variable 
"OWNE" shows a significant but negative value, which means that the state-owned enterprises in the sample have a better managerial performance compared with private firms. However, another control variable "SIZE" shows insignificant influence on managerial performance, since the $t$ value is $1.08(\mathrm{P}>0.05)$.

\section{Summary:}

- By using OLS regression and Lisrel estimates, the effect of the variables are examined and displayed in this Chapter.

- The statistical results are summarized in Table 6.21 below.

Table 6.21 Results Summary as Indicated in Statistical Analysis

\begin{tabular}{|c|c|c|c|}
\hline Hypothesis & Independent Variables: & Dependent Variables & Results \\
\hline \multirow[t]{2}{*}{$\mathrm{H}_{1} \mathrm{a}_{1}$} & The formal budgeting planning & Growth of sales revenues & $\mathrm{P}$ \\
\hline & & & $\mathrm{E}$ \\
\hline \multirow[t]{2}{*}{$\mathrm{H}_{1} \mathrm{a}_{2}$} & & Growth of profit & $\mathrm{P}$ \\
\hline & & & $\mathrm{E}$ \\
\hline \multirow[t]{2}{*}{$\mathrm{H} 1 \mathrm{~b} 1_{1}$} & Budget goal clarity & Goal achievement & $\mathrm{P}$ \\
\hline & & & $\mathrm{E}$ \\
\hline \multirow[t]{2}{*}{$\mathrm{H} 1 \mathrm{~b} 1_{2}$} & & Job satisfaction & $\mathrm{P}$ \\
\hline & & & $\mathrm{E}$ \\
\hline \multirow[t]{2}{*}{$\mathrm{H} 1 \mathrm{~b} 2_{1}$} & Budget goal difficulty & Goal motivation & $\mathrm{P}$ \\
\hline & & & $\mathrm{E}$ \\
\hline \multirow[t]{2}{*}{$\mathrm{H} 1 \mathrm{~b} 2_{2}$} & & Job involvement & $\mathrm{P}$ \\
\hline & & & $\mathrm{E}$ \\
\hline \multirow[t]{2}{*}{${\mathrm{H} 1 \mathrm{c}_{1}}$} & Budgetary sophistication & Growth of sales revenues & $\mathrm{P}$ \\
\hline & & & $\mathrm{E}$ \\
\hline \multirow[t]{2}{*}{$\mathrm{H} 1 \mathrm{c}_{2}$} & & Growth of profit & $\mathrm{P}$ \\
\hline & & & $\mathrm{E}$ \\
\hline \multirow[t]{2}{*}{$\mathrm{H}_{1 \mathrm{~d}_{1}}$} & The formal budgetary control & Growth of sales revenues & $\mathrm{P}$ \\
\hline & & & $\mathrm{E}$ \\
\hline \multirow[t]{2}{*}{$\mathrm{H} 1 \mathrm{~d}_{\mathrm{s}}$} & & Growth of profit & $\mathrm{P}$ \\
\hline & & & $\mathrm{E}$ \\
\hline \multirow[t]{8}{*}{$\mathrm{H} 2$} & Budgetary participation & Managerial performance & $\mathrm{P}$ \\
\hline & & & $\mathrm{E}$ \\
\hline & Control Variables: & & \\
\hline & Firm size & Growth of Profit & + \\
\hline & & Goal achievement & + \\
\hline & Ownership & Budgetary motivation & - \\
\hline & & Job satisfaction & - \\
\hline & & Job involvement & - \\
\hline
\end{tabular}

Notes: "P" means predicted result and "E" means empirical result; "+" represents a significant and positive impact; "/" represents an insignificant impact; "-" represents a significant but negative impact. 


\section{Chapter 7}

\section{Summary and Conclusions}

This final chapter provides a summary and conclusions from the current study. The summary covers the central research question, the methodology, and the conceptual framework of this study. This chapter also provides answers to all research questions (including four theoretical questions and four empirical questions) proposed in Chapter 1. Based on the research findings from Chapter 6, conclusions will be drawn from the main findings and contributions of the current research. In addition, this chapter describes limitations of the current research and implications for future research. Thus, the chapter proceeds as follows: Section 7.1 research summary; Section 7.2 and section 7.3 answers to the theoretical questions and the empirical questions; Section 7.4 current research contributions; Section 7.5 limitations and implications for future research.

\subsection{Current Research Review}

\section{Current Research Scope}

- (Chinese) SMEs, Budgeting, and Performance

Small and Medium-Sized Enterprises (SMEs) are vital in China. By the end of 2008, the total figure of Chinese SMEs has reached 9.7 million $^{32}$, accounting for 99.8 per cent of all enterprises. More importantly, Chinese SMEs make up a huge portion of GDP and employment. As the data of June 2009 show, their contribution to GDP is 60.6 percent and to employment 75.7 percent $^{33}$. It is further estimated by economists that over the next 15 years approximately one-third of China's GDP growth and nearly 200 million new jobs will be generated by SMEs. Despite its volume and great contribution to Chinese society, they also suffer from a series of problems. The first problem is a very low survival rate. About 40 per cent of SMEs does not survive the first three years $^{34}$. The five-year survival rate is only 32 per cent. SMEs are fragile when they encounter a crisis. According to the data released by Chinese Academy of Social Sciences in 2009, 40 per cent of SMEs announced bankruptcy this year due to the financial crisis. 49.5 per cent of SMEs reported a considerable negative impact by the financial crisis. In addition, SMEs struggle with improving their performance, and

\footnotetext{
${ }^{32}$ Source: China Knowledge, 2009

${ }^{33}$ Source: SME Annual Report by National SME Development Council, 2009

${ }^{34}$ The survival rate varies among different provinces in China. The range is from $40 \%$ to $50 \%$. For example, the survival rate of SMEs in ZheJiang province is 45.8 per cent in 2009.
} 
especially their financial performance. As the descriptive data show in Chapter 5, the financial performance for most of the sampled firms is at a very low level. The mean value for the growth of sales revenues is 2.71 . The mean for the growth of net profit is only 1.72 which is much lower than the middle value "4" (on the Linkert scale from 1 to 7). To solve the problems of SMEs, it is necessary to conduct numerous investigations. However, SMEs research, up to now, is not extensive enough. One reason is: compared to large firms, it is more difficult for researchers to get access to data from SMEs. Nevertheless, during recent years, a growing concern is paid to SMEresearch. Among those researches, many of them constantly emphasize "best practice" management activities and its impact on performance. Research with this focus is presumably triggered by a perceived need to establish a set of desirable management activities and improve the performance in SMEs. Planning, as an essential activity to structure the firms' expectations, shows strong support for the theoretical notion that planning generates positive outcomes for firms of all sizes. However, little empirical work in the past has examined the impact of planning on organizational performance in SMEs. The current research attempts to fill in the gap. It specially focuses on planning in financial perspective, namely budgeting, and tries to find out how budgeting impacts performance in SMEs.

\section{Current Research Objectives}

The objectives of the current research (stated in Chapter 1, pp.11-12) are repeated below:

- to explore the theoretical impact of budgeting on performance in small and medium-sized enterprises;

- to define and determine how to measure performance in SMEs;

- to understand how budgeting affects the performance in Chinese SMEs;

- Finally, to further investigate whether the theoretical impact changes by the corporate context (i.e. size of firm, ownership) in SMEs.

The central question of the present research (stated in Chapter 1, pp.12) is also highlighted once again as follows:

Central question: How does the budgeting process impact the performance of SMEs?

This central question consists of seven derived questions as shown in Chapter 1 (pp.1215). The first four questions are theoretical questions. The others are empirical questions. All questions have been addressed in the previous chapters by theoretical 
exploration (Chapter 2 and Chapter 3) and empirical investigation (Chapter 5 and Chapter 6). This chapter intends to compile all the answers to these questions as an overview of this study. Before answering to all research questions, it is important to emphasize the methodology used in the current study.

\section{Methodology for All Theoretical Questions}

- Desk Research

In the current study, desk research is conducted as the main research strategy (research method) to address all theoretical questions. On the one hand, this provides a way to theoretically explore how the budgeting process impacts the performance of SMEs. On the other hand, desk research leads to a wide literature review (in Chapter 2) about previous research related to budgeting activities and the behavior of business firms. Integrating several models suggested by previous research leads to the creation of a new research model to reveal the relationship between the budgeting process and performance (shown in Chapter 4, pp. 57-59). The theoretical model of this study has two sub-models: i.e., (1) the model of the formal budgeting process and firm performance and (2) the model of budgetary participation and managerial performance. The first model includes the independent variables of the formal budgeting planning, budget goal clarity, budget goal difficulty, and the formal budgetary control. The dependent variables in this model are financial performance (measured by growth of sales revenues and growth of profit), non-financial performance, including budgetary performance (measured by goal achievement and goal motivation), and other performance (measured by job involvement and job satisfaction). As to the second model, budgetary participation is regarded as the independent variable and managerial performance is the dependent variable.

\subsection{Answers to Theoretical Questions}

\subsubsection{SMEs' Definition}

Research sub-question 1: How do we define SMEs?

This question has been discussed in Chapter 3. It is found that the definition of SMEs varies in previous researches. Numerous researchers define SMEs in terms of the number employed, that is, those with 0 to 9 employees are micro-firms, those with 10 to 99 workforces are small firms, and those with 100 to 499 employees are categorized as medium-sized firms. Instead of the number of employees, some researches use other 
measures, such as production capacity, sales revenue (or turnover), or assets, to distinguish small enterprises from medium-sized enterprises. China's National Bureau of Statistics (NBS), a statistical authority in China, applies annual sales revenue to identify Chinese SMEs. For that reason, in the current study, annual sales revenue is also used to define SMEs in China. Therefore, the answer to the first question of this study is: small firms in China are those with an annual sales revenue of less than 5 million RMB; medium-sized enterprises are those with annual sales revenue above 5 million RMB but less than 30 million RMB; firms with annual sales revenues above 30 million are large firms.

\subsubsection{SMEs' Performance Measurement}

Research sub-question 2: How do we measure performance in SMEs?

Chapter 2 discussed the second research question regarding performance measurement. Both financial performance and non-financial performance are emphasized in that chapter. Financial performance is based on financial indicators which reflect the fulfillment of the economic goals of the firm. Financial measures are traditionally and widely used, because they are objective and focus directly on profitability. However, it is insufficient to merely analyze firm's performance by financial performance, especially under today's changing business environment. In this study, we advise to use non-financial performance as well to reflect the overall performance of an organization. Therefore, financial measures together with non-financial measures are used to measure SMEs' performance. The indicators adopted in the present research are sales revenue, profit (as financial measures), managerial performance, budgetary performance, job satisfaction, job motivation (as non-financial indicators). These indicators were selected since they are potentially related to the formal budgeting process.

\subsubsection{The Definition of the Formal Budgeting Process}

Research sub-question 3: What is the formal budgeting process and how does it affect performance of SMEs?

The answer to this theoretical question is given in Chapter 2 by reviewing literature. As mentioned before, previous research (Wijewardena \& De Zoysa) identifies the formal budgeting process in small and medium-sized enterprises as a formal process of budget planning and a formal process of budgetary control. Wijewardena \& De Zoysa found that a greater level of the formal budgeting process positively impacts the performance 
of SMEs. The performance measures they use are financial measures, viz. sales revenues and profit. Apart from the formal budget planning and budgetary control processes having a positive impact on the performance of an organization, previous studies also suggest considering other factors related to the budgeting process. In order to explore how the budgeting process impacts SMEs' performance, it is necessary to take all potential factors into consideration. The former literature on budget goal characteristics stresses the positive effect of budget goals on improving performance in an organization. Previous literature (Hirst, 1987; Hirst \& Yetton, 1997; Yuen, 2004) analyzes the characteristics of budget goal from two perspectives, the first is goal clarity and the second is goal difficulty. They indicate that clear goal setting improves budgetary performance, while unclear goals lead to dissatisfaction among employees. Secondly, they indicate that difficult but attainable goals are more effective to motivate employee than loose or very tough goals. It is also argued by Merchant in 1980 that the adoption of more sophisticated budgeting results in higher performance in firms. Budgetary sophistication is defined in this study as the greater use of computer, technical staff, and financial modeling. The answer to the third research question is: the formal budgeting process in SMEs is the completeness of the budgeting process from four aspects, i.e., budget planning, budget goal clarity and difficulty, budgeting sophistication, and budgetary control (see Chapter 2). Budget planning, budgeting sophistication, and budgetary control can positively affect the financial performance of SMEs, while budget goal clarity and difficulty can strongly impact on the non-financial performance of SMEs.

\subsubsection{Budgetary Participation}

Research sub-question 4: How do we define the role of budgetary participation in the budgeting process, and how does it impact performance?

As defined in Chapter 2 (pp.36), budgetary participation (BP) refers to the involvement of managers in the budgetary process and their influence in setting budgetary targets (Subramaniam \& Ashkanasy, 2001). The role of budgetary participation in the budgeting process is discussed in section 2.4.2 in Chapter 2. The agency theory assumes that an agent has private information which a principal may not know. Through communication, the principal will acquire the information from the agent. Based on the theory, in an organizational context, a front-line manager supposedly has more information about his area of responsibility than his supervisor. Therefore, budgetary 
participation provides a channel to exchange and share information among different levels of managers in a firm and finally to improve the performance of both managers and employees. In theoretical literature about budgeting, the adoption of budgetary participation is also suggested. The previous studies further suggest a positive effect of budgetary participation on managerial performance. They describe the impact from two perspectives: i.e., a psychological point of view and a cognitive point of view. The psychological factor is that participation enhances a subordinate's trust, sense of control, and ego-involvement with the organization. Jointly this leads to more acceptance of, and commitment to, the budget decisions, and causes improved managerial performance. The cognitive viewpoint states that, through budget participation, subordinates gain information from superiors that helps clarify their organizational roles (including their duties, responsibilities, and expected performance), which in turn enhances their performance. From the statements above, it is clear to see that how budgetary participation affects managerial performance in a firm.

The sections above from 7.2.1 to 7.2.4 answer all the theoretical questions in this study. It is noted that all the evidence used to answer these question comes solely from previous theoretical literature. Section 7.3 will begin providing empirical evidence for all the empirical questions of this study.

\section{Methodology for All Empirical Questions}

- A modest survey (from 75 Chinese SMEs)

A modest survey is used as the main research strategy to collect data to answer all empirical questions in this study. It is a so-called modest survey because the sample size of this study is not big. To collect data for the descriptive analysis in Chapter 5 and statistical analysis in Chapter 6, a questionnaire has been designed (see Appendix II) and distributed in the Chinese SMEs in the machine industry in three provinces (Hunan, HuBei, and GuangDong). In total, 75 Chinese SMEs are included in the statistical analysis.

\subsection{Answers to Empirical Questions}

Research sub-question 5: What is the extent of the budgeting process in Chinese SMEs?

The descriptive results in Chapter 5 show clearly the level of the formal budgeting process in Chinese SMEs. All variables related to the formal budgeting process are 
classified into low, medium, or high level, derived from the Likert scales (1-7) in the survey. The extent of the formal budgeting process in Chinese SMEs is summarized as follows:

- Firstly, the mean value of the overall formal budgeting process in Chinese SMEs is 3.75 .

- Secondly, for all sub-variables under the formal budgeting process, the mean value of the formal budgeting planning is 3.83 .

- Thirdly, for both budget goal clarity and difficulty, their mean values are relatively high, compared with other dimensions of the formal budgeting process. Their mean values are 4.81 and 4.70 respectively.

- Lastly, the mean value of budgetary sophistication is 3.57. Especially, the formal budgetary control shows the lowest mean value (2.42).

Research sub-question 6: Does the formal budgeting process positively affect Chinese SMEs' performance?

The answer to this question is given in Chapter 6. Generally, the formal budgeting process positively affects Chinese SMEs' performance. But some variables under the formal budgeting process show insignificant or even negative impacts on performance. The detailed results are as follows:

- Firstly, the formal budgeting planning has a very strong effect on the growth of sales revenues. However, its impact on the growth of profit turns out to be insignificant.

- Secondly, from the statistical results in Chapter 6, we found that both budget goal clarity and difficulty positively affect budgetary performance. However, the impact of budget goal clarity and difficulty on other performance is insignificant. In other words, a very clear budget goal will not result in a better job satisfaction among Chinese SMEs' employees, and a higher level of budget goal difficulty will lead to a higher level of job involvement of employees.

- Thirdly, the impact of budgetary sophistication on the growth of sales revenues turns out to be insignificant, while, the statistic results even show a negative effect of budgetary sophistication on profit.

- Finally, in the model of the formal budgetary control and financial performance, the formal budgetary control is found to have an insignificant impact on the growth 
of sales revenues. However, it shows a significant and positive effect on the growth of profit.

Research sub-question 7: Does budgetary participation in the budgeting process of Chinese SMEs enhance their performance?

The answer to this question is "yes". Although the extent of budgetary participation among Chinese SMEs is at a low level (the mean value is 3.76), the statistical results in Chapter 6 still prove a significant and positive impact of budgetary participation on managerial performance.

From the Lisrel estimation in Chapter 6, it can be concluded that firm size only significantly affects the growth of profit and goal achievement. These two findings can be further explained that compared to small firms, bigger firms (i.e. medium-sized firms) show a higher growth of profit and a higher level of goal achievement. The impact of firm size on other performance, however, is insignificant. For ownership, significant but negative results are found with respect to its impact on budgetary motivation, job satisfaction, and job involvement. These results tell us that compared to private firms, state-owned enterprises in China achieve a higher level of budgetary motivation, job satisfaction, and job involvement. Ownership is shown to have no relation with financial performance in this study.

\section{Conclusions from the Empirical Research}

The main question for this empirical study is "whether the budgeting process significantly and positively impacts the performance of Chinese SMEs". The empirical results summarized above provide some support for the positive effect of the formal budgeting process on firm performance. Firstly, it is found that more formalized budgeting planning leads to higher sales revenues. This finding confirms prior research conducted by Wijewardena \& De Zoysa in 2001. Secondly, budget goal characteristics strongly affect the budgetary performance of Chinese SMEs. Specifically, this conclusion tells us that clear budget goals lead to higher goal achievement. Furthermore, difficult (but attainable) budget goals increase the motivation of employees to achieve budget standards. Moreover, it is found that budget goal difficulty leads to improvement of the firm performance of Chinese SMEs. Thirdly, the results also reveal that the more formalized budgetary control tends to lead to a higher growth of profit of a firm. The underlying reason can be that due to management control, the total expense of a firm will be at most minimized, which thus results into the growth of profit of the firm. It is 
also interesting to find that the formal budgeting planning and the formal budgetary control show different patterns in terms of their effect on financial performance. The formal budgeting planning has a stronger impact on the growth of sales of SMEs, compared to the formal budgetary control. However, its impact on the growth of profit becomes very weak and the formal budgetary control, in contrast, strongly affects the growth of profit in SMEs.

A number of findings from the study, however, are not in accordance with our expectations, since their results are either insignificant or negative. Budgetary sophistication has an insignificant impact on sales. Its impact on profit even turns out to be negative. The reason for this result may be that, for most of Chinese SMEs, it is a costly investment to improve their level of budgetary sophistication. The investment includes installment and implementation of advanced financial modeling software, training and education technical staffs etc. All these expenses will cause a decrease of net profit. Two other insignificant relationships exist between budget goal clarity and job satisfaction and between budget goal difficulty and job involvement. According to this result, it is reasonable to conclude that there might be more important factors impacting job satisfaction and job involvement in Chinese SMEs. Or budget goal clarity and budget goal difficulty might with other factor/factors, affect job satisfaction and job involvement.

Some interesting and unexpected results are also found in this study. Firstly, better budgetary performance leads to higher job satisfaction and job involvement. This conclusion is drawn based on the two findings from the Lisrel estimation in Chapter 6, i.e., goal achievement is shown to have a very strong and positive effect on job satisfaction and budgetary motivation has a significant and positive effect on job involvement. Secondly, although firm size has an insignificant impact on the growth of sales revenues, it does impact the growth of profit. Small firms are found to have a lower growth of profit than medium-sized firms. The reason for this may be costcontrol inefficiency in small firms. This leads to operating expenses increasing in small firms at a higher rate than those of medium-sized firms. However, identifying the exact cause of this situation requires in-depth case studies in future. Another interesting finding is that state-owned enterprises in China are shown to have better job satisfaction and higher job involvement than private firms. It is reasonable to assume that employees, in general, may feel more secure and stable working in state-owned 
companies than in private companies. This psychological factor promotes higher job security and stability of state-owned enterprises, which in turn results in a higher level of job satisfaction and job involvement in state-owned enterprises.

\section{Key Findings Highlight:}

- More formal budgeting planning promotes higher growth of sales revenues in SMEs.

- Clear and difficult budget goals improve budgetary performance of SMEs.

- A higher level of budgetary sophistication results in a lower profit growth of SMEs.

- More formal budgetary control leads to a higher growth of profit in SMEs.

- Greater budgetary participation leads to better managerial performance.

- Medium-sized firms achieve higher profit growth than small firms.

- State-owned enterprises achieve better non-financial performance than small firms.

\subsection{Current Research Contributions}

The first contribution of the current research is the construction of a new conceptual framework to show how the budgeting process impacts the performance of SMEs. The conceptual model tells us that the formal budgeting process and budgetary participation are supposed to improve the performance of SMEs. The definition of the formal budgeting process in SMEs originally comes from the Wijewardena \& De Zoysa's research in 2001. However, through desk research in this study, the formal budgeting process is refined into the four aspects (dimensions) including the formal budgeting planning, budget goal clarity and difficulty, budgeting sophistication, and the formal budgetary control. These four dimensions of the formal budgeting process are expected to have a positive effect on performance of SMEs. Some expected relationships are, however, rejected in this study.

The second contribution is introducing participation into SMEs' research. Does budgetary participation exist in small and medium-sized enterprises? If it exists, to what extent? Does the budgetary participation in SMEs positively affect the performance of SMEs? The previous research, unfortunately, did not provide any clues for answering these questions. To fill in the research gap in this field, this study tried to address these questions by designing a model to link budgetary participation and performance in 
SMEs. Although it is found in the empirical results in Chapter 5 that the extent of budgetary participation is low among Chinese SMEs, participation is found to have a strong and positive effect on the managerial performance of SMEs.

The third contribution is using both financial and non-financial measurements to measure the performance of SMEs. Non-financial performance is claimed to be an important indicator to reflect the overall performance of a firm (Otley, 1999; Van VeenDirks \& Wijn, 2002). However, it is widely ignored by the previous SMEs' researchers. To solve this study deficiency, non-financial performance is included in this study. It consists of budgetary performance, other performance, and managerial performance. The empirical results in Chapter 6 show that budgeting strongly and positively affect the budgetary performance of SMEs and that participation in SMEs leads to the improvement of managerial performance.

Last, this study not only contributes more empirical data to the existing SMEs research, but more importantly, gives some remarkable guidance in terms of budget activities to the owners/managers of small and medium-sized firms. It is suggested by the research findings that: firstly, SMEs who plan to improve their financial performance should give more priority to develop the formality of the budgeting planning and the budgetary control; secondly, SMEs will benefit from clear and difficult (but attainable) budget goals; finally, SMEs with financial restrains are advised not to undertake a massive investment in budgetary sophistication development.

\subsection{Research Limitations and Implications for Future Research}

As with any study, this study has its limitations. First, the scope of the study is limited by its sample size and industrial coverage. Due to limited time and the difficulty to gain access to data, this study uses a modest survey to test all hypotheses. The total number of the firms in this study is 75. All firms are from one industrial sector. Compared to other quantitative research, the sample is small. The second limitation of this study concerns the nature of self-reporting questionnaire data. Thornton (1968) argues that self-report measures of performance can be subject to leniency bias. The third limitation is that a growth percentage is used for sales revenue and profit measurement. A similar absolute growth in sales revenues and/or profit can, however, result in different growth percentages for small and big firms. Another limitation of this study is that the author did not fully address the impact of budgetary participation on all performance measures 
used in this study. The current study only examined whether budgetary participation significantly and positively impacts managerial performance. Some previous studies on participation and performance, however, also tried to test the relationship between participation and budgetary performance or job satisfaction. Further research can be undertaken to test whether budgetary participation also significantly impacts budgetary performance, job satisfaction, and job involvement. In addition, there is no attempt in this study to address whether non-financial performance will finally lead to improvement of the financial performance of SMEs. 


\section{Nederlandstalige samenvatting van dit proefschrift}

\section{De invloed van budgetteren op de prestaties van midden- en kleinbedrijven in China}

\section{Yang Qi}

De onderstaande tekst is een samenvatting van het in dit proefschrift beschreven onderzoek. Achtereenvolgens zal het volgende behandeld worden: (1) introductie, (2) onderzoeksdoelen, (3) onderzoeksvragen, (4) antwoorden op theoretische vragen, (5) twee nieuwe modellen, (6) antwoorden op empirische vragen, (7) conclusies, (8) bijdrage aan wetenschappelijk onderzoek en (9) onderzoeksbeperkingen en suggesties voor toekomstig onderzoek.

\section{(1) Introductie}

Midden- en Kleinbedrijven (MKB) zijn essentieel voor China. In juni 2008 waren er in China meer dan 366 miljoen bedrijven die tot het MKB gerekend konden worden. Van alle bedrijven in China kan 99,8 procent tot het MKB gerekend worden. Het MKB draagt in grote mate bij aan zowel het Chinese BBP als de werkgelegenheid binnen China. In juni 2009 bedroeg de totale bijdrage van het MKB aan het BBP 60,6 procent. Ook werkt meer dan 75 procent van de Chinese werknemers in het MKB. De komende 15 jaar zal naar verwachting ongeveer een derde van de groei van het Chinese BBP toegeschreven kunnen worden aan het MKB. In dezelfde periode zullen er naar schatting ook 200 miljoen nieuwe banen binnen het Chinese MKB bijkomen.

Het MKB heeft echter ook te kampen met een aantal problemen. De overlevingskans van bedrijven is heel laag. Ongeveer 40 procent van de bedrijven binnen het MKB overleeft de eerste drie jaar niet. Slechts 32 procent van het MKB overleeft de eerste vijf jaar. Bedrijven binnen het MKB zijn kwetsbaar als ze in een crisis belanden. In 2009 gaat naar verwachting 40 procent van de bedrijven binnen het MKB failliet ten gevolge van de economische crisis. Meer dan 49 procent van het MKB ervaart negatieve gevolgen van de financiële crisis. Het MKB heeft moeite om de prestaties op peil te houden, en in het bijzonder de financiële prestaties. De financiële prestaties van de meeste ondernemingen in dit onderzoek staan op een laag niveau. Om de problemen binnen het MKB op te lossen moet er veel meer onderzoek worden verricht dan dat er tot nu toe is uitgevoerd. Eén van de redenen voor het gebrek aan onderzoek is dat het in vergelijking met onderzoek bij grote ondernemingen, veel moeilijker is om data te 
verzamelen binnen het MKB. Desalniettemin is er in de laatste jaren een toename te zien van MKB-gerelateerd onderzoek. Veel onderzoek is gericht op het onderzoeken van "best practice" voor management en de invloed daarvan op de bedrijfsprestaties. Dit soort onderzoek is voornamelijk gericht op het aanreiken van een aantal gewenste managementmethoden en het verbeteren van de prestaties van de bedrijven.

Planning heeft een positieve invloed op ondernemingen van alle groottes. Er is echter weinig empirisch onderzoek verricht naar de invloed van plannen op bedrijfsprestaties binnen het MKB. Het in dit proefschrift beschreven onderzoek probeert deze leemte op te vullen. We richten ons in het bijzonder op de planning binnen het financiële perspectief. We onderzoeken op welke manier budgetteren de prestaties binnen het MKB beïnvloedt.

\section{(2) Onderzoeksdoelen}

De doelen van het in dit proefschrift beschreven onderzoek zijn:

- Beschrijven van de theoretische invloed van budgetteren op prestaties in het MKB

- Definiëren en bepalen hoe prestaties binnen het MKB gemeten moeten worden

- Verklaren op welke manier budgetteren van invloed is op de prestaties in het Chinese MKB

- Onderzoeken of de theorie verandert door de bedrijfscontext (i.e., ondernemingsgrote, eigendom) in het MKB in ogenschouw te nemen

\section{(3) Onderzoeksvragen}

De centrale onderzoeksvraag van dit onderzoek luidt:

Op welke manier beïnvloedt de methode van budgetteren de prestaties van bedrijven binnen het $M K B$ ?

Om deze vraag te kunnen beantwoorden zijn vier theoretische onderzoeksvragen en vier empirische onderzoeksvragen geformuleerd.

\section{(4) Antwoorden op de theoretische vragen}

Hieronder worden antwoorden op de theoretische vragen beschreven. Om de theoretische onderzoeksvragen te kunnen beantwoorden is voornamelijk gebruik gemaakt van bureauonderzoek. Dit is een methode om te kunnen beschrijven hoe het budgetteringsproces van invloed is op de prestaties van het MKB. Het bureauonderzoek 
resulteert in een literatuuroverzicht van eerder uitgevoerd onderzoek naar budgetteren binnen ondernemingen.

Deelvraag 1: Wat is de definitie van $M K B$ ?

Verschillende onderzoekers gebruiken verschillende definities voor het MKB. Veel onderzoekers definiëren het MKB aan de hand van het aantal werknemers. Bedrijven met nul tot negen werknemers zijn micro-ondernemingen, bedrijven met 10 tot 99 werknemers zijn kleine ondernemingen, en bedrijven met 100 tot 499 werknemers zijn middelgrote ondernemingen. Andere onderzoekers gebruiken bijvoorbeeld de productie capaciteit, de omzet of activa om kleine en middelgrote ondernemingen te onderscheiden. Het Chinese Nationale Bureau voor Statistiek gebruikt de jaarlijkse omzet als maatstaf. In dit proefschrift wordt de jaarlijkse omzet gebruikt om midden- en kleinbedrijven in China te onderscheiden. Daarbij wordt gebruik gemaakt van de volgende indeling:

- Kleine bedrijven hebben een omzet die lager is dan vijf miljoen $\mathrm{RMB}^{35}$

- Middelgrote bedrijven hebben een omzet die groter is dan vijf miljoen, maar lager dan 30 miljoen RMB

- Grote bedrijven hebben een omzet van meer dan 30 miljoen RMB.

\section{Deelvraag 2: Hoe meten we prestaties binnen het MKB?}

Financiële prestaties zijn uitkomstgerichte financiële maatstaven aan de hand waarvan het behalen van de economische doelen van de onderneming kan worden weergeven. Financiële maatstaven zijn traditionele en veel gebruikte maatstaven omdat ze objectief zijn en zich direct op de winstgevendheid richten. Als echter alleen gebruik gemaakt wordt van financiële indicatoren kan dit een te beperkt beeld op leveren. Dat is zeker het geval in de veranderende wereld van vandaag. We adviseren daarom om ook gebruik te maken van niet-financiële indicatoren bij het meten van de prestaties van een onderneming. Daarom worden zowel financiële als niet-financiële indicatoren gebruikt om de prestaties binnen het MKB te meten. In dit proefschrift wordt gebruik gemaakt van financiële indicatoren (i.e., omzet en winstgroei) en niet-financiële indicatoren (i.e., management prestaties, budget prestaties, werktevredenheid en werkmotivatie) die gerelateerd zijn aan de formele budgetteringsmethode.

\footnotetext{
${ }^{35} 1$ Chinese Yuan (Renminbi) $=0,10$ euro.
} 
Deelvraag 3: Wat is het formele budgetteringsproces en hoe beïvloedt het de prestaties van het $M K B$ ?

Voorgaand onderzoek definieert het formele budgetteringsproces in kleine en middelgrote ondernemingen als een formeel planningsproces en formeel beheersingsproces. Uit eerder onderzoek kwam naar voren dat het formele budgetteringsproces een positieve invloed heeft op de prestaties binnen MKB. Naast een positieve invloed van de formele budgetplaning en het budgetbeheersingsproces zijn er ook andere factoren die de prestaties beïnvloeden. Om te achterhalen welke factoren van invloed zijn op de prestaties binnen het MKB moeten alle mogelijk factoren worden afgewogen. Voorgaande literatuur over budgetdoel benadrukt het gunstige effect van een budgetdoel op de prestaties in een onderneming. Een helder doel verbetert budgetprestaties, terwijl een onduidelijk doel in ongemotiveerde werknemers resulteert. Moeilijke maar haalbare doelen zijn meer effectief om werknemers te motiveren dan onbereikbare doelen. Eerder onderzoek laat ook zien dat een geavanceerdere budgetterinsmethode resulteert in betere bedrijfsprestaties. De geavanceerdheid van budgetteren is in dit proefschrift gedefinieerd als meer gebruik maken van computers, technische medewerkers, en financiële modellen.

Het antwoord op de tweede deelvraag is: het formele budgetteringsproces in het MKB is de compleetheid van het budgetteringsproces vanuit de volgende vier perspectieven: budgetplanning, duidelijkheid en moeilijkheid van het budgetdoel, geavanceerdheid van budgettering en budgetbeheersing. De budgetplanning, geavanceerdheid van het budget en budgetbeheersing kunnen een positieve invloed hebben op de financiële resultaten binnen het MKB. Budgetdoel, helderheid en moeilijkheid kunnen een sterke invloed hebben op niet-financiële prestaties van het MKB.

\section{Deelvraag 4: Hoe definiëren we participatie in budgetteren in het budgetteringsproces} en hoe beïnloedt dat de prestaties?

Participatie in budgetteren heeft betrekking op het betrekken van managers bij het budgetteren en de invloed van managers op het budgetteringsproces. De principaalagent theorie veronderstelt dat een agent over informatie kan beschikken waarover de principaal niet beschikt. Door middel van communicatie kan de principaal de informatie die de agent heeft achterhalen. In een organisatorische context kan worden verondersteld dat een manager meer informatie over zijn verantwoordelijkheden heeft dan zijn leidinggevende. Participatie in het budgetteringsproces maakt het mogelijk om 
informatie uit te wisselen tussen verschillende managementlagen. Daarmee kunnen dan de prestaties van de managers en werknemers verbeteren. In theorie over budgettering is participatie in budgettering ook voorgesteld om te gebruiken. Voorgaand onderzoek suggereert verder dat er een positief effect is van participatie in het budgetteringsproces op prestaties van managers. Daarbij wordt gekeken vanuit een psychologisch en een cognitief perspectief. Het psychologische effect beschrijft dat participatie leidt tot meer vertrouwen bij ondergeschikten, gevoel van beheersing, en betrokkenheid met de organisatie. Dit alles resulteert dan in meer acceptatie en/of verbondenheid met beslissingen en vervolgens in betere prestaties van het management. Het cognitieve gezichtspunt beschrijft dat door participatie in het budgetteringsproces, ondergeschikten informatie krijgen van leidinggevenden. Ondergeschikten krijgen daarmee meer duidelijkheid over hun rol binnen de organisatie, hun plichten, verantwoordelijkheden en verwachte prestaties. Hieruit kan duidelijk worden afgeleid hoe participatie in het budgetteringsproces management van prestaties beïnvloedt.

\section{(5) Twee nieuwe modellen}

Door verschillende modellen uit voorgaand onderzoek samen te voegen wordt een nieuw model gebouwd. Het theoretische model in dit onderzoek bestaat uit twee onderliggende modellen. In het eerste model worden de formele budgetteringsmethode en de bedrijfsprestaties weergegeven. In het tweede model worden de participatie in het budgetteringsproces en prestaties van het management weergegeven. Het eerste model bevat de onafhankelijk variabelen van het formele budgetteringsproces: duidelijkheid van budgetdoel, moeilijkheid van het budgetdoel, en de formele budgetbeheersingsmethode. De afhankelijke variabelen binnen dit onderzoek zijn: de financiële prestaties (gemeten aan de hand van groei van de omzetgroei en toename van de winst), niet-financiële prestaties inclusief budgetteringsprestaties (gemeten door middel van inspanningsbereidheid en tevredenheid van werknemers met hun baan). In het tweede model is participatie in het budgetteringsproces de onafhankelijke variabele. De afhankelijke variabele is de prestatie van het management.

\section{(6) Antwoorden op de empirische vragen}

Er is een survey gebruikt als belangrijkste onderzoeksstrategie om alle empirische vragen te beantwoorden. Aan de hand van vragenlijst zijn data verzameld om de beschrijvende en de statistische analyse uit te kunnen voeren. De vragenlijst is verspreid onder 150 Chinese midden- en kleinbedrijven in de machine-industrie in de provincies 
Hunan, Hu Bei en Gaung Dong. Vijfenzeventig bedrijven hebben de survey beantwoord (deelnamepercentage 50\%). De resultaten van deze 75 bedrijven zijn meegenomen in de analyses.

Deelvraag 5: In welke mate wordt er gebruik gemaakt van het budgetteringsproces in het MKB in China?

De beschrijvende analyse laat duidelijk het niveau van het formele budgetteringsproces binnen het Chinese MKB zien. Alle variabelen die zijn gerelateerd aan het formele budgetteringsproces worden ingedeeld in laag, midden of hoog. Dit is gedaan met behulp van een Likert-schaal. De mate van het formele budgetteringsproces in het Chinese MKB kan als volgt samengevat worden:

- De gemiddelde waarde van het formele budgetteringsproces binnen het Chinese $\mathrm{MKB}$ is 3,75 .

- De gemiddelde waarde van de het formele budgetplanning is 3,83.

- Zowel de helderheid van het budgetdoel als de moeilijkheid hebben een relatief hoog niveau. Deze resultaten laten zien dat de meeste bedrijven in het Chinese MKB heldere en moeilijke budgetteringstaken hebben.

- De gemiddelde waarde van de geavanceerdheid van budgetteren is 3,57. De gemiddelde waarde van de formele beheersing van budgetten heeft de laagste gemiddelde waarde $(2,42)$.

Deelvraag 6: Heeft het formele budgetteringsproces een positieve invloed op de prestaties van het MKB in China?

Over het algemeen kan gezegd worden dat het formele budgetteringssysteem een positieve invloed heeft op de prestaties van het Chinese MKB. Maar sommige variabelen zijn niet significant of hebben zelfs een negatieve invloed op prestaties.

- De formele budgetteringplanning heeft een heel sterk effect op de groei van de omzet. De invloed op de winstgroei is echter niet significant.

- Zowel de helderheid als de moeilijkheid van het budgetdoel hebben een positieve invloed op de budgetteringsprestaties. De invloed van de helderheid van het doel en de moeilijkheid op andere prestaties is niet significant. In andere woorden, een heel helder budgetteringsdoel resulteert niet in een hogere tevredenheid van de werknemers van het Chinese MKB. Een moeilijker budgetdoel resulteert in een meer betrokkenheid van werknemers. 
- De invloed van de geavanceerdheid van budgettering op de toename van de omzet is niet insignificant en zelfs negatief voor de winst.

- Voor het model van de formele budgetbeheersing en financiële prestaties is geen significante invloed gevonden van budgetbeheersing op de groei van de omzet. Er is echter een positief significant effect op de toename van de winst.

Deelvraag 7: Verbetert participatie in het budgetteringsproces de prestaties van het Chinese MKB?

Ondanks dat de mate van participatie in het budgetteringsproces zich op een laag niveau bevindt kan deze vraag met "ja" beantwoord worden. De statistische resultaten laten een significant positief effect zien van participatie in het budgetteringsproces op de managementprestaties.

De resultaten van een Lisrel test laten zien dat ondernemingsgrootte alleen significant van invloed is op de groei van de winst en het bereiken van het doel. Grote bedrijven hebben grotere winstgroei en bereiken in grotere mate de gestelde doelen dan kleine bedrijven. De ondernemingsgrootte heeft echter geen significante invloed op andere vormen van prestatie. Negatief significante resultaten worden gevonden voor de invloed van budgetmotivatie, tevredenheid met het werk en betrokkenheid bij het werk. De resultaten laten zien dat staatsbedrijven in China in vergelijking met private ondernemingen een hogere mate van budgetmotivatie, arbeidstevredenheid, en betrokkenheid hebben. Er lijkt geen relatie te bestaan tussen eigendom en financiële prestaties.

\section{(7) Conclusies}

De hoofdvraag van deze studie is of het budgetteringsproces een significante invloed heeft op de prestaties van het Chinese MKB. De empirische resultaten ondersteunen het veronderstelde effect van het budgetteringsproces op de bedrijfsprestaties.

- Formelere budgetplanning resulteert in een hogere omzet.

- Karakteristieken van budgetdoelen hebben een sterke invloed op de budgetprestaties van het Chinese MKB. Meer specifiek betekent dit dat heldere budgetdoelen leiden tot het bereiken van meer doelen en dat moeilijke (maar bereikbare) doelen leiden tot meer motivatie bij werknemers om aan de gestelde budgetten te voldoen. Een moeilijk budget leidt tot betere bedrijfsprestaties binnen het Chinese MKB. 
- Formelere budgetbeheersing lijkt in een hoger bedrijfswinst te resulteren. De onderliggende reden hiervoor kan zijn dat het management de totale uitgaven van de ondernemingen probeert te beheersen en minimaliseren. Dit alles resulteert vervolgens weer in een toename van de winst. Het is ook interessant om te zien dat de formele budgetplanning en het formele budgetbeheersingssysteem een verschillend effect lijken te hebben op de financiële prestaties. Het formele budgetteringssysteem heeft een veel grotere invloed op de groei van de omzet dan de formele budgetbeheersing. De invloed op de winstgroei lijkt zeer zwak, terwijl het formeel budgetbeheersingssystem een sterke invloed heeft op de winstgroei van het MKB.

Een aantal resultaten zijn niet significant of laten een negatief effect zien. De geavanceerdheid van het budgetteringsrapport heeft geen significante invloed op de omzet. De invloed op de winst lijkt zelfs negatief te zijn. De reden hiervoor kan zijn dat het voor de meeste bedrijven in het Chinese MKB een kostbare aangelegenheid is om het niveau van geavanceerdheid te vergroten. Er zal dan geïnvesteerd moeten worden in installaties, implementatie van geavanceerde software, training en opleiding van medewerkers, etc. Alle investeringen zullen leiden tot een lagere netto winst. Ook tussen de helderheid van het budgetdoel en arbeidstevredenheid en moeilijkheid van budgetdoel en betrokkenheid van werknemers zijn geen significante effecten te zien. Naar aanleiding van deze resultaten kan geconcludeerd worden dat er mogelijk andere factoren zijn die arbeidstevredenheid en -betrokkenheid binnen het Chinese MKB verklaren. Mogelijk hebben de helderheid en moeilijkheid van het budgetdoel samen met andere factoren invloed op arbeidstevredenheid en betrokkenheid.

Een aantal interestante en onverwachte resultaten zijn te voorschijn gekomen in dit onderzoek. De Lisrel analyse laat zien dat een betere budgetprestatie tot een hogere arbeidstevredenheid leidt. Ook komt naar voren dat budgetmotivatie een positief effect heeft op betrokkenheid bij het werk. Ondanks dat bedrijfsgrootte geen invloed heeft op de omzetgroei heeft het invloed op de winst. Kleine ondernemingen hebben een lagere winstgroei dan middelgrote ondernemingen. Dit zou verklaard kunnen worden door de kosteninefficiëntie bij kleine ondernemingen. Het leidt tot een grotere toename van uitgaven aan de bedrijfsvoering bij kleine ondernemingen dan bij middelgrote ondernemingen. Er moet meer onderzoek uitgevoerd worden om de exacte reden te achterhalen. Een andere interessante bevinding is dat Chinese staatsbedrijven een 
hogere arbeidstevredenheid hebben dan kleine private ondernemingen. Het is redelijk om te veronderstellen dat werknemers in staatbedrijven over het algemeen in een stabielere omgeving werken dan werknemers die in de private sector werken. Deze psychologische factor leidt tot een hogere baangarantie en stabiliteit van staatsbedrijven. Dit leidt dan weer tot een hoger niveau van arbeidstevredenheid en betrokkenheid van werknemers.

De belangrijkste bevindingen kunnen als volgt worden samengevat:

- Een hogere mate van formeel budgetteren leidt tot een hogere omzet binnen het MKB.

- Heldere en moeilijke budgetdoelen leiden tot een verbetering van budgetprestaties binnen het MKB.

- Geavanceerder budgetteren leidt tot lagere winstgroei binnen het MKB.

- Meer formele budgetbeheersing leidt tot hogere winst voor het MKB.

- Grotere participatie leidt tot betere managementprestaties.

- Middelgrote ondernemingen hebben een grotere winstgroei dan kleinere ondernemingen.

- Staatbedrijven hebben betere niet-financiële prestaties dan kleine bedrijven.

\section{(8) Bijdrage aan de wetenschap}

De eerste bijdrage is de constructie van een conceptueel model waarin zichtbaar wordt hoe het budgetteringsproces prestaties binnen het MKB beïnvloedt. Het conceptuele model laat zien dat het formele budgetteringsproces en budgetparticipatie tot een veronderstelde verbetering van de prestaties van het MKB leiden. De definitie van het formele budgetteringsproces zoals die door Wijewardena en De Zoysa (2001) is geformuleerd is aangescherpt met de volgende vier aspecten: formele budgetplanning, helderheid van het budget en moeilijkheid, geavanceerdheid van het budget en formele budgetbeheersing. Deze vier aspecten hebben een positief effect op de prestaties binnen het MKB.

De tweede bijdrage betreft de introductie van participatie binnen het MKB-onderzoek. Is er sprake van participatie bij budgetteren in kleine en middelgrote ondernemingen? Eerder onderzoek heeft hierover geen uitsluitsel gegeven. Ondanks dat uit dit proefschrift naar voren komt dat de mate van participatie binnen het Chinese MKB laag 
is, lijkt participatie een sterk positief effect te hebben op managementprestaties van het MKB.

De derde bijdrage van dit onderzoek heeft betrekking op financiële en niet-financiële maatstaven om prestaties te meten binnen het MKB. Eerder onderzoek laat zien dat niet-financiële indicatoren een belangrijke rol spelen bij prestatiemeting binnen ondernemingen. Onderzoekers hebben echter weinig aandacht besteed aan nietfinanciële indicatoren binnen een onderneming. Daarom zijn ook niet-financiële indicatoren meegenomen in dit onderzoek. Het gaat dan om budgetprestaties, andere prestaties, en managementprestaties. De empirische resultaten laten zien dat budgetteren een sterk en positief effect heeft op budgetprestaties binnen het MKB en leidt tot verbetering van managementprestaties.

Ten slotte levert deze studie niet alleen meer empirische data voor bestaand MKB onderzoek op, maar geeft het ook een aantal opvallende aanwijzingen voor wat betreft budgetactiviteiten van kleine en middelgrote ondernemingen. De onderzoeksresultaten lijken er op te wijzen dat financiële prestaties van ondernemingen meer prioriteit moeten geven aan het ontwikkelen van een formeel budgetteringsplan en budgetbeheersing. Het MKB heeft voordeel van heldere en moeilijke (maar bereikbare) budgetdoelen. MKB met financiële beperkte middelen wordt geadviseerd om niet teveel te investeren in geavanceerde budgetteringsmethoden.

\section{(9) Onderzoeksbeperkingen en ideeën voor toekomstig onderzoek}

Net als elk onderzoek zijn ook in dit onderzoek beperkingen. Ten eerste is het aantal bedrijven in dit onderzoek beperkt. Gegeven de beperkte tijd en moeilijkheid om toegang te krijgen tot gegevens is er gekozen voor een survey met een beperkte omvang. In totaal zijn de gegevens van 75 bedrijven uit een industriële sector in dit proefschrift verwerkt. In vergelijking met kwantitatief onderzoek is de omvang van het aantal bedrijven niet groot. Een tweede beperking heeft betrekking op de vragenlijst. Een zogenaamde "leniency bias" kan hier van invloed zijn op de uitkomsten. De keuze voor een winstgroei kan ook als een beperking worden gezien. Twee bedrijven met eenzelfde absolute winstgroei kunnen immers heel verschillende relatieve (procentuele) winstgroei hebben. Een andere beperking is dat alleen een positieve invloed van budgetparticipatie op de prestaties van managers onderzocht is. Een aantal eerdere studies heeft ook geprobeerd om de relatie tussen participatie en budgetteringsprestaties 
of arbeidstevredenheid in kaart te brengen. Verder onderzoek kan worden uitgevoerd om te testen of participatie in budgettering ook een significante invloed heeft op budgetprestaties, arbeidstevredenheid en betrokkenheid. Verder is in dit onderzoek ook niet onderzocht of niet-financiële prestaties uiteindelijk resulteren in betere financiële prestaties. Toekomstig onderzoek zou zich hierop kunnen richten. 


\section{总结}

荷兰屯特大学经济系于 2006 年 12 月批准并展开了对中小企业预算流程这一科研 项目的研究。该项目由博士生杨齐和屯特大学经济系教授, 博士生导师 Prof. P.B.Boorsma，以及屯特大学统计系副教授 Dr.P.Geurts 共同合作完成。该总结将 对这一研究项目的研究范围, 研究目的, 研究方法, 和研究结果做一个简单的介 绍和概括。我们衷心希望此项目的研究成果能够为中国中小企业的发展起到一定 的指导性作用，能够提高中国中小企业的绩效并增强其对全球金融风险和经济危 机的抵制能力。另外, 我们也特别感谢参与这项研究调查的中国 75 家中小企业 和所有关心支持这项研究的朋友们。

\section{研究范围}

此研究涉及了中小企业（中国中小企业）, 预算，和绩效三个方面。

中小企业的重要性和它对经济发展的贡献越来越受到海内外学者和企业家的重 视。根据最新统计资料显示, 到 2008 年底, 中国中小企业已经达到了九千七百 万，占所有企业总数的百分之 99.8 。中国中小企业对于 GDP 的贡献在 2009 年 6 月达到了百分之 60.6 , 并且为全国提供了百分之 75.7 的就业机会。然而, 另一 组数据也不免让我们为中小企业的发展担忧。据统计, 将近一半的中小企业在不 到 3 年时间内宣布破产。中小企业普遍面临融资难, 利润率低, 经营风险高的问 题。因此, 如何解决中小企业所面临的这些困难, 加速中小企业的发展成为现今 中小企业管理中迫切而紧要的一环。但是, 就学术界而言, 很少有对中小企业的 相关理论研究, 中小企业的预算研究更是少之又少。大部分现有的理论研究和数 据分析都是针对大型企业或是上市公司。对存在这一问题的一种可能性的解释 是, 研究人员很难收集或者得到可靠而有效的中小企业数据。数据源的缺乏导致 了中小企业的相关研究一直处于低迷状态。众多研究指出预算管理作为企业财务 管理的一个重要方面, 对企业的发展, 企业绩效起到了关键性的和积极性的作 用。但这些研究采用的数据大部分来自大型企业而非中型或者小型企业。从这些 研究中，我们并不能推导出预算对于中小企业存在积极作用。 


\section{研究目的和研究方法}

基于以上原因, 我们选择了中小企业预算流程和中小企业绩效作为我们此项研究 的研究目标。通过参考文献, 我们试图寻找出 (1) 中小企业的预算流程是如何 定义的; （2）中小企业的绩效又是如何定义的; （3）其预算流程是如何影响中 小企业绩效的; (4) 最后通过数据收集和分析进一步论证预算流程对中国中小 企业绩效的影响。

从理论到数据的研究过程决定了这项研究是以定量研究为主体的研究方法。根据 中国中小企业的实际状况, 我们设计了一份旨在反映中国中小型企业预算形式, 预算流程, 和企业绩效的相关信息的问卷。这一问卷通过邮件, 电话联系, 或者 面谈的方式被发放到了湖南, 湖北, 广东三省的机械制造行业的 150 家中小企业 中。75 家中小企业填写并完成了问卷。问卷回复率为百分之 50 。所有答复的问 卷都被用于了此项研究的数据分析。以下, 是这项研究的主要研究成果。

\section{研究成果}

首先, 基于 Wijewardena 和 De Zoysa 等一些学者对预算的研究, 我们重新定义了 中小企业的预算流程。其包括了：财务预算计划，预算目标的清晰度和难易度， 预算复杂度，和财务预算控制四个方面。

其次, 对中小企业绩效的评估不但涉及了财务绩效, 还覆盖了预算绩效, 管理绩 效，和其他绩效（其他绩效包括工作满意度和工作投入度）。

最后, 这项研究还包括了对中小企业预算参与的分析和研究。我们假定中小企业 预算参与对中小企业的管理业绩起到了积极有效的作用。

通过对数据进行统计分析后, 我们发现:

首先，中国中小企业的整体预算水平为 3.75 (其衡量值范围从 1 到 7)。

其次, 中国中小企业预算目标的清晰度和难易度的平均值分别为 4.81 和 4.70。较 预算流程的其他方面而言，其平均值相对较高。

再次, 中国中小企业财务预算计划, 预算复杂度, 和财务预算控制的平均值都相 对较低。其中, 财务预算控制平均值最低, 只有 2.42 。 
通过回归分析和 Lisrel 数据分析, 我们发现:

- 财务预算计划对中小企业收入的增长起到了决定性和积极性的作用。

- 预算目标的清晰度和难易度决定了预算绩效的好坏。

- 财务软件的普及和应用会给企业利润的增长带来负面的影响。

- 预算控制对中小企业利润的增长起到了决定性和积极性的作用。

- 预算参与会提高中小企业的管理业绩。

另外，我们还发现：

- 中型企业其利润的增长普遍高于小型企业其利润的增长。

- 国有企业职工其工作满意度和工作投入度要普遍高于私有企业。

\section{对中小企业财务预算管理的几点建议:}

根据以上研究结果, 我们对中国中小企业预算管理提出了一些合理化的建议:

首先, 我们主张财务预算在中国中小企业的实施和应用, 因为它对提高中小企业 的财务业绩起到了积极作用。

其次，我们也建议中小企业制定出清晰而明确的预算目标，并且预算目标具有一 定的难度和挑战性。

再次, 我们不主张中小企业, 特别是面临财务困难的中小企业, 对财务软件进行 盲目地和大规模地投入和应用。因为这会影响到企业利润的增长，对企业陷入财 政危机具有潜在的威胁。 


\section{References}

Abernethy, M.A., \& Brownell, P. (1999). "The Role of Budgets in Organizations Facing Strategic Change: An Exploratory Study", in: Accounting, Organization \& Society, Vol. 24 (3), pp. 189-204.

Agrawal, A., \& Knoeber, C.R. (1996). "Firm Performance and Mechanisms to Control Agency Problems between Managers and Shareholders", In: Journal of Financial and Quantitative Analysis, Vol. 31(3), pp. 377-397.

Ahrens, T., \& Chapman, C.S. (2006). "Doing Qualitative Field Research in Management Accounting: Positioning Data to Contribute to Theory", in: Accounting, Organizations \& Society, Vol. 31(8), pp. 819-841.

Altman, E.I. (1983). Corporate Financial Distress, New York: John Wiley \& Son.

Amey, L.R. (1979). Budgeting Planning and Control Systems, Pitman, London.

Anderson, E.W., Fornell, C., \& Lehmann, D.R. (1994). “Customer Satisfaction, Market Share, and Profitability, Findings from Sweden.”, in: Journal of Marketing, Vol. 58(3), pp. 53-66.

Anderson, S.W., \& Lanen, W.N. (1999). "Economic Transition, Strategy and the Evolution of Management Accounting Practices: the Case of India.”, in: Accounting, Organizations and Society, Vol. 24(5/6), pp. 379-412.

Anthony, R.N. (1965). Planning and Control Systems: A Framework for Analysis, Boston: Harvard University Press.

Aram, J.D., \& Cowen, S.S. (1990) "Strategic Planning for Increased Profit in the Family Owned Business”, in: Long Range Planning Vol. 23(6). pp. 76-81.

Atkinson, A.A., Banker, R.D., Kaplan, R.S., \& Young, S.M. (2001). Management Accounting, Prentice-Hall, $3^{\text {rd }}$ edition.

Awasthi, V.N., Chow, C.W., \& Wu, A. (1998). "Performance Measure and Resource Expenditure Choices in a Teamwork Environment: The Effects of National Culture.”, in: Management Accounting Research, Vol. 9(2), pp.119-138.

Banker, R.D., Potter, G., \& Srinivasan, D. (2000). "An Empirical Investigation of an Incentive Plan Based on Nonfinancial Measures", in: The Accounting Review, Vol. 75(1), pp. 65-94.

Barclay, M.J., \& Holderness, C.G. (1991). "Negotiated Block Trades and Corporate Control", In: Journal of Finance, Vol. 46(3), pp. 861-878. 
Bass, B.M, \& Leavitt, H.J. (1963). "Experiments in Planning and Operating”, in: Management Science, Vol. 4, pp. 574-585.

Brealey, R. A. (2006). Principles of corporate finance, McGraw-Hill, $9^{\text {th }}$ ed.

Becker, S.W., \& Green, D. (1962). "Budgeting and Employee Behavior", in: Journal of Business, Vol. 35, pp. 392-402.

Bento, A.M., \& White, L.F. (2001). "Organizational Form, Performance and Information Cost in Small Business", in: Journal of Applied Business Research, Vol. 17(4), pp. 41-61.

Berger, A.N., \& Udell, G.F. (1998). "The Economics of Small Business Finance: The Roles of Private Equity and Debt Markets in the Financial Growth Cycle.", in: Journal of Banking \& Finance, Vol. 22(6/8), pp.613-673.

Berman, J.A., Gordon, D.D., \& Sussman, G. (1997). "A Study to Determine the Benefits Small Business Firms Derive from Sophisticated Planning versus Less Sophisticated Types of Planning", in: Journal of Business and Economic Studies, Vol. 3(3), pp. 1-11.

Birnberg, J.G., \& Shields, J.F. (1989). "Three Decades of Behavioral Research: A Search for Order.”, In: Behavioral Research in Accounting, Vol. 1, pp. 23-74.

Bodie, Z., \& Merton, R.C. (2000). Finance Prentice Hall.

Bonn, I., \& Christodoulou, C. (1996). "From Strategic Planning to Strategic Management", in: Long Range Planning, Vol. 29(4), pp. 543-551.

Borcherding, Th.E., Pommerehne, W.W., \& Schneider, F. (1982). "Comparing the Efficiency of Private and Public Production: The Evidence from Five Countries", In: Journal of Economics, Suppl. 2, pp.127-156.

Bracker, J.S., \& Pearson, J.N. (1986). "Planning and Financial Performance of Small, Mature Firms", in: Strategic Management Journal, Vol. 7(6), pp. 503-522.

Bremser, W. (1988). Budgeting by Department and Functional Area, American Management Association, Watertown, MA.

Briers, M., \& Hirst, M. (1990). "The Role of Budgetary Information in Performance Evaluation", in: Accounting, Organization \& Society, Vol. 15(4), pp.737-397.

Brignall, S. (1997). “A Contingent Rational for Cost System Design in Services”, in: Management Accounting Research, Vol. 8(3), pp. 325-346.

Brownell, P. (1981). "Participation in Budgeting, Locus of Control and Organizational Effectiveness", in: The Accounting Review, Vol. 56(4), pp. 844-860. 
Brownell, P. (1982b). "The Role of Accounting Data in Performance Evaluation, Budgetary Participation, and Organizational Effectiveness", in: Journal of Accounting Research, Vol. 20(1), pp. 12-27.

Brownell, P. (1985). "Budgetary Systems and the Control of Functionally Differentiated Organizational Activities", in: Journal of Accounting Research, Vol. 23(2), pp. 502512.

Brownell, P., \& Dunk, A.S. (1991). "Task Uncertainty and Its Interaction with Budgetary Participation and Budget Emphasis: Some Methodological Issues and Empirical Investigation", in: Accounting, Organization \& Society, Vol. 16(8), pp.693-703.

Brownell, P., \& Hirst, M. (1986). "Reliance on Accounting Information, Budgetary Participation, and Task Uncertainty: Tests of a Three-way Interaction”, in: Journal of Accounting Research, Vol. 24(2), pp.241-249.

Brownell, P., \& McInnes, M. (1986). "Budgetary Participation, Motivation, and Managerial Performance”, in: Accounting Review, Vol. 61(4), pp. 587-600.

Brownell, P., \& Merchant, K.A. (1990). "The Budgetary and Performance Influences of Product Standardization and Manufacturing Process Automation", In: Journal of Accounting Research, Vol. 28(2), pp. 388-397.

Bruns Jr., W.J., \& Waterhouse, J.H (1975). "Budgetary Control and Organization Structure”, in: Journal of Accounting Research, Vol. 13(2), pp.177-203.

Bryan, J.F., \& Locke, E.A. (1967) “Goal Setting as a Means of Increasing Motivation”, in: Journal of Applied Psychology, Vol. 51(3), pp.274-277.

Burchell, S., Clubb, C., Hopwood, A., Hughes, J., \& Nahapiet, J. (1980). "The Role of Accounting in Organization and Society", in: Accounting, Organization \& Society, Vol. 5(1), pp.5-27.

Burns, T., \& Stalker, G.M. (1961). The Management of Innovation, London: Tavistock. Camillus, J.C. (1975). "Evaluating the Benefits of Formal Planning System”, in: Long Range Planning, Vol. 11(3), pp. 33-40.

Chakravarthy, B.S. (1986). "Measuring Strategic Performance”, in: Strategic Management Journal, Vol. 7(5), pp.437-458.

Chalos, P., \& Poon, M. (2000). "Participation and Performance in Capital Budgeting Teams", in: Behavioral Research in Accounting, Vol. 12, pp. 199-229.

Chapman, C.S. (1997). "Reflections on A Contingent View of Accounting", in: Accounting, Organization \& Society, Vol. 22(2), pp. 189-205. 
Chapman, C.S. (1998). "Accountants in Organizational Networks", in: Accounting, Organization \& Society, Vol. 23(8), pp.737-766.

Chau, W.F. (1986). "Radical Development in Accounting Thought", in: Accounting Review, Vol. 61(4), pp.601-631.

Chenhall, R., \& Brownell, P. (1988). "The Effect of Participative Budgeting on Job Satisfaction and Performance: Role Ambiguity As an Intervening Variable", in: Accounting, Organizations \& Society, Vol. 13(3), pp. 225-234.

Chong, V.K., \& Bateman, D. (2000). "The Effect of Role Stress on Budgetary Participation and Job Satisfaction-performance linkage: A Test of Two Different Models.”, in: Advances in Accounting Behavioral Research, Vol. 3, pp. 91-118.

Chong, V.K., Chong, K.M. (2002). "Budget Goal Commitment and Informational Effects of Budget Participation on Performance: A Structural Equation Modeling Approach.", in: Behavioral Research in Accounting, Vol. 14, pp. 65-86.

Choo, C.W., \& Bontis, N. (2002). The Strategic Management of Intellectual Capital and Organizational Knowledge, Oxford University Press, Inc.

Chow, C.W., Cooper, J.C., \& Waller, W.S. (1988). "Participative Budgeting: Effects of a Truth-inducing Pay Scheme and Information Asymmetry on Slack and Performance.”, in: The Accounting Review, Vol. 63(1), pp. 111-122.

Chow, C.W., Kato, Y., \& Merchant, K.A. (1996). "The Use of Organizational Controls and Their Effects on Data Manipulation and Management Myopia: A Japan vs. U.S. Comparison", In: Accounting, Organizations and Society, Vol. 21(2/3), pp. 381-400.

Chow, C.W., Kato, Y., \& Shields, M.D. (1994). "National Culture and The Preference for management Controls: An Exploratory Study of the Firm-Labor Market Interface", in: Accounting, Organizations \& Society, Vol. 19(4/5), pp.381-400.

Chow, C.W., Shields, M.D., \& Wu, A. (1999). "The Importance of National Culture in the Design of and Preference for Management Controls for Multi-national Operations", In: Accounting, Organization \& Society, Vol. 24(5/6), pp. 441-461.

Christensen, J. (1982). "The Determination of Performance Standards and Participation", in: Journal of Accounting Research, Vol. 20(2), pp. 589-603.

Coase, R.H. (1937). "The Nature of the Firm”, in: Economica, Vol. 4(16), pp. 386-405.

Covaleski, M.A., \& Dirsmith, M.W. (1986). "The Budgetary Process of Power and Politics", in: Accounting, Organization \& Society, Vol. 11(3), pp. 193-214. 
Covaleski, M.A., Dirsmith, M.W., \& Jablonsky, S.F. (1985). “Traditional and Emergent Theories of Budgeting: An Empirical Analysis", in: Journal of Accounting and Public Policy, Vol. 4(4), pp. 277-300.

Cronbach, L.J. (1951). "Coefficient Alpha and the Internal Structure of Tests", In: Psychometrika, Vol. 16, pp. 297-334.

Dadzie, K.Q., \& Cho, Y. (1989). "Determinants of Minority Business Formation and Survival: An Empirical Assessment.”, in: Journal of Small Business Management, Vol. 27(3), pp. 56-61.

Douglas, B.R. (1994). "The Budgeting Process in A Multinational Firm", in: Multinational Business Review, Vol. 2(2), pp.59-63.

Drury, C. (2000). Management and Cost Accounting, London: International Thomson Business Press, $4^{\text {th }}$ Edition.

Dugdale, D. (1994). "Theory and Practice: The Views of CIMA and Students", in: Management Accounting (UK), Vol. 72(8), pp. 56-59.

Dunk, A.S. (1989). "Budget Emphasis, Budgetary Participation and Managerial Performance: A Note.”, in: Accounting, Organization \& Society, Vol. 14(4), pp.321324.

Dunk, A.S. (1994). "The Effect of Budget Emphasis and Information Asymmetry on the Relation between Budgetary Participation and Slack", in: Accounting Review, Vol. 68 (2), pp. 400-410.

Easterby-Smith, M., Thorpe, R., \& Lowe, A. (2002). Management Research: An Introduction, London: Sage Publications, $2^{\text {nd }}$ ed.

Elsenhardt, K.M. (1989). "Building Theories from Case Study Research", in: Academy of Management Review, Vol. 14(4), pp. 532-550.

Estrin, S., \& Rosevear, A. (1999). "Enterprise Performance and Ownership: The Case of Ukraine", in: European Economic Review, Vol. 43(4/6), pp. 1125-1136.

Ezzamel, M., \& Hart, H. (1987). Advanced Management Accounting: An Organizational Emphasis, London: Cassell.

Ezzamel, M.K. (1990). “The Impact of Environmental Uncertainty, Managerial Autonomy and Size on Budget Characteristics", in: Management Accounting Research, Vol. 1(1), pp. 181-197.

Farragher, E.J., Kleiman, R.T., Robert, T., \& Sahu, A.P. (2001). "The Association between the Use of Sophisticated Capital Budgeting Practices and Corporate Performance", in: The Engineering Economist; Vol. 46(4), pp. 300-311. 
Firth, M. (1996). "The Diffusion of Managerial Accounting Procedures in the People's Republic of China and the Influence of Foreign Partnered Joint Ventures", in: Accounting, Organizations \& Society, Vol. 21(7), pp. 629-654.

Fisher, C. (1996). "The Impact of Perceived Environmental Uncertainty and Individual Differentces on Management Requirements: A Research Note.”, in: Accounting, Organizations \& Society, Vol. 21(4), pp. 361-369.

Flamholtz, E.G. (1983). "Accounting, Budgeting and Control Systems in Their Organizational Context: Theoretical and Empirical Perspectives", in: Accounting, Organizations \& Society, Vol. 8(2/3), pp.153-169.

Foss, N.J. (2000). The Theory of the Firm: Critical Perspectives on Business and Management, London: Routledge.

Friedlob, G.T., \& Plewa, F.J (1996). Understanding Return on Investment, New York: Wiley.

Fucot, V., \& Shearon, W. (1991). "Budgetary Participation, Locus of Control, and Mexican Managerial Performance and Job Satisfaction", in: Accounting Review, Vol. 66(1), pp.80-99.

Garrison, R.H., Noreen, E.W., \& Seal, W. (2003). Management Accounting, New York: McGraw-Hill Education, European Edition.

Gitman, L.J. (2006). Principles of Managerial Finance, Reading Addison Wesley, $9^{\text {th }}$ ed.

Glynn, et al. (2008). Accounting for Managers, Cengage Learning EMEA, $4^{\text {th }}$ ed.

Gordon, L.A., Larcker, D.F., \& Tuggle, F.D. (1978). "Strategic Decision Processes and the Design of Accounting Information System: Conceptual Linkage", In: Accounting, Organization \& Society, Vol. 3(3/4), pp. 203-313.

Grigg, N.S. (1988). Infrastructure Engineering and Management, New York: Wiley.

Gul, F.A. (1991). "The Effects of Management Accounting Systems and Environmental Uncertainty on Small Business Managers' Performance", In: Accounting and Business Research, Vol. 22(85), pp. 57-61.

Gul, F.A., Tusi, Judy S.L., Fong, Steve C.C., \& Kwok, Helen Y.L. (1995). "Decentralization as a Moderating Factor in the Budgetary Participationperformance Relationship: Some Hong Kong Evidence.”, in: Accounting and Business Research, Vol. 25(98), pp.107-113. 
Gunasekaran, L.F., \& Kobu, B. (2000). "Improving Operations Performance in a Small Company: A Case Study", In: International Journal of Operations \& Production Management, Vol. 20(3), pp. 316-335.

Hansen, S.C., Otley, D.T., \& Van der Stede, W.A. (2003). "Practice Developments in Budgeting: An Overview and Research Perspective", in: Journal of Management Accounting Research, Vol. 15, pp.95-116.

Harris, M., \& Raviv, A. (1996). "The Capital Budgeting Process: Incentives and Information", in: Journal of Finance, Vol. 51(4), pp.1139-1174.

Harrison, G.L. (1992). "The Cross-Culture Generalizability of the Relation between Participation, Budget Emphasis and Job-related Attitudes", in: Accounting, Organization \& Society, Vol. 17(1), pp.1-15.

Harrison, G.L., McKinnon, J.L., Panchapakesan, S., \& Leung, M. (1994). "The Influence of Culture on Organizational Design and Planning and Control in Australia and the United States Compared with Singapore and Hong Kong", in: Journal of International Financial Management \& Accounting, Vol. 5(3), pp.242261.

Hayes, D. (1977). “The Contingency Theory of Managerial Accounting", in: The Accounting Review, Vol. 52(1), pp. 22-39.

Heneman, H. (1974). "Comparisons of Self and Superior Rating of Managerial Performance", In: Journal of Applied Psychology, Vol. 59(5), pp. 638-642.

Hillary, R. (1999). Evaluation of Study Reports on the Barriers, Opportunities and Drivers for Small and Medium Sized Enterprises in the Adoption of Environmental Management System, UK: DTI.

Hillidge, J. (1990). "Planning for Growth in a Small Company", in: Long Range Planning, Vol. 23(3), pp.76-81.

Hirsch Jr., M.L. (1994). Advanced Management Accounting, Ohio: South-Western Publishing Co., College Division, $2^{\text {nd }}$ ed.

Hirst, M.K. (1981). "Accounting Information and the Evaluation of Subordinate Performance: Situational Approach", in: Accounting Review, Vol. 26(4), pp. 771784.

Hirst, M.K. (1987). "The Effects of Setting Budget Goals and Task Uncertainty on Performance: A Theoretical Analysis.”, In: The Accounting Review, Vol. 62(4), pp. 774-784. 
Hirst, M.K., \& Lowy, S.M. (1990). “The Linear Additive and Interactive Effect of Budget Goal Difficulty and Feedback on Performance", In: Accounting, Organizations \& Society, Vol. 15(5), pp. 425-436.

Hirst, M.K., \& Yetton, P.W. (1999). "The Effects of Budget Goals and Task Independence on the Level of and Variance in Performance: a Research Note", in: Accounting, Organization \& Society, Vol. 24, pp. 205-216.

Hofer, C.W., \& Sandberg, W.R. (1987). "Improving New Venture Performance: Some Guidelines for Success.”, in: American Journal of Small Business, Vol. 12(1), pp. $11-25$.

Hopwood, A.G. (1976). Accounting and Human Behavior, Englewood Cliffs, NJ; Prentice Hall.

Hopwood, A.G. (1972). "An Empirical Study of the Role of Accounting Data in Performance Evaluation", in: Journal of Accounting Research, Vol. 10(3), pp. 156182.

Hoque, Z. (2004). "A Contingency Model of the Association between Strategy, Environmental Uncertainty and Performance Measurement: Impact on Organizational Performance.", in: International Business Review, Vol. 13(4), pp. 485-502.

Hoque, Z., \& Hopper, T. (1994). "Rationality, Accounting and Politics: A Case Study of Management Control in A Bangladeshi Jute Mills.”, in: Management Accounting Research, Vol. 5(1), pp.5-30.

Horne, J.C., \& Wachowicz, Jr., J.M. (1998). Fundamentals of Financial Management, Prentice-Hall International, Inc. $10^{\text {th }}$ ed.

Horngren, C.T. (1977). Cost Accounting: A Managerial Emphasis, Englewood Cliffs, NJ: Prentice-Hall.

Horngren, C.T. (2002). Management and Cost Accounting, Harlow: Financial Times, Prentice Hall, $2^{\text {nd }}$ ed.

Horngren, C.T. (2006). Introduction to Financial Accounting, Upper Saddle River, NJ: Pearson/Prentice Hall, $9^{\text {th }}$ ed.

Horngren, C.T. (1996). Introduction to Financial Accounting, Prentice-Hall International, $6^{\text {th }}$ ed.

Imoisili, O.A. (1989). "The Role of Budget Data in the Evaluation of Managerial Performance Evaluation", in: Accounting, Organization \& Society, Vol. 14(4), pp. 325-335. 
Ivancevich, J.M. (1976). "Effect of Goal Setting on Performance and Job Satisfaction", in: Journal of Applied Psychology, Vol. 61(5), pp. 605-612.

Jackson, S.E., \& Schuler, R.S. (1985). “A Meta-analysis and Conceptual Critique of Research on Role Ambiguity and Role Conflict in Work Settings", in: Organizational Behavior and Human Decision Processes, Vol. 36(11), pp. 16-78.

Jefferson, G.H., Rawski, T.G., Wang, L., \& Zheng, Y. (2000). “Ownership, Productivity Change, and Financial Performance in Chinese Industry", In: The Journal of Comparative Economics, Vol. 28(4), pp. 786-813.

Joshi, P.L., Al-Mudhaki, J., \& Bremser, W.G. (2003). “Corporate Budget Planning, Control and Performance Evaluation in Bahrain”, in: Managerial Auditing Journal, Vol. 18(9), pp. 737-750.

Kaplan, R.S. (1983). "Measuring Manufacturing Performance: A New Challenge for Managerial Accounting Research", in: The Accounting Review, Vol. 58(4), pp. 686705.

Kaplan, R.S., \& Atkinson, A.A. (1998). Advanced Management Accounting, PrenticeHall, USA, $3^{\text {rd }}$ ed.

Kaplan, R.S., \& Norton, D.P. (1996). The Balanced Scorecard: Translating Strategy into Action, Harvard Business School Press, Boston, MA.

Kaplan, R.S., \& Norton, D.P. (2001). "Transforming the balanced scorecard from performance measurement to strategic management: part 1.,, in: Accounting Horizon, Vol. 15 (1), pp. 87-104.

Kapler, J.K. (2007). "The Theory of the Firm, the Theory of Competition and the Transnational Corporation", In: Competition \& Change, Vol. 11(4), pp. 287-306.

Kastens, M.L. (1976). Long-range Planning for Your Business: An Operating Manual, AMACOM, New York, NY.

Kaye, G.R. (1994). "Financial Planning Models Construction and Use”, in: San Diego, California: Academic Press INC.

Keats, B.W., \& Bracker, J.S. (1988). "Toward a Theory of Small Firm Performance: A Conceptual Model.”, in: American Journal of Small Business, Vol. 12(4), pp.41-58.

Kenis, I. (1979). "Effect of Budgetary Goal Characteristics on Managerial Attitudes and Performance", in: Accounting Review, Vol. 54 (4), pp. 707-721.

Kidder, L., \& Judd, C.M. (1986). Research Methods in Social Relations, New York: Holt, Rinehart \& Winston, $5^{\text {th }}$ ed. 
Kirby, A., Reichelstein, S., Sen, P.K., \& Paik, T-Y (1991). "Participation, Slack, and Budget-Based Performance Evaluation”, In: Journal of Accounting Research, Vol. 29(1), pp. 109-128.

Knight, R.A. (1993). "Planning: The Key to Family-Owned Business Survival", in: Management Accounting, Vol. 74(8), pp.33-34.

Kono, T. (1990). "Corporate Culture and Long-range Planning", In: Long Range Planning, Vol. 23(4), pp.9-19.

Koontz, H., \& Weihrich, H. (1998). Management, McGraw-Hill, New York.

Kren, L. (1992). "Budgetary Participation and Managerial Performance: The Impact of Information and Environmental Volatility”, in: Accounting Review, Vol. 67 (3), pp. 511-526.

Kren, L. (2003). "Effects of Uncertainty, Participation, and Control System Monitoring on the Propensity to Create Budget Slack and Actual Budget Slack Created", In: Advances in Management Accounting, Vol. 11, pp. 143-167.

Kren, L. (2007). "The Intervening Effect of Information Asymmetry on Budget Participation and Segment Slack", In: Advances in Management Accounting, Vol. 68(11), pp.141-157.

Lau, C.M., \& Sholihin, M. (2005). "Financial and Nonfinancial Performance Measurement: How do They Effect Job Satisfaction?", in: The British Accounting Review, Vol. 37(4), pp. 389-413.

Lau, C.M., Low, L.C., \& Eggleton, Lan R.C. (1995). “The Impact of Reliance on Accounting Performance Measures on Job-related Tension and Managerial Performance: Additional Evidence.”, in: Accounting, Organization \& Society, Vol. 20(5), pp.359-381.

Lauterbach, B., \& Vaninsky, A. (1999). "Ownership Structure and Firm Performance”, in: Journal of Management of Governance, Vol. 3 (2), pp. 189-201.

Lee, T.W., \& Oaks, T. (1999). Using Qualitative Methods in Organizational Research, London: Sage Publications.

Li, X., \& Ren, L. (2004). "Family Intention and Governance Behavior of PrivateOwned Firms in China”, In: Journal of Sun Yat-sen University: Social Science Edition, Vol. 6(44), pp.63-88.

Lin, Hanchuan, (2003). "Problems Faced by SMEs in their Development", In: China Social Science, Vol. 2, pp.23-30. 
Lin, J.Y., Cai, F., \& Li, Z. (1996). “The Lesson of China's Transition to A Market Economy”, In: Cato Journal, Vol. 16(2), pp. 201-231.

Lind, E.A., \& Tyler, T.R. (1988). The Social Psychology of Procedural Justice, Plenum Press, New York.

Little, H.T., Magner, N.R., \& Welker, R.B. (2002). "The Fairness of Formal Budgetary Procedures and Their Enactment", In: Group \& Organization Management, Vol. 27(2), pp. 209-225.

Locke, E.A., \& Schweiger, D.M. (1979). "Participation in Decision Making: One More Look.", in: Research in Organizational Behavior, Vol. 1, pp. 265-276.

Lumpkin, G.T., \& Dess, G.G. (1996). "Clarifying the Entrepreneurial Orientation Construct and Linking it to Performance", In: Academy of Management Review, Vol. 21(1), pp. 135-172.

Lynch, R.L., \& Cross, K.F. (1991). Measure Up, Blackwell Publishers, Cambridge, MA.

Lyne, S.R. (1988). "The Role of the Budget in Medium and Large UK Companies and the Relationship with Budget Pressure and Participation", in: Accounting and Business Research, Vol. 18(71), pp. 195-212.

Magner, N., Welker, R.B., \& Campbell, T.L. (1995). "The Interactive Effect of Budgetary Participation and Budget Favorability on Attitudes toward Budgetary Decision Makers: A Research Note.”, in: Accounting, Organizations \& Society, Vol. 20(7/8), pp. 611-618.

Mahoney, T., Jerdee, T., \& Carrol, S. (1963). Development of Managerial Performance: A Research Approach, South Western Publishing, Cincinnati.

McCarthy, B. (2003). “The Impact of the Entrepreneur's Personality on the StrategyFormation and Planning Process in SMEs", in: Irish Journal of Management, Vol. 24(1), pp.154-172.

McFarlin, D.B., \& Sweeney, P.D. (1992). "Distributive and Procedural Justice as Predictors of Satisfaction with Personal and Organizational Outcomes", in: Academy of Management Journal, Vol. 35 (3), pp. 626-637.

McKiernan, P., \& Morris, C. (1994). "Strategic Planning and Financial Performance in UK SMEs: Does Formality Matter?”, in: British Journal of Management, Vol. 5(2), pp.31-41.

McLaney, E.J., \& Atrill, P.F. (1999). Accounting: An Introduction, London: Prentice Hall. 
McLaney, E.J., \& Atrill, P.F. (2002). Accounting and Introduction, UK: FT Prentice Hall. $2^{\text {nd }}$ ed.

Mclaughilin, H.J. (1992). The Entrepreneur's Guide to Building a Better Business Plan: A Step-by-step Approach, New York: John Wiley \& Sons.

McReynolds, C.J., Koch, L.C., \& Rumrill, Jr. P.D. (2001). "Qualitative Research Strategies in Rehabilitation", in: Work, Vol. 16(1), pp. 57-65.

McWatters, C.S. (2008). Management Accounting: Analysis and Interpretation. Harlow: Financial Times/Prentice Hall.

Meigs, W.B., \& Meigs, R.F. (1996). Accounting: the Basis for Business Decision, New York: McGraw-Hill.

Merchant, K.A. (1981). “The Design of the Corporate Budgeting System: Influences on Managerial Behavior and Performance", in: Accounting Review, Vol. 56(4), pp. 813-829.

Merchant, K.A. (1985). “Organizational Controls and Discretionary Program Decision Making: A Field Study", in: Accounting, Organizations \& Society, Vol. 10(1), pp.67-85.

Merchant, K.A., \& Manzoni, J.F. (1989). "The Achievability of Budget Targets in Profit Centers: A Field Study.”, in: Accounting Review, Vol. 64(3), pp.539-558.

Mia, L. (1989). "The Impact of Participation in Budgeting and Job Difficulty on Managerial Performance and Work Motivation: A Research Note.”, in: Accounting, Organization \& Society, Vol. 14(4), pp. 347-357.

Milani, K. (1975). “The Relationship of Participation in Budget-setting to Industrial Supervisor Performance and Attitudes: A Field Study.”, in: Accounting Review, Vol. 50(2), pp.274-284.

Millward, R. \& Parker, D. (1983). Public and Private Enterprises: Comparative Behaviour and Relative Efficiency, New York: Longman.

Muksherjee, T.K., \& Henderson, G.V. (1987). "The Capital Budgeting Process: Theory and Practice", in: Interfaces, Vol. 17(2), pp.78-90.

Murphy, G.B., Trailer, J.W., \& Hill, R.C. (1996). "Measuring Performance in Entrepreneurship Research", in: Journal of Business Research, Vol. 36(1), pp.15-23. Murry, D. (1990). “The Performance Effects of Participative Budgeting: An Integration of Intervening and Moderating Variables.”, in: Behavioral Research in Accounting, Vol. 2(2), pp. 104-123. 
Nahapiet, J. (1980). "The Roles of Accounting in Organizations and Society" , in: Accounting, Organization \& Society, Vol. 5(1), pp. 5-27.

Nouri, H., \& Parker, R.J. (1998). “The Relationship Between Budget Participation and Job Performance: The Roles of Budget Adequacy and Organizational Commitment.”, in: Accounting, Organization \& Society, Vol. 23(5), pp. 467-483.

O'Connor, N.G. (1995). “The Influence of Organizational Culture on the Usefulness of Budget Participation by Singaporean-Chinese Managers", in: Accounting, Organization \& Society, Vol. 20(5), pp. 383-403.

O'Connor, N.G., Chow, C.W., \& Wu, A. (2004). “The Adoption of 'Western' Management Accounting/Controls in China's State-owned Enterprises during Economic Transition", in: Accounting, Organization \& Society, Vol. 29(3/4), pp. 349-275.

Onsi, M. (1973). "Factor Analysis of Behavioral Variables Affecting Budgetary Slack", in: Accounting Review, Vol. 48(3), pp. 535-548.

Otley, D.T. (1980). "The Contingency Theory of Management Accounting: Achievement and Prognosis.", in: Accounting, Organization \& Society, Vol. 5(4), pp. 413-428.

Otley, D.T. (1999). "Performance management: a framework for management control systems research", in: Management Accounting Research, Vol. 10(4), pp. 363-382.

Otley, D.T. (2003). "Management control and performance management: whence and whither?" in: British Accounting Review, Vol. 35(4), pp. 309-326.

Otley, D.T., \& Berry, A.J. (1998). "Case Study Research in Management Accounting and Control", in: Accounting Education, Vol. 7(4), pp. S105-S127.

Otley, D.T., \& Fakiolas, A. (2000). "Reliance on Accounting Performance measure: Dead End or New Beginning?", in: Accounting, Organization \& Society, Vol. 25(4/5), pp.497-510.

Otley, D.T., \& Pollanen, R.M. (2000). "Budgetary Criteria in Performance Evaluation: A Critical Appraisal Using New Evidence.”, in: Accounting, Organization \& Society, Vol. 25(4/5), pp.483-496.

Ouibrahim, N., \& Scapens, R.W. (1989). "Accounting for Control of a Socialist Enterprise: A Study of Algeria.”, in: Accounting, Auditing \& Accountability Journal, Vol. 2(2), pp. 7-28.

Parker, R.J., \& Kyi, L. (2006). "Vertical Information Sharing in the Budgeting Process", in: Accounting, Organization \& Society, Vol. 31(1), pp. 27-45. 
Peel, M.J., \& Bridge, J. (1998). "How Planning and Capital Budgeting Improve SME Performance", in: Long Range Planning, Vol. 31(6), pp. 848-856.

Penno, M. (1984). “Asymmetry of Pre-Decision Information and Managerial Accounting", In: Journal of Accounting Research, Vol. 22(1), pp. 177-191.

Penno, M. (1990). “Accounting Systems, Participation in Budgeting and Performance Evaluation”, In: The Accounting Review, Vol. 65(2), pp. 303-314.

Persson, H. (2004). "The Survival and Growth of New Establishments in Sweden", In: Small Business Economics, Vol. 23(5), pp. 423-440.

Pike, R.H. (1982). Capital Budgeting in the 1980s, Institute of Certified Management Accountants, London.

Poon, M., Pike, R., \& Tjosvold, D. (2001). "Budgetary Participation, Goal Interdependence and Controversy: A Study of a Chinese Public Utility.", in: Management Accounting Research, Vol. 12(1), pp. 101-118.

Reid, G.C., \& Smith, J.A. (2000). "The Impact of Contingencies on Management Accounting System Development", in: Management Accounting Research, Vol. 11(4), pp. 427-450.

Robinson, R.B., \& Pearce, J.A. (1983). “The Impact of Formalized Strategic Planning on Financial Performance in Small Organizations", in: Strategic Management Journal, Vol. 4(3), pp. 197-207.

Robson, K. (1991). "On the Arenas of Accounting Change: The Process of Translation", in: Accounting, Organization \& Society, Vol. 16(5/6), pp. 547-570.

Ross, A. (1994). "Trust as a Moderator of the Effect of Performance Evaluation Style on Job-Related Tension: A Research Note.", in: Accounting, Organizations \& Society, Vol. 19(7), pp. 629-635.

Rue, L.W. (1973). "Theoretical and Operational Implications of Long-range Planning on Selected Measures of Financial Performance in U.S. Industry", in: Ph.D Dissertation, Georgia State University.

Rue, L.W., \& Ibrahim, N.A. (1998). “The Relationship between Planning Sophistication and Performance in Small Business", in: Journal of Small Business Management, Vol. 36(4), pp.24-32.

Ryan, B. , Scapens, R.W., \& Theobald, M. (2002). Research Method and Methodology in Finance and Accounting, Thomson, London, UK, $2^{\text {nd }}$ ed.

Saunders, M., Lewis, P. \& Thornhill, A. (2003). Research Methods for Business Students, Prentice Hall Pearson Education, $3^{\text {rd }}$ ed. 
Schiff, M., \& Lewin, A.Y. (1970). "The Impact of People on Budgets", in: Accounting Review, Vol. 45(2), pp. 259-268.

Shields, J.F., \& Shields, M.D. (1998). “Antecedents of Participative Budgeting”, in: Accounting, Organization \& Society, Vol. 23(1), pp. 49-76.

Shields, M.D., \& Young, S.M. (1993). "Antecedents and Consequences of Participative Budgeting: Evidence on the Effects of Asymmetrical Information", in: Journal of Management Accounting Research, Vol. 5, pp.265-280.

Steers, R.M. (1976). "Factors Affecting Job Attitude in a Goal-setting Environment", in: Academy of Management Journal, Vol. 19 (1), pp. 6-16.

Steiner, G.A. (1962). "Making Long-range Planning Pay Off", in: California Management Review, Vol. 4, pp. 108-124.

Stoelhorst, J.W., \& Van Raaij, E.M. (2002). “On Explaining Performance differentials: Marketing and the Managerial Theory of the Firm", in: Journal of Business Research, Vol. 57(5), pp. 462-477.

Storey, D.J. (1994). Understanding the Small Business Sector, Routledge, London.

Subramaniam, N., \& Ashkanasy, N.M. (2001). "The Effect of Organizational Culture Perceptions on the Relationship between Budgetary Participation and Managerial Job-Related Outcomes”, in: Australian Journal of Management, Vol. 26(1), pp.3554.

Swieringa, R.J., \& Moncur, R.H. (1975). Some Effects of Participative Budgeting on Managerial Behavior, National Association of Accountants.

Thompson, J.D. (1967). Organization in Action. New York: McGraw-Hill.

Thornton, J.D. (1968). "The Relationship between Supervisory and Self-appraisals of Executive Performance”, in: Personnel Psychology, Vol. 21(4), pp. 441-456.

Tijdink, J.L.J.L. (1998). Issues of Personal Problematic Debt, Enschede: Twente University Press.

Tolentino, A. (2000). "Guidelines for the Analysis of Policies and Programmers for Small and Medium Enterprise Development", In: Enterprise and Management Development Working Paper-EMD/13/E.

Tsui, J.L. (2001). "The Impact of Culture on the Relationship between Budgetary Participation, Management Accounting Systems, and Managerial Performance: An Analysis of Chinese and Western Managers", In: The International Journal of Accounting, Vol. 36(2), pp. 125-146. 
Tomkins, C., \& Groves, R. (1983). "The Everyday Accountant and Researching His Reality", in: Accounting, Organization \& Society, Vol. 8(4), pp.361-374.

Van der Stede, W.A. (2000). "The Relationship between Two Consequences of Budgetary Control: Budgetary Slack Creation and Managerial Short-term Orientation", in: Accounting, Organizations \& Society, Vol. 25 (6), pp. 609-622.

Van Horne, J.C., \& Wachowicz Jr., J.M. (1998). Fundamentals of Financial Management, Mexico: Prentice-Hall International.

Van Veen-Dirks, P., \& Wijn, M. (2002). "Strategic control: meshing critical success factors with the balanced scorecard", in: Long Range Planning, Vol. 35(4), pp.402427.

Venkatraman, N., \& Ramanujam, V. (1986). "Measurement of Business Performance in Strategy Research: A Comparison of Approaches.”, In: Academy of Management Review, Vol. 11(4), pp. 801-814.

Verbeeten, Frank H.M. (2006). "Do Organizations Adopt Sophisticated Capital Budgeting Practices to Deal with Uncertainty in the Investment Decision? A Research Note”, in: Management Accounting Research, Vol. 17(1), pp.106-120.

Wang, H. (2008). "China's Automobile Industry Embracing the Energy and Environment Challenge in the $21^{\text {st }}$ Century”, $16^{\text {th }}$ GERPISA Internal Colloquium.

Wang, Y.Z. (2004). "Financing Difficulties and Structural Characteristics of SMEs in China", in: China \&World Economy, Vol. 12(2), pp.34-49.

Wei, F., \& Zhang, S. (2005). "Ownership Structure and Firm Value in China's Privatized Firms: 1991-2001”, In: Journal of Financial and Quantitative Analysis, Vol. 40(1), pp. 87-108.

Weingart, L.R. (1992). "Impact of Group Goals, Task Component Complexity, Efforts and Planning on Group Performance", in: Journal of Applied Psychology, Vol. 27(3), pp. 416-425.

Wijewardena, H., \& De Zoysa, A. (2001). "The Impact of Financial Planning and Control on Performance of SMEs in Australia”, in: Journal of Enterprising Culture, Vol. 9(4), pp. 353-365.

Wijewardena, H., De Zoysa, A., Fonseka, T., \& Perera, B. (2004). "The Impact of Planning and Control Sophistication on Performance of Small and Medium-sized Enterprises: Evidence from Sri Lanka", in: Journal of Small Business Management, Vol. 42(2), pp. 209-217. 
Wildavsky, A. (1975). Budgeting: A Competitive Theory of Budget Processes. Boston: Little Brown.

Woodward, J. (1965). Industrial Organization: Theory and Practice. London: Oxford University Press.

Wooldridge, S.C., Garvin, M.J., \& Miller, J.B. (2001). "Effects of Accounting and Budgeting on Capital Allocation for Infrastructure Projects", in: Journal of Management in Engineering, Vol. 17(2), pp. 86-94.

Xiang, H.C. (1999). "Establishing Credit Guarantee System for SMEs Loan”, In: China Township Enterprises, Vol. 7.

Xu, L. C. (2000). "Control, Incentives and Compensation: The Impact of Reform on Chinese State-owned Enterprises", in: Economics of Transition, Vol. 8(1), pp. 151173.

Young, S.M. (1985). "Participative Budgeting: The Effects of Risk Aversion and Asymmetric Information on Budgetary Slack", in: Journal of Accounting Research, Vol. 23(2), pp. 829-842.

Yuen, Desmond C.Y. (2004). "Goal Characteristics, Communication and Reward Systems, and Managerial Propensity to Create Budgetary Slack", in: Managerial Auditing Journal, Vol. 19(4), pp. 517-532. 
Appendix I:

\section{Correlation Matrix}

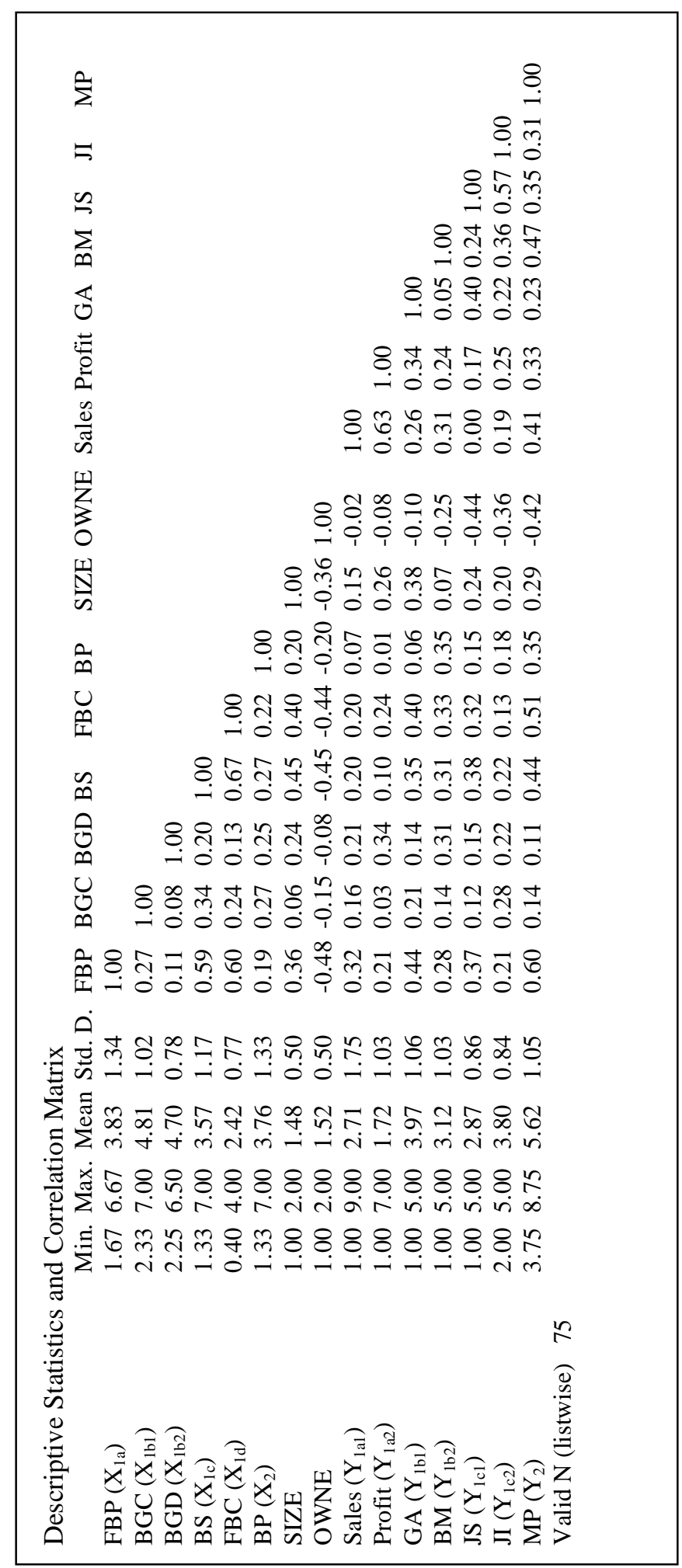




\section{Appendix II:}

\section{Sample Questionnaire}

This research aims to investigate the effects of formal budgeting process, budgetary participation, firm size, and ownership on the performance of small and medium enterprise in manufacturing sector in China. The following questionnaire consists of five parts, which asks your perceptions on the budgeting process and performance in your company. Please answer all the questions following the instructions given. Completion of the questionnaire should not take more than 10 minutes of your time. All responses will be treated in the strictest confidence and only summarized results will be published. Your time and cooperation is very much appreciated.

Thank you!

Return Address and Information:

Please return the filled out questionnaire to the address mentioned below. If you have any questions regarding this questionnaire, please contact the researcher at the following address:

In the Netherlands

In China

YangQi

YangQi

Financial and Accounting Department,

43\# 502

School of Management and Governance, Yue Yang, HuNan Province

University of Twente, P.O. Box 217

7500 AE Enschede

414007

The Netherlands

P.R. China

E-mail: q.yang@utwente.nl

E-mail: qiy416@hotmail.com 
Part A: General Information

i. The name of your company:

ii. Location of your company: Province City

iii. Your position in your company:

iv. The year of your enterprise starting its operations:

v. The annual sales revenue of your enterprise:

$\square$ Below 30 million RMB

$\square 30$ million to 0.3 billion RMB

vi. The legal status of your company:

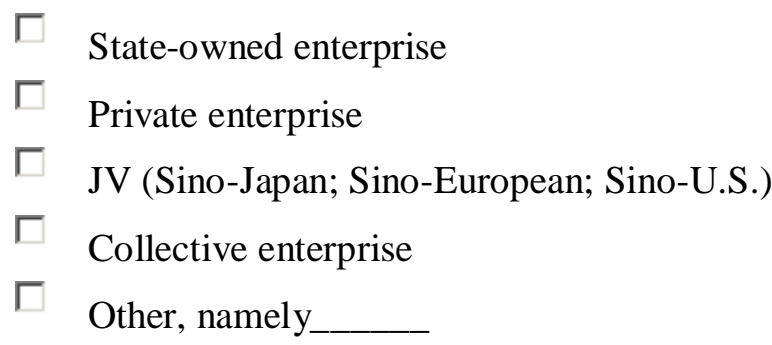

Part B: Performance

i. Financial Performance

The following section of the questionnaire seeks some information relating to your firm's performance in the recent past year. If you have no definite figures we would appreciate approximate figures.

Please indicate the intervals which best depict your enterprise's performance by circling an appropriate number for questions (a) and (b).

(a) Please indicate the growth in sales revenue of your company over the past 3 years:

$\begin{array}{llll}\text { Below } 10 \% & 1 & 51-60 \% & 6 \\ 11-20 \% & 2 & 61-70 \% & 7 \\ 21-30 \% & 3 & 71-80 \% & 8 \\ 31-40 \% & 4 & 81-90 \% & 9 \\ 41-50 \% & 5 & \text { Above } 90 \% & 10\end{array}$


(b) The growth of profit in your company over the last 3 years is:

$\begin{array}{llll}\text { Below 10\% } & 1 & 51-60 \% & 6 \\ 11-20 \% & 2 & 61-70 \% & 7 \\ 21-30 \% & 3 & 71-80 \% & 8 \\ 31-40 \% & 4 & 81-90 \% & 9 \\ 41-50 \% & 5 & \text { Above } 90 \% & 10\end{array}$

\section{ii. Managerial Performance}

Effective managerial performance may be regarded as depending on competence in the areas of managerial activity listed below (a-h). Please respond by placing a number from 1 (very low) to 9 (very high) in the appropriate space to rate your own recent performance in each area. The following scale should be used for reference:

Performance: Below average

Average

$\begin{array}{lllllllll}1 & 2 & 3 & 4 & 5 & 6 & 7 & 8 & 9\end{array}$

(Number from 1 to 9)

(a) Planning: Determining goals, policies and courses of action; work scheduling, budgeting, setting up procedures, programming.

(b) Investigating: Collecting and preparing information for records, reports and accounts, measuring output; inventorying, job analysis.

(c) Coordinating: Exchanging information with people in your organization in order to relate and adjust programs; advising and liaison with other personnel.

(d) Evaluating: Assessment and appraisal of proposals for reported or observed performance; employee appraisals, judging output records, judging financial reports; product inspection.

(e) Supervising: Directing, leading and developing your personnel; counseling, training and explaining work rules to subordinates; assigning work and handling complaints.

(f) Staffing: Maintaining the work force of your organization; recruiting, interviewing and selecting new employees; placing, promoting and transferring employees.

(g) Negotiating: Purchasing, selling or contracting for goods or services, contacting suppliers, dealing with sales representatives. 
(h) Representing: Attending conventions, consultation with other firms, business club meetings, public speeches, community drives; advancing the general interests of your organization.

iii. Budgetary Performance

a) How often do you meet the budget goals of your company (have favorable variances)?

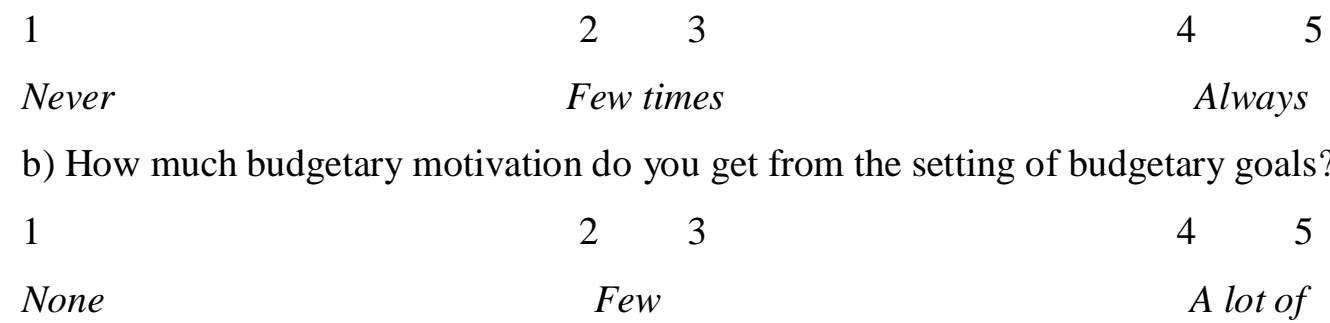

iv. Other Performance

Besides financial performance, managerial and budgetary performance, performances such as change of market share, provide more information and reveal overall performance of a company. Please ticket the proper options (yes or no) you think in the following items.

a) Are you satisfied with your job in your company?

\begin{tabular}{|c|c|c|}
\hline 1 & 3 & 4 \\
\hline $\mathrm{No}$ & Satisfied & Very Satisfied \\
\hline
\end{tabular}

b) How do you think of your job involvement in your organization?

$\begin{array}{lllcc}1 & 2 & 3 & 4 & 5 \\ \text { Low Involvement } & \text { Medium Involvement } & \text { High Involvement }\end{array}$

Part C: The Formal Budgeting Process

The formal process of budgeting in small and medium enterprise is measured from four aspects, i.e. the formal budgeting planning, the clarity and difficulty of budget goals, budgeting sophistication, and the formal budgetary control. Please respond the following questions by cycling/ticking the relevant number on seven-point scale, which you think best reflecting the budgeting process of your enterprise. (Note: if no budget use in your firms, please stop at the third question) 
i. The formal budgeting planning

The formalization of budgeting planning refers to the extent of detailed budget use with respect to different operation areas. Please firstly cycle the frequency and the extension of budget use in your company and then tick the exact operation areas that budgets are adopted.

a) -How often in a year does your organization use a budget to qualify the firm's plan for a future period?

1

Never

$\begin{array}{lll}2 & 3 & 4\end{array}$

Few times
$5 \quad 6 \quad 7$

Quite often

b) -To what extent do you think budgets are prepared to qualify different areas of operation in your organization

$\begin{array}{lrrrrrr}1 & 2 & 3 & 4 & 5 & 6 & 7 \\ \text { Not prepare } & & \text { Small extent } & \text { Great extent }\end{array}$

c) -The operation areas that budgets cover are: (please ticket at the front of corresponding items)

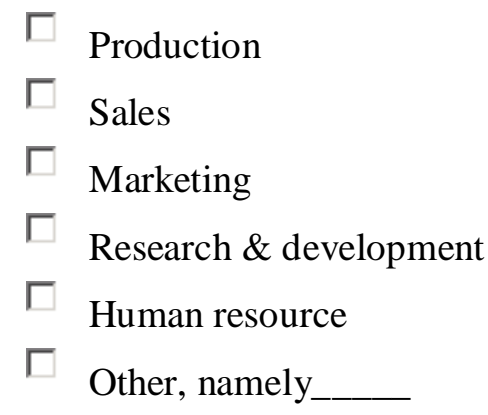

ii. The clarity and difficulty of budget goals

Goal clarity refers to the extent to which budget goals are stated specifically and clearly, and are understood by the unit managers responsible for meeting them. On the other hand, goals can vary from very loose and easily attainable goals to very tight and unattainable goals. Please cycle (or ticket) the proper number (or option), which you think best indicating the level of clarity and difficulty of budget goals of your company.

a) Budget goal clarity

\section{Do not agree at all}

Very agree

1) Budget goals of my company are

$\begin{array}{lllllll}1 & 2 & 3 & 4 & 5 & 6 & 7\end{array}$

specific and clear. I know exactly what

the budget goals are. 
2) I think the budget goals of my company $\quad \begin{array}{lllllllll}1 & 2 & 3 & 4 & 5 & 6 & 7\end{array}$ are ambiguous and unclear. I do not know exactly what the budget goals are.

3) I understand fully which of the budget goals $\begin{array}{llllllllll}1 & 2 & 3 & 4 & 5 & 6 & 7\end{array}$ of my company are more important than others.

I have a clear sense of priorities on these goals.

b) Budget goal difficulty

Do not agree at all Very agree

1) I do not have too much difficulty $\begin{array}{lllllll}1 & 2 & 3 & 4 & 5 & 6 & 7\end{array}$ in reaching my budget goals. They appear to be fairly easy.

$\begin{array}{llllllllll}\text { 2) My budget goals are quite difficult } & 1 & 2 & 3 & 4 & 5 & 6 & 7\end{array}$ to attain.

3) My budget goals require a great deal $\quad \begin{array}{llllllllll} & 1 & 2 & 3 & 4 & 5 & 6 & 7\end{array}$ of effort from me to achieve them.

4) It takes a high degree of skill and know $\quad \begin{array}{llllllllll}1 & 2 & 3 & 4 & 5 & 6 & 7\end{array}$ how on my part to attain fully my budget goals.

5) In general, how would you characterize the budgetary goals of your unit? (Please tick at front of the proper options)

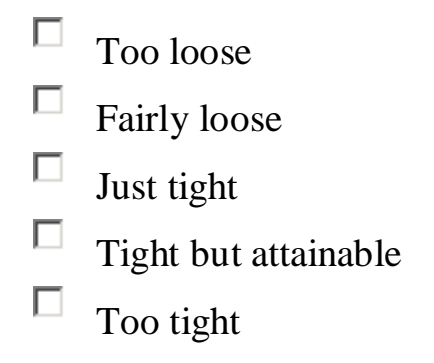

\section{iii. Budgetary Sophistication}

Greater budgeting sophistication includes greater use of computers, technical staff, and financial modeling. Please respond by cycling an appropriate number from the lowest (1) to the highest (7) in each item to rate the budgetary sophistication of your company. 
a) To what extent does software support the budget setting in your company?

$\begin{array}{llllllll}1 & 2 & 3 & 4 & 5 & 6 & 7\end{array}$

No computer support Few computer support availability of remote terminals

in an interactive mode

b) How many technical staffs are involved in the budget setting in your company?

$\begin{array}{llllllll}1 & 2 & 3 & 4 & 5 & 6 & 7\end{array}$

Not at all Few staff members Quite a lot

c) Financial modeling refers to the development and implementation of tools supporting firms, investors, intermediaries, governments and others in their financialeconomic decision making, including the validation of the premises behind these tools and the measurement of the affectivity of the use of these tools. For your company, to what extent is financial modeling used in the process of budget setting?

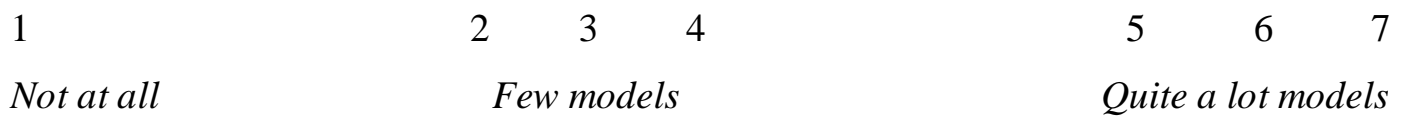

iv. The extent of formal budgeting control

a) -How often do you think your organization calculate the difference between actual performance and budgeted performance?

$\begin{array}{llllllll}1 & 2 & 3 & 4 & 5 & 6 & 7\end{array}$

Never Few times Quite often

b) -To what extent do the budget variances (calculating difference between actual performance and budgeted performance) cover with respect to different items of operation activities, revenues, and cost for taking appropriate corrective action?

$\begin{array}{llllllll}1 & 2 & 3 & 4 & 5 & 6 & 7\end{array}$

No calculation Small extent Great extent

c) -These operation areas that budget variances cover are: (please ticket at the front of corresponding items)

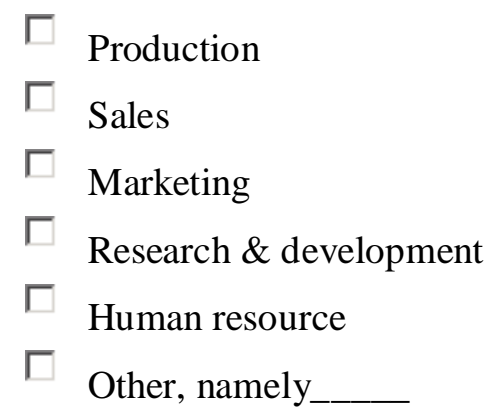


d) -Do appropriate corrective actions are taken in the case that budgeting negative variance occurs in your company?

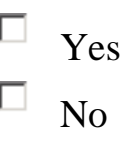

e) -Are rewards given in the case that positive budgetary variances occurs?

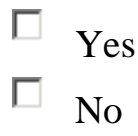

Part D: Budgetary Participation

Budgetary participation is related to the involvement of managers in the budgetary process and their influence on the setting of budgetary targets. Owner/senior manager of a company or functional managers from different department in a company will be asked some questions regarding the role that you play in the development of the budget for your group. Therefore,

I) For owner or senior managers of a company, please respond by circling a number from 1 to 7 on the scale for each of the following items.

a) Which category below best describes your activity when the budget is being set? I am involved in setting:

$\begin{array}{lrrrrrr}1 & 2 & 3 & 4 & 5 & 6 & 7 \\ \text { None of the budget } & & & & & \text { All of the budget }\end{array}$

b) How much influence do you feel you have on the final budget?

$\begin{array}{llllllc}1 & 2 & 3 & 4 & 5 & 6 & 7 \\ \text { None } & & & & & & \\ \text { Very high amount }\end{array}$

c) How do you view your contribution to the budget? My contribution is:

$\begin{array}{llllllc}1 & 2 & 3 & 4 & 5 & 6 & 7 \\ \text { Very unimportant } & & & & & & \text { Very important }\end{array}$

II) For different functional managers of a company, please respond by circling a number from 1 to 7 on the scale for each of the following items.

a) Which category below best describes your activity when the budget is being set? I am involved in setting:

$\begin{array}{lrrrrrr}1 & 2 & 3 & 4 & 5 & 6 & 7 \\ \text { None of the budget } & & & & & \text { All of the budget }\end{array}$


b) Which category below best describes the reasoning provided by your superior when budget revisions are made? The reasoning is:

$\begin{array}{lllllll}1 & 2 & 3 & 4 & 5 & 6 & 7\end{array}$

Very arbitrary Very sound

And/or illogical and/or logical

c) How often do you state your requests, opinions, and/or suggestions about the budget to your superior without being asked?

$\begin{array}{lllllll}1 & 2 & 3 & 4 & 5 & 6 & 7\end{array}$

Never Very frequently

d) How much influence do you feel you have on the final budget?

$\begin{array}{llllllc}1 & 2 & 3 & 4 & 5 & 6 & 7 \\ \text { None } & & & & & & \\ \text { Very high amount }\end{array}$

e) How do you view your contribution to the budget? My contribution is:

$\begin{array}{lllllll}1 & 2 & 3 & 4 & 5 & 6 & 7\end{array}$

Very unimportant

Very important

f) How often does your superior seek your requests, opinions, and/or suggestions when the budget is being set?

$\begin{array}{lllllcc}1 & 2 & 3 & 4 & 5 & 6 & 7 \\ \text { Never } & & & & & & \\ \text { Very frequently }\end{array}$

--The End

Thank you very much! 
各位尊敬的企业领导, 经理:

您好! 非常荣幸能有机会取得与贵公司的联系。首先, 请允许我简要介绍一 下该问卷调查的宗旨和目的。基于对企业财务管理环节之一的预算管理及其作用 和意义的探索, 荷兰屯特大学经济系于 2006 年批准并展开了对企业预算形式和 预算行为这一科研项目的研究。该项目将由博士生杨齐和屯特大学经济系教授, 博士生导师 Peter Boorsma 共同合作完成。该问卷旨在收集中国企业特别是中小型 企业预算形式, 预算流程, 和企业绩效的相关信息, 为进一步的理论分析提供数 据支持。该问卷不以单个企业的具体情况为调查重心，但是您所提供的问卷无疑 给该项目研究提供巨大帮助。

因此非常感谢贵公司和各位领导的参与合作！问卷所涉及的内容均为企业基 本的预算信息。我们以个人名义向您保证：我们会对问卷中反映的所有公司信息 （包括公司名称, 所在行业, 企业性质, 财务信息, 等等) 于以高度保密。并且 确保在任何刊物或杂志上, 也将不会有任何被怀疑为贵公司商业信息的情况发 生。

此问卷仅需用您 10 分钟时间。如果您对该研究项目有兴趣, 贵公司将会在 项目结束时收到相关的报告。我们相信该报告将有助于公司的财务管理和财务机 制的完善。

特此感谢!

博士生: 杨齐 博士生导师: Peter Boorsma 


\section{问 卷调查}

此问卷涉及了公司五个方面的基本信息, 请您根据问卷的提示和要求回答下面的 问题:

\section{第一部分：公司概况}

公司名称:

公司所在地: 省 市

您在公司的职位:

公司成立的年份:

公司的年销售收入:

$$
\begin{aligned}
& \text { } 3 \text { 千万以下 } \\
& \text { } 3 \text { 千万到3亿 }
\end{aligned}
$$

企业类型：(可选择多项)

$$
\begin{aligned}
& \square \text { 国有企业 } \\
& \square \text { 私有企业 } \\
& \square \text { 外商合资企业 (中美, 中日, 中欧等) } \\
& \square \text { 集体所有制企业 } \\
& \square \text { 股份制企业 } \\
& \square \text { 其他 }
\end{aligned}
$$

\section{第二部分：公司业绩}

以下问题将涉及到公司基本财务业绩及管理业绩的评估。请您根据相应要求作 答。

\section{1. 财务业绩}

请您在符合本公司财务业绩的数字上打圈。如果您不清楚具体数值, 请给出大致 财务数据。 
a) 贵公司在最近3年中, 销售收入的增长率是多少?

$\begin{array}{llll}10 \% \text { 以下 } & 1 & 51-60 \% & 6 \\ 11-20 \% & 2 & 61-70 \% & 7 \\ 21-30 \% & 3 & 71-80 \% & 8 \\ 31-40 \% & 4 & 81-90 \% & 9 \\ 41-50 \% & 5 & 90 \% \text { 以上 } & 10\end{array}$

b) 贵公司在最近3年中, 利润的增长率（税前）是多少?

$\begin{array}{llll}10 \% \text { 以下 } & 1 & 51-60 \% & 6 \\ 11-20 \% & 2 & 61-70 \% & 7 \\ 21-30 \% & 3 & 71-80 \% & 8 \\ 31-40 \% & 4 & 81-90 \% & 9 \\ 41-50 \% & 5 & 90 \% \text { 以上 } & 10\end{array}$

\section{2. 管理业绩}

管理绩效体现出公司管理者在管理活动中的业绩水平。以下列出公司管理活动的 八个方面 (从 $\mathrm{a}$ 到 $\mathrm{h}$ ), 请您分别对各项给出您较为客观的评分, 分值从 1 到 9 代 表:

管理绩效: 平均水平以下

平均水平

$\begin{array}{lll}4 & 5 & 6\end{array}$

平均水平以上

$\begin{array}{lll}7 & 8 & 9\end{array}$

a) 计划: 公司经营目标、发展战略、公司规章制度、行动方案的决策与执行。并 制定和确立工作计划、企业预算及作业流程。

b) 调查: 对企业相关信息的收集, 整理, 报告, 测量产出, 库存和工作分析。

c) 协调: 与公司职工间的信息交流以便对公司的相关项目进行调整, 广泛听取员 工的意见和建议。

d) 评估: 对企业发展方案, 公司财务业绩, 员工业绩, 产出进行分析和评估, 对生产 流程的监督和控制。

e) 指导: 对人事的引导和发展, 负责员工的培训, 解释公司的规章制度, 布置任务给 属下, 并处理员工的意见和建议。 
f) 人事: 包括员工的招聘, 选拔, 提升和岗位调动。

g) 合作: 购买, 销售或信誉销售商品和服务, 联系供货商和销售代表。

h) 代表: 参加会议, 同行间的相互咨询和碰商, 进行公众讲演等。

3. 预算绩效

a) 贵公司的实际绩效是否经常达到预期的预算目标?

$\begin{array}{lccc}1 & 2 & 3 & 4 \\ \text { 从未实现过 } & \text { 有少数实现 } & \text { 经常达到预算计划 }\end{array}$

b) 在公司的预算计划制订的过程中, 您得到了多少的激励?

$\begin{array}{lcccc}1 & 2 & 3 & 4 & 5 \\ \text { 从来没有 } & \text { 偶尔有些激励 } & \text { 很多激励 }\end{array}$

\section{4. 其它绩效}

其它绩效评估反映出除了财务和管理绩效之外公司(企业)整体业绩水平。请对公 司其它方面业绩给出您的评分:

a) 请您给出您对现有工作的满意程度?

1

不满意

b) 您怎样评价您的工作投入度?

\section{1}

投入较少
23

较满意

23

一般投入
45

非常满意

45

投入很多

\section{第三部分: 财务预算形式和特征}

中小企业的财务预算形式和特征将从以下四方面进行测量和评估。其包括预算计 划的正式程度, 财务预算目标的形式和特征, 预算复杂度和预算控制程度。请在 最能反映公司财务预算实际状况的选项下划勾。

\section{1. 财务预算计划}

财务预算计划的正式程度大致包含了财务预算在企业中应用的频率和覆盖的广度 及深度。请对以下问题给出您的评价。 
APPENDIX

a) 贵公司是否进行企业财务预算, 并以书面形式存在, 贵公司经常进行财务预算 吗?

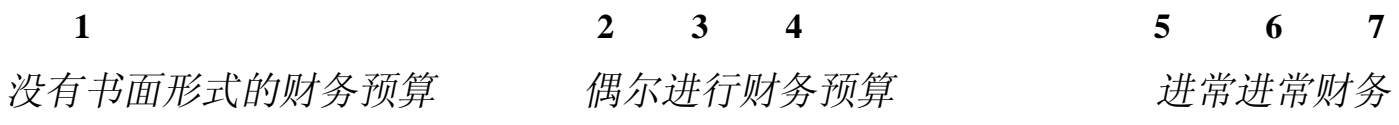
预算

b) 贵公司的财务预算应用程度如何？其覆盖了企业的各个职能部门吗？

$\begin{array}{ccccccc}1 & 2 & 3 & 4 & 5 & 6 & 7 \\ \text { 没有预算制定 } & \text { 覆盖范围窄 } & \text { 覆盖范围广 }\end{array}$

c) 其职能部门包括：（请在相关选项前打勾）

$\begin{array}{ll}\square & \text { 生产 } \\ \square & \text { 销售 } \\ \square & \text { 市场 } \\ \square & \text { 研发 } \\ \square & \text { 人力资源 } \\ \square & \text { 其它_ }\end{array}$

\section{2. 财务预算目标的特征}

财务预算目标的特征是指从多大程度上企业的财务目标被阐释得具体而清晰, 以 便各个管理阶层和所有企业员工能准确地理解和把握公司基本的经营目标和方 向。企业目标的制定可能是松散而容易达到的, 也可能是较难实现的。基于对本 公司财务目标的了解, 请您给出您对本公司财务目标的看法并在合适的选项前划 勾。

\section{a) 预算目标清晰度}

1）公司的预算目标清晰而具体。因

$$
\text { 非常不赞同 } l
$$

十分赞同

此我很清楚和了解公司的计划目标是什么。

2) 我认为公司的目标模糊不清。因此,

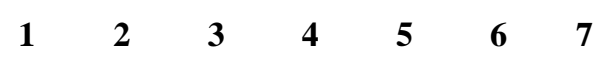

我对公司将要实现什么具体目标不清楚 也不了解。 
3)我对公司希望要达到的既定目标十分了解 $\quad \begin{array}{lllllllll} & 1 & 2 & 3 & 4 & 5 & 6 & 7\end{array}$ 也能在关键时刻分清主要目标和次要目标。

通过权衡能明确知道什么是公司应优先实现

的目标。

b) 预算目标的难易度

$$
\text { 非常不赞同十分赞同 }
$$

1) 我没有感到有任何的困难去达到 $\quad \begin{array}{llllllll}1 & & 2 & 3 & 4 & 5 & 6 & 7\end{array}$ 企业的预算目标。对我而言，企业的

预算目标十分容易实现。

2) 我认为所在企业的预算目标很难, 感 $\quad \begin{array}{llllllll} & 1 & 2 & 3 & 4 & 5 & 6 & 7\end{array}$ 到有很大压力, 几乎很难实现预算目标。

3) 我需要投入大量的工作和努力去达 $\quad \begin{array}{llllllll} & 1 & 2 & 3 & 4 & 5 & 6 & 7\end{array}$ 到公司的目标计划，但并非实现不了。

4) 本人需要相当程度的技巧, 方式和手 $\quad \begin{array}{llllllll} & 1 & 2 & 3 & 4 & 5 & 6 & 7\end{array}$ 段去实现企业预算目标。

5) 您对您所在公司或部门的预算目标的总体看法是:

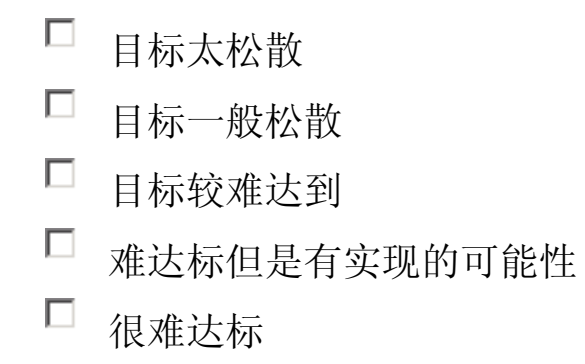

\section{3．预算复杂度}

预算复杂程度包括了对电脑, 技术人员和财务模型的使用程度。由低1到高7, 请 给出您对公司财务预算复杂程度的评分：

a) 贵公司在财务预算制定和预算管理过程中是否使用电脑来进行编制，分析和 预测? 


$\begin{array}{cccccc}1 & 2 & 3 & 4 & 5 & 6\end{array}$

b）贵公司有多少技术人员参与了公司的预算的制定?

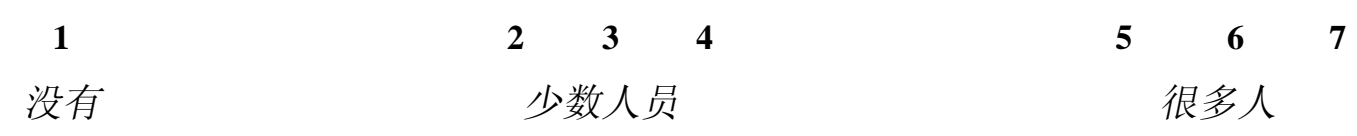

c) 财务模型化是指对财务分析工具有效的开发和应用, 财务模型有助于企业本 身、投资商和中间商、政府部门和其他机构做出准确的经营决策。

贵公司是否使用财务模型来进行财务管理？财务模型的应用程度如何?

$\begin{array}{ccccccc}1 & 2 & 3 & 4 & 5 & 6 & 7 \\ \text { 没有 } & \text { 少数财务模型的应用 } & & \text { 财务模型的广泛应用 }\end{array}$

4. 财务预算控制

a) 贵公司是否对预算绩效与实际绩效的差距进行计算?其频率如何?

$\begin{array}{lcccccc}1 & 2 & 3 & 4 & 5 & 6 & 7 \\ \text { 没有计算分析过 } & \text { 偶尔计算分析 } & & \text { 经常计算评估 }\end{array}$

b) 公司对预算差异 (即预算绩效和实际绩效的差异) 的统计和控制广泛应用到企业 生产和经营的各个领域吗?
1
没有计算过
$\begin{array}{lll}2 & 3 & 4\end{array}$
$\begin{array}{lll}5 & 6 & 7\end{array}$
小规模应用
广泛应用
c)－其包括以下运作领域:（请在相应的选项前打勾）

$\square$ 生产
$\square$ 销售
$\square$ 市场
$\square$ 研发
$\square$ 人力资源
其它_

d) 在逆差产生的情况下( 即实际绩效没有达到预期的目标)，公司是否采取相应 的改进措施或者行动方案以提高企业今后的业绩水平?
「有
口没有 
e) 在顺差发生的情况下 (即实际绩效超过预算目标), 公司是否对相关人员或其人 员所在的职能部门给予奖励?
「有
「没有

\section{第四部分：预算参与}

参与制预算主要是指全员参与到预算过程中。是预算过程的全员发动, 既企业各 职能管理部门和生产部门, 包括上下级都要参与预算的预算过程。以下有关预算 参与的问题将设计为针对企业经理或其他职能部门经理 (包括财务经理) 的问卷。 因此,

I) 您如果是企业总经理, 请对以下问题给出您的答案, 并在符合公司预算参与 情况的数字下划勾:

a) 在以下 1 至 7 由低到高不同程度中, 最能够反映您在企业预算编制过程中的参与 程度的是:

$\begin{array}{ccccccc}\mathbf{1} & \mathbf{2} & \mathbf{3} & \mathbf{4} & \mathbf{5} & \mathbf{6} & \mathbf{7} \\ \text { 没有参与任何预算的编制 } & & & & \text { 参与所有预算的编制 }\end{array}$

b) 您认为您对最终预算的确立有多大的影响力?

$\begin{array}{ccccccc}1 & 2 & 3 & 4 & 5 & 6 & 7 \\ \text { 没有任何影响力 } & & & & & \text { 有很大的影响力 }\end{array}$

c) 您怎样看待您在预算制定过程中所起的作用？我所起的作用:
12
3
4
5
$6 \quad 7$
一点也不重要
非常重要 $t$

II) 如果您是职能管理部门的经理, 请回答以下问题, 并在符合你所在公司预算 参与情况的选项下划勾:

a) 在以下 1 至 7 由低到高不同程度中, 最能够反映您在企业预算编制过程中的参与 程度的是:

$\begin{array}{lcccccc}1 & 2 & 3 & 4 & 5 & 6 & 7 \\ \text { 没有参与任何预算的编制 } & & & & \text { 参与所有预算的编制 }\end{array}$


APPENDIX

b) 当编制的预算需要修改时, 以下哪项最能反映出您的上级对修改预算所给出的 理由?

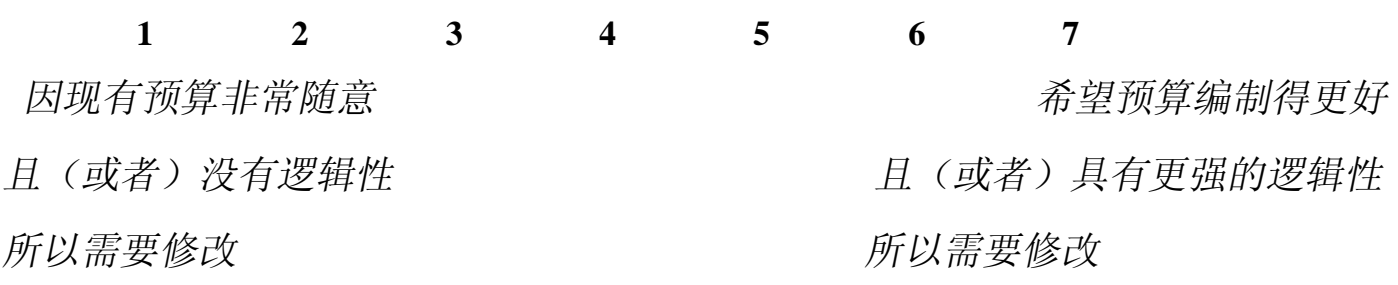

c) 在没有被要求的情况下, 您是否经常向上级反映您对企业预算的看法, 意见和 建议?

$\begin{array}{lrllllc}1 & 2 & 3 & 4 & 5 & 6 & 7 \\ \text { 从来没有 } & & & & & & \text { 经常反映 }\end{array}$

d) 您认为您对最终预算的确立有多大的影响力?

$\begin{array}{ccccccc}1 & 2 & 3 & 4 & 5 & 6 & 7 \\ \text { 没有任何影响力 } & & & & & & \text { 有很大的影响力 }\end{array}$

e) 您怎样看待您在预算制定过程中所起的作用:

$\begin{array}{rrrrrrr}1 & 2 & 3 & 4 & 5 & 6 & 7 \\ \text { 一点也不重要 } & & & & & & \text { 非常重要 }\end{array}$

f) 在预算编制过程中，您的上级经常向您询问有关预算制定的意见和建议吗?

$\begin{array}{lllllll}1 & 2 & 3 & 4 & 5 & 6 & 7 \\ \text { 从来没有 } & & & & & & \text { 经常反映 }\end{array}$

\section{问卷结束。}

再次感谢您的参与合作! 


\section{Appendix II:}

\section{Name List of the Firms in the Sample}

岳阳天力电磁设备有限公司 Yueyang Sky Force Electromagnet Co., Ltd.

岳阳万力机械有限公司 Yueyang Wanli Machinery Co., Ltd.

岳阳市永金起重永磁铁有限公司 Yueyang YongJin Permanent Magnetic Lifter Co., Ltd.

长沙佳沃工程机械有限公司 Changsha Jiawo Machinery Co., Ltd.

长沙威平机械有限公司 Changsha Weiping Machinery Co., Ltd.

长沙双龙轻工机械有限公司 Changsha Shuang Long Machinery Co., Ltd.

长沙天星减速机械有限公司 Changsha Tianxing Reducer Mechanism Co., Ltd.

长沙友联包装食品机械有限公司 Changsha Union Packing Machine Co., Ltd.

岳阳市兴工机械有限公司 Yueyang Shi Xing Gong Machinery Co., Ltd.

岳阳重力电磁机械有限公司 Yueyang Zhong Li Electromagnet Co., Ltd.

岳阳光明轻工机械有限公司 Yueyang Guang Ming Light Industry Machinery Co., Ltd.

长沙和宙利机电设备有限公司 Changsha He Zhou Li Electromechanical Equipment Co., Ltd.

长沙楚天包装机械有限公司 Changsha Chu Tian Paching Machinery Co., Ltd.

长沙日升电气设备有限公司 Changsha Sunrise Electric Co., Ltd.

长沙市成和气动成套设备有限公司 Changsha Chenghe Pneumatic Setting Co., Ltd.

长沙市博力自动化设备有限公司 Changsha Boli Automatic Equipment Co., Ltd.

岳阳海纳机械有限公司 Yueyang Hinar Machinery Co., Ltd.

岳阳润利达机器制造有限公司 Yueyang Runlida Machine Manufacturing Co., Ltd.

万中机械制造有限责任公司 Wanzhong Machinery Manufacturing Co., Ltd.

岳阳市奥斯自动化机械有限公司 Yueyang Aosi Auto. Machinery Co., Ltd.

长沙双坪铸造机械厂 Changsha Shuangping Casting Machinery Co., Ltd.

湖南普沃尔重型机械有限公司 Hu Nan Power Heavy Machinery Co., Ltd.

佛山市顺德区德远电子科技有限公司 Foshan Deyuan Electronic Equipment Co., Ltd.

珠海市莱联光电科技有限公司 Zhuhai Lailian Photoelectricity Technology Co., Ltd.

东莞市铭衡机械有限公司 Dongguan Mingheng Machinery Co., Ltd.

东莞市泽冠机械有限公司 Dongguan Zeguan Machinery Co., Ltd.

东莞市龙田过滤设备有限公司 Dongguan Longtian Filter Plant Co., Ltd.

佛山市福斯机械有限公司 Foshan Fusi Machinery Co., Ltd.

珠海润泰机电设备有限公司 Zhuhai Runtai electromechanical Co., Ltd.

广州市惟客电子设备有限公司 Guangzhou Weike Electronic Equipment Co., Ltd.

广州瑞洋机电科技有限公司 Guangzhou Ruiyang Electronic Technology Co., Ltd.

广州市越通电气设备有限公司 Guangzhou Yuetong Electric Equipment Co., Ltd.

广州市珠海区润通电气设备厂 Guangzhou Zhuhai Runtong Electric Equipment Co., Ltd.

广州凯圣机械设备有限公司 Guangzhou Kaisheng Machinery Equipment Co., Ltd.

佛山市普量电子有限公司 Foshan Puliang Electric Co., Ltd.

广州市环创通风设备有限公司 Guangzhou Huanchuang Ventilation Equipment Co., Ltd.

中山市艾森机械科技有限公司 Zhongshan Ascend Machine Technology Co., Ltd.

佛山市定中机械有限公司 Foshan Dingzhong Machinery Co., Ltd.

广州市科众风机有限公司 Guangzhou Kezhong Fan Co., Ltd.

广州市佳研特包装机械有限公司 Guangzhou Giant Packing Machinery Co., Ltd.

东莞市风能工业设备公司 Dongguan Shi Airpower Industry Devices Co., Ltd.

广东昭信企业集团有限公司 Guangdong Real Faith Enterprises Group Co., Ltd.

佛山迅发陶瓷机械制造有限公司 Xun Fa Ceramics Machinery Co., Ltd.

中国东莞英豪机械有限公司 Dongguan Yinghao Machinery Co., Ltd.

广州市盈丰机械制造有限公司 Guangzhou Yingfeng Machinery Manufacturing Co., Ltd.

珠海名晟机械制造有限公司 Zhuhai Xinfeng Machinery Manufacturing Co., Ltd.

珠海市立鼎精密机械制造有限公司 Zhuhai Liding Precision Machinery Co., Ltd.

珠海市顺志机械制造有限公司 Zhuhai Shunzhi Machinery Manufacturing Co., Ltd.

常州艾塔工具制造有限公司 Changzhou AITA Tool Co., Ltd.

黄石市三丰机械有限公司 Huangshi Sanfeng Machinery Co., Ltd. 
湖北追日电气设备有限公司 Hu Bei Zhuiri Electric Equipment Co., Ltd. 襄訤德普电气有限公司 Xiangfan Techpow Electric Co., Ltd.

襄柇市博亚机械有限公司 Xiangfan Boya Machinery Co., Ltd.

襄樊市新兴联机械有限公司 Xiangfan Xinxinglian Machinery Co., Ltd.

荆州市明德科技有限公司 Jingzhou Mingde Technology Co., Ltd.

湖北长江石化设备有限公司 Hu Bei Changjiang petrochemical equipment Co., Ltd.

荆州市巨鲸传动机械有限公司 Jingzhou Jujing transmission Machinery Co., Ltd.

湖北力帝机床股份有限公司 Hu Bei Lidi Machine Tool Co., Ltd.

十堰华昌达机电有限公司 Shiyan Hua-changda electromechanical Co., Ltd.

十堰市十勋齿汽车零部件有限公司 Shiyan Yunchi Auto Accessory Co., Ltd.

湖北神力锻造有限责任公司 Hu Bei Shenli Forging Co., Ltd.

湖北双剑鼓风机制造有限公司 Hu Bei Shuangjian Blower Machinery Co., Ltd.

荆门恒力机械有限公司 Jingmen Hengli Machinery Co., Ltd.

湖北全力铸造有限责任公司 Hu Bei Quanli Casting Co., Ltd.

武汉博能设备制造有限公司 Wuhan Boneng Installation Manufacture., Ltd.

武汉辉煌油膜轴承有限责任公司 Wuhan Hui Huang Oil Film Bearing Ltd.

东风汽车泵业有限公司 Dong Feng Motor Pump Co., Ltd.

武汉海泰机械有限公司 Wu Han Hai Tai Machinery Co., Ltd.

双飞无油轴承有限公司 Shuang Fei Oilless Bearing Co., Ltd.

黑旋风工程机械开发有限公司 Black Whirlwind Engineering Machinery Co., Ltd.

天门纺织机械有限公司 Tian Men Textile Machinery Co., Ltd.

武汉保得汽车部件有限公司 Wuhan Baode Automobile Parts Co., Ltd.

武汉东江阀业制造有限公司 Wuhan Dongjiang Valves Manufacturing Co., Ltd.

武汉泛洲机械制造有限公司 Wuhan Fanzhou Machinery Co., Ltd.

武汉万邦激光金刚石工具有限公司 Wuhan Wanbang Laser Diamond Tools Co., Ltd. 